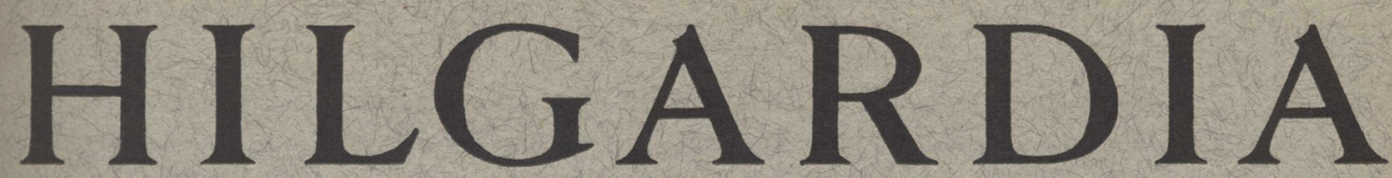

A Journal of Agricultural Science Publisbed by the California Agricultural Experiment Station

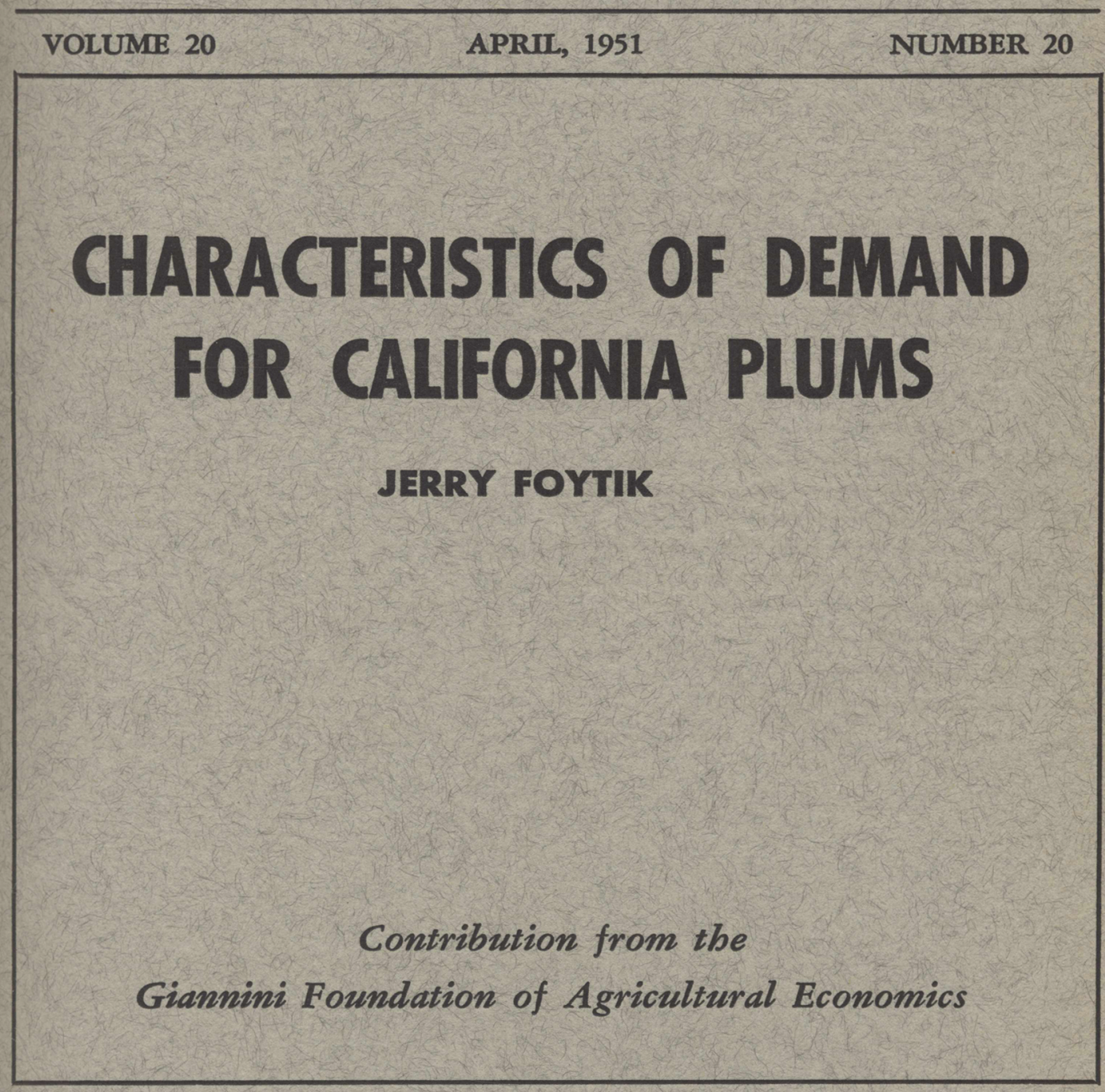

UNIVERSITY OF CALIFORNIA • BERKELEY, CALIFORNIA 


\section{CONTENTS}

Characteristics of Demand for California Plums, by Jerry Foytik

A. Some preliminary considerations . . . . . . . . . . 408

1. The market demand for California plums . . . . . . 409

2. Rationale of the empirical approach used . . . . . . . 411

3. Nature and adequacy of the data . . . . . . . . . 415

4. Procedure followed . . . . . . . . . . . . 419

B. Varietal stratification of demand . . . . . . . . . . . 421

1 The varietal problem in demand . . . . . . . . . 422

2. Method of analysis . . . . . . . . . . . . 425

3. Results obtained . . . . . . . . . . . . . . . 428

C. Temporal interrelationships in demand . . . . . . . . 441

1. The problem of temporal demand shifts . . . . . . . 442

2. Alternative hypotheses . . . . . . . . . . 443

3. Results obtained . . . . . . . . . . . . 445

D. Auction prices by size categories - . . . . . . . . . . 457

1. Size in relation to demand . . . . . . . . . . . 457

2. Formulation of hypotheses . . . . . . . . . . 459

3. Results obtained . • . . . . . . . . . . . . 461

E. Applicability to marketing control problems . . . . . . . 467

1. Nature and scope of the problem . . . . . . . . . . 467

2. Nontemporal aspects of supply allocation . . . . . . . 468

3. Temporal distribution of sales . . . . . . . . . . 469

4. Conclusion . . . . . . . . . . . . . . . 475

F. Summary and implications of the findings . . . . . . . . 476

1. Restatement of the demand problem . . . . . . . . 477

2. Recapitulation of results . . . . . . . . . . . 478

3. Validity and limitations of the study . . . . . . . . 481

4. Economic implications . . . . . . . . . . . . 486

5. Suggestions for further study . . . . . . . . . . . 490

Acknowledgments . . . . . . . . . . . . . . . . 491

Mathematical appendix . . . . . . . . . . . . 492

Statistical appendix . . . . . . . . . . . . . . 497

Literature cited . . . . . . . . . . . . . . . . 526 


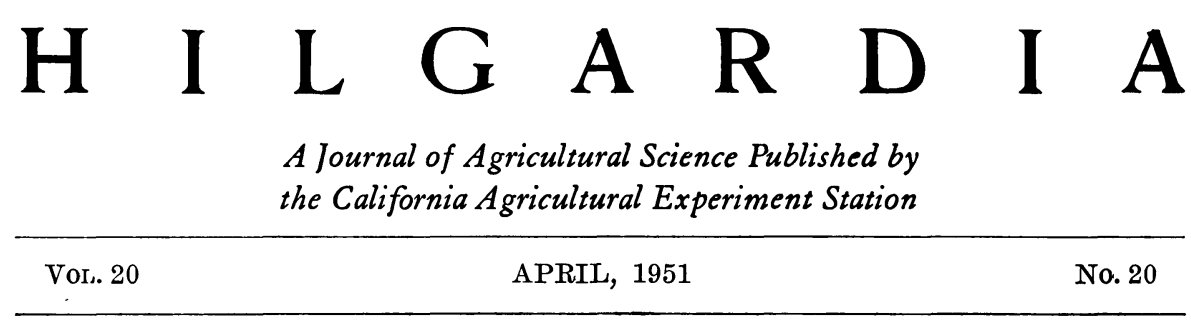

\title{
CHARACTERISTICS OF DEMAND FOR CALIFORNIA PLUMS ${ }^{1}$
}

\author{
JERRY FOYTIK ${ }^{2}$
}

The Development of the plum industry, the economic problems encountered, and attempts at their solution are similar to those of other California deciduous fruit industries. Compulsory regulations on interstate plum shipments, resembling restrictions employed for other commodities, have been imposed frequently since 1933. Continued support for this program presumably signifies the industry's confidence that grower returns are increased for the shortrun without prejudicing long-run interests. Determination of the effects generated is a crucial problem since limitations currently promulgated are based upon a subjectively determined "feel of the market."

Advocates of the plum marketing control program have advanced claims to the effect that its operation has been the salvation of the industry and that it should be expanded to cover intrastate, as well as interstate shipments. At the same time, others have regarded such efforts with skepticism, both as to their effectiveness and their desirability. A thorough appraisal of the short-run and long-run effects of market control regulations is in order. Yet no painstaking investigation has been attempted to date. ${ }^{3}$ Even the pertinent questions to which answers are to be sought have not been carefully catalogued. This study proposes to supply some of the specific information requisite for such an evaluation.

Specifically, the present report is concerned with determining the principal factors responsible for variations in wholesale prices of California plums. It

${ }^{1}$ Paper No. 126, the Giannini Foundation of Agricultural Economics. Slightly revised from portions of the author's doctoral dissertation: "The California Plum Industry: An Economic Study." 401 p. Berkeley, 1949. (Unpublished.) Manuscript submitted for publication May 16, 1950.

${ }_{2}^{2}$ Assistant Professor of Agricultural Economics and Assistant Agricultural Economist in the Experiment Station and on the Giannini Foundation, Davis.

3 The only studies dealing with the economic problems of the California plum industry which the author has been able to locate include: several outlook and other brief studies, a few general price analyses (using annual data), and a single longer investigation written a generation ago (Rauchenstein, 1928). (See "Literature Cited" for citations referred to in the text by author and date.) 
describes the empirical study undertaken, presents the results obtained, and discusses their implications.

The study is not oriented toward a direct consideration of consumers' demand (as reflected by their behavior at the retail counter) nor of the pricequantity relation encountered by growers in disposing of their crop at the farm level. Rather, the investigation attempts a statistical derivation of "demand" relations facing handlers who sell plums at auction markets. These results may be taken as representative of price-quantity relations at the terminal market level, since the bulk of California plums shipped from the state, exclusive of exports, are sold at auction markets. Although not necessarily descriptive of theoretical demand curves, the findings provide considerable insight into the actual behavior of terminal market prices.

California plums cannot be presumed to constitute a homogeneous product in the sense used by the theorist. The demand for this commodity, therefore, is conceived as a series of separate, though possibly related, demands for individual varieties of several quality-size categories. The varietal, temporal, and size aspects of the aggregate demand are considered separately in sections B (p. 421), C (p. 441), and D (p. 457) of this report. In section E (p. 467) these results are applied to problems involving marketing controls. The validity and limitations of the empirical results and their economic implications are discussed in the concluding section. Before proceeding with the analysis itself, attention is focused first upon some preliminary considerations in order to obviate the necessity of repeated reference to these points throughout the succeeding sections.

Confusion sometimes exists as to the distinction intended between a "prune" and a "plum." Originally, these terms were used as synonyms for the fruit of many hundred varieties comprising several different species. A differentiation in meaning has developed and is currently recognized by the industry. "Prune" designates a variety which can be and normally is dried without removal of the pit. The term refers to both the fruit in its fresh state and to the dried product.

"Plum," on the other hand, specifies a variety grown primarily for other uses (i.e., for fresh use, and, to a limited extent, for canning, freezing, crushing, and jam- and jelly-making). The "fresh prune," which is produced extensively in the Pacific Northwest, is equally well suited to, and has been utilized in substantial volume for three purposes: fresh use, canning, and drying. These terms will be used as indicated here.

\section{A. SOME PRELIMINARY CONSIDERATIONS}

Some of the aspects of the California plum industry of particular relevance to the price analyses are recapitulated briefly to indicate the character of the market and the nature of the demand for California plums. The rationale of the empirical approach employed, the nature and adequacy of the data used, and the general methodology followed are discussed below insofar as this is 
possible, without elaborating extendedly upon details which can be explained more appropriately as each analysis is presented.

\section{The Market and Demand for California Plums}

Commercial production of plums in the United States is confined principally to a few specialized areas in California, especially to the foothill regions of Placer County and to the lower San Joaquin Valley. Although many varieties can be grown successfully, commercial production within the state is limited largely to 15 or 20 varieties which show striking differences in tree growth and productiveness, in physical characteristics (such as color, shape, size, and taste), and in consumer acceptance. These varieties are marketed in a staggered fashion throughout the plum season in accordance with progressively later maturity dates.

Plums, one of California's highly perishable fruits, are used chiefly for fresh consumption, mainly in the heavily populated industrial region of the North Central and Northeastern states. For example, during the past two decades one-fifth of the harvested crop was utilized within California (3 per cent in processing outlets and 18 per cent for fresh use) while four-fifths were shipped from the state for fresh consumption ( 7 per cent to foreign countries, mainly Canada, and 72 per cent to domestic markets outside of California). Normally, one-third of these interstate shipments, exclusive of exports, are made at private markets and two-thirds at auction markets (30 per cent at the New York auction, 10, 8, and 7 per cent, respectively, at Chicago, Philadelphia, and Boston, and 12 per cent at the eight minor auction markets).

At present almost half of the interstate shipments of plums arriving at eastern markets are sold by mid-July, i.e., during the first six or seven weeks of the plum marketing season. The remainder is marketed primarily during the succeeding two-month period, although sales, of much smaller volume, continue until mid-October or a little later. A general idea of the relative supplies of the various deciduous and citrus fruits available during the plum season may be secured by reference to unload and other data. Cherries are marketed mainly during the period of May 15 to July 15, and apricots from mid-June to mid-July. ${ }^{4}$ Unloads of other fruits at New York and Chicago for the five years 1934-1938, as summarized in table 1, may be taken to indicate relative quantities normally available at terminal markets. From this information it is apparent that supplies of other fruits are small during the initial part of the plum season, when the early varieties are sold, but increase rapidly during July, August, and September, as midseason varieties and finally late plums are marketed.

Many fresh fruits are used by the consumer in a variety of ways. In addition to being eaten out-of-hand they may be used extensively as ingredients in salads, for culinary purposes, and for home canning, juice, and home-making of jams and jellies. Although the physical and chemical characteristics of

${ }^{4}$ Unload data for these two fruits are not reported. The information given is based upon published weekly shipment data, lagged appropriately to allow for transit time. 
California plums permit their use for canning and the making of jams and jellies by the housewife, the fruit is so used to only a limited extent. ${ }^{5}$

Ordinarily, 30 cents from each dollar received for plums at the eastern wholesale market remain to reimburse the grower for the preharvest expenses incurred in producing plums. The other 70 per cent of the wholesale price is

TABLE 1

\begin{tabular}{|c|c|c|c|c|c|c|c|c|c|}
\hline Fruit & $\begin{array}{l}\text { Jan.- } \\
\text { April }\end{array}$ & May & June & July & Aug. & Sept. & $\begin{array}{l}\text { Oct.- } \\
\text { Dec. }\end{array}$ & Total & $\underset{\text { receipts }}{\text { Truck }}$ \\
\hline New York & & & & & & & & & \\
\hline Plums, California ${ }^{c}$. & 0 & 15 & 179 & 273 & 289 & 31 & 0 & 787 & 0 \\
\hline Prunes, fresh ${ }^{c}$ & 0 & 0 & 0 & 0 & 102 & 358 & 91 & 551 & 72 \\
\hline Strawberries. & 482 & 289 & 22 & 3 & 0 & 0 & 1 & 797 & 1,236 \\
\hline Cantaloupes ${ }^{\mathrm{d}}$. & 345 & 347 & 1,284 & 1,676 & 779 & 853 & 390 & 5,675 & 1,374 \\
\hline Watermelons. & 4 & 41 & 614 & 1,135 & 403 & 20 & 0 & 2,216 & 130 \\
\hline Peaches..... & 15 & 76 & 783 & 1,430 & 784 & 132 & 22 & 3,242 & 1,632 \\
\hline Pears. . & 573 & 84 & 26 & 273 & 554 & 565 & 1,031 & 3,106 & 312 \\
\hline Grapes. & 407 & 124 & 27 & 158 & 553 & 980 & 5,649 & 7,897 & 274 \\
\hline Apples. & 1,898 & 359 & 227 & 64 & 94 & 242 & 1,558 & 4,443 & 4,673 \\
\hline Oranges. & 7,398 & 1,915 & 1,499 & 1,084 & 1,048 & 1,007 & 4,450 & 18,401 & 3 \\
\hline \multicolumn{10}{|l|}{ Chicago } \\
\hline Plums, California ${ }^{c}$. & 0 & 3 & 47 & 99 & 51 & 0 & 0 & 200 & 0 \\
\hline Prunes, fresh ${ }^{c}$. & 0 & 0 & 0 & 0 & 37 & 155 & 42 & 234 & 18 \\
\hline Strawberries.. & 441 & 342 & 36 & 3 & 0 & 0 & 0 & 822 & 434 \\
\hline Cantaloupesd. & 11 & 101 & 493 & 638 & 260 & 215 & 98 & 1,816 & 350 \\
\hline Watermelons. & 0 & 26 & 415 & 1,120 & 660 & 110 & 5 & 2,336 & 21 \\
\hline Peaches. & 0 & 4 & 143 & 497 & 443 & 143 & 10 & 1,240 & 495 \\
\hline Pears... & 52 & 4 & 5 & 91 & 205 & 223 & 248 & 828 & 95 \\
\hline Grapes. & 32 & 9 & 13 & 104 & 215 & 362 & 1,401 & 2,136 & 259 \\
\hline Apples. & 1,154 & 145 & 96 & 104 & 73 & 346 & 1,678 & 3,596 & 858 \\
\hline Oranges. & 2,350 & 586 & 471 & 370 & 366 & 341 & 1,622 & 6,106 & 0 \\
\hline
\end{tabular}

a Includes boat receipts reduced to carlot equivalents but excludes l.c.l. receipts.

b Incomplete.

c Unloads for plums and fresh prunes reported without segregation. The data shown were secured by assuming all unloads to consist of California plums for successive months until the total indicated as originating in California is secured. The balance (mostly Northwest Italian prunes and Eastern damson plums) is entered as prunes, fresh. $\mathrm{d}$ Includes casabas, honey balls, honey dews, persian melons and mixed melons of these classes.

Source OF DATA: U. S. Bureau of Agricultural Economics, "Carlot Unloads of Certain Fruits and Vegetables in 66 Cities." Annual summaries for 1934-1938, Washington, D.C. (Mimeo.).

almost evenly divided between transportation costs and the total of all other marketing charges. Transportation costs remain fairly stable over the business cycle, especially in comparison to the combined cost of all other marketing services. These other costs (picking and hauling expenses, packinghouse charges, and selling commission) tend to fluctuate in proportion to the auction price. ${ }^{6}$ In other words, the marketing charges incurred in moving plums from

${ }^{5}$ During former years, before the rapid expansion of commercial canning, some quantities of California plums shipped from the state, especially to markets in the midwestern states, were used for home canning. It is not known how extensive this practice was in the past. But the rapid development of commercial canning during the past three decades has served to confine the use of California plums reaching out-of-state markets largely to fresh consumption. California consumers, however, use some of the plums purchased in fresh form for making jams and jellies. Information as to the quantity involved is not available, but it is not presumed to be very large.

${ }^{6}$ See Foytik (1949), Section C-2, Chapter II, for a full discussion. 
the California producer's orchard to the eastern wholesale market are substantial and vary much less than does the auction price. Policies followed by retailers in establishing resale prices of plums (or, for that matter, of fruits in general) are not definitely known. It does not appear unreasonable, however, to assume that normally the retailers' markup is neither a constant amount nor a constant percentage. Possibly elements of both methods of pricing are in general use. On a priori grounds the derived demand at the auction level is expected to be somewhat less elastic, at specified levels of sales, than the consumer's demand schedule. Furthermore, the net price-quantity relation facing the grower probably is still less elastic.

\section{Rationale of the Empirical Approach Used}

The problem studied is one of describing price-quantity relations facing sellers at wholesale markets, as reflected by auction sales and prices. To deduce the demand function numerous observations over a considerable period of time are used. Such statistically derived demand functions take into account only the more important variables, consider an imperfectly homogeneous commodity, and refer to average ex-post relations prevailing during the specific time interval under study. A theoretical demand schedule, on the other hand, indicates for a particular instant of time various alternative quantities of a perfectly homogeneous commodity that the ultimate consumer would take at different prices, when the influence of all other factors is held constant. A brief statement of the theorist's derivation of the law of demand will serve to draw attention to the difference existing between the purely theoretical and the empirical approaches to the problem.

The theorist assumes either diminishing marginal utility or diminishing marginal rate of substitution, depending on whether the utility theory or the indifference approach is used in the derivation of the law of demand. Both of these fundamental assumptions are taken from common observation and are intended to describe the individual's reactions on the consumers' market without necessarily specifying the psychological and sociological basis for this behavior. By either route a negatively sloping individual demand curve is secured. It expresses a functional relation between price and quantity of the commodity when the individual's tastes, attitudes, and income, the market prices and selection of commodities, and all other relevant factors remain fixed. The market demand function is conceived to be a summation of the schedules for all individuals included within the market area.

In contrast, the empirical analyses to be made are descriptive of forces operative during a particular past period associated with variations in auction prices and, consequently, are historical summaries of average relations among the specific variables used in the study. The equations secured are not theoretical demand curves. They do, however, relate to the demand side of the market and give some considerable insight into the price-quantity relations prevailing on the terminal market. To the extent that the original observations are representative and the underlying conditions do not change dras- 
tically, the results offer some guidance concerning the immediate future beyond merely providing estimators for the statistician's use in making forecasts.

Statistical data will trace out a theoretical demand curve if that curve remains fixed while the supply curve shifts, and, conversely, a supply curve is established if movements are confined to the demand curve. In the case of plums the supply curve does shift from period to period in response to changes in crop conditions and in other factors. The demand schedule, however, cannot be assumed to remain fixed. Erratic shifts may be induced by abrupt changes in some of the factors affecting demand-e.g., the supply of other fruits. Yet it seems plausible to assume that the demand curve for California plums is subject to less violent random shift elements than is the supply function: the total production is subject to the whims of weather, the supply is produced by many growers acting more or less independently, the commodity is perishable and must be marketed as it matures, marketings are made within definite time periods, but consumer tastes for and attitudes toward plums remain fairly stable. Even if both curves shifted considerably, the parameters of the theoretical demand schedule could be determined "if (1) the form of the demand curve, (2) the complete set of shift variables, and (3) the distribution functions of the random components were known." (Kuznets and Klein, 1943.) Although this information is not available, useful demand equations can be obtained from detailed empirical study of the statistical data.

Some assumptions regarding the nature of the demand schedule and the interrelation of variables are necessary. The fundamental hypothesis made in this empirical study is that the unknown demand function may be approximated by a more or less simple empirical equation. Specifically, this implies that:

1. A routine of demand exists so that the relations remain relatively stable instead of being unduly disturbed by changes in consumer tastes, income distribution, and other factors.

2. This routine can be revealed by the statistical data, i.e., the available observations are sufficient in number to give a series of equilibrium points, instead of merely a single one.

3. The demand schedule can be approximated by an empirical function fitted to the observed data.

For the purpose of empirically deriving price-quantity functions a stochastic model rather than a functional relation is posited. It seems more logical to expect a range of values, reflecting varying degrees of probability, for the dependent variable to be determined on successive observations when specific values are assigned to the independent variables. The above description specifies the rationale of the empirical investigation. It is implied that:

1. The important factors producing shifts in the demand function can be enumerated and measured satisfactorily, on the basis of considerations of the theoretical aspects of the problem, of information about the commodity and its marketing, and of "noneconomic" factors. 
2. Suitable hypotheses to be tested can be developed-these will express the type of expected relations, a priori expectations as to signs and relative magnitudes of the parameters, and the treatment of disturbances.

3. Adequate methods for statistically testing the hypotheses can be prescribed.

These matters will now be discussed.

The first problem to be considered is whether it is possible, by statistical analysis of data not experimentally controlled, to derive demand functions at one stage in the marketing process without taking into account the relations obtained at the other marketing levels. It can be argued that the forces operative at the various points in the distributive system are definitely interrelated and that the wholesale stage occupies a central position in the system employed for distributing California plums. ${ }^{7}$ The exact nature of these interactions is not known and will not be considered here.

Wholesalers .buy plums merely as intermediary handlers for resale to retailers, who, in turn, distribute them to ultimate consumers. Retail demand is established by a multitude of forces which determine the quantities that consumers will buy at a series of alternative prices. The price bids made by wholesalers represent their estimates of the retail price-quantity relation and of the retailer's markup. (Complexities arising from speculative purchases and problems of alternate uses are not here discussed.) Wholesale demand is determined by the same forces, operating in approximately the same manner, as influence the retail demand. Thus the statistical derivation of the wholesale demand function can be attempted without specifying the forces involved at each

${ }^{7}$ Producers market their plums through various shipping agencies. Generally, they are paid on the basis of delivered or f.o.b. prices, with appropriate deductions being made for all marketing charges incurred. Since plums are perishable, they must be marketed within a relatively short time after they first become mature enough to be shipped. After plums arrive at the wholesale market, they are distributed promptly to numerous retail outlets. To a considerable extent retailers set their selling prices on the basis of prices they pay. But, of course, the quantity they are ready to purchase for retail distribution is based upon the rapidity of their own sales-or, more precisely, for short periods of time, by the amount they expect to sell. Thus, the consumers' demand schedule indirectly, but nonetheless effectively, influences the demand prevailing at the wholesale level. The price-quantity relation there established is, in turn, reflected back to the farm level. With a perishable commodity being marketed after an entire season's supply is produced, with a large number of producers and ultimate consumers, and with a substantial, though appreciably smaller number of middlemen handling plums at the various stages of the distributive system, monopolistic and monopsonistic pricing practices are precluded except to the extent that they may be fostered in connection with operation of the marketing control program. At least, with respect to whatever quantity is marketed (in contrast to the amount produced), it may be said that "competitive" forces operate to determine prices of California plums at the different stages of the distributive system. Once supplies are started on their way to market by being made available for packing by the grower, quantities to be handled at each stage during successive subperiods of the season are determined. Simultaneously, the price at each stage, starting with the retail level, is predicated upon the net price-quantity relation at that stage of the marketing process. This description of the mechanism by which prices of California plums are determined excludes from consideration the role of expectations, the conditioning effect of various institutional and technological factors, and the dynamic adjustments in the character of the market structure. Yet it is likely to provide an adequate indication of the major factors involved. 
point of the entire distributive system. This relation, by being properly adjusted to include the retailer's markup, can be used as an approximation for consumer demand. Furthermore, when marketing costs incurred in moving supplies from growers to wholesalers are subtracted, an approximation to the price-quantity relation at the farm level can be obtained.

Auction price is used as the dependent variable because the empirical study is designed to "explain" fluctuations in wholesale prices of California plums. This choice was made since the problem is one of indicating the average or expected price corresponding to any set of values assigned to the other related variables. It does not imply that causation necessarily flows from quantity to price rather than conversely. It should be noted, however, that a plausible argument for this type of cause-and-effect connection can be advanced. ${ }^{8}$ Errors of measurement probably are relatively smaller for prices than for quantitieswhich means that possibly more suitable statistical results would be secured if sales were used as the dependent variable. Nonagricultural income, however, is much more highly correlated with prices than with sales. ${ }^{9}$ Thus it may be preferable not to use both price and income as independent variables.

After a particular function is fitted to the data, the problem arises as to whether the equation as a whole and each of the parameters are significant from the statistical point of view. Certain tests have been devised and are currently used. These are essentially negative in character since they do not determine whether the particular hypothesis under study is true. They merely indicate the probability that the relation found for the observations considered could have arisen as the result of chance fluctuations in sampling of a universe in which such a relation does not exist. Yet the tests serve as a warning against drawing hasty and unwarranted generalizations from the statistical analysis of the facts and emphasize the limited applicability of the results.

Frequently, it is held that the testing procedures developed for general use in making inference statements are not applicable to time series data since repeated drawings from the universe are not possible. If the time sequence of observations is presumed to be completely unique, the possibility of any analysis is precluded. An alternate and defensible view can be taken which permits statistical inferences to be made from analysis of time series data.

Statistical inference consists in generalizing about the estimated value of a measurement relating to a hypothetical universe containing an infinite number

\footnotetext{
${ }^{8} \mathrm{~A}$ certain quantity (the total crop) becomes available for fresh sale during a particular season, and in general must be so marketed (except for such amounts as are to remain unutilized) because plums are highly perishable and can be used for processing to only a limited extent. The price obtaining is dependent upon the quantity offered for sale, instead of the quantity sold being dependent upon the price set. This view does not deny the fact that sellers watch the markets carefully and adjust supplies accordingly - within the limits imposed by the perishable nature of the commodity. Such adjustments, however, cannot be extended beyond a certain point. In any case it does not appear illogical to accept the view expressed above and consider the problem as one of measuring the relative strength of forces causing variations in auction prices. For a discussion of the use of the cause-effect principle in selecting the dependent variable see Waugh (1943), p. 210-14; and Ezekiel (1943), p. 214-16.

${ }_{9}$ For example, in the varietal analysis the correlation between auction prices and nonagricultural income was $r=0.90$, compared to a correlation of $r=0.18$ between auction ales and nonagricultural income.
} 
of elements on the basis of results obtained for a sample. The problem faced is one of determining the limits within which these estimates would probably fluctuate if based upon a number of different samples drawn from the same universe. It is assumed that uniformity in the characteristic being measured and not utter chaos exists. This assumption implies that a certain stability in results obtained for the successive samples from the universe is to be expected. Testing procedures, designed to specify the confidence which can be placed in the value derived, are based upon the notion that the population or universe of which the observed data are a random sample is imaginary.

The most direct application of notions of probability and statistical inference is to cases of sampling from finite populations since it is possible to obtain experimental results by successive samples. Even in such cases, however, many statisticians prefer to view the finite population as itself a sample from an imaginary infinite population..$^{10}$ In the same way the time series data may be considered as a set of drawings - one drawing from some hypothetical population at each point of time. Thus, the mere fact that repeated drawings are not possible does not constitute a serious obstacle to generalizing the results obtained from an analysis of time series data.

\section{Nature and Adequacy of the Data}

The price and quantity series used for the empirical studies described in this report are the data on auction sales and prices for plums sold at the New York and Chicago markets. The influence of the general price level is introduced by the index of United States nonagricultural income payments. Supplies of other fruits are indicated by official U. S. Department of Agriculture data on the production and shipments of the particular fruits involved. The foregoing are the series selected as approximations to the "true" variables. ${ }^{11}$ It is believed that these series are sufficiently accurate to yield acceptable results for the price analyses attempted. Their usefulness and limitations are indicated by the following description of the data.

\footnotetext{
${ }^{10}$ The views expressed by W. G. Cochran (1939) and R. A. Fisher (1946) might be mentioned in this connection. Cochran indicates that "In sampling for enumeration the population is usually large and it will rarely be expedient to sample more than a small fraction of the total. ... The finite population should itself be regarded as a random sample from some infinite population; thus the sample which is taken for enumeration is regarded as a subsample from a larger sample of the same infinite population.... Further, it is far removed from reality to regard the population as a fixed batch of known numbers. In economic and sociological studies the population is changing from day to day." (p. 505-07.)

In the introductory chapter to his book, Statistical Methods for Research Workers, Fisher states: "the populations studied are always to some extent abstractions ... [since] in a real sense, statistics is the study of populations, or aggregates of individuals, rather than of individuals. ... Just as a single observation may be regarded as an individual, and its repetition as generating a population, so the entire result of an extensive experiment may be regarded as but one of a population of such experiments. The salutary habit of repeating important experiments, or of carrying out original observations in replicate, shows a tacit appreciation of the fact that the object of our study is not the individual result, but the population of possibilities of which we do our best to make our experiments representative.... Even in the simplest cases the values (or sets of values) before us are interpreted as a random sample of a hypothetical infinite population of such values as might have arisen in the same circumstances." (p. 1-7.)

${ }^{11}$ See Statistical Appendix, tables A-1 to A-12, B-1, and B-4 for the actual data used.
} 
Prices for sales of individual lots of plums are reported in the fruit catalogs published by the different auction companies. These data give information on each transaction and have been summarized into various tabulations. Although the detailed summaries have not been published, the tabulations were available to the author and form the basis for the price and quantity series employed.

For the New York auction market (where some 30 per cent of the interstate domestic sales occur), auction prices and sales for each of approximately 25 different varieties of plums are available on a weekly basis for the entire period since 1920. In addition, for several recent years (1937-1941 and 19461948) information is available on a size basis for each important variety and each week of the season. Similar data except for the detail by sizes are available for the Chicago market covering the period since 1922. These auction prices and sales apply only to fruit sold in standard crates, representing about 90 per cent of the volume marketed. For the period since 1935, weekly sales and prices at the ten other auctions are also available. ${ }^{12}$

The data for the New York and Chicago auction markets were blended into separate series representing annual prices and sales since 1922 for three groups of plums (classified on a varietal basis) for use in the varietal analysis. ${ }^{13}$ Such information covers approximately 40 per cent of the interstate domestic sales. Data for sales at the other ten auctions, representing another 25 to 30 per cent of the total volume, were not included in any of the price analyses attempted. The bulk of these statistics could have been secured, but their inclusion would have necessitated making compilations from original sources giving information on individual transactions. The compilations required are too numerous to be justified for this study. Data on private sales are not readily available and, consequently, could not be included for the entire period even if their inclusion were deemed advisable and feasible. For the temporal and size analyses, price and quantity data relating only to crate sales at the New York auction were used. These data relate to almost one-third of all plums sold in interstate markets (and to almost half of those marketed at auction) and are assumed to be adequately representative to provide satisfactory series for use in these analyses.

12 The New York data are summarized in typewritten tabulations prepared by the Fruit and Vegetable Branch, Production and Marketing Administration, U.S.D.A., from data furnished by S. W. Shear, Giannini Foundation of Agricultural Economics, University of California, for 1920-1936, and from the New York Daily Fruit Reporter, "Detailed Deciduous Report"' for 1937 to date. Annual prices and quantities of Chicago sales for the period 1922-1934 were compiled by the author on a varietal basis from data available in files maintained by S. W. Shear. Weekty summaries, similar to those available for New York, were not made in view of the magnitude of the clerical computations involved. Weekly data, by varieties and types of coutainers, for each of the 12 auction markets are published annually (for each year since 1935), in a single report, by the Federal-State Market News Service.

${ }_{13}$ The prices are weighted annual averages for crate sales at New York and Chicago. Although noncrate sales involve less than 10 per cent of the total volume, on the average, it was deemed advisable to include sales in lugs and boxes (which are the two containers other than crates in common use) on an equivalent crate basis. In some instances the correction so applied to the quantity series may be significant since the relative importance of sales in noncrate containers varies considerably from variety to variety and season to season. 
The price and quantity data used are quite accurate in the sense that they do reflect auction sales and the corresponding average unit prices without substantial errors of measurement. It must not be assumed, however, that they are equally representative of prices and sales of all plums sold (i.e., including both private and auction sales). There is considerable justification for assuming that auction and private-sales prices are highly correlated. Yet the two price levels are not equal, even though differences can be explained in terms of sizes and varieties marketed during the various weeks of the season. In this connection it should be noted that the proportion of total shipments sold at the auction markets is not the same for each variety, for each week of the season, and for different years. Generally, the relative importance of private sales is (1) greater for the varieties marketed early in the plum season and smaller for the later varieties, (2) greater for the earlier sales of any particular variety and decreases during successive weeks, and (3) greater during years when the crop is small than when it is large. The size composition may, and sometimes does, vary considerably as between private and auction sales. Such differences also prevail with respect to sales at the various auction markets; however, they are much less pronounced. Consequently, sales and prices at the New York and Chicago auctions may be accepted as representative for all auction markets and as somewhat less satisfactory with respect to private transactions.

To summarize, the price and quantity series used in the following analyses relate to a significant portion of the entire interstate movement of California plums and are fairly representative of all auction markets. They are compiled in sufficient detail to permit stratifying the demand for plums so as to reveal the effect exerted by "variety," "week of season," and "size." By using these influences as additional variables in the analyses, the homogeneity of the "commodity" can be considerably increased. That is, the supply of plums used in the varietal, weekly, and size analyses represents a commodity which is considerably more homogeneous with respect to physical characteristics, consumer demand, and marketing practices than would be the case if the various components of supply were aggregated for each season. It will be noted later, as each analysis is described, that even on this basis the supply considered is not a completely homogeneous commodity in the sense used by the theorist. But further refinements could not be introduced conveniently without expanding the investigation considerably. It is felt, however, that by segregating supply on the basis of variety, week of season, and size, the price and sales data used apply to a reasonably homogeneous commodity.

In this study, it has been assumed that the price-quantity relations prevailing on the auction markets reflect and can be derived from the demand schedule of the final consumer. Changes in the general price level (i.e., in the purchasing power of money) are accounted for in part by using the index of United States nonagricultural income payments. Nonagricultural income payments were used instead of total payments because the bulk of the plums are sold in the larger and medium-size cities. Only a small volume is marketed in 
rural areas and small towns. It might have been preferable to use a regional index applicable to the industrial area of the Northeast and North Central states, since this represents the primary market for plums shipped from California. Data on state income payments, however, are fragmentary, are compiled on an annual basis, and do not cover the entire period under study. It should be noted that fluctuations in income for the different regions of the country are very similar in direction of change, though the relative magnitudes are not necessarily equal. The indexes used are based upon the data published by the Bureau of Agricultural Economics and the Bureau of Domestic and Foreign Commerce. In the temporal analysis derived weekly figures were used. ${ }^{14}$ Simple averages of monthly figures for the six-month period, MayOctober, were employed for the varietal analysis. These six months cover that portion of the year when plums are shipped and sold. Actually, the marketing season is somewhat shorter, but during particular years it may start early (in May); while in other years some sales are made throughout October. The specific period of months used is not extremely important because practically identical averages are secured whether data for four, five, or six months are employed. Thus, by using the six-month period, May-October, the results of the varietal analysis are not substantially different from those that would be obtained if a different period, say June-September, were used for averaging the monthly figures of nonagricultural income.

Possibly a more suitable index would be one from which expenditures for necessities had been eliminated. This view would be based on the premise that the demand for plums is affected more by the residual income available to nonagricultural consumers than by the size of their total income. Although the actual index used may not be entirely satisfactory for reflecting changes in the general price level in the study of auction prices, no better data are available.

The last set of data used relates to supplies of other fruits marketed during the plum season. It was felt that the demand for plums may be related to supplies of certain other fruits. In order to test such a hypothesis, it would have been desirable to use price and sales data similar to those compiled for plums. But, for various reasons, such information is not obtainable for the particular fruits that were considered as most likely to be related to California plums. It became necessary, therefore, to approximate the effect of sales at New York and Chicago by using production and shipment series. Quite obviously such figures cannot be considered to be exactly correlated with the ideal data sought. Interstate shipment data can be presumed to have a fairly high correlation with actual amounts sold at the particular consumer markets. Total production figures were used in those cases where suitable shipment data are not available. Of course, these production data, though the best currently available, do not necessarily reflect with exactitude changes in supplies marketed in northern markets.

${ }^{14}$ For the method used in obtaining the approximate weekly data see section C-1 (p. 442). 
These series on supplies of related fruits are the most suspect of the data used. Substantially better data are required before an accurate measurement can be made of the effect on plum prices exerted by supplies of these other fruits. Yet in spite of their admitted shortcomings, it was deemed advisable to introduce the series rather than omit them entirely from consideration. Some attempt at measuring, even approximately, the possible effect of supplies of other fruits on auction prices for plums seemed advisable.

\section{Procedure Followed}

The index of nonagricultural income payments and the volume of sales are presumed to be the most important variables to be taken into account for "explaining" variations in auction prices of plums. As has already been indicated, the other factors considered in the analyses include the supply of other fruits and the temporal, varietal, and size composition of sales. No direct allowances are made for population growth, changes in income distribution, shifts in consumer tastes and preferences, alterations in marketing methods, changes in the length of the season, maturity and "condition" of the fruit, and many other factors which might be enumerated as exerting some influence on the demand for California plums. These additional variables were excluded for various reasons. The effect of some is already included, though indirectly, by the shift variables listed above; some cannot be quantified easily; others have at most a negligible effect; many independent variables could not be accommodated because of the limited number of observations; and so on.

Since the neglected factors may have a significant aggregate effect, even though the influence of each may be negligible, a "time" variable was introduced into the study as a proxy for that part of the combined effect of these omitted variables which causes demand for plums to change smoothly and slowly. The part consisting of sudden abrupt changes in demand still remains excluded. This is in accord with the practice commonly followed in statistical demand studies. It should be noted, however, that the analyst must be on guard so that the contribution of "time" in explaining variations in price is not large relative to that of the other independent variables. The occurrence of such a situation would indicate that some major factor has not been identified and used.

Some students favor the use of various deflators as a means of reducing the number of variables, especially when observations are obtainable only for a limited time period. Others claim that there is a real economic justification for the adjustment of the original data. Since adjustors were not used in this study for the purpose of deflating the actual data, it may be well to comment briefly upon the principal types of adjustment frequently employed.

The use of per-capita data (for sales, income, etc.) implies that population changes are significant primarily as a percentage expansion of the market. It may be questioned whether, at least in the case of plums, this is the actual situation. Possible changes in the composition of the population (e.g., as to age, racial characteristics, size of family, nativity status, and degree of urbani- 
zation) are just as important a population characteristic in accounting for shifts in demand. Price and income data may be reduced to real terms, i.e., in relation to the general price level, by deflating each series by an index of wholesale or retail prices. However, the relation of the particular price and income data to the general price level may not necessarily be represented very adequately by a constant factor of proportionality. Sometimes each series is corrected for trend to eliminate the growth factor. It is not to be denied that if a definite pronounced upward or downward trend exists with respect to the successive observations for a particular set of data that different results may be secured when the trend is removed than if the original data are used directly. In many cases, however, the determination of the trend to be removed becomes a difficult problem if a smooth, regular, long-term movement of the series is to be isolated. Furthermore, the exact economic meaning of its elimination is not clear. In this study a time-trend factor is introduced into the regression equation in place of correcting each series for trend. The use of first differences has also been proposed as a means for eliminating the trend influence. Their use implies that differences of the same magnitude are of equal importance.

The implication of proportionality (or some other definite relation) between the deflator and the variable adjusted often is not warranted. Actually, the procedure may introduce distortions and spuriousness into the relations which are to be described by the analysis. The use of adjusted and actual data often give substantially the same results. But even if they do not there remains the problem of making certain that the difference is not secured merely as a byproduct of the method of adjustment employed.

Years prior to 1922 were not used in the analyses chiefly because comparable data for earlier years are difficult to obtain. It should be noted, however, that their inclusion would have introduced the period of the first world war, which was not deemed advisable since the basic conditions are substantially different from those prevailing during later years. For the same reason the war years 1943-1945 were excluded from the study. By early 1943 the food rationing program was set into operation (because of the large governmental requirements) and price ceilings were in effect for several important fresh fruits and vegetables. During the following two years price control was extended to sales of plums. But this program was not particularly effective in 1944 because of the extensive serious hail damage to the plum crop. In 1945 the operation of price control served to reduce auction sales to much below normal. At the time the calculations for this study were made all of the information for the 1948 season was not available. Thus the period covered for the varietal analysis includes 1922 to 1947 , exclusive of 1943-1945. Since only New York auction data were used to represent prices and sales in the temporal and size analyses and the 1948 data for New York were obtainable, the period studied includes the 1948 season.

The equations used are of conventional form. Linear functions of the shift variables and, in a few cases, of their logarithms were fitted to the data. This 
means that shifts in the demand schedule, as the independent variables assume different values, are constrained to parallel movements - arithmetically or logarithmically. Although the procedure is rigid, it serves as a convenient starting point in the analysis. Other net relations may fit the data as well, or even better, and may rest on a sounder theoretical basis. The major difficulty encountered in using more complicated relations is one of specifying the particular form that the alternate functions should take.

Generalization of the equations may be accomplished in several ways. Two methods of introducing flexibility were used. First, it is desirable to permit the parallel shifts in the demand schedule to occur in some manner other than by the uniform amount or rate, per unit change in the magnitude of an independent variable, implied by the linear equations. This is accomplished by using second and higher degree terms. Secondly, the influence of a particular factor need not remain constant regardless of the values assumed by the other independent variables. By introducing product terms into the equation (i.e., products of two or more of the factors as additional separate variables) the net effect of a particular factor can be made to depend upon the values of other variables. This procedure is used in connection with the temporal analysis, for which 270 observations were used, and will be discussed in full, in section C-2 (page 443), when this phase of the study is described.

While linear functions are employed consistently throughout these analyses, their use should not be interpreted to imply that the true net relations are presumed to be of approximately this form. In fact, it is recognized that curvilinearity probably characterizes the underlying relations. However, within the range of observations available for these analyses, the degree of curvilinearity may be slight. The fitting procedure becomes difficult because there is no suitable basis available for selecting, on an empirical basis, between various alternate hypotheses as to the type of curvilinearity employed. Recognition will be given to the fact that even though some arbitrarily selected curvilinear relations may fit the data better than the functions used, they will have to be rejected unless their form does not contradict a priori expectations deduced from theory as logically satisfactory explanations. Residuals derived from the equations fitted to the data were plotted about the various net regression lines. This was done to determine whether curvilinearity (or some other modification) should be introduced into the equations. The net regression charts were studied also to see if the residuals are distributed irregularly, particularly with respect to time.

\section{B. VARIETAL STRATIFICATION OF DEMAND}

Naturally, the question arises as to whether the net regressions of prices on each of the independent variables remain approximately the same or are significantly different for the several varieties. That is the problem considered by this varietal analysis of California plum auction prices. A brief recapitulation of the more pertinent information bearing on the price analysis is given at the 
beginning of this section. The method of analysis employed is then described. Finally, the results obtained for the analyses of auction prices for early, midseason, and late varieties are presented.

\section{The Varietal Problem in Demand}

There are marked differences among important plum varieties with respect to appearance (size, shape, and color), palatability (texture, juiciness, and sugar content), and shippability. The different varieties are not marketed simultaneously, but in a staggered fashion in accordance with progressively later maturity dates. Consequently, the kinds and quantities of other fruits available to the consumer change as different varieties are marketed. The quantity of each variety produced and sold, relative to the total, varies from year to year, since fluctuations in weather conditions affect the several varieties differently. Finally, there have been pronounced upward trends in the relative importance of some varieties and offsetting downward trends for others during the past several decades. ${ }^{15}$ The commodity designated as California plums, therefore, does not remain homogeneous during successive weeks of any particular season, may change from one year to the next, and its composition has undergone a secular change. In view of these facts, it would appear reasonable to increase homogeneity by considering the demand for plums as a series of separate, though possibly related, demands for individual varieties. These varietal demands may be similar or distinct depending on the effect of the various forces at work.

In view of the number of varieties which may be considered of commercial importance, the analysis is approached by considering three varietal groups, each representing 25 to 40 per cent of the total sales. For this purpose, the 16 main commercial varieties, representing 95 per cent of the auction sales of all plums, are classified as early, midseason, and late varieties. Sales of early varieties, confined largely to June and early July, are practically completed before substantial quantities of other plums arrive on the market. About twothirds of the season's volume of the midseason varieties are sold during the period from mid-July to mid-August. By the end of this period late plums are beginning to arrive in substantial volume. These late varieties continue in plentiful supply until the close of the plum season in late October. Thus, there is a distinct separation of the marketing seasons for early and midseason varieties and again between the periods during which midseason and late plums are sold.

Since currently available information indicates a decided consumer preference for Japanese varieties, in comparison to European plums, the individual varieties included in each group should be noted. The four early varieties (Beauty, Santa Rosa, Formosa, and Climax) are all Japanese plums. Midsea-

\footnotetext{
15 Thus, for example, sales of four varieties (Beauty, Santa Rosa, Duarte, and President) have increased rapidly and steadily from one-sixth to over one-half of the total volume of all plums sold. Seven varieties (Climax, Burbank, Tragedy, Diamond, Grand Duke, Giant, and Gros Hungarian) declined sharply from 60 to 20 per cent. Combined sales of all other varieties remained at one-quarter of the total.
} 


\section{TABLE 2}

New York-Chicago Auction Prices and Sales of Early, Midseason, and Late California Plums, a Annual Data, 1922-1949

\begin{tabular}{|c|c|c|c|c|c|c|}
\hline \multirow{2}{*}{ Season } & \multicolumn{3}{|c|}{$\begin{array}{l}\text { Auction price, New York and Chicago } \\
\text { (for crate sales only) }\end{array}$} & \multicolumn{3}{|c|}{$\begin{array}{l}\text { Auction sales, New York and Chicago } \\
\text { (all sales reduced to equivalent crates) }\end{array}$} \\
\hline & $\begin{array}{c}\text { Early } \\
\text { varieties } \\
P_{1}\end{array}$ & $\begin{array}{l}\text { Midseason } \\
\text { varieties } \\
P_{2}\end{array}$ & $\begin{array}{c}\text { Late } \\
\text { varieties } \\
P_{3}\end{array}$ & $\begin{array}{c}\text { Early } \\
\text { varieties } \\
Q_{1}\end{array}$ & $\begin{array}{l}\text { Midseason } \\
\text { varieties } \\
\quad Q_{2}\end{array}$ & $\begin{array}{c}\text { Late } \\
\text { varieties } \\
Q_{3}\end{array}$ \\
\hline \multirow[t]{2}{*}{1} & 2 & 3 & 4 & 5 & 6 & 7 \\
\hline & \multicolumn{3}{|c|}{ dollars per standard crate } & \multicolumn{3}{|c|}{1,000 equivalent crates $^{b}$} \\
\hline 1922 . & 1.55 & 1.51 & 1.47 & 289 & 409 & 279 \\
\hline 1923. & 1.59 & 1.30 & 1.52 & 412 & 606 & 343 \\
\hline $1924 \ldots \ldots \ldots \ldots$ & 1.92 & 1.97 & 2.10 & 245 & 302 & 221 \\
\hline $1925 \ldots \ldots \ldots$ & 1.84 & 1.78 & 1.60 & 381 & 430 & 320 \\
\hline $1926 \ldots \ldots \ldots$ & 1.41 & 1.45 & 1.49 & 606 & 635 & 438 \\
\hline $1927 \ldots \ldots \ldots$ & 1.70 & 1.83 & 1.96 & 379 & 508 & 312 \\
\hline $1928 \ldots \ldots \ldots$ & 1.66 & 1.57 & 1.86 & 533 & 560 & 350 \\
\hline $1929 \ldots$ & 2.20 & 2.61 & 2.41 & 374 & 307 & 254 . \\
\hline $1930 \ldots$ & 1.61 & 1.36 & 1.38 & 595 & 794 & 615 \\
\hline 1931. & 1.21 & 1.52 & 1.46 & 517 & 507 & 412 \\
\hline 1932. & 1.15 & 1.30 & 1.32 & 543 & 615 & 373 \\
\hline $1933 \ldots$ & 1.38 & 1.20 & 1.43 & 451 & 533 & 348 \\
\hline $1934 \ldots$ & 1.34 & 1.37 & 1.36 & 468 & 568 & 427 \\
\hline $1935 \ldots$ & 1.72 & 1.38 & 1.63 & 310 & 467 & 273 \\
\hline 1936. & 1.28 & 1.41 & 1.36 & 426 & 532 & 375 \\
\hline $1937 \ldots$ & 1.74 & 1.77 & 1.52 & 522 & 442 & 349 \\
\hline $1938 \ldots$ & 1.52 & 1.23 & 1.28 & 402 & 531 & 467 \\
\hline $1939 \ldots \ldots \ldots$ & 1.53 & 1.44 & 1.59 & 492 & 519 & 291 \\
\hline $1940 \ldots$ & 1.82 & 1.40 & 1.55 & 505 & 599 & 329 \\
\hline $1941 \ldots$ & 1.78 & 1.70 & 1.71 & 496 & 494 & 389 \\
\hline $1942 \ldots \ldots$ & 2.58 & 2.55 & 2.36 & 536 & 468 & 353 \\
\hline $1943 \ldots \ldots$ & 3.85 & 4.36 & 4.56 & 579 & 406 & 349 \\
\hline $1944 \ldots \ldots \ldots$ & 3.23 & 2.46 & 2.48 & 404 & 569 & 369 \\
\hline $1945 \ldots$ & 3.42 & 3.39 & 3.45 & 154 & 103 & 83 \\
\hline $1946 \ldots \ldots \ldots$ & 3.60 & 2.93 & 2.35 & 631 & 585 & 430 \\
\hline $1947 \ldots \ldots \ldots$ & 4.11 & 3.42 & 3.30 & 496 & 444 & 343 \\
\hline $1948 \ldots \ldots \ldots$ & 4.71 & 2.94 & 2.83 & 490 & 673 & 295 \\
\hline $1949 \ldots \ldots \ldots$ & 3.22 & 2.36 & 2.80 & 786 & 432 & 276 \\
\hline Mean ${ }^{\mathrm{c}}$. & 1.8365 & 1.7391 & 1.7396 & 461.261 & 515.435 & 360.478 \\
\hline S. D. c & .6992 & .5747 & .4725 & 98.821 & 104.408 & 81.076 \\
\hline
\end{tabular}

a Early varieties include Beauty, Santa Rosa, Climax, and Formosa. Midseason varieties include Tragedy Wickson, Burbank, Gaviota, Duarte, Sugar, and Diamond. Late varieties include Kelsey, President, Grand Duke, Giant, and Gros Hungarian.

$b$ Sales in lugs and boxes converted to crate equivalents using 1,000 and 0.667 as conversion factors.

c For 1922-1942 and 1946-1947.

Source of DATA: Statistical Appendix, tables A-1, A-2, A-3.

son plums include four Japanese varieties (Wickson, Burbank, Gaviota, and Duarte) and three European varieties (Tragedy, Sugar, and Diamond). Within the midseason category, the relative importance of the Japanese varieties has been steadily increasing. Now about two-thirds of the sales consist of these varieties compared to less than half of the total 25 years ago. Late varieties include Kelsey plums (the last important Japanese variety) and four European varieties (President, Grand Duke, Giant, and Gros Hungarian). The 


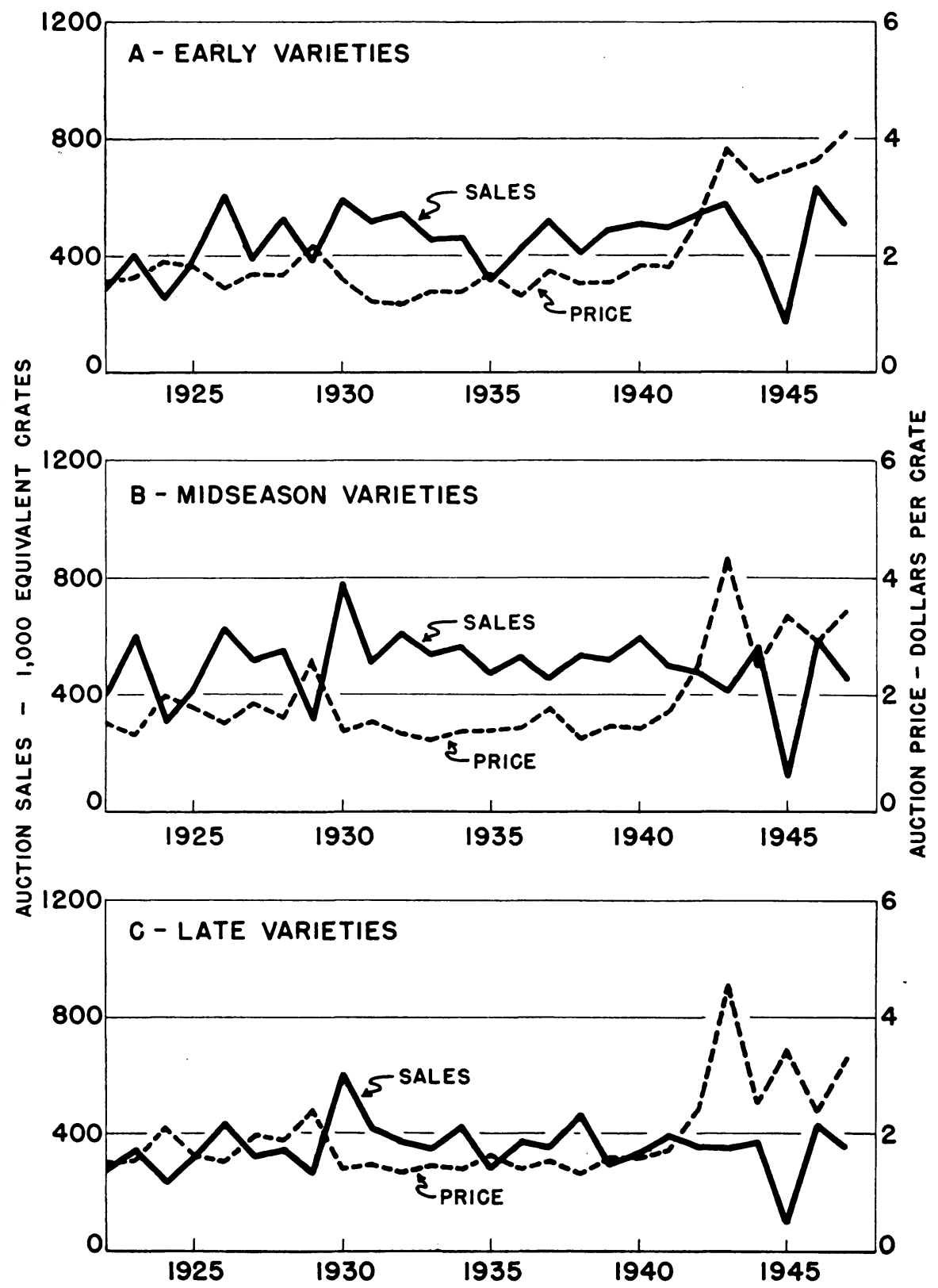

Fig. 1. California plums: auction sales and prices, at New York and Chicago, of early, midseason, and late varieties, annual data, 1922-1947. Data from table 2. 
most significant shift in relative importance of the different late varieties is the rapid increase in sales of President plums and a corresponding decline for the other three European varieties.

The price and quantity series employed in analyzing the demand for early, midseason, and late plums relate to about 40 per cent of the total volume shipped to interstate markets which is sold at the New York and Chicago auction markets. ${ }^{16}$ The course of these data for the period since 1922 is portrayed in figure 1. At this point it may be well to point out that shipments to out-of-state markets have increased about 20 per cent during the past 25 years, i.e., at approximately the same rate as the growth of the United States population. Sales, which show a marked upward trend for each varietal group, increased somewhat less rapidly for late plums than in the case of the other two groups. ${ }^{17}$ Sales of minor varieties, excluded from the above three categories, remained at approximately 2.5 per cent of the total quantity of all plums marketed until an expansion in relative importance began about a decade ago. At present they constitute 6 per cent of all sales. Fluctuations in prices of the three varietal groups are similar, but a number of differences in yearto-year movements may be observed.

\section{Method of Analysis}

As already indicated the auction price is used as the dependent variable. For each varietal group, prices $\left(P_{i}\right)$ are related to auction sales of the same varieties and of varieties represented in the group marketed immediately previously during the plum season $\left(Q_{i}\right.$ and $\left.Q_{i-1}\right)$, the index of U. S. nonagricultural income payments $(I)$, supply of other fruits $\left(S_{k}\right)$, and a time-trend factor $(T)$. Observations for 23 years, covering the period 1922-1947, exclusive of the war years 1943-1945 were used. ${ }^{18}$ The relation fitted to the data is of the form:

$$
P_{i}=a_{i}+b_{i} Q_{i}+c_{i} I+d_{i} Q_{i-1}+e_{i} S_{k}+f_{i} T
$$

where $i=1,2,3$ and $k=1, \cdots, 5$.

Of course, the inclusion of $Q_{i}$ and $I$ as independent variables in the equation is based upon theoretical considerations which need not be repeated at this point. The term $Q_{i-1}$ is used in order to test the hypothesis that sales during an

\footnotetext{
${ }^{16}$ See table 2. Average auction prices for crate sales of each variety (on a seasonal basis) were combined into a single average annual price for each varietal group, using sales in standard crate containers at New York and Chicago as weights. These prices represent approximately 90 per cent of the auction sales made at these two auction markets and are representative of prices received for plums marketed in other containers and at other markets. The cquantity series include sales in standard crates and the crate equivalent of plums sold in lugs and boxes. The factors used in converting sales made in lug and box containers to crate equivalents were 1.000 and 0.667 respectively. These reflect approximately the ratios of net contents of plums in the various containers.

${ }_{17}$ During the 1920's, sales of early varieties increased, relative to the volume of all plums sold, while relative sales of midseason varieties (and, to a lesser extent, of late plums) declined. Thereafter, the relative importance of the three varietal groups remained approximately constant, except possibly for a slight decrease in the relative sales of late varieties.

${ }_{18}$ Auction price and sales data appear in table 2. Data for the shift variables are presented in the Statistical Appendix, table B-1.
} 
earlier part of the season tend "to make or break" the market for later varieties..$^{19}$ The particular series used to reflect supplies of other fruits were developed after giving careful consideration to the data presented in table 1 and to the reliability of the various statistics available for this purpose. The obstacles encountered in the selection of suitable series are discussed below. A time-trend factor was introduced as a proxy for the net effect of variables not explicitly used in the equations which operate smoothly and gradually over time.

Considerable difficulty was experienced in securing satisfactory data to reflect the supplies of related fruits. The selection of series used was guided by consideration of securing data with relatively small errors of measurement and of including fruits which are marketed largely during those periods when the different varieties of plums are sold. ${ }^{20}$ Supplies of strawberries were excluded because their marketing season normally draws to a close as sales of early plums begin. Sales of apples, pears, and citrus (other than lemons) are at seasonal lows when early and midseason plums are sold. In spite of this fact, it might have been desirable to include these fruits in the analyses. The data which are readily available, however, could not be accepted as providing a satisfactory approximation of supplies sold in competition with the different varietal groups of plums. Even where shipment or unload statistics may be assumed to be sufficiently correlated with sales (on an appropriately lagged basis), these data could not be used, since there remains too much arbitrariness in the selection of beginning and ending dates for specifying the periods to be considered. For example, in the case of apples, sales from the previous seasons' crop are declining rapidly with the approach of the plum season and the movement of the new crop does not get well under way until the bulk of plum sales is consummated. Thus, during the plum season, the patterns of weekly sales for the two fruits are roughly inverse to one another. An error of even one week in the selection of either end of the period might increase the "supply" of apples used in the analysis for early plums by as much as 50 per cent. This additional supply would be marketed during the particular week when the sales of early plums were very small.

The use of banana supplies in the analysis was precluded by the fact that

${ }^{19}$ This thesis is frequently advanced by the plum industry, and, therefore, deserves being tested. Furthermore, information as to whether the assertion is correct could be of considerable importance to the industry. Certainly, the establishment of a marketing policy in connection with the operation of a marketing control program and long-range plans aimed at modifying the varietal distribution of acreage should give consideration to this factor. Possibly a more generalized hypothesis for indicating the nature of the interrelations of demands for different varieties should be recognized. For example, it might be held that sales of each varietal group should be addet as a separate independent variable in all three equations. Consideration might also be given to various patterns of joint correlation. These extensions were not attempted.

${ }_{20}$ This view excludes from consideration whatever dependence may exist between prices of plums and supplies of other fruits marketed at earlier periods and the role of expectations to the extent to which plum prices may be influenced by the quantities of other fruits anticipated to become available. It is felt that these factors are secondary in importance to those included. But in any case the required data, particularly with respect to anticipations, are not available and, therefore, could not be introduced, without making tentative assumptions of one sort or another, which by their nature would tend to control the results secured. 
the only data available relate to imports. Such statistics could be assumed to be reasonably satisfactory except for the fact that bananas are not sold immediately after being imported. They are moved into storage for ripening purposes and are sold from storage after varying time lags depending on market conditions.

Of the remaining fruits, cherries and apricots are sold more or less simultaneously with early plums, i.e., during June and the first half of July. Apricot production is limited almost entirely to California. Sweet cherries, the only varieties used extensively in fresh form, are produced chiefly in several western states. During recent years, fresh sales have been about equally divided between California, Washington, and "all other states." The required utilization information for earlier years, however, is obtainable only for California. Thus, the search for suitable data on supplies of fruits competitive with early plums narrows down to California apricots and cherries. Since both fruits are used in substantial quantities for processing, interstate shipment data are used as an indicator of supplies available in competition with early plums sold at the New York and Chicago auction markets. This series is identified as $S_{1}$ the data used appear in Appendix table B-1.

In the case of midseason plums, it is particularly desirable to test whether early peaches may be considered a competitive fruit. The industry has long maintained that such is the case. The best available data for use in the analysis relate to production in four southern states (Georgia, South Carolina, North Carolina, and Arkansas). Production data must be used because separate information on utilization is not available. The selection of these four states is quite arbitrary. These states include the important regions which ship peaches to northern markets in large quantities at approximately the same time that midseason plums are sold (mid-July to mid-August). The bulk of the crop produced in these states is moved to interstate markets. Consequently, this production (represented by $S_{2}$ in Appendix table B-1) may be assumed to be quite highly correlated with quantities sold in northern markets.

Three fruits, which are sold during approximately the same period that late plums are marketed (August 15 to September 30), were selected for the analysis: supplies of midseason peaches, shipments of California Thompson grapes, and shipments of Oregon-Washington fresh prunes (variables $S_{3}, S_{4}$, and $S_{5}$, respectively). The appropriate series for peach supplies consist of production in seven states (New York, New Jersey, Pennsylvania, Illinois, Michigan, Tennessee, and Virginia) plus interstate shipments of California freestones. California grapes for table use, other than the Thompson Seedless variety; are sold largely after the peak of the season for late plums has been passed. It might have been desirable to have included data for Red Malaga variety. The necessary data, however, are not available for the earlier years of the period..$^{21}$ Since year-to-year fluctuations in shipments are closely correlated,

${ }^{21}$ Undoubtedly, estimates could have been made to extend the series back to 1922 . Since supplies of Thompson Seedless grapes did not prove to be significantly related to auction prices of late plums, however, it appeared unnecessary to introduce a variable representing supplies of Red Malaga grapes. 
the larger volume represented by Thompson grapes may be used to reflect the influence of both varieties. Shipments of fresh prunes from the Pacific Northwest are made somewhat later than shipments of late California plums. Yet there is an overlapping period of approximately a month when both fruits are being moved in substantial volume. Idaho prunes are marketed later than

TABLE 3

Early California Plums: Regression Coefficients and Auxiliary Constants, 1922-1947, Excluding 1943-1945

\begin{tabular}{|c|c|c|c|c|c|c|c|}
\hline \multirow{2}{*}{ Equation } & \multirow{2}{*}{$\begin{array}{c}\text { Dependent } \\
\text { variable }\end{array}$} & \multirow{2}{*}{$\begin{array}{c}\text { Constant } \\
\text { term }\end{array}$} & \multicolumn{4}{|c|}{ Net regression coefficients ${ }^{\mathrm{a}}$} & \multirow{2}{*}{$\begin{array}{c}\text { Adjusted } \\
\text { coefficient } \\
\text { of multiple } \\
\text { correlation } \\
\bar{R}\end{array}$} \\
\hline & & & $\begin{array}{c}\text { Sales of } \\
\text { early plums } \\
Q_{1}\end{array}$ & $\begin{array}{c}\text { Nonagric. } \\
\text { income } \\
I\end{array}$ & $\underset{T}{\operatorname{Time}}$ & $\begin{array}{c}\text { Supply of } \\
\text { other fruits } \\
S_{1}\end{array}$ & \\
\hline 1 & $P_{1} \ldots \ldots \ldots$ & 0.7713 & $\begin{array}{c}-0.0140 \\
(3.74)\end{array}$ & $\begin{array}{c}+0.0141 \\
(19.55)\end{array}$ & $\ldots \ldots \ldots$ & $\ldots \ldots \ldots$ & 0.9733 \\
\hline 1.2 & $P_{1} \ldots \ldots \ldots$ & 0.7801 & $\begin{array}{c}-0.0143 \\
(3.53)\end{array}$ & $\begin{array}{c}+0.0140 \\
(15.63)\end{array}$ & $\begin{array}{c}+0.0016 \\
(0.23)\end{array}$ & $\ldots \ldots \ldots$ & 0.9719 \\
\hline 1.3 & $P_{1} \ldots \ldots \ldots$ & 0.7790 & $\begin{array}{c}-0.0137 \\
(3.33)\end{array}$ & $\begin{array}{c}+0.0142 \\
(17.72)\end{array}$ & $\ldots \ldots$ & $\begin{array}{c}-0.0019 \\
(0.16)\end{array}$ & 0.9719 \\
\hline \multirow[t]{2}{*}{1.4} & $P_{1} \ldots \ldots \ldots$ & 0.7900 & $\begin{array}{c}-0.0140 \\
(3.19)\end{array}$ & $\begin{array}{c}+0.0141 \\
(14.76)\end{array}$ & $\begin{array}{c}+0.0017 \\
(0.25)\end{array}$ & $\begin{array}{c}-0.0023 \\
(0.19)\end{array}$ & 0.9704 \\
\hline & & & $\log Q_{1}$ & $\log I$ & $T$ & & $\bar{R}$ \\
\hline 1.5 & $\log P_{1} \ldots \ldots$ & -0.7471 & $\begin{array}{c}-0.3343 \\
(3.24)\end{array}$ & $\begin{array}{c}+0.9125 \\
(12.50)\end{array}$ & $\ldots \ldots \ldots$ & $\ldots \ldots \ldots$ & 0.9360 \\
\hline 1.6 & $\log P_{1} \ldots \ldots$ & -0.5746 & $\begin{array}{c}-0.3742 \\
(3.36)\end{array}$ & $\begin{array}{c}+0.8693 \\
(10.15)\end{array}$ & $\begin{array}{c}+0.0018 \\
(0.97)\end{array}$ & & 0.9358 \\
\hline
\end{tabular}

a Figures in parentheses are $t$-ratios.

$P_{1}-$ New York-Chicago auction price for early varieties, average for crate sales only, in dollars per crate. $Q_{1}$-New York-Chicago auction sales of early varieties, sales in all containers, in 10,000 equivalent crates. $I$-Index of U. S. nonagricultural income payments, May-October average, 1935-1939=100. $T$-Time, in years, with origin at 1921 .

$S_{1}$-Interstate shipments of California apricots and cherries, in 1,000 tons.

those from Oregon and Washington and just as the season for California plums is drawing to a close. Therefore, the series used relates to total shipments of fresh prunes from Oregon and Washington.

\section{Results Obtained}

Several formulations, expressing auction prices of each varietal group as different functions of the independent variables, were fitted to the data. The various results secured, as given in tables 3,4 , and 5 , will be discussed separately by varietal groups. In each case one function was selected as the final equation. These are identified as equations (1), (2), and (3), respectively, for early, midseason, and late ṕlums. Net regression charts, showing the scatter of residuals derived from the final equations, appear as figures 2,3 , and 4 . At the end of this section some general comparisons of the results for the three varietal groups are given. Further comment about the results and their limitations and implications is deferred to the concluding section of this article after the temporal and size analyses are discussed. 
Early Varieties. An equation expressing auction prices of early plums as a linear function of auction sales of early plums and the index of nonagricultural income provides an excellent fit to the data (see equation 1 in table 3 ). Since the adjusted coefficient of multiple correlation ${ }^{22}$ is high $(\bar{R}=0.973)$ and no curvilinearity is indicated by the net regression chart (figure 2), it is quite apparent that the use of curvilinear relations or the introduction of additional independent variables is not likely to improve the fit significantly. Nevertheless, two alternate formulations were made to determine whether some different equations might give equally satisfactory empirical descriptions for the period 1922-1947.

A linear form in the logarithms of the variables was used. Such equations are often employed by some investigators to determine whether good results can be secured when it is assumed that the various elasticities remain constant during the period of study. The two logarithmic equations do not fit the data as well as the linear form-the value of the coefficient of multiple correlation is reduced from $\bar{R}=0.973$ to $\bar{R}=0.936$.

The second alternate set of regression equations was secured by introducing additional variables into the formulation. For this purpose $T$ and $S_{1}$, representing the "time" trend and interstate shipments of California apricots and cherries, respectively, were used separately and in combination. The $t$-ratios ${ }^{23}$ secured for these variables in the new equations are small (all less than 0.3), indicating that the null hypothesis (i.e., that the net regression coefficients actually have zero values) cannot be rejected. Thus the statistical evidence does not justify accepting $S_{1}$ and $T$ as being significantly related to auction prices of early plums. Reference to the table reveals that the addition of $T$ and/or $S_{1}$ to the equation does not materially affect the net regressions of price on quantity and on income. When $T$ is added to the logarithmic equation, the coefficients of price flexibilities with respect to income and sales (i.e., the coefficients of $\log I$ and $\log Q_{1}$ ) are changed, but not significantly. For equation (1.5) the net regressions of price on quantity and income, calculated at the centroid $(-0.0133$ and +0.0139$)$, are approximately equal to the values determined for the linear equations.

The empirical fit to the data is not improved by either a logarithmic formulation of the relation or the introduction of shipments of California cherries and apricots (the variable considered as the most likely to measure any possible competitive supply) and of a residual time-trend. The residuals plotted about

${ }^{22}$ Frequently the correlation coefficient is adjusted for degrees of freedom since it is felt that the "corrected value . . . is a somewhat more conservative estimate of the true correlation." (Eackiel, 1930, p. 122.) It should be noted, however, that the procedure followed does not give an unbiased estimate of the coefficient, even though the value is "corrected." Actually the adjustment factor is slight for high values of the coefficient. In deference to common practice the correlation coefficients derived in this chapter will be "adjusted."

${ }^{23}$ Reliability of the net regression coefficients derived in the empirical study is indicated by $t$-ratios to determine whether the values secured can be explained merely in terms of chance fluctuations in sampling from a universe in which the true values are zero. This test is applied even though it is recognized that time series data may not adequately fulfill the fundamental assumptions underlying this test. See section F for a brief discussion of how adequately the assumption of the least squares approach are met. 


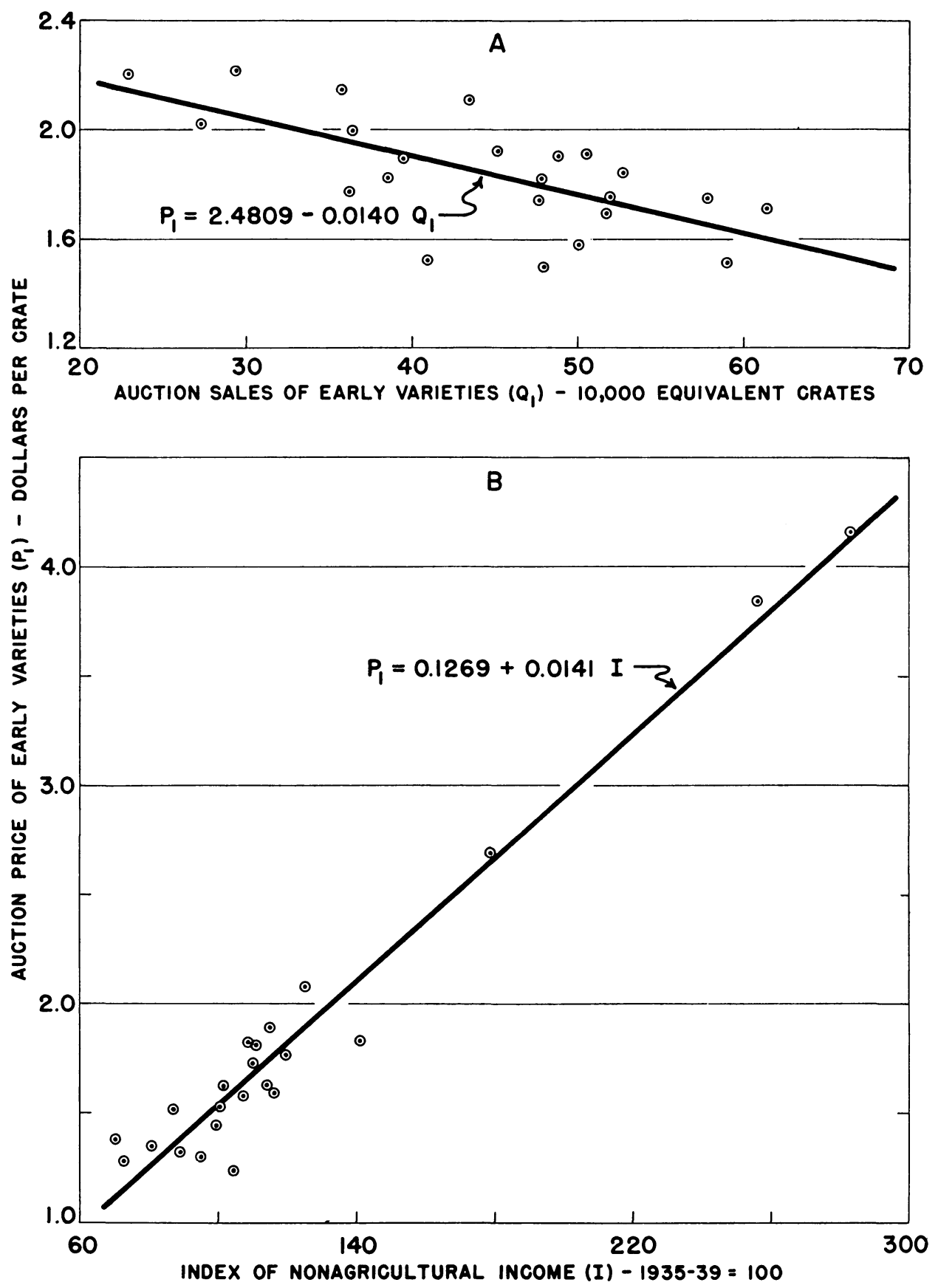

Fig. 2. Early California plums: net regressions of auction price on (A) auction sales of early varieties and (B) index of nonagricultural income. Based on equation (1). 
the two net regressions for equation (1) reveal that linearity is a reasonable description of the relations. ${ }^{24}$ Furthermore, the scatter of points in the regression chart (figure 2) is distributed in an irregular, rather than a systematic, way. On this basis equation (1) is accepted as the best of the various formulations attempted.

Midseason Varieties. Auction prices of midseason plums can be related to auction sales of these varieties and nonagricultural income by a linear func-

TABLE 4

Midseason California Plums: Regression Coefficients and Auxiliary Constants, 1922-1947, Excluding 1943-1945

Price $\left(P_{2}\right)$ as the Dependent Variable

\begin{tabular}{|c|c|c|c|c|c|c|c|}
\hline \multirow[b]{2}{*}{ Equation } & \multirow[b]{2}{*}{$\begin{array}{c}\text { Constant } \\
\text { term }\end{array}$} & \multicolumn{5}{|c|}{ Net regression coefficients ${ }^{\mathbf{a}}$} & \multirow{2}{*}{$\begin{array}{l}\text { Adjusted } \\
\text { coefficient } \\
\text { of multiple } \\
\text { correlation } \\
\bar{R}\end{array}$} \\
\hline & & $\begin{array}{c}\text { Sales of mid- } \\
\text { season plums } \\
Q_{2}\end{array}$ & $\begin{array}{c}\text { Nonagricul- } \\
\text { tural income } \\
I\end{array}$ & $\underset{T}{\operatorname{Time}}$ & $\begin{array}{c}\text { Sales of } \\
\text { early plums } \\
Q_{1}\end{array}$ & $\begin{array}{c}\text { Supply of } \\
\text { other fruits } \\
S_{2}\end{array}$ & \\
\hline 2.1 & 1.5429 & $\begin{array}{c}-0.0191 \\
(5.50)\end{array}$ & $\begin{array}{c}+0.0098 \\
(13.75)\end{array}$ & $\ldots$ & $\ldots \ldots \ldots$ & $\ldots \ldots$ & 0.9554 \\
\hline 2.2 & 1.5108 & $\begin{array}{c}-0.0182 \\
(5.30)\end{array}$ & $\begin{array}{c}+0.0106 \\
(11.68)\end{array}$ & $\begin{array}{c}-0.0094 \\
(1.44)\end{array}$ & & $\ldots+$ & 0.9577 \\
\hline 2.3 & 1.5345 & $\begin{array}{c}-0.0236 \\
(4.37)\end{array}$ & $\begin{array}{c}+0.0092 \\
(10.58)\end{array}$ & $\ldots \ldots$ & $\begin{array}{c}+0.0066 \\
(1.08)\end{array}$ & $\ldots \ldots \ldots$ & 0.9558 \\
\hline 2.4 & 1.7606 & $\begin{array}{c}-0.0197 \\
(6.33)\end{array}$ & $\begin{array}{c}+0.0109 \\
(13.86)\end{array}$ & $\ldots \ldots$ & $\ldots \ldots$ & $\begin{array}{c}-0.0277 \\
(2.47)\end{array}$ & 0.9647 \\
\hline 2.5 & 1.7269 & $\begin{array}{c}-0.0188 \\
(6.19)\end{array}$ & $\begin{array}{c}+0.0117 \\
(12.83)\end{array}$ & $\begin{array}{c}-0.0091 \\
(1.57)\end{array}$ & $\ldots \ldots$ & $\begin{array}{c}-0.0273 \\
(2.53)\end{array}$ & 0.9672 \\
\hline 2.6 & 1.7711 & $\begin{array}{c}-0.0258 \\
(5.51)\end{array}$ & $\begin{array}{c}+0.0103 \\
(12.28)\end{array}$ & $\ldots \ldots \ldots$ & $\begin{array}{c}+0.0089 \\
(1.68)\end{array}$ & $\begin{array}{c}-0.0305 \\
(2.82)\end{array}$ & 0.9678 \\
\hline 2 & 1.7271 & $\begin{array}{c}-0.0270 \\
(6.48)\end{array}$ & $\begin{array}{c}+0.0112 \\
(13.56)\end{array}$ & $\begin{array}{c}-0.0131 \\
(2.47)\end{array}$ & $\begin{array}{c}+0.0125 \\
(2.55)\end{array}$ & $\begin{array}{c}-0.0311 \\
(3.25)\end{array}$ & 0.9750 \\
\hline
\end{tabular}

a Figures in parentheses are $t$-ratios.

$P_{2}-$ New York-Chicago auction price for midseason varieties, average for crate sales only, in dollars per crate. $Q_{2}$-New York-Chicago auction sales of midseason varieties, sales in all containers, in 10,000 equivalent crates. $Q_{1}-$ New York-Chicago auction sales of early varieties, sales in all containers, in 10,000 equivalent crates. $I$-Index of United States nonagricultural income payments, May-October average, $1935-1939=100$. $T$-Time, in years, with origin at 1921 .

$S_{2}$-Supply of early peaches (total production in Georgia, South Carolina, North Carolina, and Arkansas), in million bushels.

tion, as was done in the case of early varieties. The fit secured is very good $(\bar{R}=$ 0.955). Inspection of the regression chart (Statistical Appendix, figure B-1) indicates, however, that the residuals are distributed in a more regular fashion than prevailed in the case of early plums. This suggests that further study is required to determine whether the introduction of additional independent variables or the use of curvilinear relations may be justified.

The addition of "time" $(T)$, auction sales of early plums $\left(Q_{1}\right)$, and supply of early peaches $\left(S_{2}\right)$ singly into the equation suggests that each of these variables

${ }^{24}$ This statement, of course, is not intended to imply that whatever curvilinearity is suggested and justified by theoretical considerations should be disregarded. It is felt, however, as was indicated previously in section A-4, that a reasonable case can be established for postulating linear relations, at least as first approximations, to describe the range of observations included in the study. No attempt is made to force the use of curvilinearity unless its introduction improves, or at least does not decrease, the empirical fit to the data. 

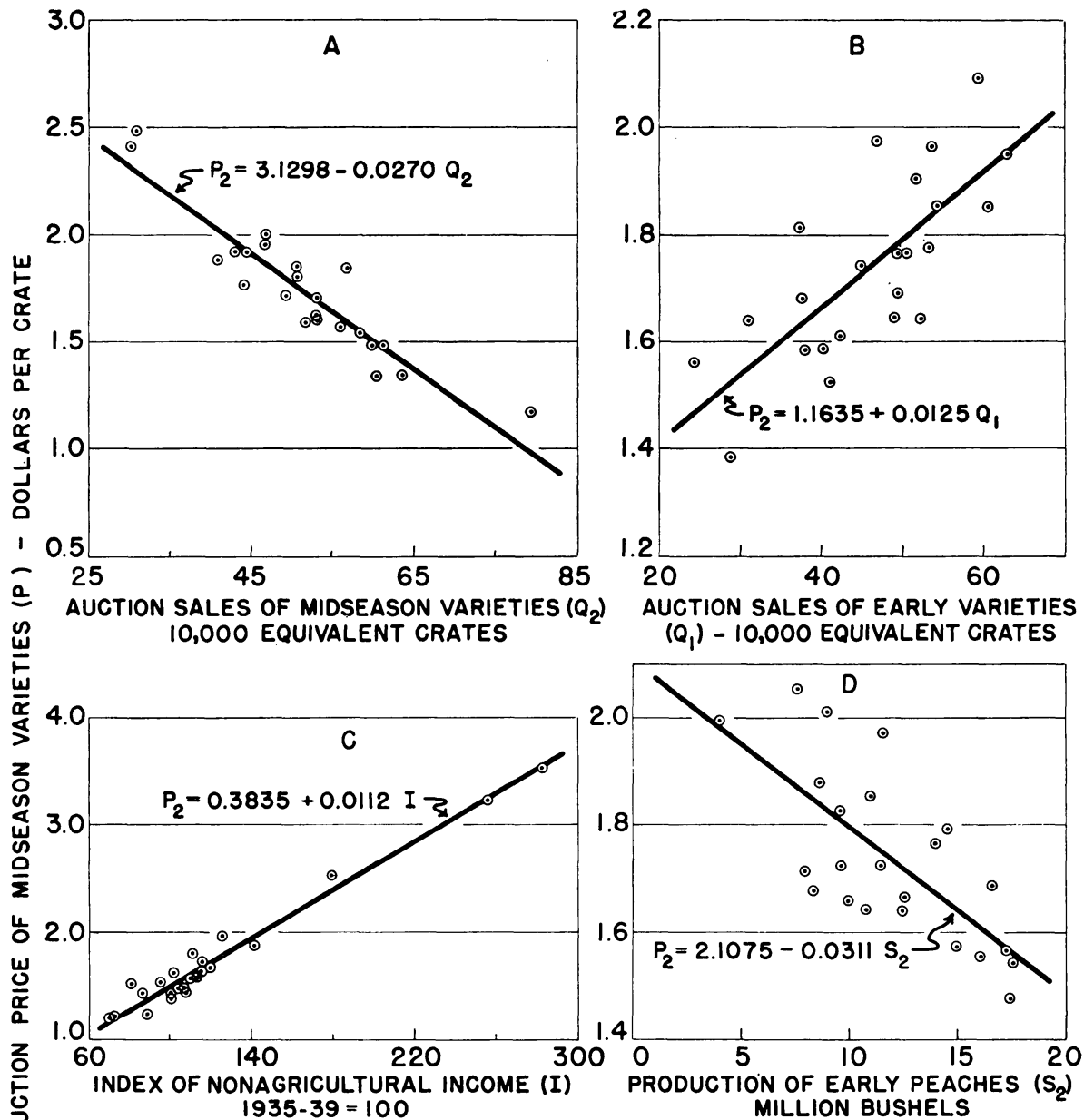

PRODUCTION OF EARLY PEACHES $\left(S_{2}\right)$ MILLION BUSHELS

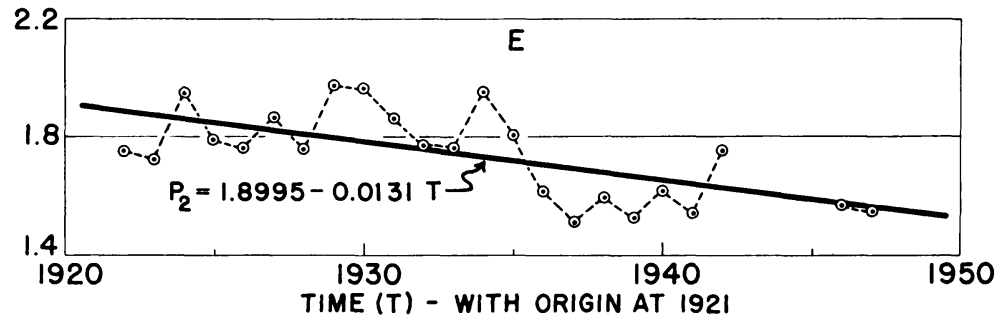

Fig. 3. Midseason California plums : net regressions of auction price on (A) auction sales of midseason varieties, (B) auction sales of early varieties, (C) index of nonagricultural income, (D) production of early peaches, and (E) time. Based on equation (2). 
may be significantly related to auction prices of midseason varieties of plums. In each new equation the net regression coefficient of the added variable has a $t$-value greater than 1.0. When all three variables are introduced simultaneously the $t$-value for each regression coefficient is increased considerably. In fact, the lowest value is almost 2.5 which indicates that each of the added variables-as well as sales and income -is statistically significant at the 5 per cent level. The residuals derived from this augmented equation (No. 2 in table 4) are plotted as scatters about the net regression lines in figure 3. A suggestion of slight curvilinearity in the net price-quantity relation remains. The departure from linearity, however, is not considered large enough to require using a curvilinear price-quantity relation..$^{25}$ Otherwise, the residuals appear to be distributed irregularly about the net regression relations.

Equation (2), relating auction prices of midseason varieties to auction sales of midseason and early plums, nonagricultural income, supply of early peaches, and time, was considered the most satisfactory empirical explanation for the period 1922-1947. The adjusted coefficient of multiple correlation is 0.975 , practically the same value as secured for early plums by equation (1). It should be noted that the value of $\bar{R}$ for equation (2) is not substantially larger than the value obtained for the other equations listed in table 3 . However, taking into account the $t$-ratios of the various net regression coefficients and the theoretical aspects of the problem, the formulation employing five independent variables seems preferable.

It is of considerable interest to note the dependence of the price of midseason plums on the sales of early varieties. The average effect of a change of 10,000 crates in the quantity of early plums sold at the New York and Chicago auction markets amounted to a change in the same direction of 1.25 cents per crate in the auction price of midseason varieties. A change of 10,000 crates in the sales of midseason varieties was associated, on the average, with an opposite change of 2.70 cents in the crate price. Thus, the auction price of midseason plums was affected to approximately the same extent by a change of 4,600 crates in the sales of midseason varieties and a change in the opposite direction of 10,000 crates in volume of early varieties sold.

Early and midseason plums behave as complementary commodities. The direction of this apparent influence is in accord with claims advanced by shippers of California plums. Possibly the explanation for this behavior is to be found in the physical characteristics of the different varietal classifications and in the marketing seasons during which they are normally sold. It will be recalled that the early plums are of the Japanese varieties and are marketed during the period from mid-June to mid-July, before any appreciable volume of later plums is sold. Because of better appearance and palatability these early Japanese plums have a greater consumer appeal than do European varieties.

${ }^{25}$ The problem of introducing curvilinearity was considered in conjunction with the analysis for late varieties since in the latter case there was greater evidence of its desirability. For midseason plums, the use of additional independent variables raised the coefficient of multiple correlation to such an extent that it appeared very questionable whether a curvilinear price-quantity relation would improve the fit. 
Midseason plums include four Japanese and three European varieties. Aside from this explanation there is no basis for an a priori statement as to what the direction of influence should be.

For the period under consideration auction prices of midseason varieties were significantly related to the "supply of other fruits." The production of early peaches (in Georgia, South Carolina, North Carolina, and Arkansas), which is taken as a proxy for supplies of peaches available at northeastern and central markets during the season for early plums, is related inversely to prices of early plums. In other words, it may be assumed that peaches marketed from this region are competitive with early plums. The net regression coefficient is -3.11 cents per crate in the price of midseason plums for a change of 1.0 million bushels in the peach crop. Since the change in the size of the crop from one season to the next exceeds 4.5 million bushels infrequently (only one year in six), the influence exerted by variations in the supply of southern peaches is usually confined to 15 cents per crate of midseason plums. Occasionally, however, an effect of 30 cents or even more may occur.

For midseason plums "time," representing the combined influence of omitted factors which change slowly and smoothly over time is statistically significant at the 5 per cent level. An annual downward shift in the net pricequantity relation, amounting to 1.3 cents per crate, was indicated. This underlying tendency for a decrease in the net price-quantity relation is of some importance to the plum industry and merits attention when plans for marketing and long-run shifts in production are formulated.

Late Varieties. A simple relation expressing auction prices as a linear function of auction sales and nonagricultural income provides a good fit to the data $(\bar{R}=0.918)$. As in the case of midseason varieties, inspection of the regression chart (Statistical Appendix, figure B-2) indicated that the residuals were distributed in a systematic fashion. An improvement in the fit was sought by using additional independent variables and by introducing curvilinearity into the net price-quantity relation. Supply of other fruits was included by means of three factors: shipments of Oregon-Washington fresh prunes $\left(S_{3}\right)$, shipments of California Thompson Seedless grapes $\left(S_{4}\right)$, and supplies of intermediate peaches $\left(S_{5}\right)$. Sales of midseason plums $\left(Q_{2}\right)$, and "time" $(T)$ were also used as additional variables. The different equations obtained are shown in table 5. Introduction of these variables separately indicated that possibly all except $S_{4}$ may be correlated with auction prices of late varieties. Equations (3.6) and (3.8) show that $S_{5}$ is not particularly important and that $T$ may be of only doubtful significance (since the $t$-ratio is merely 1.5). The former of these equations might be accepted except for two other disturbing indications. The $t$-ratio for the net regression coefficient of price on sales has been reduced to 1.45 and the scatter of residuals about this regression line is definitely curvilinear-more pronounced than in the case of midseason plums.

It seemed desirable, therefore, to attempt a formulation including curvilinearity. For this purpose the variable $Q_{3}$ was introduced as a logarithmic 
TABLE 5

Late California Plums: Regression Coefficients and Auxiliary Constants, 1922-1947, ExCLUding 1943-1945

Price $\left(P_{3}\right)$ as the Dependent Variable

\begin{tabular}{|c|c|c|c|c|c|c|c|c|c|}
\hline \multirow{3}{*}{ Equation } & \multirow{3}{*}{$\begin{array}{c}\text { Constant } \\
\text { term }\end{array}$} & \multicolumn{7}{|c|}{ Net regression coefficients (figures in parentheses are $t$-ratios) } & \multirow{3}{*}{$\begin{array}{c}\text { Adjusted } \\
\text { coefficient } \\
\text { of } \\
\text { multiple } \\
\text { correla- } \\
\text { tion } \\
\bar{R}\end{array}$} \\
\hline & & \multirow{2}{*}{$\begin{array}{c}\text { Sales } \\
\text { of late } \\
\text { plums } \\
Q_{3}\end{array}$} & \multirow{2}{*}{$\begin{array}{c}\text { Nonagric. } \\
\text { income } \\
I\end{array}$} & \multirow{2}{*}{$\underset{T}{\operatorname{Time}}$} & \multirow{2}{*}{$\begin{array}{c}\text { Sales of } \\
\text { midseason } \\
\text { plums } \\
Q_{2}\end{array}$} & \multicolumn{3}{|c|}{ Supply of other fruits } & \\
\hline & & & & & & $S_{3}$ & $S_{4}$ & $S_{5}$ & \\
\hline 3.1. & 1.5485 & $\begin{array}{c}-0.0219 \\
(4.43)\end{array}$ & $\begin{array}{c}+0.0081 \\
(10.32)\end{array}$ & & & & & & 0.9179 \\
\hline 3.2 . & 1.5179 & $\begin{array}{c}-0.0205 \\
(4.19)\end{array}$ & $\begin{array}{c}+0.0090 \\
(9.13)\end{array}$ & $\begin{array}{c}-0.0107 \\
(1.47)\end{array}$ & $\ldots$ & $\ldots$ & & & 0.9226 \\
\hline 3.3 . & 1.7003 & $\begin{array}{c}-0.0126 \\
(1.51)\end{array}$ & $\begin{array}{c}+0.0079 \\
(9.92)\end{array}$ & $\ldots \ldots$ & $\begin{array}{c}-0.0088 \\
(1.36)\end{array}$ & & & & 0.9214 \\
\hline 3.4. & 1.3444 & $\begin{array}{c}-0.0244 \\
(5.23)\end{array}$ & $\begin{array}{c}+0.0077 \\
(10.33)\end{array}$ & $\ldots \ldots$ & $\ldots \ldots \ldots$ & $\begin{array}{c}+0.0225 \\
(2.22)\end{array}$ & . & & 0.9319 \\
\hline 3.5 . & 1.5774 & $\begin{array}{c}-0.0217 \\
(4.26)\end{array}$ & $\begin{array}{c}+0.0083 \\
(8.86)\end{array}$ & & & $\ldots \ldots$ & $\begin{array}{c}-0.0013 \\
(0.39)\end{array}$ & & 0.9141 \\
\hline 3.6 . & 1.7165 & $\begin{array}{c}-0.0226 \\
(4.62)\end{array}$ & $\begin{array}{c}+0.0085 \\
(10.18)\end{array}$ & & & & & $\begin{array}{c}-0.0170 \\
(1.30)\end{array}$ & 0.9208 \\
\hline 3.7 . & 1.4999 & $\begin{array}{c}-0.0098 \\
(1.45)\end{array}$ & $\begin{array}{c}+0.0079 \\
(9.21)\end{array}$ & $\begin{array}{c}-0.0086 \\
(1.46)\end{array}$ & $\begin{array}{c}-0.0134 \\
(2.45)\end{array}$ & $\begin{array}{c}+0.0280 \\
(3.05)\end{array}$ & & $\ldots+\cdots$ & 0.9499 \\
\hline 3.8 . & 1.6013 & $\begin{array}{c}-0.0097 \\
(1.41)\end{array}$ & $\begin{array}{c}+0.0082 \\
(8.54)\end{array}$ & $\begin{array}{c}-0.0088 \\
(1.46)\end{array}$ & $\begin{array}{c}-0.0134 \\
(2.41)\end{array}$ & $\begin{array}{c}+0.0025 \\
\quad(2.46)\end{array}$ & & $\begin{array}{c}-0.0077 \\
(0.65)\end{array}$ & 0.9481 \\
\hline 3.9 . & 3.8985 & $\begin{array}{c}-2.0389 \\
(5.13)\end{array}$ & $\begin{array}{c}+0.0082 \\
(11.29)\end{array}$ & ........ & $\ldots \ldots$ & $\ldots \ldots$ & & $\ldots \ldots \ldots$ & 0.9302 \\
\hline 3.10 & 3.9417 & $\begin{array}{c}-2.2662 \\
(6.29)\end{array}$ & $\begin{array}{c}+0.0078 \\
(11.75)\end{array}$ & & . & $\begin{array}{c}+0.0236 \\
(2.61)\end{array}$ & & $\ldots \ldots$ & 0.9464 \\
\hline 3.11 . & 2.8581 & $\begin{array}{c}-1.2036 \\
(2.07)\end{array}$ & $\begin{array}{c}+0.0080 \\
(9.79)\end{array}$ & $\begin{array}{c}-0.0073 \\
(1.28)\end{array}$ & $\begin{array}{c}-0.0108 \\
(2.02)\end{array}$ & $\begin{array}{c}+0.0276 \\
(3.18)\end{array}$ & & & 0.9552 \\
\hline 3. & 3.0223 & $\begin{array}{c}-1.3327 \\
(2.28)\end{array}$ & $\begin{array}{c}+0.0073 \\
(11.14)\end{array}$ & $\ldots \ldots$ & $\begin{array}{c}-0.0106 \\
(1.96)\end{array}$ & $\begin{array}{c}+0.0286 \\
(3.24)\end{array}$ & & & 0.9535 \\
\hline
\end{tabular}

$P_{3}$-New York-Chicago auction price for late varieties, average for crate sales only, in dollars per crate.

$Q_{3}$-New York-Chicago auction sales of late varieties, sales in all containers, in 10,000 equivalent crates.

$Q_{2}$-New York-Chicago auction sales of midseason varieties, sales in all containers, in 10,000 equivalent crates.

$I$-Index of United States nonagricultural income payments, May-October average, 1935-1939 = 100 .

$T$-Time, in years, with origin at 1921 .

$S_{3}-$ Shipments of Oregon-Washington fresh prunes, in 100 carlots.

$\mathrm{S}_{4}$-Interstate shipments of California Thompson Seedless grapes, in 100 carlots.

$S_{5}$-Supply of intermediate peaches (total production in New York, New Jersey, Pennsylvania, Illinois, Michigan, Virginia, and Tennessee plus interstate shipments of California freestone peaches), in million bushels.

term. ${ }^{26}$ The various equations derived using $\log Q_{3}$ in place of $Q_{3}$ are shown in the lower portion of table 5 .

It will be noted that the successive addition of $S_{3}, Q_{2}$, and $T$ to the logarithmic formulation improves the fit, in the sense that the adjusted coefficient of multiple correlation is increased. In fact, equations (3.9), (3.10), and (3.11) provide a closer fit to the data than each of the corresponding arithmetic equations. The factor $T$ was eliminated from the equation since it is statis-

${ }^{26}$ Curvilinearity may be provided for in several ways. It is felt that using second and higher power terms of one (or more) of the independent variables has drawbacks. One of the most serious objections to using a Taylor expansion in this way lies in the fact that extremal values for the dependent variable are introduced into the hypothesis. If one of these (either a maximum or minimum) occurs within the range of observations, considerable difficulty may be encountered in justifying the results on theoretical grounds. A logarithmic term, on the other hand, gives a monotonic increasing or decreasing function (depending on the sign of the coefficient) and, thereby, generally provides a relation which is less likely to be in contradiction with a priori considerations. 
tically significant at only the 20 per cent level. Regression coefficients for $Q_{2}$ and $S_{3}$ have considerably higher $t$-ratios and were accepted as being statistically significant. Equation (3) is taken as a suitable explanation of variations
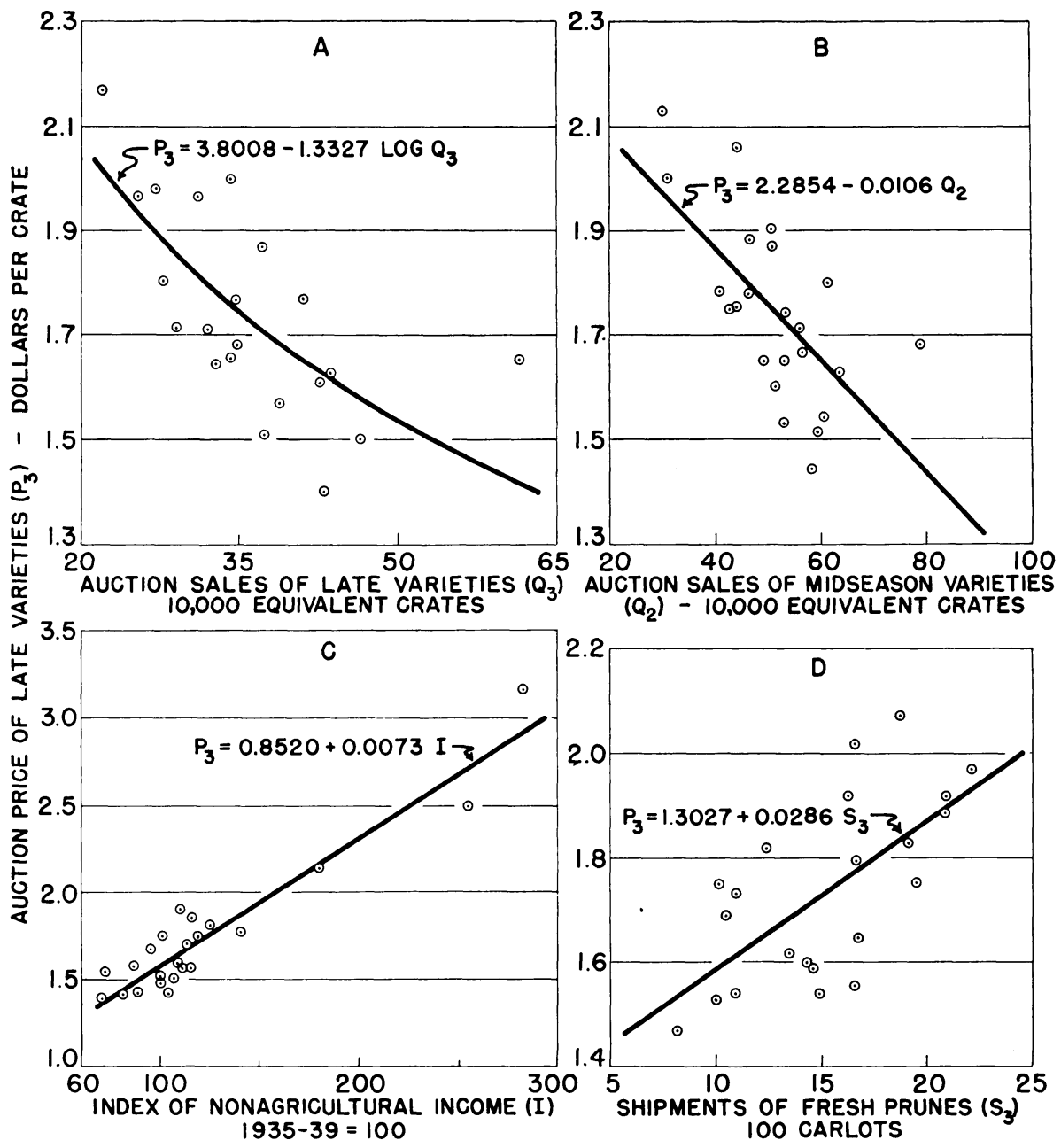

Fig. 4. Late California plums: net regressions of auction price on (A) auction sales of late varieties, (B) auction sales of midseason varieties, (C) index of nonagricultural income, and (D) shipment of fresh prunes. Based on equation (3).

in auction prices of late plums, in spite of the fact that the adjusted coefficient of multiple correlation $(\bar{R}=0.954)$ is not appreciably larger than in the case of several of the other equations, and is slightly lower than for equation (3.11). Residuals for equation (3) are plotted in figure 4.

The auction price of late plums was found to be related to the quantity of midseason varieties sold. The magnitude of the average effect is almost as 
large as was secured for the influence of sales of early varieties upon the price of midseason plums. However, the direction of the influence is reversed. Midseason and late plums seem to be competing commodities. There is no basis for rejecting this direction of influence as unreasonable. The separation between the marketing periods for midseason and late plums is quite clear-cut. Furthermore, four of the five important varieties classified as "late plums" are European varieties, which are not as acceptable to consumers as Japanese plums.

As was indicated above the "supply of other fruits" was introduced into the equation by three separate variables. Two of these (the supply of intermediate peaches, and interstate shipment of California Thompson Seedless grapes) do not appear to be related to auction prices of late plums. Shipments of fresh prunes from Oregon and Washington, however, proved to be a significant variable. The positive sign of the regression coefficients is of particular interest for it indicates that a change in the volume of fresh prunes shipped was, on the average, associated with a change in the same direction in the price received. This positive relation requires some explanation. Ordinarily, the peak of shipment of late plums is reached during the second week in August and almost the entire quantity is shipped from the state before the peak movement of fresh prunes from Oregon and Washington occurs. Thus, even though the marketing seasons for the two fruits are approximately the same, the pattern of shipments is sufficiently different so that only during a period of about two weeks (the middle part of August) are sales of both commodities large. Furthermore, Oregon-Washington prunes have a three-way outletdrying, canning, and fresh use. ${ }^{27}$

It would appear reasonable to say that when the combined influence of the factors omitted from the formulation (i.e., in equation 3 ) is such that a higher demand for late plums would prevail than is indicated by the equation, there would be a tendency for sales of fresh prunes to be increased at the expense of processing. Similarly when a low level of demand for late plums (and probably for all fresh fruits) exists, a relatively larger quantity of fresh prunes will tend to be processed. The net regression coefficient $(0.0286)$ indicates that, on the average, a change of 100 carlots in the shipments of fresh prunes during 19221947 was associated with a change in the same direction of 2.86 cents per crate in the auction price of late plums. Only infrequently is the variation in shipments of fresh prunes from one year to the next associated with a change of as much as 20 cents per crate in the price of late plums. This evidence of a complementary relation between late California plums and Northwest fresh prunes seems to suggest that possibly sales of late plums help to make or break the market for fresh prunes which are sold primarily after rather than during the plum season.

${ }^{2 \pi}$ It is recognized, however, that fresh supplies come largely from the eastern portions of Oregon and Washington whereas quantities for processing are drawn principally from the crop produced in the western areas. Yet when demand is particularly strong in one outlet, relative to the other, there is a significant amount of western prunes sold in fresh form or of eastern prunes processed, as the case may be. 
Summary. The final regression equations (Nos. 1, 2, and 3), relating auction prices of California plums as simple functions of auction sales and a few shift variables, were found to fit the data closely for the period 1922-1947, exclusive of the war years 1943-1945 (see table 6). The results obtained do not contradict expectations deduced from theoretical considerations. For each varietal group 91 to 95 per cent of the variation in auction prices is "accounted for" by the combined influences of and variations in auction sales, nonagricultural

TABLE 6

California Plums: Summary of Statistical Measurements for Varietal Regression Analysis

\begin{tabular}{|c|c|c|c|}
\hline Item & $\begin{array}{c}\text { Early } \\
\text { varieties }\end{array}$ & $\begin{array}{c}\text { Midseason } \\
\text { varieties }\end{array}$ & $\begin{array}{c}\text { Late } \\
\text { varieties }\end{array}$ \\
\hline \multicolumn{4}{|l|}{ A: Oriuinal obsercations ${ }^{\mathrm{a}}$} \\
\hline Average price $\left(P_{i}\right)$-dollars per crate. & 1.837 & 1.739 & 1.740 \\
\hline Standard deviation of prices.......... & 0.699 & 0.575 & 0.473 \\
\hline A verage sales $\left(Q_{2}\right)-10.000$ crates.... & 46.126 & 51.543 & 36.048 \\
\hline Standard deviation of sales........ & 9.882 & 10.441 & 8.108 \\
\hline Coefficient of variation for sales-per cent. & 21.42 & 20.26 & 22.49 \\
\hline \multicolumn{4}{|l|}{ B: Final equations b } \\
\hline Net regression of price on sales............ & -0.0140 & -0.0270 & $-0.0161^{\mathrm{c}}$ \\
\hline Net regression of price on preceding sales ${ }^{d}$. & $\ldots \ldots \ldots$ & +0.0125 & -0.0106 \\
\hline Net regression of price on income......... & +0.0141 & +0.0112 & +0.0073 \\
\hline Net regression of price on "other fruits" & $\ldots \ldots \ldots$ & -0.0311 & +0.0286 \\
\hline Coaff cient of multiple correlation $(\bar{R}) \ldots$ & 0.973 & 0.975 & 0.954 \\
\hline Coefl cient of multiple determination $\left(\bar{R}^{2}\right)$ & 0.947 & 0.951 & 0.909 \\
\hline Standard error of estimate $(\bar{S}) \ldots \ldots \ldots \ldots$ & 0.164 & 0.131 & 0.146 \\
\hline Flexibility of price at centroid $(\lambda) \ldots \ldots$ & -0.352 & -0.800 & -0.333 \\
\hline Reciprocal of flexibility $(1 / \lambda)^{f} \ldots \ldots \ldots$ & -2.841 & -1.250 & -3.005 \\
\hline
\end{tabular}

a For 1922-1942 and 1946-1947. The income series has an average of 120.870 and standard deviation of 51.032

b Equations (1), (2), and (3).

c The net regression of price on sales $(\partial P / \partial Q)$ varies with the level of sales since $Q_{3}$ is introduced in logarithmic form. The value given in the table is the net regression for average sales (36.048).

d That is, regression of price $\left(P_{i}\right)$ on $Q_{i}-1$.

"Production of "early peaches" and shipments of fresh prunes for midseason and late varieties, respectively.

f Computed by the formula $\lambda=\frac{\partial P}{\partial Q} \bar{Q} / \bar{P}$.

Source of Data: Tables 2 to 5 and calculations derived from equations (1), (2), and (3).

income, and the other independent variables used in the analyses. The adjusted coefficients of multiple correlation determined are $0.973,0.975$, and 0.954 , respectively, for early, midseason, and late varieties. In accordance with a priori expectations, the net price-quantity relations are negative and the net price-income relations are positive.

Auction prices of midseason and late plums are related to the volume of sales for the preceding varietal group. Sales of early plums have a positive effect upon the auction price received for midseason varieties, whereas sales of the latter affect the auction price of late plums negatively. The direction of these influences is in accord with opinions frequently expressed by many plum shippers. The magnitudes of these influences (see table 6) appear reasonable, particularly when compared with the net regressions of price on 
sales of the same variety. At least, there is no basis for expecting substantially higher or lower values for the net regression coefficients.

Production of early peaches $\left(S_{2}\right)$ and shipments of Oregon-Washington fresh prunes $\left(S_{3}\right)$, taken to represent the "supply of other fruits," are correlated with auction prices of midseason and late varieties, respectively. The $t$-ratios of the two net regression coefficients are 3.25 , indicating that the values obtained are significant at even the 1 per cent level. Justification for the negative sign in the first case and the positive sign in the second has already been given.

The time-trend factor proved to be a significant variable in the case of midseason varieties but not for early or late plums. For midseason plums there is a persistent decline in the net price-quantity relation over time after allowance is made for the influence of sales (of early and midseason varieties), income, and supply of other fruits. The upward trend over time in the residuals for early varieties and the downward trend in the residuals for late plums were not considered to be significant. ${ }^{28}$ Since the analyses cover the period since 1922, during which the size of the consuming market expanded substantially and changes in the "commodity" and in consumer preferences occurred, it might be presumed that the net effect of the various trend factors represented by "time" might be considerable. At least a partial explanation of why "time" does not appear as an important factor in the analyses is given by the data. The index of nonagricultural income and the volume of auction sales show definite and pronounced upward trends during 1922-1947. Consequently, a portion of the influence of "time" actually may be entering through the variables $I$ and $Q_{i}$.

It is of considerable interest to compare the net price-quantity and priceincome relations for the three varietal groups (see figure 5). On the average for the period under study, a change of 10 percentage points in the index of nonagricultural income was accompanied by a change in the same direction of $14.0,11.2$, and 7.3 cents per crate in the auction price of early, midseason, and late plums, respectively. A change of 10,000 crates in auction sales (at New York and Chicago) had a net influence on price (in the opposite direction) of $1.40,2.70$, and 1.61 cents per crate..$^{29}$

Thus the net regression of price on income decreases within the season as later varieties are marketed-i.e., prices become less and less responsive to changes in income as the season advances. The net regression of price on sales is considerably greater in magnitude for midseason plums than for earlier or later varieties-indicating that changes in sales affect prices considerably more in the case of midseason varieties.

${ }^{28}$ These residuals were computed from equations 1 and 3 , respectively. The largest $t$-values for the net regressions of price on time obtained for any of the equations fitted (see tables 3 and 4 ) are 0.97 and 1.46. The time series plot of the residuals for equations 1,2 , and 3 are shown in figure B-3 of Appendix B.

${ }^{29}$ In the case of late plums the net regression indicated represents the slope of a tangent to the net price-quantity relation at the average volume of sales $(360,480$ crates $)$. For sales of 280,000 and 440,000 crates $\left(\bar{Q}_{3} \pm S D_{3}\right)$ the negative slopes of the tangent are 2.07 and 1.32 cents per crate for a change of 10,000 crates in sales. 


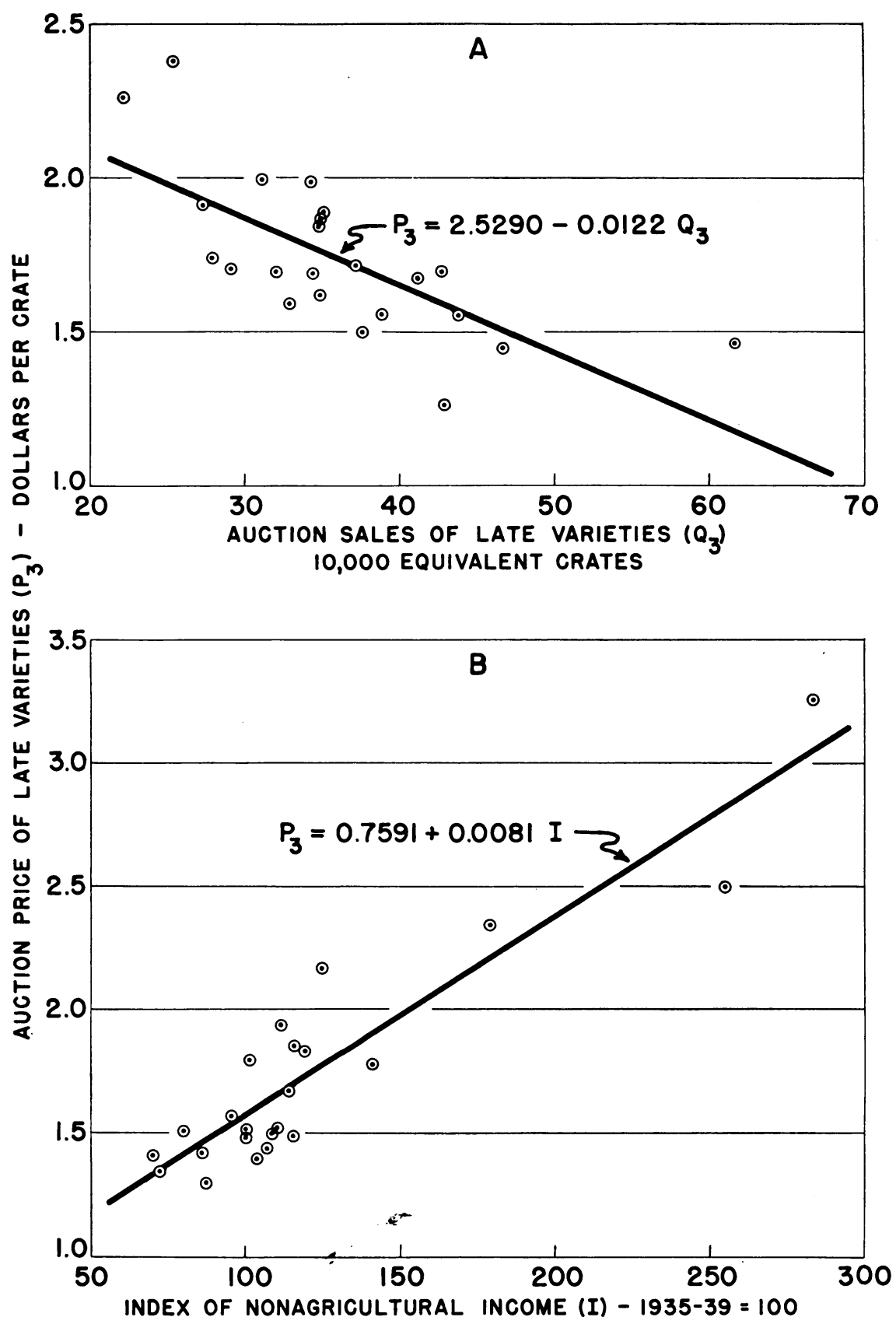

Fig. 5. California plums by varietal groups : net regressions of auction price on (A) auction sales and (B) index of nonagricultural income. Based on equations (1), (2), and (3). 
In order to indicate how responsive prices are to changes in sales, coefficients of price flexibility were calculated at the centroids. ${ }^{30}$ The values secured for early, midseason, and late varieties are $-0.352,-0.800$, and -0.333 - with reciprocals of $-2.84,-1.25$, and -3.00 . The value determined for early varieties by equation (1) is approximately equal to that obtained for the logarithmic equations (see table 3 ). For midseason varieties lower values (ranging down to $\lambda=-0.53$ ) are given by the other equations listed in table 4 . The arithmetic equations for late plums (see table 5) give values for $\lambda$ varying from -0.20 to -0.51 . This information indicates that auction prices are not very responsive to changes in quantity, i.e., that demand, at the auction level, is fairly elastic.

The interpretation of the results obtained must be modified if the assumption that the 23 residuals determined for each of the final equations have come from a population with no autocorrelation has to be rejected..$^{31}$ The ratio of mean square successive difference to the variance $\left(\delta^{2} / S^{2}\right)$ is often used currently to test the existence of correlation between successive values of residuals where

$$
\delta^{2}=\frac{1}{n-1} \sum_{i=2}^{n}\left(x_{i}-x_{i-1}\right)^{2}, \quad S^{2}=\frac{1}{n} \sum_{i=1}^{n}\left(x_{i}-\bar{x}\right)^{2}
$$

and $n$ is the number of residuals. ${ }^{32}$

For 23 observations the admissible range at the 1 per cent level is $1.1456 \leqq$ $\frac{\delta^{2}}{S^{2}} \leqq 3.0362$. The computed values of the ratio are $2.5116,1.3265$, and 1.8225 for the final equations for early, midseason, and late varieties. This means that the hypothesis of zero autocorrelation in the residuals need not be rejected. In this connection it might be noted that the correlation of residuals lagged one year gives $r_{i(i-1)}=-0.206,0.331$, and 0.045 for the three varietal groups.

\section{TEMPORAL INTERRELATIONSHIPS IN DEMAND}

Results of the above varietal analysis suggest the possibility that the net regressions of auction prices on some of the independent variables do not remain fixed throughout a marketing season. This temporal analysis represents

${ }^{30}$ The formula used is $\lambda=\frac{\partial P_{i}}{\partial Q_{i}} \bar{Q}_{i} / \bar{P}_{i}$. For the linear formulation (equations 1 and 2 ), this reduces to $\lambda=b_{i} \bar{Q}_{i} / \bar{P}_{i}$, where $b_{i}$ is the net regression coefficient of price on sales and $\bar{Q}_{i}$ and $\bar{P}_{i}$ are the means of auction sales and auction prices $(i=1,2)$. For equation (3), $\frac{\partial P_{i}}{\partial Q_{i}}=-\frac{b_{3}}{Q_{3}} \log _{10} e$ so that at the centroid $\lambda=-0.4343 b_{3} / \bar{P}_{3}$. The coefficient of elasticity of demand is calculated by $\eta=\frac{\partial Q_{i}}{\partial P_{i}} \bar{P}_{i} / \bar{Q}_{i}$ where $\frac{\partial Q_{i}}{\partial P_{i}}$ is the regression slope determined from the equation using sales as the dependent variable, rather than merely being the reciprocal of $\frac{\partial \hat{P}_{i}}{\partial Q_{i}}$ which was used in computing $\lambda$. Where the coefficient of partial correlation is high the two regression slopes will tend to be reciprocals of each other and, therefore, $1 / \lambda$ may be taken as an approximation for $\eta$.

${ }^{31}$ The residuals for equations (1), (2), and (3) are plotted as time series in the Statistical Appendix, figure B-3.

${ }^{32}$ For an explanation of this test see: Von Neumann, Kent, Bellison, and Hart (1941); and Von Neumann (1941). A table of probabilities for the ratio $\delta^{2} / S^{2}$ is given in Hart (1942). 
an attempt to determine the extent to which the levels and slopes of the net regression relations may change in some systematic manner as the season progresses. It is necessary first to indicate the nature and importance of this problem and to direct attention toward several alternative hypotheses which might be formulated as a basis for determining the principal factors responsible for variations in weekly auction prices of California plums. The results obtained for the analysis are presented in considerable detail in the third part of this section.

TABLE 7

California Plums: Weekly New York Auction Prices and Sales Averages and Standard Deviations for 1928-1948, Excluding 1942-1945

\begin{tabular}{|c|c|c|c|c|}
\hline \multirow{2}{*}{ Week of season } & \multicolumn{2}{|c|}{ New York auction price } & \multicolumn{2}{|c|}{ New York auction sales } \\
\hline & Average & $\begin{array}{l}\text { Standard } \\
\text { deviation }\end{array}$ & Average & $\begin{array}{l}\text { Standard } \\
\text { deviation }\end{array}$ \\
\hline & \multicolumn{2}{|c|}{ dollars per crate } & \multicolumn{2}{|c|}{1,000 crates } \\
\hline $2 \ldots$ & 3.012 & 1.752 & 21.44 & 10.52 \\
\hline $3 \ldots$ & 2.489 & 1.324 & 47.22 & 15.32 \\
\hline $4 \ldots \ldots$ & 2.129 & 1.088 & 71.72 & 19.29 \\
\hline $5 \ldots$ & 1.916 & 0.915 & 84.33 & 16.37 \\
\hline $6 \ldots \ldots \ldots$ & 1.936 & 0.933 & 94.67 & 24.22 \\
\hline 7 . & 2.071 & 1.058 & 103.17 & 39.57 \\
\hline 8. & 2.038 & 0.978 & 99.94 & 22.76 \\
\hline 9. & 1.963 & 0.788 & 83.44 & 20.19 \\
\hline 10. & 1.834 & 0.696 & 86.78 & 22.73 \\
\hline $11 \ldots \ldots \ldots \ldots$ & 1.814 & 0.612 & 74.00 & 21.29 \\
\hline 12. & 1.773 & 0.539 & 72.33 & 20.62 \\
\hline 13. & 1.696 & 0.404 & 58.22 & 21.48 \\
\hline $14 \ldots \ldots \ldots$ & 1.771 & 0.585 & 39.83 & 15.94 \\
\hline$\ldots \ldots \ldots \ldots$ & 1.826 & 0.698 & 26.22 & 14.76 \\
\hline 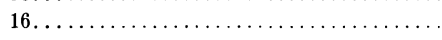 & 2.011 & 0.829 & 16.00 & 12.35 \\
\hline $2-16 \ldots$ & 2.019 & 0.994 & 65.29 & 34.90 \\
\hline
\end{tabular}

Source of Data: Statistical Appendix, tables A-6, A-7.

\section{The Problem of Temporal Demand Shifts}

The typical patterns of weekly auction sales and prices of plums have undergone considerable change during the past several decades. Gradually sales have become more uniformly distributed throughout the season and, as a result, the variation in weekly prices has been considerably reduced. Average variations in weekly prices and sales for the period 1928-1948 are shown in table 7 . Reference to these data indicates that during early weeks prices generally decline as the quantity sold increases. Then after the peak of the season is passed and sales decrease, prices rise again but at a somewhat slower rate than the preceding decline. This pattern and the results obtained for the varietal analysis suggest the possibility that the net regression relations may not remain constant, even approximately, as to level or slope during successive weeks of a season. 
Such intraseasonal shifts, if they exist, are of importance to all shippers. They assume particular significance when centralized direction over marketings is undertaken in an endeavor to increase total returns by modifying, directly or indirectly, the temporal distribution of sales. The principal problem to be considered here is one of determining the extent to which fluctuations in weekly prices may be "explained" by variations in weekly sales and of indicating the importance of a weekly shift in the net price-quantity relation.

Data on weekly prices and sales for weeks 2 through 16 of each season were used in this analysis. ${ }^{33}$ Because of the magnitude of the computations that would be involved in using data relating to several markets, the study is confined to the New York auction market. However, since almost half of the total auction sales (and approximately one-third of the plums shipped from California) are sold on this market, it is felt that the results secured would not be altered significantly if data representing a larger proportion of the total sales had been used in the analysis. The period covered is 1928-1948. As in the case of the varietal analysis, the war years, 1943-1945, were excluded. Thus price and quantity data for fifteen weeks during eighteen seasons, i.e., 270 separate observations, were included in this study (see Statistical Appendix, tables A-6, A-7).

Using a single value of the index of nonagricultural income, as was done in the varietal analysis, for all fifteen weekly observations of each season does not appear to be a satisfactory procedure. It seems advisable to provide for intraseasonal variations in the index. An arbitrary rule was adopted for deriving weekly values of the index from the published monthly figures. The value of the index for the month into which a particular week falls (according to actual calendar dates) was used for the second and third weeks. For the first and fourth (or fifth) weeks a simple average of the values of the index for the two adjacent months was used. By this procedure the values of the index used for successive weeks (Statistical Appendix, table B-4) form a smoother series than would be the case if all weeks within each calendar month were given the same value.

\section{Alternative Hypotheses}

Weekly prices can be expressed as a function of weekly sales and of the shift variables in several different ways. Each separate formulation implies a specific hypothesis as to how the influences effect changes in the price level. Unfortunately, there is no statistical basis for comparing one hypothesis with another. It is well, therefore, to contrast two ultimate procedures in order to

${ }_{33}$ The second week of each season was numbered week 2 and succeeding weeks were designated as weeks $3,4,5$, etc., regardless of their calendar classification. This was done as a means of getting greater comparability between observations. The arbitrary nature of this procedure is fully recognized. An alternative adjustment would have been one aimed at attempting to synchronize the entire season's sales for each year in some way or another. The various "rules" which come to mind (such as counting as "week 2" that 7-day period during which accumulated sales amount to some specified portion of the season's total) are difficult to apply satisfactorily and become as arbitrary as the method used. It is felt that considerable improvement over the calendar classification has been made by the above procedure. 
indicate clearly the differences involved. By limiting attention to these two, it is not intended to imply that these are the only suitable formulations which can be made. Actually, other reasonable relations can be postulated.

For this exposition it will be assumed that weekly auction prices $\left(P_{i}\right)$ are to be related to weekly auction sales for the current week $\left(Q_{i}\right)$ and for the preceding week $\left(Q_{i-1}\right)$, to the index of nonagricultural income $\left(I_{i}\right)$, and to the week of the season $(W=i)$. For convenience the following explanation is confined to arithmetic equations, including only the most important independent variables. These equations can be generalized easily by adding other shift variables and introducing curvilinearity and various joint effects.

First, it might be assumed that the level and slope, and even the form, of the net price-quantity and other relations should be left free to vary from week to week. ${ }^{34}$ In essence, the procedure involves considering the data as several sets of observations, one for each week of the season and fitting the data for each week separately to the relevant data. The types of changes permitted to occur are implied by the equations used. Thus, the equations used for each week may be of the form:

(a) $\quad P_{i}=a+b Q_{i}+c I_{i}+d Q_{i-1}$, where $i=$ week of season.

The data used in the fitting may be either the actual values or their logarithms. In either case the differences for the various weeks are limited to changes in levels and slopes. If on the other hand, the specific terms included in the equations are altered from week to week, the type of relation is also left free to change.

To the extent that uniformity in the shifts of the net regression lines might be indicated, the investigator would be tempted to "smooth out" the pattern. Presumably, the differences in levels and slopes would be considered of small, or at least not striking, significance unless an "orderly fan-shaped arrangement of the regression lines" 35 is noted. The lack of some such systematic arrangement is likely to be accepted as evidence indicating that the differences obtained are not significant.

The reverse of this procedure gives an alternative approach. It provides the basis for the hypotheses tested in the following temporal analysis. This second approach considers all the weekly observations as an entirety, rather than as a set of several series of data, uses a generalized formulation, and tests whether systematic changes in the regression lines are statistically significant. Parallel shifts in the net price-quantity relation may be secured by introducing "week of the season" as a new independent variable $(W)$. By using a power series in $W$ nonuniform parallel shifts of any degree of curvilinearity may be specified.

Obviously, this hypothesis should be generalized to provide for changes in the slopes, as well as in the levels, of the net regressions as the season progresses. By adding specified products of the variables $\left(Q_{i}, Q_{i-1}, I_{i}\right.$ and $\left.W\right)$ the in-

${ }^{34}$ This is the substance of the procedure used by Mehren and Erdman (1946) in their study of weekly prices of Louisiana strawberries.

${ }^{35}$ Ibid., p. 594. 
vestigator can relate such systematic shifts in the slopes to the influence of any desired variables. Thus, for example, it may be desired to permit the various net regression lines to rotate (i.e., to increase or decrease in slopes) at a uniform rate as the season advances. Introducing both changes (in levels and slopes) simultaneously gives the following equation to be compared with (a):

$$
\text { (b) } P_{i}=a+\left(b+b^{\prime} W\right) Q_{i}+\left(c+c^{\prime} W\right) I_{i}+\left(d+d^{\prime} W\right) Q_{i-1}+\left(e+e^{\prime} W\right) W
$$

where $i=W=$ week of season.

An objection might be raised that this provision for a uniform rate of change in the demand curve places a severe constraint on the data. By the use of second and higher degree terms of $W$ in the brackets of (b), however, the rates at which the net regression coefficients change over the season may be increased or decreased gradually, or altered in some other and more intricate fashion. There remains also the possibility of using other product terms, such as $Q I$ and $Q I W$. It should be pointed out that the more complex the function is made, by the use of such additional terms, the more difficult it is to make a suitable economic justification even though the statistical fit is improved.

The approach represented by equations of type (b) restricts the shifts (in level and slope) of the net regression lines to a well-defined, smooth pattern. The view that the underlying relation can be so described is defensible if the forces producing the shifts may be assumed not to change the magnitude of their influence abruptly. Of course, the question might be posed as to whether this procedure assumes too much. At any rate, it may be desirable to consider it again in contrast to the method specified by (a). It would appear that the principal difference between the two procedures lies in the view taken as to the desirability of taking the entire set of weekly observations and fitting a generalized function which embodies the various types of changes justified by a priori considerations or of fitting separate functions to the data for successive weeks and then noting the uniformity in changes of the regression lines.

This study of temporal interrelations in the auction demand for California plums is made on the basis of equation (b). Actually, the approach underlying method (a) was used indirectly as a preliminary step to provide indications as to the extent to which departures from uniformity in intraseasonal demand shifts occur. Thus, for example, the results of the varietal analysis were accepted as evidence suggesting that the net price-quantity and price-income relations should be permitted to change in slope.

\section{Results Obtained}

Several equations based on formulation (b) were fitted to the 270 observations covering weekly prices and sales at the New York auction market for 1928-1948, excluding the war years 1943-1945. Four independent factors were used: auction sales of the current and immediately preceding week $\left(Q_{i}\right.$ and $\left.Q_{i-1}\right)$, index of nonagricultural income $\left(I_{i}\right)$, and week of season $(W=i)$. Changes in the general formulation were secured by introducing the independ- 
ent variables in various combinations. Results for the seven equations fitted to the data are summarized in table 8 . In each case the adjusted coefficient of multiple correlation has a high value (between 0.88 and 0.93 ), indicating that 79 to 85 per cent of the variations in weekly auction prices during 1928-1948 may be "explained" by the combined influence of covariations in auction sales, consumer income, and week of season. The signs of the regression coefficients do not contradict a priori expectations as to direction of influence. Generally,

TABLE 8

California Plums: Regression Coefficients and Auxiliary Constants for Weekly Analysis, 1928-1948, Excluding 1943-1945

Price $\left(P_{i}\right)$ as the Dependent Variable

\begin{tabular}{|c|c|c|c|c|c|c|c|c|c|}
\hline \multirow{3}{*}{ Equation } & \multirow{3}{*}{$\begin{array}{c}\text { Constant } \\
\text { term }\end{array}$} & \multicolumn{7}{|c|}{ Net regression coefficients (figures in parentheses are $t$-ratios) } & \multirow{3}{*}{$\begin{array}{l}\text { Adjusted } \\
\text { coefficient } \\
\text { of } \\
\text { multiple } \\
\text { correla- } \\
\text { tion } \\
\bar{R}\end{array}$} \\
\hline & & \multirow{2}{*}{$\begin{array}{c}\text { Sales of } \\
\text { current } \\
\text { week } \\
Q_{i}\end{array}$} & \multirow{2}{*}{$\begin{array}{c}\text { Nonagric. } \\
\text { income } \\
I\end{array}$} & \multirow{2}{*}{$\begin{array}{c}\text { Week } \\
\text { of } \\
\text { season } \\
W\end{array}$} & \multirow{2}{*}{$\begin{array}{c}\text { Sales of } \\
\text { previous } \\
\text { week } \\
Q_{i}-1\end{array}$} & \multicolumn{3}{|c|}{ Product terms } & \\
\hline & & & & & & $W Q_{i}$ & $W I$ & $W^{2}$ & \\
\hline & 1.6820 & $\begin{array}{c}-0.0941 \\
(11.28)\end{array}$ & $\begin{array}{c}+0.0118 \\
(29.13)\end{array}$ & $\begin{array}{c}-0.0739 \\
(11.00)\end{array}$ & $\ldots$ & & . & - & 0.8863 \\
\hline 4.2 . & 1.6497 & $\begin{array}{c}-0.0877 \\
(4.08)\end{array}$ & $\begin{array}{c}+0.0119 \\
(28.50)\end{array}$ & $\begin{array}{c}-0.0707 \\
(5.98)\end{array}$ & $\ldots \ldots \ldots$ & $\begin{array}{c}-0.00077 \\
(0.33)\end{array}$ & . & & 0.8859 \\
\hline 4.3 . & 0.5583 & $\begin{array}{c}-0.0826 \\
(11.56)\end{array}$ & $\begin{array}{c}+0.0194 \\
(24.06)\end{array}$ & $\begin{array}{c}+0.0416 \\
(3.32)\end{array}$ & & $\ldots \ldots$ & $\begin{array}{c}-0.00083 \\
(10.35)\end{array}$ & & 0.9202 \\
\hline 4.4 . & -0.3482 & $\begin{array}{c}-0.1267 \\
(10.11)\end{array}$ & $\begin{array}{c}+0.0120 \\
(29.91)\end{array}$ & $\begin{array}{c}+0.0765 \\
(1.73)\end{array}$ & .. & & $\ldots \ldots$ & $\begin{array}{c}-0.0087 \\
(3.43)\end{array}$ & 0.8910 \\
\hline 4.5 . & 0.4533 & $\begin{array}{c}-0.0996 \\
(8.98)\end{array}$ & $\begin{array}{c}+0.0192 \\
(23.72)\end{array}$ & $\begin{array}{c}+0.1134 \\
(2.97)\end{array}$ & . & & $\begin{array}{c}-0.00080 \\
(9.81)\end{array}$ & $\begin{array}{c}-0.0044 \\
(1.99)\end{array}$ & 0.9211 \\
\hline 4.6 . & 0.5325 & $\begin{array}{c}-0.0665 \\
(5.54)\end{array}$ & $\begin{array}{c}+0.0194 \\
(24.11)\end{array}$ & $\begin{array}{c}+0.0463 \\
(3.62)\end{array}$ & $\begin{array}{c}-0.0188 \\
(1.67)\end{array}$ & & $\begin{array}{c}-0.00083 \\
(10.36)\end{array}$ & $\ldots \ldots$ & 0.9208 \\
\hline 4. & 0.3022 & $\begin{array}{c}-0.0804 \\
(6.44)\end{array}$ & $\begin{array}{c}+0.0189 \\
(23.70)\end{array}$ & $\begin{array}{c}+0.1882 \\
(4.24)\end{array}$ & $\begin{array}{c}-0.0402 \\
(3.15)\end{array}$ & & $\begin{array}{c}-0.00076 \\
(9.47)\end{array}$ & $\begin{array}{c}-0.0084 \\
(3.33)\end{array}$ & 0.9238 \\
\hline
\end{tabular}

$P_{i}$-New York auction price for week $i$, average for crate sales only, in dollars per crate.

$Q_{i}$-New York auction sales of week $i$, crate pack only, in 10,000 crates.

$I$-Index of United States nonagricultural income pay ments, derived weekly figures, $1935-1939=100$.

$W$ - "Week of season" numbered in sequence (regardless of calendar classification) from week of first sales.

the $t$-ratios for the net regression coefficients are quite large, indicating that even if the 1 per cent probability level were used, the null hypothesis would be rejected.

Equations Derived. For those cases where the net regression relations are permitted to change their slope as well as their level as the season advances, the different equations give equally good empirical fits to the data: $\bar{R}$ being approximately 0.92 for each equation. The selection of the appropriate equation cannot be made primarily on statistical grounds, however, since no statistical procedure currently avańlable can be used to indicate which one of several equations, fitting the data equally well, should be employed. Considerations of simplicity, economic theory, and the nature of the commodity must serve as guides in this choice of the proper function. A brief discussion of the various equations, summarized in table 8 , will indicate their comparative usefulness as explanations. 
If weekly auction prices are related linearly to auction sales, nonagricultural income, and week (equation 4.1), a satisfactory fit is secured $(\bar{R}=0.886)$ and the $t$-ratios for the net regression coefficients are extremely high. Plotting the residuals about the net price-week regression indicates that an irregular distribution is not secured. Furthermore, when the residuals are plotted about the other two net regression lines, it becomes quite apparent that the eighteen residuals for each week, corresponding to the different years, show pronounced departures from the average relations established for the entire set of 270 observations. Particularly in the case of the net price-income relation there appears to be a clear indication that the slope of this regression changes in some systematic fashion as the season advances.

Several product terms $\left(W Q_{i}, W I\right.$, and $\left.W W\right)$, therefore, were introduced to allow the regression lines to change their slopes uniformly (see equations 4.2, 4.3 , and 4.4).

The best improvement in fit is secured by the addition of $W I$, i.e., by permitting the net regression of price on income to change its slope from week to week. The $t$-ratio (10.4) is very high and indicates that this product term is definitely significant. From a theoretical point of view such a shift is justified. However, postulating a uniform shift may be too simple a hypothesis even though it may serve as a useful first approximation. Apparently, the net pricequantity relation does not change its slope in this simple manner-the $t$-ratio for the net regression coefficient of $W Q_{i}$ is only 0.3 . Adding $W^{2}$ to equation 4.1 improves the fit slightly but makes the $W$ term much less significant $(t=1.7)$ than it is when $W^{2}$ is not used. It appears, therefore, that $W I$ and $W^{2}$ should be introduced simultaneously.

Consideration should also be given to introducing the temporal interdependence of plum supplies in some manner. Because of the perishable nature of the commodity, the limited use of storage, and the declining pattern of prices during the season, the exclusion of future supplies from consideration as a factor affecting prices during any particular week seems defensible. This does not deny the possibility that prospective volume and distribution of supplies during the balance of the season may, at least during some years, influence weekly prices. There is, however, no overwhelming justification for assuming that expectations play a decisive role in systematically affecting weekly prices. A new variable $\left(Q_{i-1}\right)$, representing sales for the preceding week, was introduced linearly as the simplest way of including the influence of past sales.

Equations (4.5), (4.6), and (4) show the results secured when the product terms are introduced in combination and sales of the preceding week are added as a nêw independent variable. Two facts emerge sharply from a comparison of these equations. First, the data may be fitted with approximately equal precision by any of these three equations. Second, the $t$-ratios are sufficiently high to force rejection of the hypothesis that any of the factors $\left(Q_{i}, Q_{i-1}, I\right.$ and $W)$ or the product terms $\left(W I, W^{2}\right)$ are not statistically significant. Since the net price-quantity relation did not appear to shift its slope in equation 4.2 , the $W Q_{i}$ product term was not reintroduced into the latter equations. For this 
same reason it seemed unnecessary to add a product term $W Q_{i-1}$ to provide for changes in the net regression of price on sales of the preceding week.

Equation (4), while not simple, is not unduly complex. It includes the influence of sales during the preceding week (as a first approximation to the combined effect of sales of plums during weeks of the season other than the particular one upon which attention is temporarily focused) and provides for a uniform shift in the net price-income relation as the season progresses. Actually, the fit secured is no improvement over equations (4.3), (4.5), or (4.6) in which fewer terms are used. The net regression coefficients for price on income and on the product term $W I$ are practically the same for all four equations. The regressions of price on "week" at various levels of income, however, are quite different for the various equations. Finally, there is a substantial difference between them with respect to the net regression of price on sales.

The Final Function. In view of the above comparison of results for the various functions, equation (4) is selected as an adequate description of the relation prevailing during 1928-1948. It does not contradict any expectations as to direction of influence deduced from theory and acquaintance with the commodity and its marketing. The relation includes the most important factors affecting changes in weekly auction prices for California plums and provides a very good fit to the weekly data $(\bar{R}=0.924)$. The $t$-ratios for the various net regression coefficients are high - the lowest value corresponds to a probability level of approximately 0.1 per cent. ${ }^{36}$ This final equation may be written in several alternative ways, for example:

$$
\begin{aligned}
P_{i}= & 0.3022-0.0804 Q_{i}-0.0402 Q_{i-1} \\
& +(0.1882-0.0084 W) W+(0.0189-0.00076 W) I
\end{aligned}
$$

or

$$
\begin{aligned}
P_{i}=0.3022-0.0804 Q_{i}-0.0402 Q_{i-1}+0.0189 I \\
+(0.1882-0.00076 I-0.0084 W) W
\end{aligned}
$$

Several facts of considerable interest and importance can be noted easily from the above. The net regressions of price on current sales and on preceding week's sales are negative in agreement with expectations, and remain constant (at -0.0804 and -0.0402 , respectively) regardless of the level of income or week of season considered. On an average during the period under study, a change in the current week's sales was associated with twice as large a price effect as was produced by an equal change in the sales of the preceding week. The net regressions of price on income and on week change with $W$ and $I .{ }^{37}$

\footnotetext{
${ }^{36}$ Of course, there may be considerable doubt as to whether the successive observations may be considered to constitute set of random drawings. This difficulty restricts the interpretation given to the $t$-values, since the computed standard errors lose some of their relevance, if the successive residuals are interdependent. This problem will be discussed below in section $\mathrm{F}$.

${ }^{37}$ From $P_{i}=0.3022-0.0804 Q_{i}-0.0402 Q_{i-1}+0.0189 I+0.1882 W-0.00076 W I-0.0084 W^{2}$ $\frac{\partial P_{i}}{\partial I}=0.0189-0.00076 \mathrm{~W}$ and $\frac{\partial P_{i}}{\partial W}=0.1882-0.00076 I-0.0168 \mathrm{~W}$.

The regression of price on income $\left(\frac{\partial P_{i}}{\partial I}\right)$ becomes negative for $W \geqq 24.9$, which is con-
} 
As the season advances, the net price-income relation decreases, i.e., the positive slope is diminished for larger values of $W$. The net price-week relation changes with variations in both $W$ and $I$ and is curvilinear (concave from below). The maximum point on this relation moves to the left (i.e., corresponds to earlier weeks of the season) as higher levels of income are considered.

\section{TABLE 9}

California Plums: Weekly Regression Equations and Estimated Weekly Prices at Three Income Levels. 1928-1948, Excluding 1943-1945

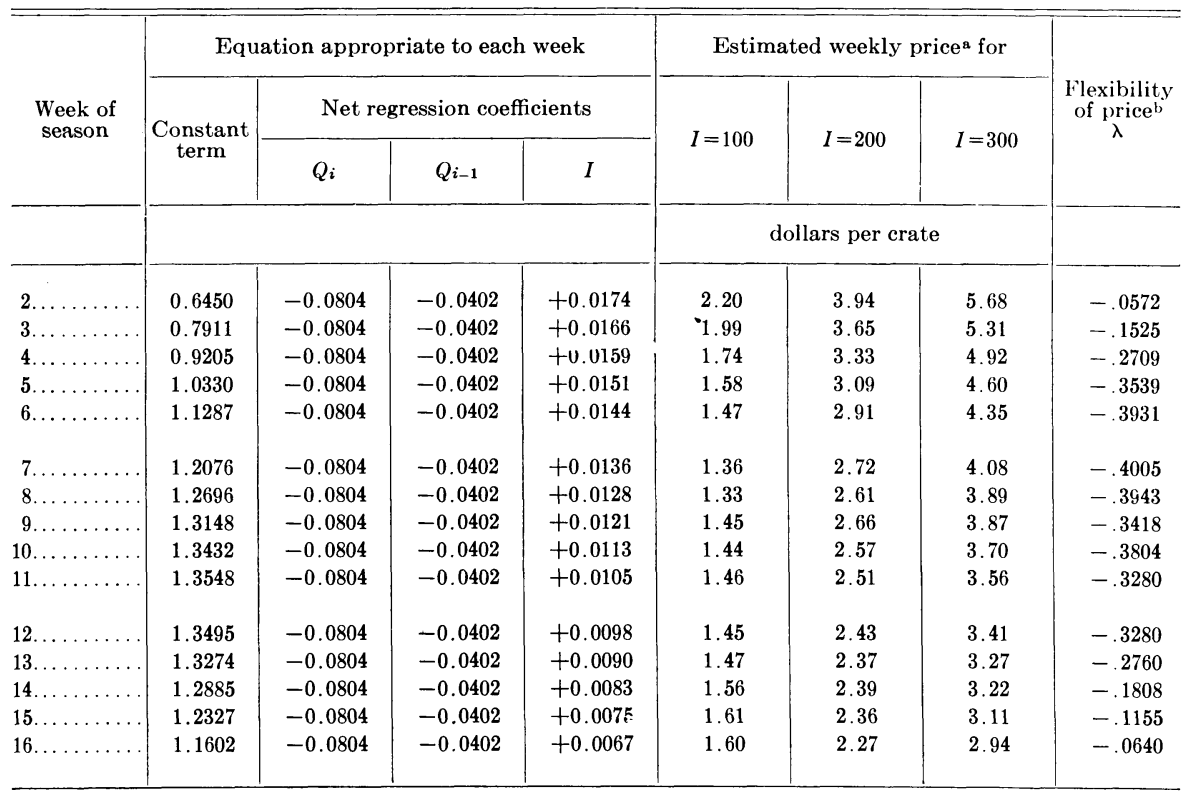

a With $Q_{2}$ and $Q_{i-1}$ held at weekly means (i.e., at the averages for the eighteen observations of that week).

b Computed as $\lambda=b_{12} \bar{Q}_{i} / \bar{P}_{i}$, where $b_{12}$ is the net regression coefficient of price on sales $(-0.0804)$ and $\bar{Q}_{i}$ and $\bar{P}_{i}$ are the means of the observations of weekly auction sales and weekly auction prices for week $i$ during the 18 years.

For meaning of the variables see table 8 .

Source OF DATA: Derived from equation (4) of table 8:

$P_{i}=0.3022-0.0804 Q_{i}-0.0402 Q_{i-1}+0.0189 I-0.00076 W I+0.1882 W-0.0084 W^{2}$.

Equations for the various weeks of the season, i.e., for $W=2,3, \cdots, 16$ (derived from equation 4) are tabulated for convenient reference in table 9. From this summary it is possible to trace the movement of the net price-quantity relations for different income levels. By substituting the weekly averages for $Q_{i}$ and $Q_{i-1}$ into these equations the "normal" price variations during the season at any level of income can be noted. These computations, for $I=100$, 200 , and 300 , are shown in the right-hand portion of the table. The warping

siderably beyond the range of observations used in the analysis. The maximum point on the net price-week relation is given by $W=11.20-0.0452 I$, i.e., $I=247.63-22.11 W$. The price-week relation $\left(\frac{\partial P_{i}}{\partial W}\right)$ is negatively sloped throughout the entire season, provided the level of nonagricultural income exceeds $I=203$. For lower income the decline for later weeks is preceded by increases during the early weeks. 
WEEKLY PRICE $\left(P_{i}\right)$ - DOLLARS PER CRATE
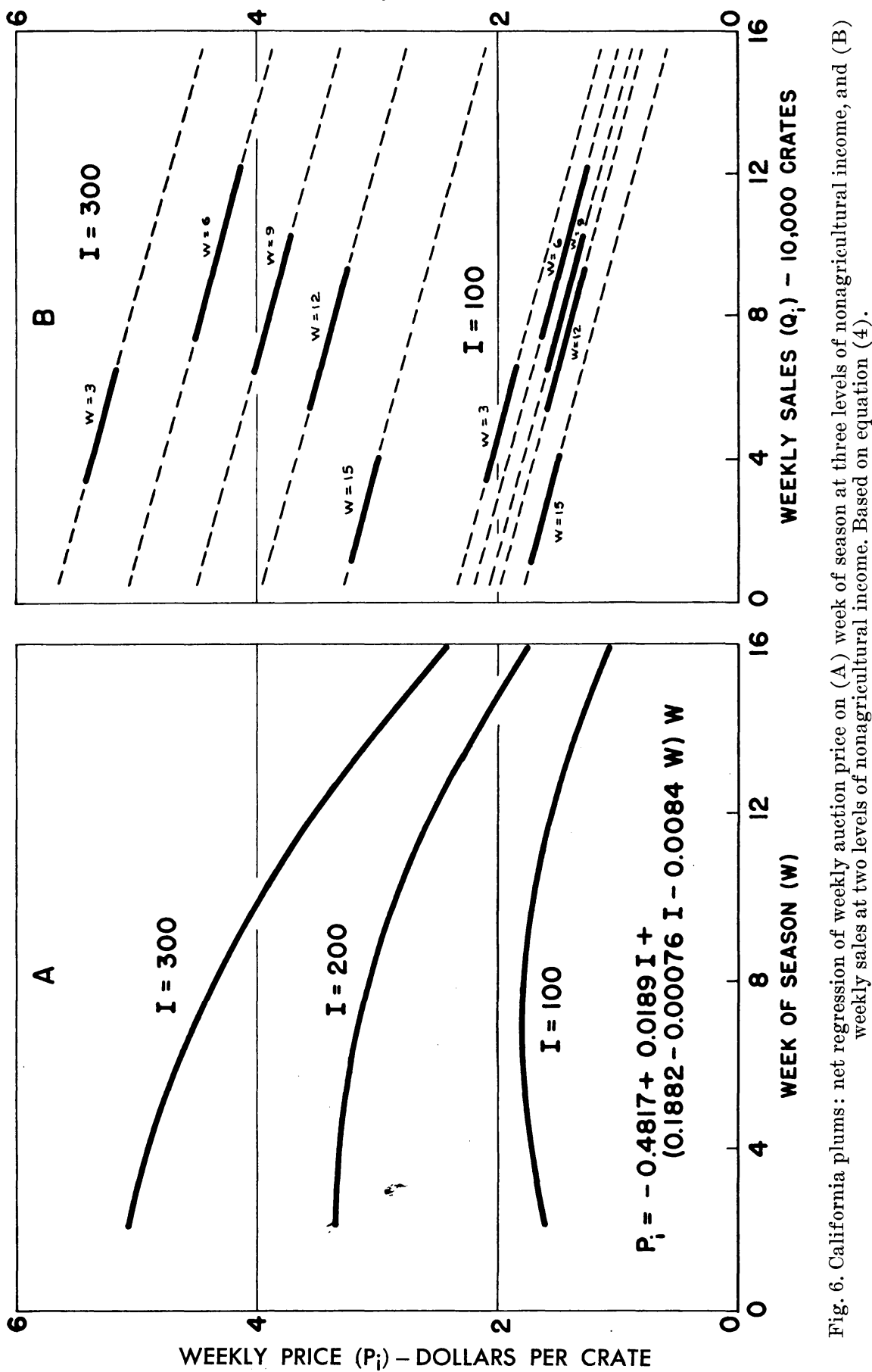
of this seasonal pattern merits careful consideration in the development of a marketing control program.

These changes in the net regressions of price on week at three levels of nonagricultural income are portrayed in panel $\mathrm{A}$ of figure 6 . Panel $\mathrm{B}$ shows the

TABLE 10

California Plums: Estimated Weekly Price $\left(P_{i}\right)$ with Varying Sales $\left(Q_{i}\right.$ and $\left.Q_{i-1}\right)$, InCOMe $(I)$, ANd WeEk of Season $(W)$, For

1928-1948, ExCLUDING 1942-1945

\begin{tabular}{|c|c|c|c|c|c|c|c|c|c|c|c|c|}
\hline \multirow{3}{*}{$\begin{array}{c}\begin{array}{c}\text { Week } \\
\text { of } \\
\text { season } \\
(W)\end{array} \\
\text { (W) }\end{array}$} & \multicolumn{4}{|c|}{ Income at $I=100$} & \multicolumn{4}{|c|}{ Income at $I=200$} & \multicolumn{4}{|c|}{ Income at $I=300$} \\
\hline & \multicolumn{4}{|c|}{ Sales of current week $\left(Q_{i}\right)$} & \multicolumn{4}{|c|}{ Sales of current week $\left(Q_{i}\right)$} & \multicolumn{4}{|c|}{ Sales of current week $\left(Q_{i}\right)$} \\
\hline & 2 & 6 & 10 & 14 & 2 & 6 & 10 & 14 & 2 & 6 & 10 & 14 \\
\hline & \multicolumn{12}{|c|}{ Sales of preceding week at $Q_{i-1}=2$} \\
\hline 3 . & 2.21 & 1.89 & 1.57 & 1.25 & 3.87 & 3.55 & 3.23 & 2.91 & 5.53 & 5.21 & 4.89 & 4.57 \\
\hline 6. & 2.33 & 2.01 & 1.68 & 1.36 & 3.77 & 3.45 & 3.12 & 2.80 & 5.21 & 4.89 & 4.56 & 4.24 \\
\hline 9. & 2.28 & 1.96 & 1.64 & 1.32 & 3.49 & 3.17 & 2.85 & 2.53 & 4.70 & 4.38 & 4.06 & 3.74 \\
\hline 12 . & 2.09 & 1.77 & 1.45 & 1.12 & 3.07 & 2.75 & 2.43 & 2.10 & 4.05 & 3.73 & 3.41 & 3.08 \\
\hline \multirow[t]{2}{*}{$15 \ldots \ldots$} & 1.82 & 1.50 & 1.18 & .86 & 2.65 & 2.33 & 2.01 & 1.69 & 3.48 & 3.16 & 2.84 & 2.52 \\
\hline & \multicolumn{12}{|c|}{ Sales of preceding week at $Q_{i-1}=6$} \\
\hline & 2.05 & 1.73 & 1.41 & 1.08 & 3.71 & 3.39 & 3.07 & 2.74 & 5.37 & 5.05 & 4.73 & 4.40 \\
\hline $6 \ldots$ & 2.17 & 1.85 & 1.52 & 1.20 & 3.61 & 3.29 & 2.96 & 2.64 & 5.05 & 4.73 & 4.40 & 4.08 \\
\hline $9 \ldots$ & 2.12 & 1.80 & 1.48 & 1.16 & 3.33 & 3.01 & 2.69 & 2.37 & 4.54 & 4.22 & 3.90 & 3.58 \\
\hline $12 \ldots$ & 1.93 & 1.61 & 1.28 & .96 & 2.91 & 2.59 & 2.26 & 1.94 & 3.89 & 3.57 & 3.24 & 2.92 \\
\hline \multirow[t]{2}{*}{15.} & 1.66 & 1.34 & 1.02 & .70 & 2.49 & 2.17 & 1.85 & 1.53 & 3.32 & 3.00 & 2.68 & 2.36 \\
\hline & \multicolumn{12}{|c|}{ Sales of preceding week at $Q_{i-1}=10$} \\
\hline $3 \ldots$ & 1.89 & 1.57 & 1.25 & .92 & 3.55 & 3.23 & 2.91 & 2.58 & 5.21 & 4.89 & 4.57 & 4.24 \\
\hline $6 \ldots$ & 2.01 & 1.68 & 1.36 & 1.04 & 3.45 & 3.12 & 2.80 & 2.48 & 4.89 & 4.56 & 4.24 & 3.92 \\
\hline 9. & 1.96 & 1.64 & 1.32 & 1.00 & 3.17 & 2.85 & 2.53 & 2.21 & 4.38 & 4.06 & 3.74 & 3.42 \\
\hline 12. & 1.77 & 1.45 & 1.12 & .80 & 2.75 & 2.43 & 2.10 & 1.78 & 3.73 & 3.41 & 3.08 & 2.76 \\
\hline \multirow[t]{2}{*}{15.} & 1.50 & 1.18 & .86 & .54 & 2.33 & 2.01 & 1.69 & 1.37 & 3.16 & 2.84 & 2.52 & 2.20 \\
\hline & \multicolumn{12}{|c|}{ Sales of preceding week at $Q_{i-1}=14$} \\
\hline $3 \ldots$ & 1.73 & 1.41 & 1.08 & .76 & 3.39 & 3.07 & 2.74 & 2.42 & 5.05 & 4.73 & 4.40 & 4.08 \\
\hline $6 \ldots$ & 1.85 & 1.52 & 1.20 & .88 & 3.29 & 2.96 & 2.64 & 2.32 & 4.73 & 4.40 & 4.08 & 3.76 \\
\hline 9. & 1.80 & 1.48 & 1.16 & .84 & 3.01 & 2.69 & 2.37 & 2.05 & 4.22 & 3.90 & 3.58 & 3.26 \\
\hline 12. & 1.61 & 1.28 & .96 & .64 & 2.59 & 2.26 & 1.94 & 1.62 & 3.57 & 3.24 & 2.92 & 2.60 \\
\hline 15. & 1.34 & 1.02 & .70 & .37 & 2.17 & 1.85 & 1.53 & 1.20 & 3.00 & 2.68 & 2.36 & 2.03 \\
\hline
\end{tabular}

For meaning of the variables see table 8 .

Soukce of DATA: Derived from weekly equations given in table 9 .

net price-quantity regression for several weeks during the season for income at a low level (equal to the 1935-1939 average) and at a high level (approximately 1948). The solid segments of the regression lines refer to the value of weekly sales represented by the mean plus and minus one standard deviation in order to indicate the quantity of plums usually sold at the New York auction 


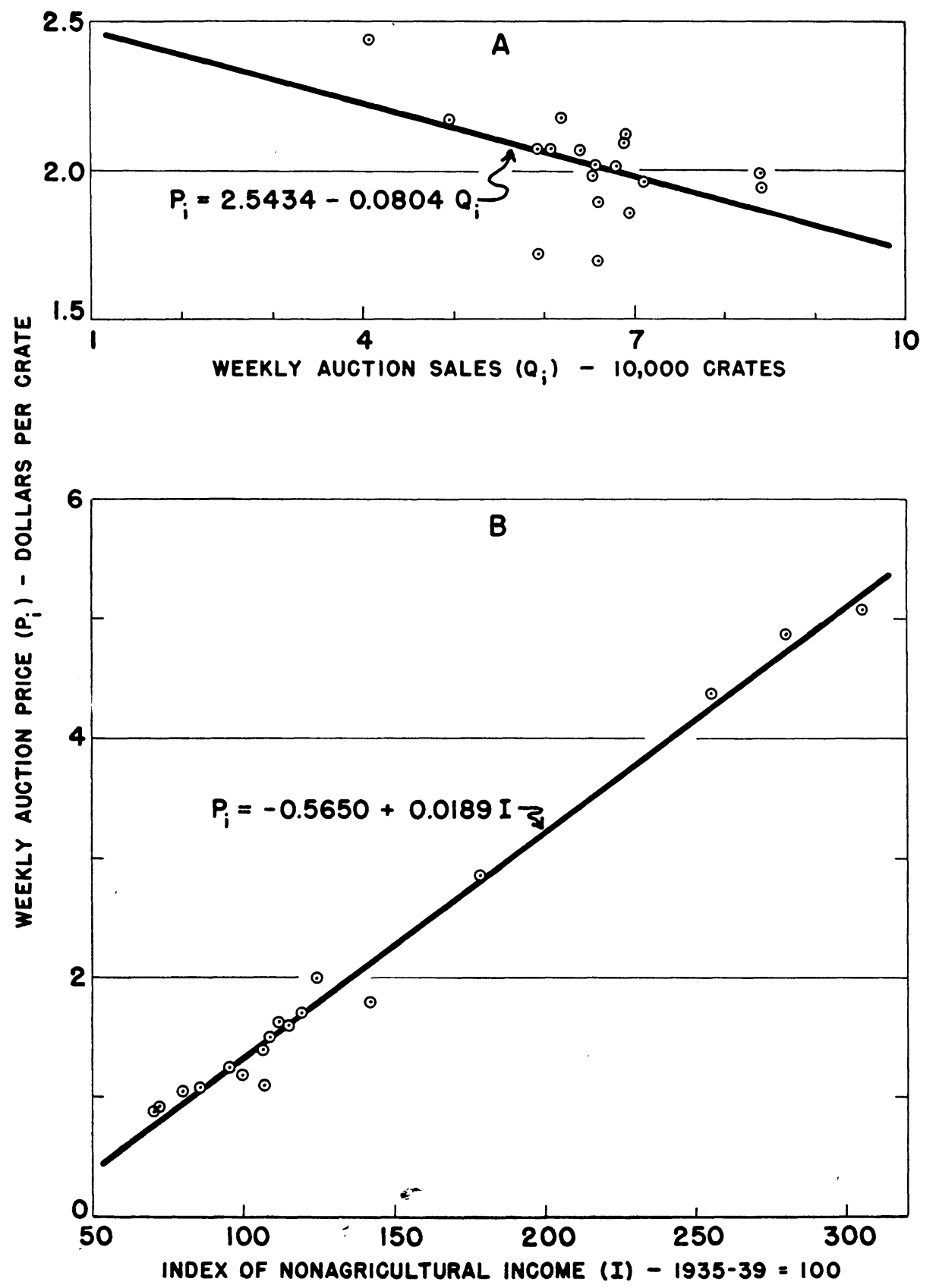

Fig. 7. California plums: net regressions of weekly auction price on (A) weekly auction sales and (B) index of nonagricultural income. Based on equation (4). Dots shown represent annual averages of 15 weekly observations. 
market during different weeks of the season. The level of these regression lines is placed so that each passes through the point determined by substituting average prices, current sales, and lagged sales of the relevant week into equation (4). The regression lines in the two sets-and for any other levels of income - are, of course, parallel to each other. Of considerable interest is the pattern of parallel shifts revealed for high as compared to low levels of nonagricultural income.

Estimated weekly prices derived from equation (4) for specific values of the independent variables are presented in table 10. These are arranged in such a manner that it is possible to trace the shifts in the net regression of price on any one independent variable when all but one of the remaining factors are held constant. Thus in the upper left-hand portion of the table, with $I=100$ and $Q_{i-1}=2$, changes may be noted in the net price-quantity relation for several weeks of the season, and in the net price-week regression for different quantities of current sales. At different levels of income and sales during the preceding week, the same relations appear in the 11 other blocks of the table. Changes in the net price-income and price-preceding-week's sales may also be traced in a similar way.

The coefficients of price flexibility given in table 9 (last column) are somewhat smaller than the values obtained for the varietal analysis (see table 6 above). However, they indicate the same general pattern as was derived previously. Price is more responsive to changes in sales during the peak of the season than for the early or late weeks of the season.

The Residuals. With 270 observations it is possible to make a more careful study of the distribution of residuals than was attempted in the case of the varietal analysis where only 23 observations were used. The residuals, derived from equation (4) applied to the data given in the Statistical Appendix, tables A-6, A-7, B-4 (see Statistical Appendix table B-6), were plotted about the net regressions of price on sales and on nonagricultural income (figure 7) and as a time series (figure 8). In the first chart averages of the fifteen residuals for each season, instead of the individual weekly residuals, were plotted against the average weekly values of the index of nonagricultural income and of sales for corresponding years. ${ }^{38}$ Reference to this chart indicates that the introduction of curvilinearity, with respect to independent variables $I, Q_{i}$, and $Q_{i-1}$, into the equation is not necessary.

All 270 weekly residuals were plotted in figure 8 . Thus, corresponding to each year there appear fifteen points. In addition, the averages of these weekly residuals are shown so that the general trend of the values may be seen more easily" There seems to be some indication of a trend factor. Since "time" was not introduced explicitly into the equation as a variable, it is desirable to

${ }^{38}$ For this type of comparison it is not necessary to make the additional plot of residuals about the regression of price on lagged sales. Since the season values for averages of weekly sales for current weeks (12-16) will be practically the same as the values for preceding weeks (1-15), the scatter of points would duplicate that shown in panel A of figure 7 . The main difference would lie in the fact that the regression line would be only half as steep. 


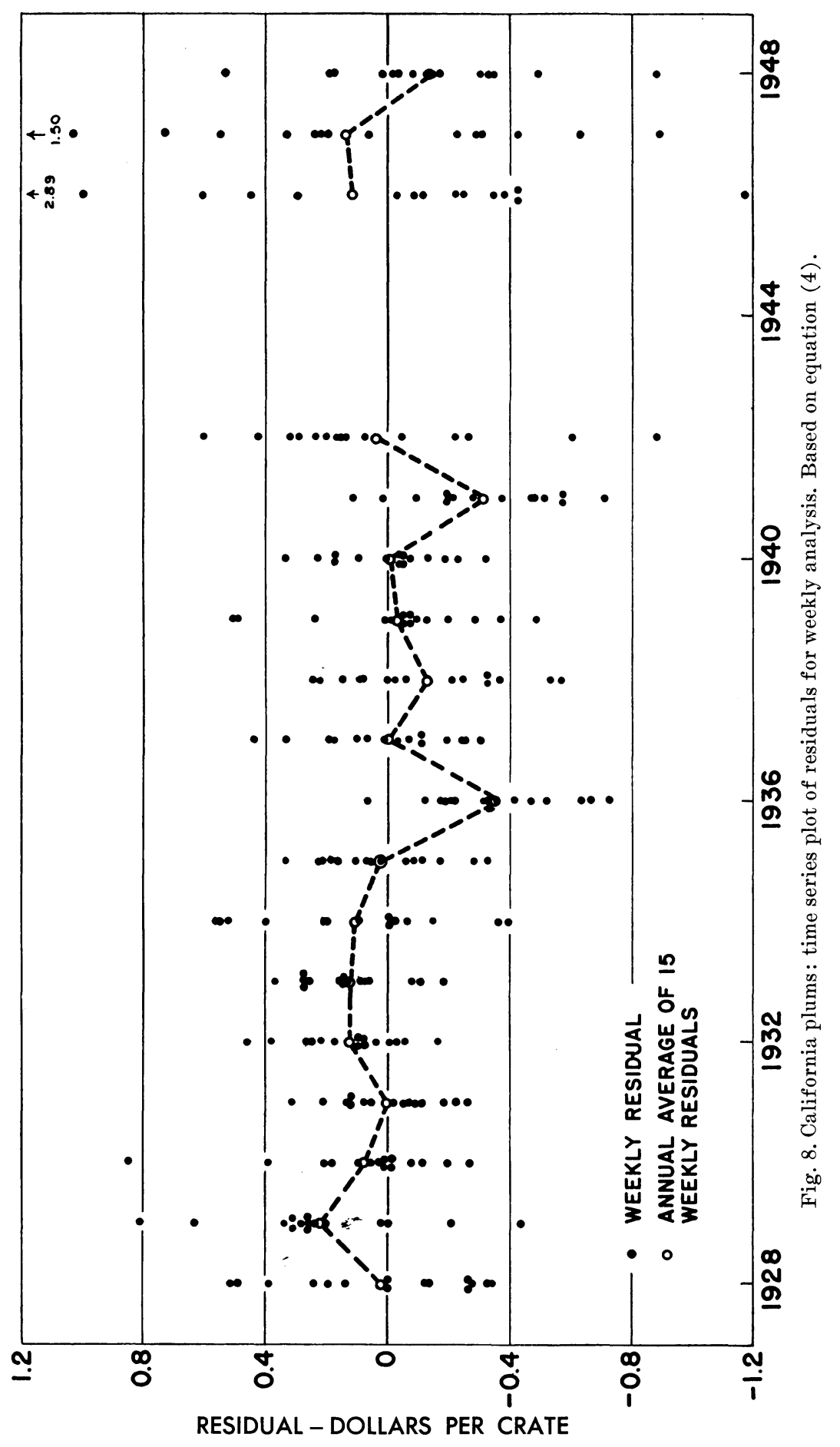


determine whether the apparent trend may actually be significant enough to affect the fit materially.

It is difficult to say what type of trend should be eliminated. For the period 1928-1942 the residuals appear to drift downward. A continuation of this trend for the postwar years does not seem justified, even when the extreme residuals are disregarded. In order to determine the maximum improvement in fit which could be secured the correlation ratio was computed. ${ }^{39}$ The adjusted correlation ratio is 0.9308 compared to a value of 0.9238 for the adjusted coefficient of multiple correlation obtained for equation (4). This indicates that the amount of variation in weekly prices "explained" by the combined influence of the independent variables would be increased but slightly by the introduction of a "trend" passing through all the means of the residuals. Probably no attempt would be made to fit a trend more complex than a third or fourth degree parabola to the data. In that case the adjusted coefficient of multiple correlation is not likely to be raised sufficiently to correspond to a net price-time regression which would be statistically significant at the 5 per cent level. In fact, the value of the adjusted correlation coefficient might actually be reduced rather than increased.

At this point it will be well to draw attention to the large residual for week 2 of $1946\left(+\$ 2.89\right.$ or $\left.+7.7 \sigma_{z}\right)$. Observations for $1943-1945$ were excluded from the analysis because it was argued that conditions during the war period were sufficiently different from those prevailing for the other years to justify their exclusion. Week 2 of 1946 represents the first observation following the three war years omitted from the analysis. It should be recalled that the price ceilings for plums in effect during 1944 and 1945 were scheduled to be continued for the 1946 season. But just as shipments for the season were about to begin, the price control program for plums was terminated. ${ }^{40} \mathrm{It}$ is believed that this disturbance provides a sufficient basis for excluding this particular observation from the analysis. Even if this contention is not granted it is of interest to determine what the resulting effect would be.

It was not deemed necessary to make a new set of calculations for the entire analysis. A measure of the effect on $\bar{R}$ produced by excluding this observation is obtained by assuming that values of the regression coefficients determined for equation (4) would remain unaffected. For the remaining 269 residuals (i.e., exclusive of the specified observation) computed by equation (4) the value of $\bar{R}$ would becomé 0.941 compared to 0.924 determined for all 270 observations. In other words, the improvement in fit to be secured by excluding this one observation from consideration is appreciably greater than the

${ }^{39}$ The correlation ratio $(\eta)$ is a measure analogous to the correlation coefficient. The variance of the values (the residuals in this case) is computed about the means of the arrays (i.e., about the average residual for each year) instead of being calculated about the regression line. This measure is described in most elementary statistics textbooks.

${ }_{40}$ The suspension order terminating price ceilings became effective on May 7, 1946-a full month before the second week (June 9-14). In comparing these two dates an allowance of about 12 days for transportation time must be made. Thus sufficient time had elapsed to permit an adjustment of supply. But still the situation was unsettled because of uncertainty as to the action to be taken in the case of other fruit ceilings. 
maximum improvement that could be obtained by the introduction of "time" into the equation. ${ }^{41}$

In addition, the residuals computed should be tested for normality and independence. The chi-square test may be used as a measure of the magnitude of discrepancy between observed and theoretical frequencies. An actual count of the number of residuals falling within specified class intervals was made to give the observed frequencies corresponding to class intervals of 15, 20, and 25 cents. The corresponding theoretical frequencies were computed by reference to the area of the normal curve in terms of the abscissa, where the abscissa were expressed in terms of the standard deviation of residuals. Since it

TABLE 11

Chi-Square Values for Normal Curve of Error Fitted to Weekly Residuals

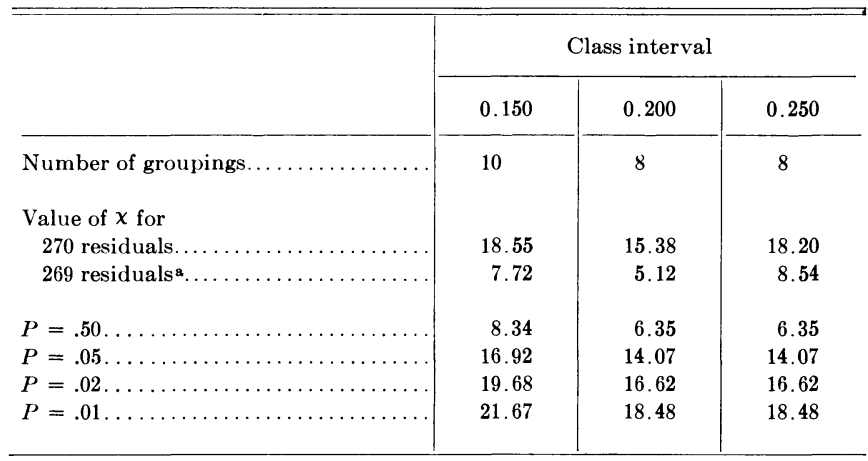

a Residual for week 2 of 1946 omitted. Source of Data: Statistical Appendix, table B-7.

is felt that a sound basis has been presented for excluding the observation for week 2 of 1946, the calculations of chi-square were made for the set of residuals excluding this one observation, as well as for all 270 residuals. ${ }^{42}$ The computed values of chi-square and the values for selected values of $P$ are summarized in table 11.

Fitting the normal curve of error to the distribution of residual obtained for the weekly analysis (by use of equation 4 ), gives values of chi-square that are too high (corresponding to approximately the 2 per cent probability level) when all 270 residuals are considered. If the single extreme residual is excluded, however, the chi-square values are markedly reduced (taking into account the decrease in the standard deviotion of residuals). The discrepancies remaining between observed and theoretical frequencies could easily have arisen as a result of chance $(P=.50$, approximately). These results are not inconsistent with the hypothesis that the weekly residuals are normally distributed.

The ratio of mean square successive difference to the variance $\left(\delta^{2} / S^{2}\right)$, pre-

${ }^{41}{\overline{K^{2}}}_{(270)}=0.8534 ;{\overline{K^{2}}}_{(269)}=0.8862 ; \bar{\eta}^{2}=0.8664$.

${ }^{42}$ Excluding the residual for week 2 of 1946 reduces the standard deviation of residuals from 37.64 to 33.17 cents per crate. 
viously used in section B-3 to test for the existence of correlation between successive values of the residuals, was applied to the residuals derived from equation (4). For 270 observations it may be assumed that the $\left(\delta^{2} / S^{2}\right)$ is normally distributed with

$$
\begin{gathered}
\text { mean } \quad M=\frac{2 n}{n-1}=2.0074 \text { and } \\
\text { standard deviation } S D=\frac{2 n}{n-1} \sqrt{\frac{n-2}{(n-1)(n+1)}}=0.1217 .
\end{gathered}
$$

At the 1 per cent level the admissible range for $\delta^{2} / S^{2}$ is $1.694 \leqq \delta^{2} / S^{2} \leqq 2.321$, corresponding to $M \pm 2.575 S D$. For the set of 270 residuals $\delta^{2} / S^{2}=1.003$, which is clearly outside the admissible range. Thus the hypothesis of the absence of dependence in the residuals must be rejected. The lagged (one week) correlation of residuals $r_{i(i-1)}=0.500$ probably is significant considering the relatively large number of residuals on which it is based. ${ }^{43}$ It appears, therefore, that the interpretation to be attached to the results secured may have to be modified to recognize the apparent dependence in residuals. Even though dependence may exist, the estimates of the regression coefficients are still unbiased. Their standard errors, however, cannot be computed without specifying the magnitude of the autocorrelation in the population.

\section{AUCTION PRICES BY SIZE CATEGORIES}

The basic feature of the marketing control program operated by the California plum industry is its reliance upon regulations restricting the shipment of small sizes and low grades to out-of-state markets. This action is premised on the notion that net returns to producers can be improved substantially in the short-run by such limitations without having adverse long-run effects. The extent to which returns are changed depends upon several factors. The shape and level of the demand functions for the various grade-size categories of each variety at eastern and California markets and the nature of their interrelations are of prime importance. In this section consideration will be given to describing how auction prices of different sizes of specified varieties are interrelated and to determining the extent to which changes in the size composition of sales may alter the total returns realized during a given season.

\section{Size in Relation to Demand}

Representatives of the industry maintain that for any given situation the auction price for plums of a specific size is affected by the size distribution of

${ }^{43}$ The extreme residual for week 2 of 1946, the five largest, and the ten largest residuals were excluded from the set of observations to determine whether their exclusion would affect the result appreciably. Values ranging from 0.9 to 1.1 were obtained for $\delta^{2} / S^{2}$. Therefore, no change in the conclusion drawn is suggested. 
all sales as well as by the total quantity being marketed. The argument is that when the quantity of large sizes is greater (or less) than "normal" relative to sales of small sizes, the premium paid for the large sizes is less (or more) than average. On the basis of deductive analysis and other evidence it appears reasonable to assume that the demand functions for plums of different sizes may be interdependent. ${ }^{44}$

The problem becomes one of determining how the demand functions in the various size outlets are interrelated. Since under the regulations which have actually been promulgated only the very small sizes (representing a small portion of the sales of all plums) were eliminated, particular interest is attached to the effect produced upon the demand for larger plums when sales of the smallest sizes are reduced substantially. In order to obtain a clear and definite size differentiation the analysis should consider the behavior of prices for sizes at the extremes of the size distribution for each variety. Yet if this were done, the analysis would be restricted to data which are not reliable because sales representing these size categories constitute only a small proportion of the total sales during the season, and are, therefore, subject to all sorts of erratic influences. This situation necessitates making a compromise. Here it was deemed necessary to direct attention toward determining the interrelations prevailing among prices for sizes marketed in relatively large quantities in the hope that the information secured would shed some light on the specific problem encountered in the operation of a marketing control program. ${ }^{45}$

It will be assumed that for each variety the choice of the two size categories including the largest portion of total sales will suffice. For convenience these will be labeled as the "large size" and the "small size." 46 In order to reduce the amount of work entailed attention is directed to only four varieties (Beauty, Tragedy, Wickson, and President). Table 12 shows that these represent plums of markedly different physical characteristics, which are sold at different times during the plum marketing season.

For the following analysis the two size categories are conceived as representing two separate commodities, which presumably are close substitutes. The higher the degree of competition between the two sizes, the more important will the price of one be in affecting the price of the other. Actually there is no a priori basis for saying that the auction price of large sizes $\left(P_{L}\right)$ is determined at a premium over the auction price of small sizes $\left(P_{S}\right)$-which is established

${ }^{44}$ Unless such is the situation the rationale for size restrictions is invalidated. If alterations in size composition do not have any significant influence upon the demand functions themselves, the major result of size regulations would be to divert sales of the smallest sizes to local markets.

45 The only data available relate to weekly prices and sales at the New York auction market covering eight seasons, 1937-1941 and 1946-1948, when size regulations were issued. A preliminary examination indicated that data for 1939 , when regulations were reimposed after a year of inactive control, seem to be inconsistent with those for other seasons. Consequently, this year was excluded from the analysis.

${ }_{46}$ These designations are not intended to convey the idea that the larger (or smaller) size of each variety is actually larger (or smaller) than the average size of all plums. It should be noted that for several important varieties about 90 per cent of all sales consist of two sizes. For other varieties a third size category may also represent a large volume of fruit. See table 12 for sizes actually used in the analysis. 
at a particular level depending upon the values of the various independent variables-or that $P_{S}$ is determined at a discount below $P_{L}$. No attempt will be made at specifying either of these two prices as the more basic from the point of view of causation. ${ }^{47}$

TABLE 12

Four California Plums: Marketing Period, Physical Characteristics, and Size Distribution of Crate Sales

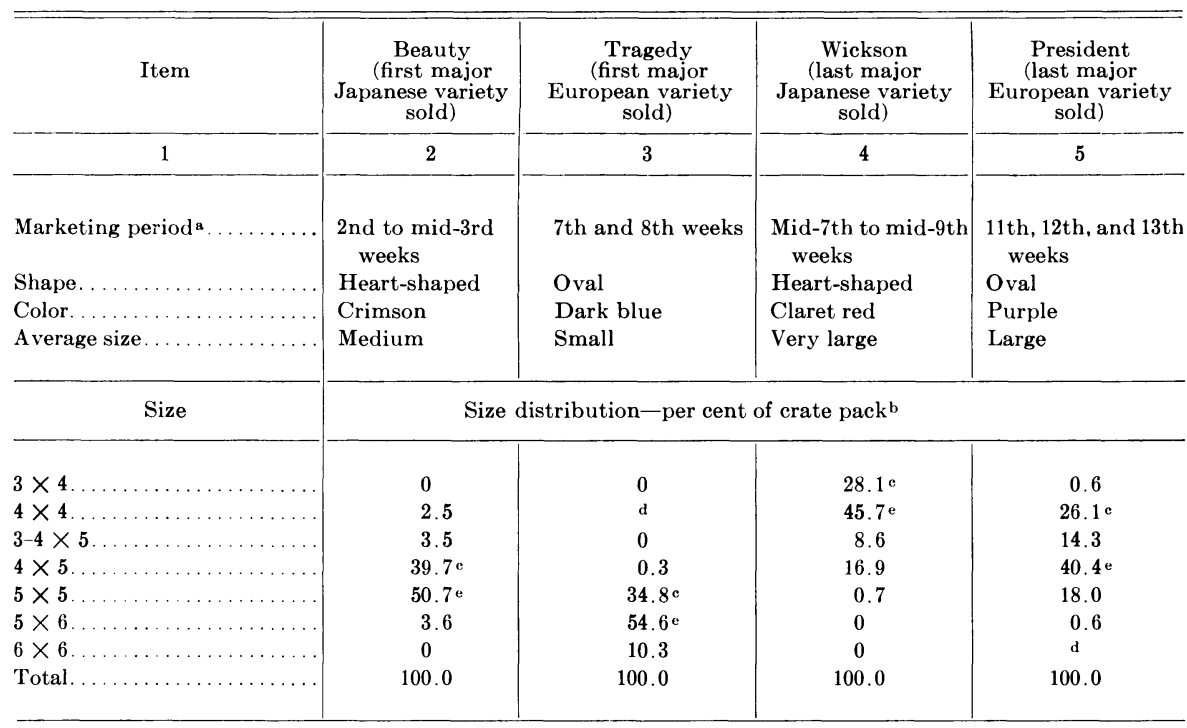

a Refers to weeks of the plum season during which median 50 per cent of sales of the variety are normally made. b Distribution of sales (crate pack only) at New York auction market during 1944-1948. These data are approximately equivalent to the size distribution of total interstate shipments during 1941-1946.

c Used as large size in this analysis.

d Less than 0.05 per cent.

e Used as small size in this analysis. For President variety price of small plums refers to $4 \times 5$ size but quantity relates to all plums of size $3-4 \times 5$ and smaller.

Source of DAta: Based upon data tabulated by Fruit and Vegetable Branch, Production and Marketing Administration, U. S. Department of Agriculture (typewritten summaries) from the New York Daily Fruit Reporter: "Detailed Deciduous Report," except information on "shape," "color," and "average size."

\section{Formulation of Hypotheses}

One of the simplest ways of expressing a relation between $P_{L}$ and $P_{S}$ is by means of the following equation:

$$
P_{L}=a+b P_{S}+g(I, W, \cdot \cdot){ }^{48}
$$

where $F *$ represents some index of consumer purchasing power (or general business activity) and $W$ designates the week of the season. The term $g(I$,

${ }^{47}$ Such a demonstration, even if it could be made, is of no particular interest for this empirical investigation. However, it is believed that small and large plums are highly competitive and that the prices of both are determined simultaneously by the quantities of both offered and the various shift variables.

${ }_{48}$ In the various equations herein described, it is to be understood that observations for successive weeks of several seasons are used. The second subscript $(W)$ is omitted for convenience. 
$W, \cdots)$ is used merely to permit the average relation between $P_{L}$ and $P_{S}$ to change with different values for $I, W$, and the other shift variables.

Quantities of small and large plums sold $\left(Q_{S}\right.$ and $\left.Q_{L}\right)$ may be added explicitly to the equation by using the ratio $Q=Q_{S} / Q_{L}$ (or its reciprocal). For this formulation it is convenient to use the price-ratio $P=P_{S} / P_{L}$ as the dependent variable. It must be recognized, however, that the average relation between $P$ and $Q$ may change as the season advances. For example, the "normal" influence exerted by the quantity of other fruits marketed may be substantially different early in the season than during later weeks. Thus we may write,

$$
P=a+b Q+c W+g(Q, W, \cdots),
$$

where the final term represents the higher degree and product terms in $Q, W$, and the other variables. The dependent variable may also be represented by the price premium received for large sizes (expressed as a ratio to the season average price for sales of all sizes). Then the equation becomes:

$$
\begin{array}{r}
P^{\prime}=a+b Q+c W+g(Q, W, \cdots), \quad \text { where } \\
P^{\prime}=\frac{P_{L}-P_{S}}{P_{T}} \quad \text { and } \quad P_{T}=\frac{\sum\left(P_{L} Q_{L}+P_{S} Q_{S}\right)}{\sum\left(Q_{L}+Q_{S}\right)} .
\end{array}
$$

In order to indicate how changes in the quantity of either size sold affect the prices of both large and small plums, and, consequently, the returns received by growers, it is necessary to specify separate functions for auction prices of each size in terms of $Q_{L}, Q_{S}, I$, and possibly other variables. Since the number of observations available for study is not large, it becomes necessary to limit the number of variables used in the equation. A linear relation will be used as a first approximation. The results secured in the weekly analysis (section $\mathrm{C}$ above) will be helpful in indicating which additional variables might profitably be introduced into the following equations: ${ }^{49}$

$$
\begin{aligned}
& P_{L}=a_{0}+a_{1} Q_{L}+a_{2} Q_{S}+a_{3} I+g(W, I, \cdots) \\
& P_{S}=b_{0}+b_{1} Q_{S}+b_{2} Q_{L}+b_{3} I+h(W, I, \cdots)
\end{aligned}
$$

where $g(\cdots)$ and $h(\cdots)$ include variables other than those shown and possibly various higher degree and product terms.

These four equations express in mathematical form certain definite types of relations which may reasonably be expected to prevail. The first three provide specific relations between auction prices of the two sizes. They do not permit a direct determination of the total returns received for a given volume of sales of large and small plums. Equations (d), however, can be used for this purpose. Other reasonable relations could be formulated and tested.

${ }^{49}$ In the weekly analysis it was determined that (1) the net price-income relation shifts its slope as the season advances, whereas the net price--quantity relation remains fixed, and (2) sales of the preceding week have a statistically significant influence upon the current week's price. 


\section{Results Obtained}

The gross correlation between the auction prices of large and small sizes is very high - the coefficient of correlation is approximately 0.99 for each of the four varieties tested (see table 13). It is obvious that the introduction of either

TABLE 13

California Plums: Price of Large Size Related to Price of Small Size and Nonagricultural Income, $1937-1948^{a}$

\begin{tabular}{|c|c|c|c|c|c|c|}
\hline \multirow{2}{*}{ Equation } & \multirow{2}{*}{$\begin{array}{c}\text { Number of } \\
\text { weeks }\end{array}$} & \multirow{2}{*}{$\begin{array}{c}\text { Dependent } \\
\text { variable }\end{array}$} & \multirow{2}{*}{$\begin{array}{c}\text { Constant } \\
\text { term }\end{array}$} & \multicolumn{2}{|c|}{ Net regression coefficienth } & \multirow{2}{*}{$\begin{array}{c}\text { Adjusted } \\
\text { coefficient of } \\
\text { correlation } \\
\bar{R}\end{array}$} \\
\hline & & & & $P_{s}$ & $I$ & \\
\hline \multicolumn{7}{|c|}{ Beauty variety } \\
\hline $\begin{array}{l}5.1 \\
5.2\end{array}$ & $\begin{array}{l}28 \\
28\end{array}$ & $\begin{array}{l}P_{L} \\
P_{L}\end{array}$ & $\begin{array}{r}.0885 \\
-.0818\end{array}$ & $\begin{array}{l}1.1627 \\
(44.42) \\
1.0804 \\
(32.94)\end{array}$ & $\begin{array}{l}\ldots \ldots \\
.00213 \\
(3.39)\end{array}$ & $\begin{array}{l}.9932 \\
.9952\end{array}$ \\
\hline \multicolumn{7}{|c|}{ Tragedy variety } \\
\hline $\begin{array}{l}6.1 \\
6.2\end{array}$ & $\begin{array}{l}28 \\
28\end{array}$ & $\begin{array}{l}P_{L} \\
P_{L}\end{array}$ & $\begin{array}{r}.0468 \\
-.0528\end{array}$ & $\begin{array}{r}1.1512 \\
(43.57) \\
.8850 \\
(18.90)\end{array}$ & $\begin{array}{l}\ldots \ldots \\
.00428 \\
(6.10)\end{array}$ & $\begin{array}{l}.9930 \\
.9971\end{array}$ \\
\hline \multicolumn{7}{|c|}{ Wickson variety } \\
\hline $\begin{array}{l}7.1 \\
7.2\end{array}$ & $\begin{array}{l}28 \\
28\end{array}$ & $\begin{array}{l}P_{L} \\
P_{L}\end{array}$ & $\begin{array}{l}-.0588 \\
-.0838\end{array}$ & $\begin{array}{r}1.1345 \\
(47.44) \\
.9280 \\
(15.58)\end{array}$ & $\begin{array}{l}\ldots \ldots \\
.00286 \\
(3.67)\end{array}$ & $\begin{array}{l}.9941 \\
.9971\end{array}$ \\
\hline \multicolumn{7}{|c|}{ President variety } \\
\hline $\begin{array}{l}8.1 \\
8.2\end{array}$ & $\begin{array}{r}49 \\
49\end{array}$ & $\begin{array}{l}P_{L} \\
P_{L}\end{array}$ & $\begin{array}{l}-.1033 \\
-.1436\end{array}$ & $\begin{array}{l}1.3823 \\
(30.60) \\
1.0396 \\
(21.74)\end{array}$ & $\begin{array}{l}\ldots \cdots \\
.00418 \\
(8.81)\end{array}$ & $\begin{array}{l}.9753 \\
.9907\end{array}$ \\
\hline
\end{tabular}

a Data for seven years (1937-1938, 1940-1941, and 1946-1948) were used.

b Figures in parentheses are $t$-ratios.

$P_{L}-$ New York auction price for large size, in dollars per crate.

$P S-$ New York auction price for small size, in dollars per crate.

curvilinearity or additional variables cannot improve the empirical fit significantly. Nevertheless their use might provide a different-and possibly a more acceptable - description of the relation. The addition of the index of nonagricultural income increases the value of the adjusted coefficient of correlation only slightly but diminishes the net regression of the price of large sizes on the price of small sizes. In any case it is apparent that either price can be expressed 
almost entirely in terms of the other price (and of certain shift variables). This implies that the prices of the two size categories fluctuate together within a very narrow range.

In view of this situation it is interesting to apply the "rough test," originally proposed by Henry Schultz, for determining whether two goods, for example two sizes of plums, compete with or complete each other in consumption. ${ }^{50}$ For the four varieties, the coefficients of variation and their ratios are given in the following tabulation. Since the quantity ratios fluctuate much more than do the price ratios, it may be concluded that the rough test indicates a high degree of substitutability between large and small sizes of each variety of plums. ${ }^{51}$ Thus a definite pattern of price relationships tends to prevail even though the quantities of various sizes offered for sale are altered considerably.

\begin{tabular}{|c|c|c|c|}
\hline \multirow{2}{*}{ Variety } & \multicolumn{2}{|c|}{ Coefficients of variation } & \multirow{2}{*}{$\frac{\text { Ratio }}{V_{Q} \div V_{F}}$} \\
\hline & $\underset{\left(V_{Q}\right)}{\text { Quantity ratios }}$ & $\begin{array}{l}\text { Price ratios } \\
\quad\left(V_{P}\right)\end{array}$ & \\
\hline Beauty.. & 50.78 & 6.42 & 7.8 \\
\hline Tragedy..... & 45.32 & 4.50 & 10.1 \\
\hline Wickson....... & 88.19 & 4.47 & 19.7 \\
\hline President..... & 52.25 & 8.75 & 6.0 \\
\hline
\end{tabular}

These two results (very high correlation between $P_{L}$ and $P_{S}$ and large values for $V_{Q} / V_{P}$ ) suggest that changes in the size composition of sales, even if of substantial magnitude, may not have any appreciable effect upon the relative prices that will prevail. Equations (b) and (c), of section 2, were fitted to the data to determine the extent to which the price ratios and price premiums were affected by fluctuations in the relative quantities of large and small plums sold. For this purpose separate equations were determined with the $W$ and $Q W$ terms excluded and included. The most significant equations are summarized in table 14.

${ }^{50}$ See: Schultz (1938), p. 571-72, and several applications throughout chapters 18 and 19. In making the test relative variations in price and quantity ratios (i.e., the coefficients of variation) are compared. The presumption is that if the prices of the two goods tend to maintain a constant ratio regardless of the relative quantities being purchased, the two commodities are close substitutes. Conversely, if the quantity ratio remains relatively stable while the price ratio fluctuates widely, the two goods are said to complete each other since they tend to be purchased in a definite proportion irrespective of changes in their relative prices. Originally, it was maintained that if the two ratios fluctuate to approximately the same extent, the commodities could be assumed to be independent goods. Generally, however, the ratio of the two coefficients of variation will be different from 1 when the goods are independent of each other in consumption. (See the demonstration by G. M. Kuznets given in Hoos (1942), p. 528, footnote 3.)

${ }_{51}$ The relatively higher value of $V_{Q} \div V_{P}$ secured for Wickson plums should not be given undue weight. There is no basis for concluding that a considerably larger value for this ratio is to be interpreted as a correspondingly greater degree of substitutability. Furthermore, the result, in part, can be explained on statistical grounds. The quantity of large Wickson plums $\left(3 \times 4\right.$ size) sold during some weeks was very small so that the ratio $Q_{S} \div Q_{L}$ became very large. This increased both the average and standard deviation out of proportion to the importance of these extreme observations. For example, if the two extreme quantity ratios are eliminated from the computation the value of $V_{Q} \div V_{P}$ is reduced to 16.6. 
TABLE 14

California Plums: Price Ratio and Price Premium Related to

Quantity Ratio and Week, 1937-1948 a

\begin{tabular}{|c|c|c|c|c|c|c|c|}
\hline \multirow{2}{*}{ Equation } & \multirow{2}{*}{$\begin{array}{l}\text { Number } \\
\text { of weeks }\end{array}$} & \multirow{2}{*}{$\begin{array}{l}\text { Dependent } \\
\text { variable }\end{array}$} & \multirow{2}{*}{$\underset{\text { term }}{\text { Constant }}$} & \multicolumn{3}{|c|}{ Net regression coefficient ${ }^{b}$} & \multirow{2}{*}{$\begin{array}{l}\text { Adjusted } \\
\text { coefficient of } \\
\text { correlation } \\
\vec{R}\end{array}$} \\
\hline & & & & $Q$ & $W$ & $Q W$ & \\
\hline \multicolumn{8}{|c|}{ Beauty variety } \\
\hline 5.3 & 28 & $P$ & .8875 & $\begin{array}{c}-.0430 \\
(2.56)\end{array}$ & $\ldots \ldots$ & $\ldots \ldots$ & .4347 \\
\hline 5.4 & 28 & $P$ & .8721 & $\begin{array}{c}-.0496 \\
(2.62)\end{array}$ & $\begin{array}{l}.0066 \\
(0.66)\end{array}$ & $\ldots \ldots \ldots$ & .4135 \\
\hline 5.5 & 35 & $P^{\prime}$ & .0981 & $\begin{array}{c}.2548 \\
(5.86)\end{array}$ & $\cdots \cdots$ & $\begin{array}{c}-.0531 \\
(6.49)\end{array}$ & .7366 \\
\hline 5.6 & 35 & $P^{\prime}$ & .1552 & $\begin{array}{r}.3151 \\
(13.14)\end{array}$ & $\begin{array}{c}-.0411 \\
(9.11)\end{array}$ & $\begin{array}{l}-.0524 \\
(12.07)\end{array}$ & .9336 \\
\hline \multicolumn{8}{|c|}{ Tragedy variety } \\
\hline 6.3 & 28 & $P$ & .8898 & $\begin{array}{c}-.0235 \\
(2.23)\end{array}$ & $\ldots \ldots$ & & .3581 \\
\hline 6.4 & 28 & $P$ & .8964 & $\begin{array}{c}-.0243 \\
(2.14)\end{array}$ & $\begin{array}{c}-.0016 \\
(0.23)\end{array}$ & $\ldots \ldots$ & .3088 \\
\hline 6.5 & 35 & $P^{\prime}$ & .0991 & $\begin{array}{c}.0318 \\
(2.77)\end{array}$ & $\begin{array}{c}.0070 \\
(1.07)\end{array}$ & & .3789 \\
\hline 6.6 & 35 & $P^{\prime}$ & .0870 & $\begin{array}{l}.0392 \\
(2.00)\end{array}$ & $\begin{array}{l}.0115 \\
(0.99)\end{array}$ & $\begin{array}{c}-.00314 \\
(0.47)\end{array}$ & .3496 \\
\hline \multicolumn{8}{|c|}{ President variety } \\
\hline 8.3 & 49 & $P$ & .7949 & $\begin{array}{c}-.0129 \\
(2.09)\end{array}$ & & & .2296 \\
\hline 8.4 & 49 & $P$ & .8272 & $\begin{array}{c}-.0123 \\
(1.88)\end{array}$ & $\begin{array}{c}-.0057 \\
(1.22)\end{array}$ & 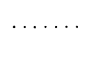 & .2518 \\
\hline 8.5 & 56 & $P^{\prime}$ & .2655 & $\begin{array}{c}-.0165 \\
(0.85)\end{array}$ & $\ldots \ldots$ & $\begin{array}{l}.0133 \\
(2.50)\end{array}$ & .2718 \\
\hline 8.6 & 56 & $P^{\prime}$ & .2756 & $\begin{array}{c}-.0218 \\
(0.72)\end{array}$ & $\begin{array}{c}-.0024 \\
(0.23)\end{array}$ & $\begin{array}{c}.0149 \\
(1.71)\end{array}$ & .2388 \\
\hline
\end{tabular}

a Data for seven years (1937-1938, 1940-1941, and 1946-1948) were used. Results for Wickson plums are not shown since for all equations the adjusted coefficient of correlation was zero.

b Figures in parentheses are $t$-ratios.

$P$-Price ratio (price of small size divided by price of large size).

$P^{\prime}$-Price premium (for large size compared to small size, expressed as a percentage of season average price for all sizes of the given variety).

$Q-$ Quantity ratio (sales of small size divided by sales of large size).

$W$-Week of season, numbered in sequence, beginning with $W=2$ for first week used in the analysis.

Probably the most striking feature about these results is the fact that the independent variables introduced do not provide a satisfactory explanation for changes either in the ratio of prices for small sizes to prices for large sizes or in the premium paid for large plums. Only in the case of Beauty plums are the correlation coefficients significant at the 5 per cent level. ${ }^{52}$ For this variety

${ }^{52}$ Correlation coefficients of approximately 0.35 and 0.25 were secured for Tragedy and President plums. These values correspond to approximately the 10 per cent probability level and are not considered significant. For Wickson variety the adjusted correlation coefficient is zero for each of the four equations fitted and each net regression coefficient is smaller than its standard error. 
a very good fit to the data is obtained when the price premium is expressed as a linear function of the quantity ratio $(Q)$, week $(W)$, and $Q W$. Although the results for the other varieties are not satisfactory, some interesting general comparisons can be made. For this purpose results obtained for Beauty, Tragedy, and President varieties are compared. Those for Wickson plums are omitted because of the low values secured for the correlation and regression coefficients. If, however, only the direction of influence is considered, the results for this variety would agree with the generalizations made on the basis of results for the other varieties.

For each variety the net regression of the price ratio $\left(P_{S} / P_{L}\right)$ on the quantity ratio $\left(Q_{S} / Q_{L}\right)$ is negative and is statistically significant at the 5 per cent level - considering only one tail of the $t$-distribution. That is, the price of small sizes tends to change (relative to the price of large sizes) in the opposite direction to which sales of small sizes (relative to sales of large sizes) are changed. This conclusion is in accord with expectations. The introduction of $W$ into the equation is not justified statistically because the net regressions of $P$ on $W$ are not significantly different from zero. If, however, no significance is attached to the standard errors of these regression coefficients, it may be maintained that as the season advances the price ratio $\left(P_{S} / P_{L}\right)$ tends to increase, with respect to any given size distribution of sales, for Beauty and Wickson plums (both Japanese varieties) and to decrease for Tragedy and President plums (both European varieties).

This apparent relation probably is not of particular significance, since the net change in the price ratio between the first and last week used in the study is not large.

On an a priori basis one would expect the premium paid for large sizes to change in the same direction that the quantity ratio $\left(Q_{S} / Q_{L}\right)$ changes. The equations determined are in agreement with this surmise. For a given size distribution of sales, the premium for large sizes declines from week to week during the season in the case of Beauty plums (the first important variety sold) and increases for Wickson, Tragedy, and President plums. One equation from this set-No. (5.6) - provides an excellent fit to the empirical data $(\bar{R}=0.93)$.

Residuals corresponding to the equations presented in table 14 were not computed. Possibly if these were calculated and plotted about the net regressions it would be possible to determine what curvilinear relations should be introduced into the analysis. Also these plots might suggest additional product terms which would improve the empirical fit.

The results determined indicate that the price ratio and price premium are related to the size distribution of sales and that the average relations probably change throughout the season. Since the data which can be utilized for this investigation are limited, additional computations do not appear justified at present.

The final set of results refers to separate functions determined for auction prices of large and small sizes related to auction sales of both size categories 
and to the index of nonagricultural income. As indicated above, the equations fitted are of the form:

$$
P_{L}=a_{0}+a_{1} Q_{L}+a_{2} Q_{S}+a_{3} I \text { and } P_{S}=b_{0}+b_{1} Q_{S}+b_{2} Q_{L}+b_{3} I .
$$

TABLE 15

California Plums: Prices of Large and Small Sizes Related to Sales and Nonagricultural Income, 1937-1948

\begin{tabular}{|c|c|c|c|c|c|c|c|}
\hline \multirow{2}{*}{ Equation } & \multirow{2}{*}{$\begin{array}{l}\text { Number } \\
\text { of weeks }\end{array}$} & \multirow{2}{*}{$\begin{array}{l}\text { Dependent } \\
\text { variable }\end{array}$} & \multirow{2}{*}{$\underset{\text { term }}{\text { Constant }}$} & \multicolumn{3}{|c|}{ Net regression coefficientb } & \multirow{2}{*}{$\begin{array}{l}\text { Adjusted } \\
\text { coefficient of } \\
\text { correlation } \\
\vec{R}\end{array}$} \\
\hline & & & & $I$ & $Q s$ & $Q_{L}$ & \\
\hline
\end{tabular}

Beauty variety

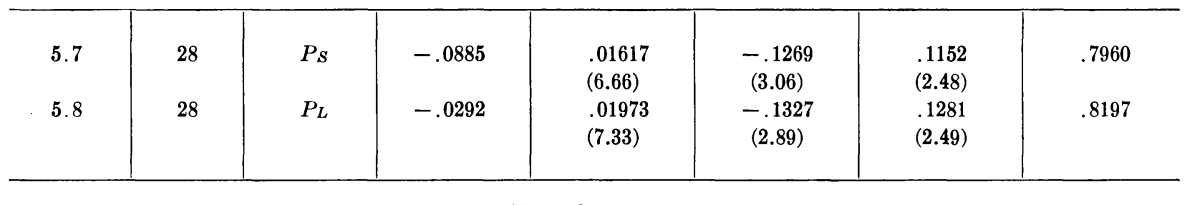

\begin{tabular}{|c|c|c|c|c|c|c|c|}
\hline \multicolumn{8}{|c|}{ Tragedy variety } \\
\hline 6.7 & 28 & $P_{S}$ & .3830 & $\begin{array}{r}.01417 \\
(13.36)\end{array}$ & $\begin{array}{c}-.0696 \\
(3.03)\end{array}$ & $\begin{array}{l}.0290 \\
(0.98)\end{array}$ & .9513 \\
\hline 6.8 & 28 & $P_{L}$ & .3119 & $\begin{array}{c}.01674 \\
(16.90)\end{array}$ & $\begin{array}{c}-.0594 \\
(2.77)\end{array}$ & $\begin{array}{l}.0214 \\
(0.78)\end{array}$ & .9687 \\
\hline
\end{tabular}

\begin{tabular}{|c|c|c|c|c|c|c|c|}
\hline \multicolumn{8}{|c|}{ Wickson variety } \\
\hline $\begin{array}{l}7.7 \\
7.8\end{array}$ & $\begin{array}{l}28 \\
28\end{array}$ & $\begin{array}{l}P_{S} \\
P_{L}\end{array}$ & $\begin{array}{l}.2693 \\
.1999\end{array}$ & $\begin{array}{c}.01232 \\
(15.01) \\
.01427 \\
(17.42)\end{array}$ & $\begin{array}{c}-.0361 \\
(1.89) \\
-.0311 \\
(1.63)\end{array}$ & $\begin{array}{l}.0399 \\
(1.31) \\
.0258 \\
(0.85)\end{array}$ & $\begin{array}{l}.9464 \\
.9593\end{array}$ \\
\hline \multicolumn{8}{|c|}{ President variety } \\
\hline $\begin{array}{l}8.7 \\
8.8\end{array}$ & $\begin{array}{r}49 \\
49\end{array}$ & $\begin{array}{l}P S \\
P_{L}\end{array}$ & $\begin{array}{l}1.0184 \\
1.0143\end{array}$ & $\begin{array}{c}.00793 \\
(10.56) \\
.01242 \\
(15.54)\end{array}$ & $\begin{array}{c}-.0301 \\
(2.87) \\
-.0263 \\
(2.35)\end{array}$ & $\begin{array}{r}.0072 \\
(0.25) \\
-.0240 \\
(0.78)\end{array}$ & $\begin{array}{l}.8519 \\
.9195\end{array}$ \\
\hline
\end{tabular}

a Data for seven years (1937-1938, 1940-1941, and 1946-1948) were used.

h Figures in parentheses are $t$-ratios.

$P_{L}-$-New York auction price for large size, in dollars per crate.

$P S-$ New York auction price for small size, in dollars per crate.

$Q_{L}$-New York auction sales of large size, in 1,000 crates.

$Q_{S}$-New York auction sales of small size, in 1,000 crates.

$I-$ Index of United States nonagricultural income payments, 1935-1939 = 100 .

The results obtained for the four varieties are summarized in table 15. For each equation fairly high values for the adjusted coefficients of correlation (ranging from $\bar{R}=0.80$ to $\bar{R}=0.96$ ) were secured. Thus simple relations expressing auction prices as linear functions of auction sales and nonagricultural income provide good fits to the data, especially for the two midseason varieties (Tragedy and Wickson). 
For each pair of equations the net regression of price on income is greater for $P_{L}$ than for $P_{S}{ }^{53}$ Furthermore, the regression coefficients are greatest for Beauty (an early variety), are smaller for Tragedy and Wickson (two midseason varieties), and are least for President (a late variety). This progression in values is in accord with the results secured for the varietal and weekly analyses (see table 6 of section B and table 9 of section C). In fact, the actual values determined are in very close agreement with the values given by the weekly analysis for weeks corresponding to the heaviest volume of sales of each of these four varieties. The corresponding regression coefficients secured for the varietal analysis are approximately 20 to 25 per cent smaller (in absolute value). It appears, therefore, that the results secured herein as to the influence of income on price of each size are not in conflict with those previously determined.

In all eight equations the net regressions of price (for both large and small sizes) on the quantity of small sizes are negative. The standard errors of seven of these coefficients are sufficiently small (relative to the coefficients) to justify rejecting the null hypothesis (at the 5 per cent level, considering one tail of the $t$-distribution). The remaining coefficient (for $P_{L}$ on $Q_{S}$ for Wickson) is correct as to sign and its value is reasonable in view of the regression of $P_{S}$ on $Q s$.

The net regression coefficients of price on sales of large size, however, are not consistent with a priori expectations. Seven of the eight values are positive, which would seem to suggest that prices of both large and small plums fluctuate in the same direction as the quantity of large-size plums is changed. It is true that six of these values are not statistically significant. But both coefficients for Beauty plums are positive with sufficiently large $t$-ratios (at the 5 per cent level) to suggest acceptance of results. It may be suspected that these results are obtained because of high intercorrelations between certain of the variables. The coefficients of correlation between $Q_{S}$ and $Q_{L}$ (i.e., the sales of small and large sizes), however, do not exceed $r=0.75$. It hardly seems probable that the results can be explained on this basis.

In an attempt to determine whether the introduction of other variables would serve to reverse the sign of this regression coefficient, a series of additional computations were undertaken for the price of large Beauty plums. Several of the new equations gave considerably better empirical fits to the data, indicating that the added variable is significantly related to $P_{L}$. But in none of the cases did the use of additional shift variables result in a negative net regression of $P_{L}$ on $Q_{L}{ }^{54}$

\footnotetext{
${ }^{53}$ By approximately 20 per cent for Beauty, Tragedy, and Wickson varieties and by almost 60 per cent for President plums.

${ }^{54}$ Addition of $W$ and $W I$ improved the fit considerably $(\bar{\kappa}=0.917$ and 0.952 respectively). This indicates that the relation of $P_{L}$ and $Q_{L}$ with $Q_{S}$ and $I$ probably shifts to a lower level as the season advances - the signs of both regression coefficients are negative. Using $Q$ (i.e., $\left.Q_{S} / Q_{L}\right)$ or $Q$ together with $W$ also results in a better fit $(\bar{R}=0.870$ and 0.935$)$. However, their introduction into the equation makes $Q_{S}$ and $Q_{L}$ statistically insignificant. This would suggest that the size distribution of sales is important but that the total volume is not. Such a conclusion is not acceptable.
} 
Unfortunately, the results of this investigation are not as satisfactory as could be desired. Two methods were used to show that prices for large and small sizes of each variety tend to maintain a definite relation. As a result of this situation attempts at relating the price ratios (for small and large sizes) and the price premium (received for large sizes) with the quantity ratios and week of season were not consistently successful. The equations derived, however, did show a definite tendency (in the case of each variety) for changes in the quantity of small sizes, relative to the quantity of large sizes, to be associated with (1) opposite changes in the ratio of price for small sizes to price for large sizes, and (2) changes, in the same direction, in the premium received for large sizes. These results agree with $a$ priori expectations. The equations expressing prices of large and small sizes separately as linear functions of sales of each size and nonagricultural income are not entirely consistent with expectations. Net regressions of price on income and on sales of small sizes are correct in sign and their magnitudes are statistically significant. Furthermore, they are in agreement with the results secured for the varietal and weekly analyses. The net regressions of price on sales of large sizes, however, are not of the correct sign. Yet it is apparent, on the basis of the other results discussed, that plums of the different size categories are close substitutes.

\section{E. APPLICABILITY TO MARKETING CONTROL PROBLEMS}

From the foregoing discussion there emerge several factors of considerable relevance to the question of the effectiveness of using grade and size regulations to modify the distribution of supplies among different outlets-classified geographically, temporally, or by quality categories. The prospect of a substantial increase in the quantity of plums available for fresh distribution during the immediate future, coupled with increases in supplies of other fruits, suggests reductions (possibly of considerable magnitude) in plum prices at terminal markets-particularly, if consumer purchasing power declines. At the same time marketing costs are likely to decline at a slower rate. The resulting reduction in farm prices is expected to stimulate a greater desire to use the marketing agreement program as an important aid in maintaining net returns to growers at levels above those which would prevail if no controls over distribution were attempted.

\section{Nature and Scope of the Problem}

Gräde and size restrictions of the type and severity issued during the past 15 years do not materially affect the total quantity of plums sold in fresh form nor the marketing costs incurred subsequent to harvest. Production costs may be raised, but the increase is not likely to be substantial. A significant increase (percentagewise) in picking costs is possible. However, since such expenses usually are a relatively small expenditure, the over-all increase in production and marketing costs will not be large. Regulations of the type here con- 
sidered, if effective, will alter the geographical distribution of the different grade-size segments of the crop and also may change the seasonal pattern of sales. It is presumed (by the control agency) that these alterations are of such a nature as to increase net returns to growers. ${ }^{55}$ Since the data requisite for determining a suitable approximation to the true supply-response function are not available, the probable long-run effects of the program cannot be given.

In view of this situation the following comments are intended primarily as an indication of the probable short-run effects of a marketing control program on net returns to all plum producers as a group. The extent to which regulations may affect various producers differently (especially, when classified according to time period during which the bulk of their plums are sold) will become apparent from the discussion, but will not be elaborated upon. The particular problem of immediate interest is to determine how a contemplated set of regulations will affect net returns to producers in the short-run-specifically, under what conditions will returns be increased by the limitations. Since there are a number of important varieties sold at temporally interdependent markets, attention must be directed toward varietal, temporal, and grade-size interrelations.

As a means of reducing the problem to manageable size, it will be approached by neglecting varietal interrelations. It is believed that this procedure is not likely to modify the conclusions significantly. During any particular season the supply of each variety is fixed and the important problem consists of distributing that quantity (temporally and geographically) so as to secure as large a net return for all sales as possible. Nontemporal aspects of grade and size regulations insofar as these have a bearing on short-run net returns to producers are discussed briefly below. The empirical results derived in the earlier sections of this study provide information required for determining how changes in the temporal distribution of sales influence the net returns obtained for the entire season. Considerable attention will be devoted to this topic.

\section{Nontemporal Aspects of Supply Allocations}

Grade and size regulations are imposed upon out-of-state shipments primarily as a means of reducing the volume of "inferior quality" plums sold at eastern markets. Thus, the geographical distribution of the various quality segments of the crop is changed-in addition, of course, the temporal sales pattern may be modified. The average quality (i.e., grade-size composition) is raised at eastern markets and lowered for California sales. It becomes necessary, therefore, to determine whether such marketing restrictions serve to raise the composite demand function sufficiently to offset the influence induced by a less favorable temporal allocation of sales. That is the problem to be discussed immediately.

\footnotetext{
${ }^{55}$ If the regulations issued do not cause a significant change in either the temporal or geographical distribution of sales, returns to producers will not be affected appreciably. Furthermore, the mere fact that the allocation of supplies is altered materially does not necessarily assure a substantial change (either an increase or decrease) in grower returns.
} 
It may be argued that the net demand function for any quality category is more elastic for sales made locally and that at each market this function is more elastic for lower quality than for plums of larger size and better grade. ${ }^{56}$ On this basis it might be claimed that shifts of the type generated by grade and size restrictions are likely to increase the total net returns realized for the combined sales at all geographical markets. This conclusion, however, is not supported (or contradicted) by any empirical evidence which can be brought to bear on the problem. The limited data currently available are not sufficient to permit computing separate demand functions for different quality plums at both California and eastern markets. Until such equations can be approximated it is not possible to give a quantitative indication of the extent to which net returns for the season are affected by a reallocation of supplies among nontemporal markets.

\section{Temporal Distribution of Sales}

Of course, it is recognized that-in view of the perishability of plums-there are definite limits as to the extent to which the sales pattern actually can be changed. Yet it is a fact that growers can advance or delay the picking date, even though by only a few days. Furthermore, several varieties can be stored successfully. Consequently, it will be profitable to contrast the optimum sales pattern (that is, the temporal allocation of available supplies which maximizes net returns for the entire season) with the actual distribution and to compare the net returns obtainable with different distribution patterns. The results should serve to indicate whether the indirect effect of grade and size restrictions arising from such changes in the temporal distribution of sales as are induced tend to reinforce or to offset whatever increases in net returns may be ascribed to the other effects of these regulations. The comparison is relevant for indicating whether the maintenance of an approximately uniform price or a reasonably steady flow of supplies to market will raise the season average price- that is, increase net returns to growers. Finally, it shows whether the control agency should encourage or discourage storage of plums when such storage merely delays sales from early to late weeks but does not result in extending the entire season during which plums are sold.

For this purpose the price-quantity relation determined for weekly auction sales at New York is used to derive an equivalent net demand function- "net"

${ }^{56}$ Of course, the comparisons made refer to elasticities at points on the demand functions at which sales actually occur. "Net demand function" is used to specify the price-quantity relation facing plum producers. Marketing charges are relatively fixed (with respect to changes in volume sold during the season) and are considerably higher for plums shipped to distant markets. Furthermore, plums as well as other fruits are more widely used by California consumers. Thus plums are available to consumers in the lower income groups more generally at local markets. It seems impossible to escape the conclusion that, within the relevant range, the price-quantity relation at the terminal level will be more elastic for intrastate sales and that the corresponding farm demand will be still more elastic relative to the farm demand for the portion of the crop shipped to eastern markets. There is no statistical evidence to indicate the relative elasticities of demand for different qualities. Deductive analysis, buttressed with subjective information, however, strongly suggests that demand at the terminal market level is more elastic for the better qualities. 
in the sense of specifying the relation between sales and farm prices. This equation (No. 4 from section 3 ) is

$$
\begin{gathered}
P_{W}=0.3022+(0.0189-0.00076 W) I+(0.1882-0.0084 W) W \\
-0.00804 Q_{W}-0.00402 Q_{(W-1)} . .^{57}
\end{gathered}
$$

To derive the demand function at the farm level selling charges equal to seven per cent of the auction price and an estimate of all other marketing costs (based on the information given in Statistical Appendix, table A-13) are to be subtracted. Thus, by definition

$$
P^{\prime}{ }_{W}=0.93 P_{W}-M_{i} .
$$

Substituting this value into (1) gives

$$
\begin{gathered}
P_{W}^{\prime}=0.2810-M_{i}+(0.0176-0.000707 W) I+(0.1750-0.0078 W) W \\
-0.00748 Q_{W}-0.00374 Q_{(W-1)} .
\end{gathered}
$$

A family of weekly net demand functions corresponding to specified conditions can be obtained from equation (3) by substituting into that equation appropriate values for $I$ and $M_{i}$.

Definition (2) suggests an alternative procedure of determining the net demand function. A new equation with $P_{W}^{\prime}$, as defined by (2), being considered as the dependent variable could be calculated using the original data employed in computing (1). Since $M_{i}$ may vary from year to year the net regression coefficients of the equation so derived will, in general, differ from those shown in (3). A choice between the two procedures must be made. In section A-2, it was indicated that the focal point for determining prices of fresh plums is at the terminal markets rather than at the farm level. From this point of view, it is doubtful whether this second method is preferable to equation (3) for the present purpose. ${ }^{58}$

The pattern of weekly demand functions specified by (3) changes as the level of nonagricultural income varies. It may be well, therefore, to contrast the situation specified by high and low income levels-represented by averages for 1946-1948 and 1935-1939, respectively. At both levels the net returns secured for the actual temporal distribution of supplies are compared with those

${ }^{57}$ The following notation is to be used in the equations:

$W$ - Week of season, numbered in sequence from the week of first sales at the New York auction market.

$I$ - Index of nonagricultural income payments, $1935-1939=100$.

$Q_{W}$ - New York auction sales for week $W$, in 1,000 crates.

$P_{W}$ - New York auction price for week $W$, in dollars per crate.

$P^{\prime} W$ - Derived on-tree price for week $W$, in dollars per crate.

$M_{i}$ - Marketing charges (exclusive of selling commission) for year $i$, in dollars per crate- that is, $M$ is assumed constant during a season but is permitted to vary from year to year.

${ }^{58}$ It will be noted later in the discussion that the determination of the optimum sales pattern is not very sensitive to changes in the net regression coefficients of price on current and lagged sales but is affected considerably by a change in the pattern of weekly demand functions. This means that changes in the values of the net regressions of price on income and on week may result in significantly different optimum sales patterns. 
obtaincble if alternative sales patterns were followed. For these comparisons the quantity to be sold is held constant at approximately the average for the past decade - a value of one million crates at the New York auction market is u.sed. Consequently, the season average prices computed for the different sales patterns can be compared directly to indicate how net returns are affected by modifications in the distribution of a given volume of supplies.

To maximize net returns from the sale of a given quantity distributed among temporally interdependent markets, the appropriate allocation of supplies must be determined. In the derivation of a procedure for computing this optimum sales pattern it is assumed that:

1. The total quantity to be sold during the season remains fixed.

2. The level of the weekly demand curves is not affected by changes in grade-size composition resulting from the modification of the temporal distribution of sales.

3. Expenses for operating the program can be neglected from consideration.

4. Net prices can be related to current and lagged sales by a linear equation of form (3). ${ }^{59}$

Weekly sales for four distribution patterns at both high and low levels of income together with the corresponding weekly prices (computed from the net demand functions) are given in table 16. Case A represents the average actual sales pattern prevailing during 1928-1948. The optimum distribution, determined in accordance with the procedure specified for maximizing net returns for the entire season, is case B. Some indication of the sensitivity of the pattern determined to variations in the net regression coefficients is needed since it is recognized that the coefficients determined in equation (3) may not be the true parameters. An important variable in the formula for computing the optimum sales pattern is $(b / c)$ - the ratio of the net regression of price on current sales to the net regression of price on lagged sales. Hence it appears desirable to use a second net demand function in which the value $(b / c)$ is altered considerably. This was accomplished by decreasing the value of the net regression of price on current sales $(b)$ by approximately one standard error and increasing the value of the net regression of price on lagged sales $(c)$

${ }^{59}$ The computational procedure utilized is derived and discussed in the Mathematical Appendix. At first glance these assumptions appear formidable. But this is not the case. The first three are merely made for convenience. Although the quantity sold may be changed after the crop is ready for harvest due to economic conditions (for example, when prices are very low the entire crop may not be offered for sale), it does not change substantially merely because a control program is operated. Variations in the average quality sold during specific weeks may change the level of weekly demand functions. If so, this influence is to be taken into account separately. Expenses of the control agency are only a fraction of a cent for each crate of plums sold. When these costs are to be included it is merely necessary to specify that the increase in net returns must exceed a predetermined amount (equivalent to the agency's budget) before it is considered to be an actual increase. The last assumption is the only one of a restrictive nature. It is essential to the derivation of the method for calculating the optimum sales pattern presented in the appendix note. If a linear equation cannot be assumed as a reasonably adequate first approximation to the covariation existing, then the procedure cannot be applied. 
TABLE 16

California Plums: Estimated Weekly Farm Prices for Different Sales Patterns a with Nonagricultural Income at High and Low Levels

\begin{tabular}{|c|c|c|c|c|c|c|c|c|}
\hline \multirow{2}{*}{$\begin{array}{c}\text { Week of } \\
\text { season } \\
W\end{array}$} & \multicolumn{4}{|c|}{ Sales $-1,000$ crates $(Q w)$} & \multicolumn{4}{|c|}{ Price-dollars per crate $\left(P^{\prime} \boldsymbol{F}\right)^{\mathrm{b}}$} \\
\hline & Case A & Case B & Case C & Case D & Case A & Case B & Case C & Case D \\
\hline & \multicolumn{8}{|c|}{ High nonagricultural income (1946-1948 average) } \\
\hline 2. & 22 & 136 & 159 & 33 & 3.02 & 2.18 & 2.20 & 2.94 \\
\hline $3 \ldots$ & 48 & 95 & 74 & 72 & 2.68 & 1.91 & 1.86 & 2.46 \\
\hline $4 \ldots$ & 73 & 103 & 114 & 95 & 2.33 & 1.94 & 1.98 & 2.08 \\
\hline $\mathbf{5} \ldots$ & 86 & 94 & 86 & 100 & 2.04 & 1.87 & 1.85 & 1.86 \\
\hline $6 \ldots$ & 97 & 92 & 95 & 100 & 1.82 & 1.82 & 1.84 & 1.74 \\
\hline 7. & 105 & 85 & 82 & 95 & 1.58 & 1.75 & 1.74 & 1.65 \\
\hline $8 \ldots$ & 102 & 78 & 78 & 90 & 1.43 & 1.67 & 1.68 & 1.55 \\
\hline $9 \ldots \ldots$ & 85 & 73 & 72 & 85 & 1.42 & 1.60 & 1.60 & 1.47 \\
\hline $10 \ldots \ldots \ldots$ & 88 & 64 & 64 & 80 & 1.28 & 1.50 & 1.50 & 1.34 \\
\hline $11 \ldots \ldots \ldots$ & 76 & 55 & 53 & 72 & 1.16 & 1.41 & 1.41 & 1.22 \\
\hline $12 \ldots$ & 74 & 47 & 47 & 64 & 1.03 & 1.31 & 1.31 & 1.12 \\
\hline $13 \ldots$ & 60 & 36 & 35 & 52 & .92 & 1.19 & 1.19 & 1.01 \\
\hline $14 \ldots \ldots \ldots$ & 40 & 27 & 26 & 32 & .90 & 1.08 & 1.09 & .99 \\
\hline $15 \ldots$ & 28 & 15 & 15 & 20 & .80 & .94 & .94 & .89 \\
\hline $16 \ldots$ & 16 & 0 & 0 & 10 & .66 & $\ldots$ & $\ldots$ & .73 \\
\hline \multirow[t]{2}{*}{ Season. } & 1,000 & 1,000 & 1,000 & 1,000 & 1.551 & 1.738 & 1.751 & 1.629 \\
\hline & \multicolumn{8}{|c|}{ Low nonagricultural income (1935-1939 average) } \\
\hline $2 \ldots$ & 22 & 83 & 96 & 33 & 1.06 & .60 & .62 & .97 \\
\hline $3 \ldots$ & 48 & 64 & 52 & 72 & .84 & .50 & .48 & .62 \\
\hline $4 \ldots$ & 73 & 73 & 79 & 78 & .62 & .56 & .59 & .49 \\
\hline $5 \ldots$ & 86 & 72 & 67 & 82 & .46 & .56 & .56 & .47 \\
\hline $6 \ldots \ldots \ldots$ & 97 & 74 & 75 & 85 & .35 & .57 & .59 & .46 \\
\hline $7 \ldots \ldots \ldots$ & 105 & 74 & 72 & 85 & .25 & .57 & .57 & .44 \\
\hline $8 \ldots$ & 102 & 73 & 73 & 83 & .23 & .56 & .57 & .44 \\
\hline $9 \ldots \ldots$ & 85 & 72 & 71 & 80 & .34 & .54 & .55 & .45 \\
\hline $10 \ldots \ldots \ldots$ & 88 & 70 & 70 & 75 & .33 & .52 & .52 & .45 \\
\hline $11 \ldots \ldots \ldots$ & 76 & 67 & 65 & 73 & .35 & .48 & .49 & .42 \\
\hline $12 \ldots \ldots$ & 74 & 64 & 65 & 73 & .34 & .44 & .44 & .36 \\
\hline $13 \ldots \ldots \ldots$ & 60 & 59 & 56 & 67 & .35 & .40 & .41 & .31 \\
\hline $14 \ldots \ldots \ldots$ & 40 & 56 & 59 & 54 & .45 & .34 & .33 & .32 \\
\hline $15 \ldots \ldots \ldots$ & 28 & 47 & 40 & 40 & .49 & .29 & .31 & .35 \\
\hline $16 \ldots \ldots \ldots$ & 16 & 52 & 60 & 20 & .48 & .14 & .14 & .41 \\
\hline Season...... & 1,000 & 1,000 & 1,000 & 1,000 & .403 & .488 & .494 & .453 \\
\hline
\end{tabular}

a Case A: actual sales pattern, average for 1928-1948.

Case B: optimum sales pattern using determined regression coefficients (see text).

Case C: optimum sales pattern using altered regression coefficients (see text).

Case D: arbitrarily selected "intermediate" sales pattern.

b Prices at "high" and "low" nonagricultural income computed by

$P^{\prime} W=3.259-(0.0229+0.0078 W) W-0.0748 Q W-0.0374 Q W-1$ and

$P^{\prime} W=1.038+(0.1043-0.0078 W) W-0.0748 Q_{W}-0.0374 Q_{W-1}$ for cases A, B, and D:

$P_{W}^{\prime}=3.267-(0.0229+0.0078 W) W-0.0625 Q W-0.0500 Q_{-1} \quad$ and

$P_{W}^{\prime}=1.046+(0.1043-0.0078 W) W-0.0625 Q W-0.0500 Q_{W-1} \quad$ for case C. 
by one standard error. The results secured using this altered equation are designated as case C. Finally, an indication should be given as to how much net returns are affected when the temporal distribution of sales is modified toward the optimum pattern to the extent justified by practical considerations. One such arbitrarily selected intermediate distribution is indicated by case D. Possibly changes of the magnitude used cannot be made-it does seem probable that a greater modification in the sales pattern is not feasible.

The optimum allocation of supplies among related temporal markets appears to be affected to only a limited extent by changes, of even substantial magnitude, in the values of the net regressions of price on current and lagged sales. The optimum distributions of sales for cases $\mathrm{B}$ and $\mathrm{C}$-contrasting the situations with a considerable change in these coefficients-are very similar (at both high and low income levels) and give practically the same season average prices. On the other hand, the configuration of this optimum sales pattern changes considerably as the income level varies. When income is high, sales should-in order to maximize net returns-begin with a large quantity and decline more or less regularly during subsequent weeks to a small volume of sales toward the end of the season. When the level of income is low, however, an approximately uniform rate of sales throughout the season is indicated.

Figure 9 shows clearly the extent to which changes in income affect the distribution of supplies which should be attempted. The chart also indicates that there is a substantial discrepancy between the actual weekly distribution of sales and that required to maximize total net returns. If sales could be made in accordance with the optimum pattern - at least for income at approximately the two levels used in the illustrations of table 16-the season average price and, therefore, total net returns would be increased by about 20 per cent. A comparison between cases $\mathrm{A}$ and $\mathrm{D}$ suggests that net returns can be increased significantly (by 5 to 10 per cent) by "feasible" alterations in the temporal distribution of sales toward the optimum pattern. It can also be shown that net returns are decreased when the sales pattern is altered in the opposite direction-and, furthermore, this reduction in net returns becomes larger and larger as the allocation of sales is distorted further. ${ }^{60}$

This relation between the temporal distribution of sales and total net returns is of considerable practical consequence to the industry. Effort should be directed toward increasing the proportion of the total supply marketed early in the season. Sales immediately thereafter (during approximately weeks 6-12) should be curtailed rather than expanded. ${ }^{61}$ Maintenance of a uniform rate

\footnotetext{
${ }^{60}$ For example, the season average price is decreased by 2 per cent if sales during early weeks are reduced by 20,000 crates (and a corresponding increase is made late in the season). The reduction in price is only half as great when sales are decreased (by 20,000 crates) during midseason and increased by this amount during late weeks.

${ }_{61}$ In passing, it is well to point out that the current shift in productive capacity is in the direction of producing such a long-run change in the sales pattern. The proportion of the season's total supply sold during the first three weeks has increased substantially during the past decade and will increase further during the immediate future as acreage recently planted comes into bearing. Sales during weeks 6-8 are being reduced.
} 

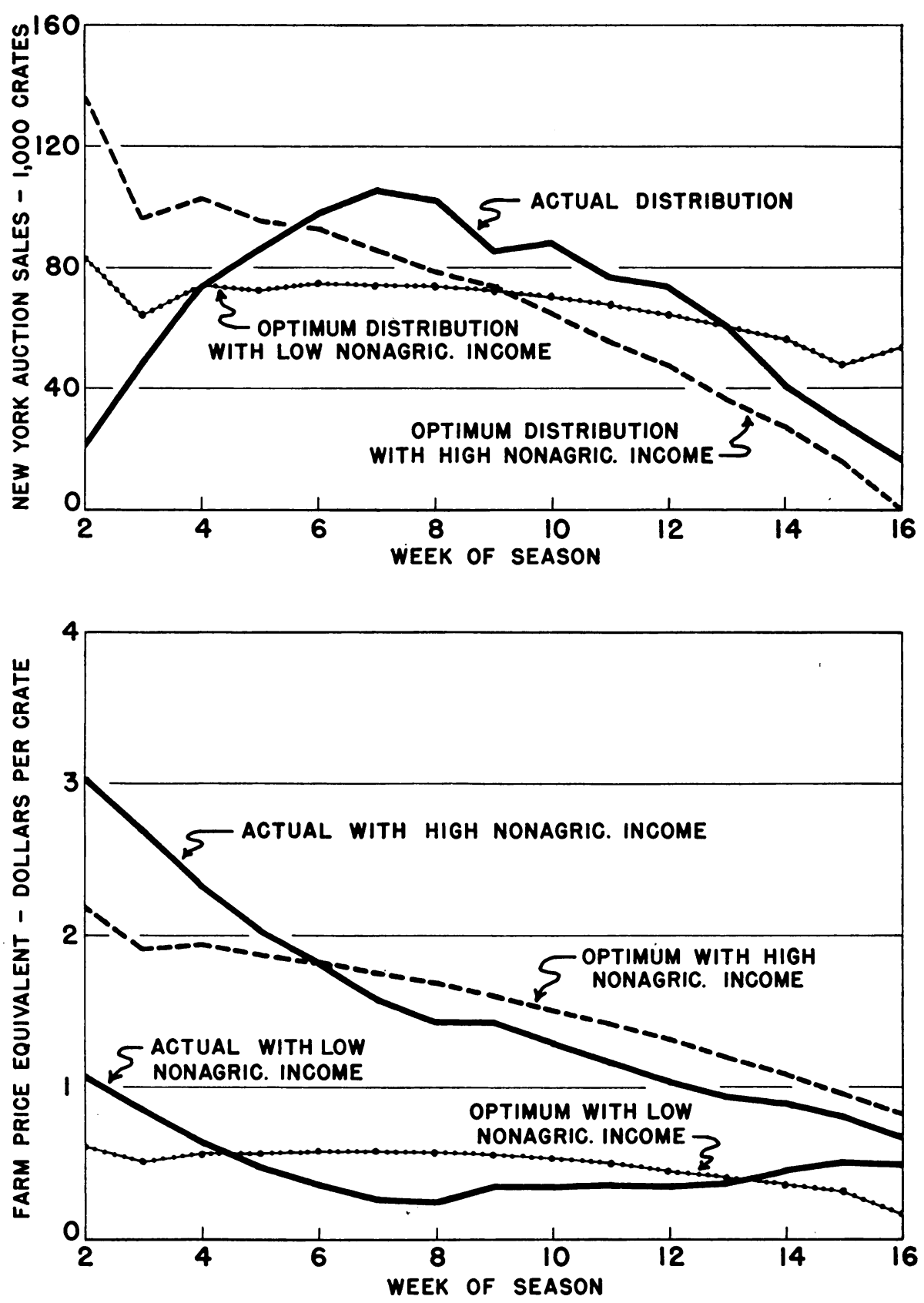

Fig. 9. California plums: actual and optimum weekly sales and equivalent weekly farm prices for high and low levels of nonagricultural income payments (1946-1948 and 19351939, respectively). Based on table 16. 
of sales appears desirable only when the level of consumer purchasing power is low. However, a constant price throughout the season is not indicated even in this case. The results suggest a lower price at the beginning of the season and a more gradual decline during subsequent weeks than is the case with the present temporal distribution of sales.

\section{Conclusion}

Insofar as the indirect effect of an alteration in the temporal distribution of sales is concerned, it appears that the present method of imposing grade and size regulations serves to define a less favorable sales pattern (that is, one involving a decrease in net returns for the season) than would prevail without restrictions. Although it is difficult to determine to what extent these restrictions actually do modify the weekly pattern of sales, it does appear that normally they tend to delay the sale of a portion of the total supply of most major varieties. Usually, grade regulations are not changed during the year, whereas size restrictions often are relaxed as the season advances. ${ }^{62}$ Such action conflicts, particularly during years of high consumer purchasing power, with the results indicated above as to how the temporal distribution of sales should be modified in order to increase net returns. Thus, the indirect effect of grade and size regulations, by specifying a less favorable temporal distribution of sales, offsets, at least partly, the increase in net returns, if any, accruing from the direct influence of lifting the composite demand function.

There has been some agitation under certain control programs for employing regulations to increase the use of storage. If the attempt results in postponing the sale of a portion of the total supply beyond the normal marketing season it may provide a suitable means for increasing net returns. ${ }^{63}$ However, if the program merely delays marketing during the normal season, a decrease in net returns may be expected-and in addition storage costs are incurred.

The optimum allocation of sales, determined by the method employed above, can be used to advantage when grade and size restrictions are to be imposed. Estimates of the quantity of plums to be sold and of the level of nonagricultural income for the season are substituted into the formula, giving the sales pattern which maximizes net returns. Then every effort should be made to utilize regulations which induce modifications in the distribution of sales toward the optimum pattern. For example, during early weeks regulations should be used sparingly since a reduction in sales at this time tends to decrease net returns considerably. More severe restrictions later in the season appear to have a less detrimental effect upon net returns. Of course, the de-

${ }^{62}$ The minimum sizes permitted to be shipped to eastern markets were increased (that is, the restrictions were made more severe) early during the 1937 season and were not changed in 1939. During other years, however, these minima were reduced after a significant portion of the supply of each major variety was shipped. In fact, in 1945, 1946, and 1948 all regulations were revoked during midseason.

${ }^{63}$ Attention must be given to two considerations. The decrease in returns during the regular season (since a smaller quantity is sold and demand is elastic) should be compared to the net returns secured for these postponed sales when made after the close of the season. The net increase so obtained must also be compared to the costs of storage for this portion of the crop. 
crease in net returns induced by a less favorable weekly allocation of supplies must be compared with the increase resulting from the fact that a more preferred grade-size composition may lift the level of the composite net demand curve-for the portion of the season under consideration.

When consideration is being given to the effect which grade and size regulations have on net returns for the whole season, two facts must be kept in mind. The imposition of such restrictions will alter, at least to a limited extent, the temporal distribution of sales and that modification is likely to cause a less favorable temporal allocation of sales. The resulting decrease in net returns may not be negligible, especially if severe limitations are used during the early weeks of the season. Secondly, the actual reallocation of sales among related nontemporal markets does not necessarily increase net returns, even though the optimum distribution, if it were known, probably would have this effect. In a practical situation the combined influence of both effects must be determined.

A control program designed to regulate weekly shipments could increase net returns substantially. In view of the perishable nature of the commodity and the difficulty of advancing the picking date more than a few days, however, it is not possible to allocate supplies in accordance with the optimum temporal pattern. Yet some increase in net returns can be secured by an intelligent use of grade and size regulations. Every effort should be made to insure that the restrictions do not cause a less favorable sales pattern than would prevail without any controls-since a movement in this direction, even when of not too great magnitude may decrease total net returns appreciably.

\section{F. SUMMARY AND IMPLICATIONS OF FINDINGS}

Detailed consideration has already been given to the varietal, temporal, and size aspects of demand for California plums. This empirical investigation has used the methods of classical regression analysis to determine the average ex post relations between auction prices and selected independent variables. In this study no attempt is made:

1. To consider the effect of all variables - some factors such as maturity, grade, and brands were omitted although they presumably exert some influence on prices.

2 . To provide a systematic treatment of complementarity relations between plums and other commodities-series representing supplies of related fruits were introduced on a trial and error basis.

3. To expand the analysis to cover other outlets-e.g., all auction markets, private transactions, and intrastate sales.

4. To integrate the various aspects of the problem into a single hypothesis providing for the concomitant operation of different influences.

5. To determine whether the pattern of relations prevailing during the particular period studied is an adequate description for different subperiods. 
The primary purpose of this section is to consider the validity and limitations of the results (including some discussion of the above-mentioned aspects of the demand problem, which were not investigated) and to indicate their economic implications. Before proceeding with these matters, however, it seems advisable to restate the demand problem being considered and to recapitulate the important results that were obtained.

\section{Restatement of the Demand Problem}

In this study demand is conceived as the price-quantity relation confronting wholesale sellers of California plums. The analyses are oriented toward the problem of specifying the forces which are related to variations in auction prices. It was assumed that the unknown price-quantity relation can be approximated by a simple empirical function fitted to the data available for the period studied. Thus the results are descriptive of the average relations (of the type specified by the equations used) existing among the selected variables during the period under investigation. Although the functions derived admittedly do not correspond to the theoretical demand curves, they do specify relations among the selected variables which prevailed in the past and which may be assumed to describe the future when certain conditions are met. Thus the derived statistical relations provide suitable functions from which qualified forecasts can be made.

Plums are one of California's perishable fruits which must be sold soon after harvest. They are used chiefly for fresh consumption, mainly in the heavily populated industrial region extending roughly from Chicago to New York (and surrounding areas). Over half of the total crop is shipped early in the summer before large supplies of the major fruits become available. Except for fresh prunes grown in the Pacific Northwest, plums are not produced commercially to any considerable extent in states other than California. Complications arising from storage, competing plum production areas, and multiple uses do not exist. Even competition from other fruits is less pronounced than is generally the case with other fruits. From this viewpoint the analytical problem is considerably simplified. Certain other difficulties, however, must be considered. The "commodity," plums, includes a large number of varieties with striking differences in physical characteristics (size, shape, and color), in marketing seasons, in consumer acceptance, and in other respects. That is, the problem really deals with a family of distinct, though closely related, commodities. In an endeavor to increase the homogeneity of the product considered as a single commodity, demand for plums is stratified on varietal, temporal, and size bases.

In order to permit a quantitative evaluation of the grade and size control program at least four price-quantity relations must be computed from the empirical data. For this purpose the grade-size composition of sales may be considered under a single quality caption. Insofar as possible for this analysis, plums should be segregated into these two quality classes in such a way that grades and sizes generally permitted to be shipped under the regulations are 
separated from those portions of the crop which are subject to limitation. Two functions, one for the preferred quality and the other for the poorer quality, should be determined for out-of-state markets; the corresponding two relations for local sales are also needed. For a more general consideration of the problem several quality categories for each separate varietal group at both intrastate and interstate markets would be necessary.

TABLE 17

California Plums: Net Regression of Auction Price on Nonagricultural Income by Three Analyses

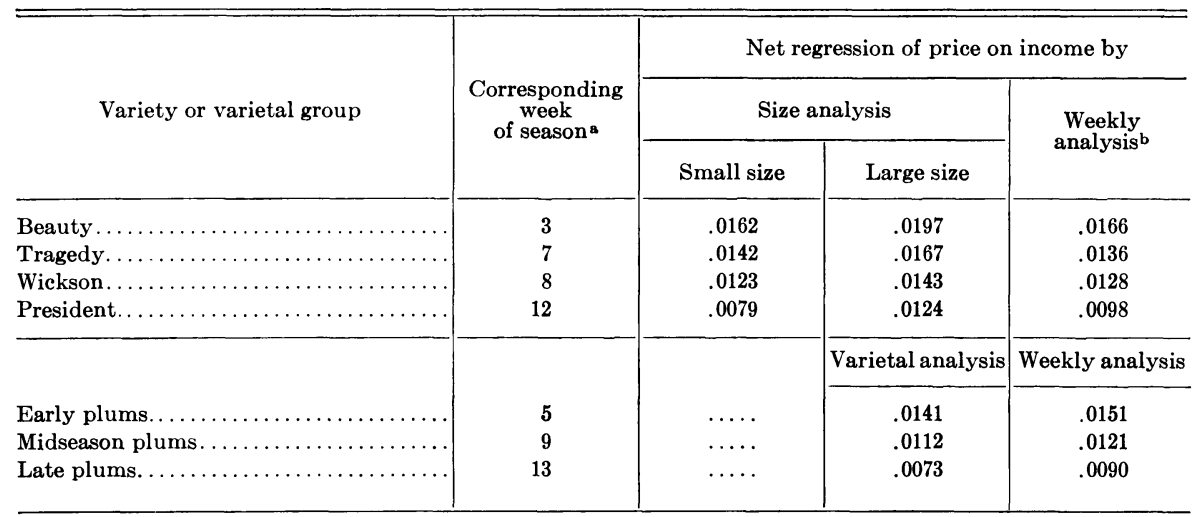

a Week of the plum marketing season during which the cumulative sales for the variety (or varietal group) equals 50 per cent of the season's total sales.

$\frac{\partial P_{i}}{\partial I}=0.0189-0.00076 \mathrm{~W}$.

Source of Data: Tables 6,9 , and 15 .

\section{Recapitulation of Results}

An extensive restatement of the results does not appear warranted since the findings are discussed in considerable detail in the foregoing sections. Yet it may be well, at this point, to summarize the main conclusions and to compare the results for the various segments of the investigation. The simple equations used, with auction price as the dependent variable, generally provide excellent fits to the data-most of the values of the correlation coefficient exceed 0.90 . Considerable difficulty was experienced, however, in securing satisfactory equations in the size analysis. Several of these results are not acceptable even though the values for the correlation coefficient are high because the signs of all of the net regression coefficients do not agree with a priori expectations. A comparison of the net regression coefficients determined is particularly interesting since the equations for the three analyses were fitted to observations for different time periods.

These analyses indicate that the net price-income relation declines during the season as later varieties of plums are marketed and give approximately the same values for this regression at comparable periods during the seasonsee the data summarized in table 17. The consistency with which this pattern 
is revealed is one of the most striking features of the empirically determined functions. During the period from the third to twelfth week the value of the net regression coefficient is reduced by approximately 40 per cent for both the size analysis (average for the two sizes) and the weekly analysis. In the varietal analysis the regression slope is just half as steep for late varieties as for early plums. The values determined for the varietal analysis are only 10 per cent less than those obtained from the weekly analysis (when reference is made to weeks corresponding to the dates by which half of the season's total sales are made). For the size analysis the values are almost identical with those for the weekly analysis when small sizes are considered, but somewhat higher in the case of large sizes. The regression of price for large sizes on income exceeds the regression of price for small sizes on income by almost 60 per cent for President plums and by about 20 per cent for each of the other three varieties.

These results for the net price-income relations are mutually consistent and are in agreement with what might be expected from a knowledge of the commodity and its marketing. It appears reasonable that a given change in income is associated with a greater variation in price early in the season (while supplies are still limited and the more preferred varieties are being marketed) than during later weeks. A higher net price-income regression for larger sizes than for smaller sizes also seems justified for this reason and in view of the fact that the net contents of crates of large sizes are heavier than the net contents for smaller sizes.

Both the varietal and weekly analyses indicate a definite interrelation between temporal markets. In the weekly analysis the net regression of price on quantity is exactly twice as large for current sales as for sales of the preceding week. It should be noted, however, that this result represents the average relation for the various weeks of the season and need not adequately describe the relative importance of past and present sales upon the price for any specific week. Actually this result should be compared with that secured from the varietal analysis. The net regression of price for midseason plums on sales of early varieties is positive, whereas the price of late varieties is negatively related to sales of midseason plums. An explanation for this change in type of relation has already been given (see section B-3) and need not be repeated here. This apparent reversal in the direction of influence is important. It clearly indicates that the result obtained for the weekly analysis cannot be used to describe satisfactorily for each week of the season the actual price influence being exerted by past sales.

From these comments it becomes clear that the analyses establish the existence of an interrelation of temporal markets but do not definitely indicate just how that relation changes from week to week. It appears that on the average: (1) sales of early plums are positively related with prices of midseason varieties, (2) sales of midseason varieties are negatively related with prices of late varieties, and (3) weekly sales are negatively related, on the average, with prices for the following week. In these two analyses past supplies were introduced into the equations by linear terms. Presumably the use of more complex 
relations, for example, a third degree parabolic expression for preceding week's sales, might improve the empirical fit to the weekly data and bring the results into consistence with the relations for the varietal analyses. This procedure hardly seems justified, however, unless at the same time it is possible to generalize the relation between weekly price and current sales (and the other independent variables). Also additional variables should be introduced and consideration should be given to representing past sales by supplies during the second preceding and earlier weeks. If an attempt were made to expand the equation to this extent, the weekly analysis would become unwieldily complex and the computational work would be increased considerably.

A direct detailed comparison of the magnitudes of the net regression of price on sales (as was done above for the price-income relations) is not possible. Although the quantities used in the three analyses are all expressed in a common unit, the meaning of a change by a given amount varies from analysis to analysis. A few general comments, however, may be useful.

In the varietal analysis the net regression of price on sales was almost twice as large for midseason plums as for early or late varieties. The influence of current sales on prices of midseason and late varieties is more than twice the effect of an equivalent change in the sales of the preceding varietal group. For the weekly analysis the net price-quantity relations (with respect to both current and past sales) remain unchanged in slope regardless of the week of the season or the level of income. Values of these factors, however, determine the level of both price-quantity relations. Thus as the season advances the regression line changes its position-generally to a lower level. The exact pattern of parallel shifts, as indicated in section C-3, depends upon the level of income prevailing. Net regressions of prices for both large and small sizes on sales of small sizes become smaller (with a negative sign) as later varieties are sold. For three of the four varieties considered sales of small sizes have a smaller effect (about 15 per cent less) on price of larger sizes than on price of smaller sizes. The influence, however, is slightly greater in the case of larger Beauty plums.

In the varietal analysis supplies of related fruits and a "time" trend factor were introduced explicitly as linear terms into the equations. Supplies of early peaches and Northwest fresh prunes appear to be definitely related to the auction prices of midseason and late plums respectively. Prices of early plums were not related to any of the series representing supplies of other fruits. Supplies of other fruits were not used as additional variables in the weekly and size analyses. ${ }^{64} \mathrm{~A}$ time series plot of residuals reveals a downward trend in the case of midseason varieties. For early and late plums and in the weekly analysis the trends are not pronounced enough to be considered significant. No attempt was made to introduce the time factor into the size analysis.

${ }^{64}$ Supplies of related fruits, even for the cases where a definite relationship was established, do not seem to have a large influence upon prices of plums. Furthermore, considerable difficulty would have been encountered in setting up a satisfactory set of data to represent weekly supplies of related fruits. 
The residuals determined from the final equations were tested for "independence." The results of this test indicate that absence of autocorrelation in the residuals may be accepted as a suitable hypothesis for all three varietal analyses. In the weekly analysis, however, there is no basis for such a conclusion. The test was not applied to the size analysis because of the negative nature of the results obtained.

To summarize, the demand for California plums at the New York and Chicago auction markets shows the following characteristics:

1. Temporal markets are definitely interrelated-that is, current prices are affected by sales made earlier in the season as well as by sales made currently.

2. Plums of different size categories are close substitutes-and hence, changes in the size composition, even when of considerable magnitude, do not affect relative prices substantially.

3. The net price-income relation becomes materially less steep as the season advances.

4. Price is more responsive to changes in sales during the peak of the season than earlier or later-thus demand is less elastic during midseason than for either earlier or later sales.

5. The level of consumer purchasing power is the most important factor producing shifts in the price-quantity relation.

6. Changes in supplies of early peaches (from Southern states) and of Northwest fresh prunes are related to variations in auction prices of midseason and late plums, respectively.

Current grade-size regulations apparently do not materially affect the quantity sold nor production and marketing costs (other than harvesting expenses). They do, however, alter the geographical grade-size and the temporal distribution of sales. By delaying sales such restrictions tend to offset rather than reinforce increases in net returns to growers for the season which may result from changes in the quality composition of sales made at local and out-of-state markets. A control program designed to modify the pattern of weekly shipments could increase net returns substantially. Ordinarily, however, it is not possible to allocate supplies in accordance with the indicated optimum temporal sales pattern because of the perishable nature of the commodity. This optimum pattern - which varies in shape depending upon the level of purchasing power-can be utilized so that regulations aimed at lifting the level of the composite net demand curve do not simultaneously effect a temporal distribution of sales which is too unfavorable.

\section{Validity and Limitations of the Study}

Severe criticism frequently has been levied against attempts at statistical derivation of demand functions. The major objections raised are:

1. Time series data, such as are usually used, represent a unique sequence of observations which precludes any possibility of analysis. 
2. Classical regression techniques do not provide a satisfactory method for estimating values of structural parameters.

3 . The results derived are not descriptive of the theoretical demand functions.

This is not the place to enter into the subtleties of the controversy as to whether these objections represent insurmountable obstacles to endeavors at empiricizing the relations used by the economist. The author is in agreement with the opinion expressed by Henry Schultz:

"It is a notorious fact that the 'givens' of economic science are, in fact, unknown and must be determined empirically. Economic theorists explain changes in prices and in purchases and sales-in fact, the entire working of the pricing process - in terms of the traders' demand functions, supply functions, and 'liquidity preferences,' which must be assumed as known. Actually they are unknown, and it is this void in our knowledge which is responsible for much of the aridity of present-day economics." 65

Some of the limitations of the empirical approach have already been indicated at various points in the foregoing discussion. In this study time series data are conceived as constituting a set of drawings selected at random from imaginary infinite populations and, from this point of view, the impossibility of repeating drawings is not construed to be a serious difficulty. It is maintained that for predictive purposes the ordinary-least-squares approach can be applied to derive suitable relations between variables. The results obtained, although not necessarily descriptive of the theorist's concept of demand, relate to the demand side of the market and provide some useful information about the actual behavior of auction prices.

Although a methodological discussion does not seem justified, it may be helpful to restate briefly the assumptions underlying the particular least squares procedure used and to indicate the effect produced if the assumptions are not fulfilled. The method assumes:

1. All the important independent variables are known and are included in the set used.

2. Errors of measurement and other random disturbances are confined to the dependent variable.

3. The random error term (for the dependent variable) has a constant variance.

4. The values of the dependent variable come from a population with zero autocorrelation.

5. The dependent variable is normally distributed.

If the first four conditions are met, then the best linear unbiased estimates of the coefficients in a linear relationship between the variables are given by the method of least squares. "This is true even if the independent variables are autocorrelated, provided we can consider them as fixed in repeated sam-

${ }^{65}$ Schultz (1938), p. ix (the opening paragraph in the preface). 
ples. If in addition the error term is normally distributed then the least square estimates are maximum likelihood estimates. In many economic relationships it is an oversimplification to assume that error terms are independent in time. If we have a relationship in which the error term is autocorrelated, it has been shown by Aitken that the method of least squares still yields the best linear unbiased estimates of the regression coefficients provided the lack of independence in the error series is taken into account." ${ }^{66}$

In the analyses described herein an attempt was made to introduce all variables considered to be significantly related to auction prices. It cannot be presumed, however, that all important variables actually have been included since it is not known exactly what factors must be used. If any important independent variables have been omitted, the estimates of the regression coefficients are biased and their computed standard errors are not completely relevant as measures of reliability.

The independent variables used (except the time-trend and the week of season), as well as the dependent variable are subject to errors of measurement. Consequently, the estimates do not possess all of the optimum properties specified by the theory of linear estimates.

Whether the variance of the dependent variable remains constant has not been tested. It is presumed, however, that for economic data the coefficient of variation rather than the variance remains approximately fixed. Residuals were tested for independence, but in some cases it cannot be concluded that they are independent. Although assumptions (3) and (4) may not hold, unbiased estimates of the regression coefficients are obtained by least squares procedures. The computed standard errors, however, lose some of their relevance.

The assumption of normality is made in order that tests of significance can be applied. Since each regression coefficient of the relation is a linear function of random variables, this assumption is no more restrictive when used for the regression coefficients than when it is applied to the mean.

The above comments indicate that the various conditions for the valid application of least squares methods are not all met by the data at our disposal. In particular the computed standard errors lose a good deal of their validity and, consequently, may no longer serve as adequate indicators of the reliability of the values obtained for the regression coefficients. On the whole, however, the methods employed are no more restrictive in terms of assumptions imposed and, in fact, require less information than other statistical methods of approximating relations among economic variables. The remainder of this section is devoted to a consideration of the validity and limitations of the specific results derived by the varietal, weekly, and size analyses. Underlying these studies is a fundamental assumption (discussed in section A-2), which may be rephrased in a condensed manner: Purchases of California plums (at auction markets) are sufficiently routinized so that the relations between actual observation series remain relatively stable and may be approximated by simple empirical functions fitted to observed data. In essence, from this

${ }^{66}$ Cochrane and Orcutt (1949), p. 34-35. 
point of view, the problem becomes one of considering the type of relations postulated, the variables used in and omitted from the equations, the adequacy of the data, and the agreement of results with a priori expectations.

Throughout the investigation simple equations, generally linear and logarithmic functions, were used. In a few cases flexibility was introduced by adding second degree and product terms. It is recognized that the underlying relations possibly cannot be adequately described by such simple equations. These functions, however, may provide convenient first approximations for the range of observations used in the study. Furthermore, when more complex relations are to be fitted, considerable ambiguity exists as to what specific alternative equations should be used. The procedure followed can be used to derive good forecasting equations even in cases where the results do not satisfactorily describe the true relations. To the extent that these latter relations are not adequately established, forecasting becomes more difficult especially if extrapolation beyond the limits of the original observations is necessary. Since the production of plums (especially the early varieties) and of the related fruits shows an upward trend, values for the various quantity series may, at least during some future years, exceed the range established by the past. Thus, some uncertainty will be encountered since the precise position of the lower end of the net price-quantity relations is less definitely established than are the middle portions of the curves.

Only a limited number of shift variables was used in the equations. Yet, it is recognized that the price of California plums - as in the case of other commodities-is determined by the combined influence of numerous factors. Some of these factors had to be omitted because satisfactory measurements could not be secured. Others were deliberately excluded since they were presumed to have only a negligible effect or to be adequately represented by the variables already introduced. In the analyses attempted it was assumed that the most important factors producing shifts in the demand function were the level of nonagricultural income payments, sales of plums during other periods of the season, supplies of certain other fruits, and the temporal, varietal, and size distribution of plum sales. The "time" variable was introduced to determine whether the aggregate effect of the neglected factors results in a persistent smooth time shift in the net price-quantity relation.

From a conceptual viewpoint it is regrettable that certain factors, such as maturity, grade, and brands could not be introduced since they undoubtedly affect prices. However, quantitative measurements for these influences, although possible, are not available. In actuality this omission may not be serious. Since these quality factors are definitely related to size, their influence should be partially reflected by the effect observed for the size factor. If, as seems to be indicated by the size analysis, size composition is not a very important factor in explaining variations in relative prices on a size basis, the separate introduction of the quality factors would not be significant. Furthermore, there is good reason for assuming that size may be more important than any one of the quality factors (or all of them taken together) in affecting the 
per-crate price. Since there is a substantial difference in the net contents of a crate of small and of large plums, size should be of significance in explaining differences in per-crate prices even though the various sizes are almost perfect substitutes pound for pound.

Geographical differences in demand were not investigated. It is recognized that the net regressions of price on each of the independent variables may be different for the various auction markets. In view of the high intercorrelations between prices and between sales at the different markets, it does not appear probable that the results for the various markets would be significantly different. For this reason (and because of the volume of additional work involved in compiling the data and making the calculations) separate varietal and weekly analyses were not made for the different auction markets. Separate analyses for private transactions could not be made because the required data were not available. It is believed, however, that the results would be substantially similar to those obtained for the auction markets.

By limiting the demand study to the New York and Chicago auction markets certain interrelations, such as the interdependence of spatial markets, could not be investigated. However, sales at these two markets represent a large part of the total volume sold. Furthermore, the correlation is very high among prices at the different geographical markets and among the corresponding sales. Thus, it appears justified to claim that the results which would have been secured if data relating to all sales could have been used would be in substantial agreement with the findings obtained.

This study of the factors affecting auction prices could be extended in several ways. Exclusion of the less important auction markets is not as important as is the fact that private transactions at out-of-state markets are omittednecessarily so because the required data were not available. Also, a comparable demand study covering intrastate sales is desirable. Data on sales are available but the corresponding wholesale prices cannot be obtained. When these additional data can be secured, geographic interrelations between eastern and California markets should be investigated.

A more comprehensive treatment of complementarity relations between plums and other fruits seems desirable. In the present varietal analysis several series representing supplies of other fruits were added by a trial and error method. They were not even considered in the weekly and size analyses. From a theoretical point of view this is not an entirely satisfactory procedure. However, in view of the practical difficulties of getting adequate quantity data and of the lack of suitable theoretical bases for determining when these variables should be added, a different treatment did not appear feasible.

Separate studies were made of factors affecting annual prices (for varietal groups), weekly prices (for all varieties sold during those weeks), and prices by two size categories (weekly for specific varieties). It is quite apparent that by considering each of the different aspects of the problem in isolation, important intercorrelations may be overlooked. Information relating to other phases of the demand situation must be secured before a complete study is possible. 
Yet, certain interesting and consistent results are derived even though the various facets of the problem were not woven into a single hypothesis.

Of particular concern to growers and shippers of California plums is the extent to which the relations remain stable over time. In this study each analysis was referred to a particular time interval and, therefore, describes the average relations existing during that period. No attempt was made at determining the extent to which similar results would be secured if the various functions were fitted to different subperiods. Such a determination would require making separate calculations for several shorter periods and comparing the results to determine whether differences in the values for the net regression coefficients are statistically significant.

\section{Economic Implications}

The following discussion is oriented primarily toward indicating the implications of the results to the California plum industry. A few marginalia will be added whenever they appear to be particularly relevant to the marketing of other perishable fruits or to economic theory. The apparent nature of the demand relation facing wholesale sellers of California plums will be considered specifically as it relates to two principal questions:

1. What type of marketing program should be adopted as a means of improving net returns to California plum growers in the short run?

2. How should production plans be formulated in order that the long-run interests of the industry are not jeopardized?

From the previous discussion of results derived for the price-quality relations prevailing at the auction level, several conclusions of considerable importance for the establishment of a marketing program can be made. ${ }^{67}$

Within the range representing quantities usually sold and limitations of the statistical methods used it would appear that the demand function for California plums appears to be elastic at the auction market and less elastic (though generally not inelastic) at the farm level. ${ }^{68}$ The position of the pricequantity relation is influenced most by changes in the level of nonagricultural income. During periods of severe depression, the entire crop, particularly if it is large, cannot be sold without decreasing net returns to growers below what could be secured from the sale of a smaller quantity. Ordinarily, however, the demand encountered at the terminal market and at the farm level

\footnotetext{
${ }^{67}$ It should be noted that the characteristics of the demand which are about to be enumerated are of equal significance whether the marketing program is formalized in specific regulations under a marketing agreement, consists of a voluntary set of restrictions, or merely represents the net contribution of individual efforts of the various selling agencies.

${ }_{68}$ The selling commission is figured at 7 per cent of the auction price. Harvesting, packing, and transportation costs (representing about 90 per cent of all marketing charges), remain approximately constant during a given season regardless of the quantity sold (within rather broad limits), although they may change substantially from one year to the next. Thus the price-quantity relation at the farm level may be approximated by merely lowering the "demand" function derived for auction sales by a constant amount representing usual marketing costs. Then the elasticity at any point on the former curve will be less than the elasticity on the second curve for the corresponding volume of sales.
} 
is elastic. Hence a program of volume restriction generally will tend to lower rather than raise gross returns to producers.

It has been shown that demands in the various temporal markets are interdependent and that the level of demand generally shifts downward in a parallel fashion as the season advances. ${ }^{69}$ If these results approximate the actual situation, any action which postpones a portion of the total supply for sale during later weeks of the season will reduce growers' returns since the marginal returns foregone during early weeks exceed the increase in returns for subsequent weeks. The basis for this conclusion was presented above in section $\mathrm{E}$, where it was shown that the optimum pattern of weekly sales requires that sales be made in greater volume during early weeks than actually occurs-or is even feasible. It is well to bear in mind, at the same time, that the marketing of plums cannot actually be hastened appreciably in comparison to the rate of movement that would naturally result when plums are sold as soon as possible after harvest. Thus attempts at regulating the rate of weekly shipments, imposing picking and shipping holidays, and establishing surplus control and reserve pools are not effective means of improving grower returns. In fact, during most seasons such controls are likely to decrease net returns for the season as a whole.

It was stated that a plausible argument can be advanced for maintaining that the price-quantity relation at the farm level for intrastate sales is more elastic than the corresponding relation for interstate sales. The evidence available seems to bear out this contention-however, a careful investigation of this phase of the problem has not been made. To the extent that this situation exists, it will be advantageous to institute a marketing policy directed at increasing sales within California even though this means that price differentials between local and eastern sales (for plums of comparable variety, grade, size, and date of marketing) exceed the difference in marketing costs incurred. The adoption of such a program requires some techniques for allocating sales on the two markets among different sellers. One method is by means of quotas made directly to various shippers. The same result has been secured indirectly under the California plum control program by the promulgation of grade and size regulations, which restrict the shipment of lower grades and smaller sizes to eastern markets.

Whether grade and size restrictions are a good mechanism for increasing grower returns depends upon the extent to which the average price is affected by changes in relative sales of different qualities. The results secured in the size analysis indicate that variations in the size composition is not an important factor influencing the relative prices for different sizes. The average price for small and large sizes, however, is directly associated with size composition. That is, the more large sizes sold the higher is the weighted average price.

${ }^{69}$ The results also seem to show that for the first few weeks of the season during years when the level of nonagricultural income is low the demand function may actually shift upward before beginning its downward drift. At the same time it appears that increased sales of early varieties have a positive effect upon prices received for midseason varieties (as well as reducing the average realized for early varieties), whereas a greater supply of midseason plums reduces the price of both midseason and late varieties. 
The empirical results support the conclusion, which also appears reasonable from a consideration of other evidence, that grade and size restrictions appear to be preferable to volume curtailment or regulation of rate of shipment as a device for increasing returns to growers in the short-run..$^{70}$ Grade and size control can raise net returns directly by increasing the average price at eastern markets for a given volume of sales and indirectly by altering the geographic allocation of supplies. Against these two gains must be set the decrease in returns obtainable from local sales. When grade and size regulations are imposed the quality of plums sold in California markets is lowered, so that the average price received is decreased.$^{71}$ The severity with which such limitations should be imposed during any particular season depends upon the level of nonagricultural income prevailing and the quantity of related fruits available for marketing. These shift variables determine the level of the demand function and, therefore, the elasticity of demand when any specified quantity of plums is available for sale. From the analyses made it appears that the demand curve shifts in a parallel fashion as nonagricultural income changes. ${ }^{72}$ If this result is an approximation to the true relation, and if the demand curves for eastern and local sales shift by the same amount, then changes in nonagricultural income affect the magnitude of returns received by growers but not the increase which can be gained by a program designed to equalize marginal net returns from local and eastern sales instead of equating net prices. ${ }^{73}$

70 This proposition may actually be applicable to a wide range of horticultural commodities for which marketing controls are operated. Often the demand is elastic even at the farm level and prices decline throughout each season. Furthermore, where supplies from competing areas of production must be considered, the usefulness of volume restrictions and regulations over rate of flow may be even more limited than is indicated for plums. Since several current marketing agreements are apparently based on a contrary assumption, it would be of considerable importance to determine the facts for each case.

${ }_{71}$ If in addition the quantity marketed is curtailed by extending the grade and size control to intrastate sales (or by any other means), net returns are further decreased in most years - since the price-quantity relation ordinarily is elastic for the range representing the quantity of actual sales.

${ }_{72}$ This result if it is generally true for fruits is of interest for economic theory and is of considerable importance from the practical standpoint of developing marketing policies. If the curve changes its slope significantly as well as shifting its position, the marketing program to be followed might be altered substantially.

${ }_{73}$ The following algebraic demonstration shows the results clearly. Let $q_{1}$ and $q_{2}, p_{1}$ and $P_{2}, M R_{1}$ and $M R_{2}$, be the quantity sold, the net price received, and the marginal net returns, for sales at eastern and local markets, respectively. Let $T R$ be the total net returns received for the sale of quantity $Q=q_{1}+q_{2}$. Then for $P_{1}=a_{1}-b_{1} q_{1}$ and $P_{2}=a_{2}-b_{2} q_{2}$ net prices are equalized $\left(p_{1}=p_{2}\right)$ :

$$
q_{1}=\frac{a_{1}-a_{2}+b_{2} Q}{b_{1}+b_{2}}, \quad q_{2}=\frac{a_{2}-a_{1}+b_{1} Q}{b_{1}+b_{2}}, \quad \text { and } \quad T R=\frac{\left(a_{1} b_{2}+a_{2} b_{1}-b_{1} b_{2} Q\right) Q}{b_{1}+b_{2}}
$$

If, however, marginal net returns are equalized $\left(M R_{1}=M R_{2}\right)$ :

$$
q_{1}{ }^{\prime}=\frac{a_{1}-a_{2}+2 b_{2} Q}{2\left(b_{1}+b_{2}\right)}, \quad q_{2}^{\prime}=\frac{a_{2}-a_{1}+2 b_{1} Q}{2\left(b_{1}+b_{2}\right)}, \quad \text { and } \quad T R^{\prime}=T R+\frac{\left(a_{1}-a_{2}\right)^{2}}{4\left(b_{1}+b_{2}\right)}
$$

The two solutions are identical when $a_{1}=a_{2}$. Ordinarily, however, returns can be increased by $\frac{\left(a_{1}-a_{2}\right)^{2}}{4\left(b_{1}+b_{2}\right)}$ if marginal net returns, instead of net prices, are equalized. It will be noted that if both demand curves are shifted by any amount, $K$, the difference $\left(a_{1}-a_{2}\right)$ remains constant, i.e., the distribution of sales between the two markets (whether net prices or marginal net returns are being equalized) which maximizes total net returns remains unaffected. Furthermore, the gain to be secured from price discrimination also remains fixedi.e., it becomes less important percentagewise - as the curves are raised. 
Numerous factors must be considered when plans are being laid for changing the productive capacity of an individual orchard or of the entire plum industry. One of these is the outlook for relative prices of the different varieties. ${ }^{74}$ The empirical analyses provide some tentative results which need to be taken into account.

The price-quantity relation for midseason varieties has a definite downward trend. Although the shift is slight from one season to the next the total effect is substantial during the productive life of a tree-several decades. Actually the problem is not so simple. Long-run trends in the other factors related to prices of midseason plums must be considered. For example, supplies of peaches from the southern states and sales of early plums show definite upward trends. This means that the negative effect of increasing supplies of peaches will tend to be offset by the positive influence of having a greater volume of early plums sold. Caution must be exercised, however, in extrapolating these effects beyond the range of past observations. It may be that in the future, as the average quality of all plum varieties is considerably improved, the stimulant to prices of midseason varieties provided by sales earlier in the season of plums which have more consumer acceptance may become less than was the case during the past. $^{75}$

The gradual decline in the regression of price on nonagricultural income as the season advances (which was observed in each analysis attempted) indicates that during the course of the business cycle demand during early weeks shifts its level to a considerably greater extent than demand later in the season. Thus prices for late plums are relatively more stable than prices for earlier varieties. This conclusion is borne out by the facts. For 1922-1947 (excluding 1943-1945), the coefficients of variation of auction prices for early midseason and late varieties are 38,33 , and 27. A similar decline during the season is noted if calculations are made for successive weeks. The fortunes of individual producers of most fruits (particularly where the supplies are destined for fresh outlets) may be substantially affected by the varieties planted, especially if these are usually marketed during different portions of the season. From this point of view it would be of considerable importance to determine separate demand functions and see whether the results secured in the case of plums generally apply.

These brief comments indicate the manner in which the results of the price analyses can be used as a guide to production planning and in the development of a marketing policy for a specific season. In order to make more definite statements as to how productive capacity should be altered (e.g., changes in

\footnotetext{
${ }^{74}$ Of course, consideration must also be given to relative yields, relative production and harvest costs, comparative trends in acreage and production, and to many cultural and environmental factors. These aspects of the problem are not to be considered here since this discussion is intended to be suggestive rather than inclusive.

${ }_{75}$ Separate consideration of each varietal group is possible because the annual analysis was split up into several related parts. This procedure is significant since it permits the use of different factors for the several varietal groups and the determination of the effectiveness of each for the different segments of the total crop. Of course, by making the commodity more homogeneous a closer approximation to the theoretical "commodity" is obtained.
} 
total acreage or shifts in relative acreages planted to different varieties) or how each year's crop should be allocated among different temporal and geographic markets additional factors must be taken into accounts.

\section{Suggestions for Further Study}

Although several aspects of demand were investigated, the foregoing discussion contains some gaps stemming from the fact that all relations having a significant bearing on the conclusions could not be studied. It is particularly difficult to use the results obtained in attempting to evaluate the effectiveness of the marketing control program. A few specific suggestions for additional studies are indicated briefly.

An adequate evaluation of even the short-run effects of marketing regulations requires that additional information about demand responses be secured. Actually the immediate concern is with the net demand functions (that is, the price-quantity relations at the farm level) for "superior" and "inferior" quality plums sold at eastern and California markets. None of these four relations was determined directly. The analysis attempted was directed toward securing the average $e x$ post price-quantity relations prevailing at the eastern auction market. From these results and some deductive analysis the effect of grade and size regulations on net returns during a given season was inferred.

In addition to securing separate functions for different portions of the total supply sold in fresh form, the study of factors affecting plum prices could be extended in several ways. The results of the size analysis are not satisfactory since they seem to indicate that size-grade composition is not very important in explaining variations in relative prices. Yet there is a considerable $a$ priori basis for expecting such a measure of quality to be related to plum prices. Hence, it seems desirable to make another attempt in this direction as soon as additional data become available. Demand differences between geographical markets and between auction and private markets were not investigated. The most serious aspect of this omission probably is the fact that interrelations between these outlets are not taken into account. Supplies of other fruits were introduced more or less arbitrarily on a trial and error basis. A more comprehensive treatment of complementarity relations seems desirable. Interdependences among temporal and varietal markets were introduced separately. Possibly the nature of these interrelations may be different from that indicated because the various effects act simultaneously.

Finally, it should be noted that the analyses made refer to average relations (of specified and relatively simple types) existing during specific periods of time. Some attempts should be made to determine the extent to which these relations remain autonomous over time. Actually what is desired is an understanding of how the complicated mechanism for determining prices is put together and how it operates in order to have a better basis for estimating the true parameters and for making guesses about the future whether conditions remain constant or change. The models used in the analyses may be inadequate. The methods employed may have given biased estimates. Hence a 
more satisfactory evaluation of the economic problems facing this industry requires that additional attention be given both to specifying more suitable models and to developing improved techniques of analysis. ${ }^{76}$

It may be well to check the current studies periodically as data for additional seasons become available to examine how adequately the equations determined for the situation existing during the period used will describe postwar conditions. If the relations derived seem to fit the observations for succeeding years, considerably more confidence can be placed in their use as forecasters - though, not necessarily, in their specification of the true values for the parameters.

An extended digression into an empirical investigation of supply response was not an appropriate part of this demand study. Quite obviously, however, a satisfactory determination of long-run effects of marketing control presupposes that the supply response function can be approximated. For this purpose forces effecting variations in acreage and yield-the two determinants of production for a tree crop-must be examined. Such information is necessary to supplement our present limited knowledge as to how growers formulate their plans to change the productive capacity of their orchards in the longrun-and also during any given season.

\section{ACKNOWLEDGMENTS}

A person engaged in statistical research needs many friends to permit its completion. My indebtedness to those who helped me in one way or another with this study is much greater than an acknowledgment can indicate. For their keen interest, helpful guidance, and kindly criticism, I am greatly indebted to the Committee in charge of this doctoral dissertation: Professors G. M. Kuznets, W. L. Crum, and S. S. Hoos. My chairman, Dr. Kuznets, was very generous with his time and ideas during the actual process of writing. My sincere thanks are also due Dr. S. W. Shear of the Giannini Foundation of Agricultural Economics, the California Tree Fruit Agreement, the California Crop and Livestock Reporting Service, and the Fruit and Vegetable Branch, Production and Marketing Administration, U.S.D.A., for making available certain unpublished data which rendered the empirical phases of the study more useful. Professor Edmund Pinney (of the Department of Mathematics, Berkeley) gave me valuable assistance with the mathematical derivations appearing in the Mathematical Appendix. The compilation of many of the original data and the voluminous subsequent calculations were performed under the direction of Miss Angela d'Artenay. The excellent charts were drawn by Miss Leslie Galvan.

${ }^{76}$ Of course, this is the situation encountered in practically all statistical investigations. 


\section{MATHEMATICAL APPENDIX}

\section{Maximization of Net Returns for Related Temporal Markets ${ }^{1}$}

Ordinarily, when no artificial limitations are placed upon sales made by numerous shippers (who are assumed to act independently of each other) supplies tend to be distributed so as to equalize net prices of each quality component sold at different markets. The principle has been established ${ }^{2}$ that total net returns are maximized by allocating sales among independent markets so as to equate marginal net returns. The assumption that the various demand functions are independent is not, in many cases, a realistic description of the underlying price-quantity relation. For plums (and for other fruits) it seems desirable to recognize that the demand functions for different segments of the crop actually are interdependent in the sense that the demand at a particular market is systematically related to sales (or prices) realized or anticipated at other markets.

The nature of this interrelation should be taken into account when a control agency establishes regulations designed to alter the distribution of supplies from the pattern that would prevail otherwise. A theoretical study of this problem is needed in order to provide a sound basis for determining how the regulations promulgated affect net returns to producers. Markets may be interrelated in numerous ways. This note is limited to a considertaion of the situation of related temporal markets-where the demand functions can be approximated by linear equations. The material presented is intended to be suggestive rather than an exhaustive consideration.

Suppose $Q$ is the total and fixed quantity to be sold during the time interval $t_{1}, t_{n}$, where sales are to be allocated among the $n$ supberiods of the season so as to maximize the total net returns, $T R$, received from the sale of $Q$. Let $q_{t}$ and $p_{t}$ represent sales and the net price during period $t$, where $p_{t}$ is presumed to depend upon $q_{t}$ and $q_{t-1}$ (that is, price is related to current and lagged sales). If linear functions are assumed as suitable first approximations to the true relations, the model describing the situation is specified by : ${ }^{3}$

$$
\begin{aligned}
& P_{t}=a_{t}-b_{t} q_{t}-c_{t} q_{t-1}, \quad \text { where } a_{t}, b_{t}, c_{t}>0 . \\
& T R=\int_{t_{1}}^{t_{n}} p_{t} q_{t} d t \\
& Q=\int_{t_{1}}^{t_{n}} q_{t} d t, \quad \text { where } \quad q_{t} \equiv 0 \text { for } t<t_{1} \text { and } t>t_{n} .
\end{aligned}
$$

${ }^{1}$ The author is greatly indebted to Professor Edmund Pinney (of the Mathematics Department) for indicating the solution to the problem posed here.

${ }^{2}$ A detailed discussion and mathematical proof of the principle of equalizing marginal net returns appears in Waugh, Burtis, and Wolf (1936), p. 1-41.

${ }^{3}$ For convenience the subperiods are assumed to be of short duration so that the model can be stated in terms of integrals. 
We wish to maximize the quantity

$$
T R=\int_{t_{1}}^{t_{n}}\left(a_{t} q_{t}-b_{t} q_{t}^{2}-c_{t} q_{t} q_{t-1}\right) d t
$$

subject to the constraint indicated by (3). Introducing a Lagrange multiplier, $\lambda$, gives a new function to be maximized:

$$
\begin{aligned}
I & =\int_{t_{1}}^{t_{n}}\left[\left(a_{t}-\lambda\right) q_{t}-b_{t} q_{t}^{2}-c_{t} q_{t} q_{t-1}\right] d t . \quad \text { Then } \\
\delta I & =\int_{t_{1}}^{t_{n}}\left(a_{t}-\lambda-2 b_{t} q_{t}-c_{t} q_{t-1}\right) \delta q_{t} d t-\int_{t_{1}-1}^{t_{n}-1} c_{t+1} q_{t+1} \delta q_{t} d t,
\end{aligned}
$$

where the range of integration in the last term has been shifted by one unit. The solution for $\delta I=0$ is

$$
c_{t+1} q_{t+1}+2 b_{t} q_{t}+c_{t} q_{t-1}-a_{t}+\lambda=0 .
$$

This is a difference equation for $q_{t}$ and can be solved when values for the parameters are available.

Case I: It is convenient to consider first the specialized situation where changes in the demand function are confined to parallel shifts.

With $b_{t}=b$ and $c_{t}=c$, (5) becomes

$$
c q_{t+1}+2 b q_{t}+c q_{t-1}-a_{t}+\lambda=0 .
$$

It can be verified that the desired solution to (6) is ${ }^{4}$

$$
q_{t}=M_{t}+\lambda N_{t}, \quad \text { where } \quad \lambda=\left(Q-\sum_{t_{1}}^{t_{n}} M_{t}\right) / \sum_{t_{1}}^{t_{n}} N_{t} .
$$

Here $M_{t}$ and $N_{t}\left(t=t_{1}, \cdots t_{n}\right)$ are defined by

$$
\begin{aligned}
& \left\{\begin{array}{l}
M_{t}=\frac{1}{c}\left[F(t) \sum_{t_{1}}^{t}{ }_{i} G(i) a_{i}+G(t) \sum_{t+1}^{t_{n}}{ }_{i} F(i) a_{i}\right] \\
N_{t}=\frac{1}{2(b+c)}\left[F(t)+F\left(t_{1}+t_{n}-1\right)-1\right], \quad \text { where }
\end{array}\right. \\
& F(t)=\frac{H_{t_{n}+1-t}}{H_{t_{n}-t_{1}+2}}, \quad G(t)=\frac{H_{t-t_{1}+1}}{H_{1}}, \\
& H_{i}=\alpha^{i}-\alpha^{-i}, \quad \text { and } \quad \alpha=-\frac{b}{c}-\frac{1}{c} \sqrt{b^{2}-c^{2}} .
\end{aligned}
$$

${ }^{4}$ This type of equation was originally solved by Euler and Lagrange. A solution is given by A. E. Heins (1940). 
It should be noted that a real solution exists if and only if $b>c$, for otherwise $\alpha$ is imaginary. Thus net returns to growers can be maximized (where the demand function is linear and changes from period to period are limited to parallel shifts) provided current sales are more important than lagged sales in influencing the current price. The set of equations $(7)-(8)$ is easily adapted to computational procedure. ${ }^{5}$

Equation (6) may also be written as

$$
\lambda=M R_{t}-c q_{t+1}, \quad \text { where } \quad M R_{t}=a_{t}-2 b q_{t}-c q_{t-1} .
$$

Then

$$
\lambda \int_{t_{1}}^{t_{n}} d t=\int_{t_{1}}^{t_{n}} M R_{t} d t-c \int_{t_{1}}^{t_{n}} q_{t+1} d t . \quad \text { Since } \quad \int_{t_{1}}^{t_{n}} d t=n
$$

we get

$\lambda=\overline{M R}-c Q^{\prime}, \quad$ where $\quad \overline{M R}=\frac{1}{n} \int_{t_{1}}^{t_{n}} M R_{t} d t \quad$ and $\quad Q^{\prime}=\frac{1}{n}\left(Q-q t_{1}\right)$. From (6)

$$
q_{t+1}=\frac{1}{c}\left(M R_{t}-\overline{M R}\right)-Q^{\prime} ; \quad \text { also } \quad q_{t}=\frac{1}{c}\left(M_{t-1}-M R\right)+Q^{\prime} .
$$

Thus

$$
q_{t+1}-q_{t}=\frac{1}{c}\left(M R_{t}-M R_{t-1}\right) .
$$

This result means that net returns are maximized when sales are increased or decreased from one period to the next by $1 / c$ times as fast as marginal net returns rise or fall during the preceding period, where $1 / c$ is the negative reciprocal of the net regression of price on lagged sales. A substantially different result is secured in case the various markets are independent-this case will be considered below in Case III.

Case II: For the general case no restriction is placed on the manner in which the demand function changes.

Thus equation (5) remains as originally stated. Substituting $q_{t}=M_{t}+\lambda N_{t}$, as defined by (7) and (8), into (5) gives

$$
\begin{array}{ll}
c_{t+1} M_{t+1}+2 b_{t} M_{t}+c_{t} M_{t-1}-a_{t}=0 & \text { and } \\
c_{t+1} N_{t-1}+2 b_{t} N_{t}+c_{t} N_{t-1}+1=0
\end{array}
$$

subject to the boundary conditions: $M_{t+1}, M_{t-1}, N_{t+1}, N_{t-1}=0$.

\footnotetext{
${ }^{5}$ The optimum sales pattern for a 15-period problem can be determined in two to three hours.
} 
These second order difference equations can be solved step by step in terms of the lower order terms. Possibly the simplest procedure is first to assume $M_{t_{1}}=0$ in (1) and obtain solutions $M_{i_{1}-1}^{\prime}, \cdots, M_{t_{n}}^{\prime}$. Next assume $M_{t_{1}}=1$ and denote the new solutions by $M_{t_{1}-1}^{\prime \prime}, \cdots, M_{t_{n}}^{\prime \prime}$. Then the solution to (1) is

$$
M_{t}=M_{t}^{\prime}-k M_{t}^{\prime \prime},
$$

where $k$ is determined by substituting (12) for $t=t_{n}$ into (10) and noting the boundary condition, $M_{t+1}=0$. The value is given by

$$
k=-\frac{2 b t_{n} M_{t_{n}}^{\prime}+c t_{n} M t_{n-1}^{\prime}-a_{t_{n}}}{2 b_{n} M_{t_{n}}^{\prime}+c t_{n} M_{t_{n-1}}^{\prime}} .
$$

Substituting this value for $k$ into (12) determines all the $M_{t}$ 's. The $N_{t}$ 's are calculated similarly using (11). Then the Lagrange multiplier can be determined and the $q_{t}$ 's can be computed from (7).

A value for $q_{t+1}-q_{t}$ can be determined as before. However, the expression is quite complex to state in words. Since it is not needed in the application to which the result is to be put, the statement is omitted.

Case III: The foregoing can be specialized to the case of independent markets by setting $c_{t}=0 .^{6}$

Here equation (5) becomes

$$
2 b_{t} q_{t}-a_{t}+\lambda=0, \quad \text { i.e., } \quad \lambda=a_{t}-2 b_{t} q_{t}=M R_{t} .
$$

Since $\lambda$ is a constant multiplier, marginal revenues for the different time periods must be equal, say $M R$. Substituting this value into (13), solving for $q_{t}$, and determining $p_{t}$ from (1) gives as the sales and price which maximize total net returns the following:

$$
q_{t}=\frac{1}{2 b_{t}}\left(a_{t}-M R\right) \quad \text { and } \quad p_{t}=\frac{1}{2}\left(a_{t}+M R\right) .
$$

The relations between sales and prices for two consecutive periods are:

$$
\left\{\begin{array}{l}
q_{t+1}-q_{t}=\frac{1}{2}\left(\frac{a_{t+1}}{b_{t+1}}-\frac{a_{t}}{b_{t}}\right)-\frac{M R}{2}\left(\frac{1}{b_{t+1}}-\frac{1}{b_{t}}\right) \\
p_{t+1}-p_{t}=\frac{1}{2}\left(a_{t+1}-a_{t}\right) .
\end{array}\right.
$$

Hence total net returns are maximized when sales are changed from one period to the next so that price increases or decreases exactly half as much as the price-intercept of the demand curve is raised or lowered. This result is

\footnotetext{
${ }^{6}$ This is the situation considered by J. M. Thompson (1938). Thompson uses $q_{t}$ as the dependent variable and derives his results somewhat differently from the method indicated here.
} 
independent of the slope of the demand function. If the demand curve remains fixed throughout the season, a uniform price, and, therefore, a constant rate of sales must be maintained. If the demand curve changes by parallel shifts, both sales and the price must be increased or decreased half as fast as the demand curve rises or falls. In the general case, where the slope and level of the demand curve change, the change required in sales is rather difficult to express in words and can be easily seen from (15). The maintenance of either a fixed price or a constant rate of sales throughout the season (assuming a linear demand) is incompatible with maximizing net returns to growers except in the unlikely case that the demand curve remains fixed during the entire season. 


\section{STATISTICAL APPENDIX}

This appendix is divided into three parts: (A) "Basic Statistical Data"; (B) "Auxiliary Information for Price Analyses"; and (C) "The Addition of Recent Data."

Part A includes

Tables A-1 to A-5: Auction data used in varietal analysis.

Tables A-6 and A-7: Auction data used in weekly analysis.

Tables A-8 to A-12: Auction data used in size analysis.

Table A-13: Marketing charges for California plums, 1920-1948.

Part B includes

Figures B-1 and B-2: Net regression charts for equations (2.1) and (3.1).

Figure B-3: Time series plot of residuals for varietal analysis.

Tables B-1 to B-3: Auxiliary information for varietal analysis.

Tables B-4 to B-7: Auxiliary information for weekly analysis.

Table B-8: Auxiliary information for size analysis.

Part C includes a short discussion of the residuals secured when the equations derived are applied to data for the 1948 and 1949 seasons. 


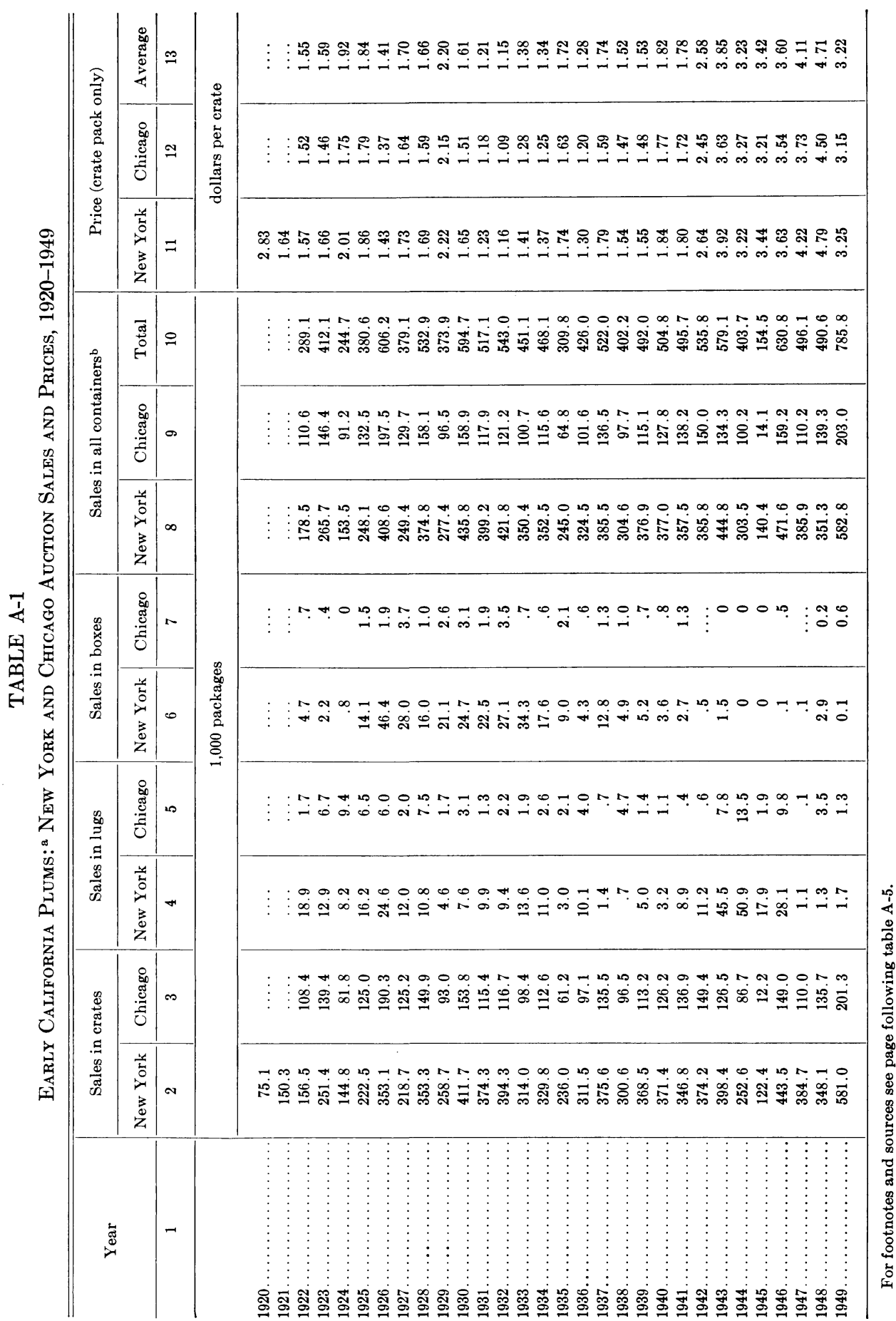




\begin{tabular}{|c|c|c|c|c|c|}
\hline \multirow{3}{*}{\multicolumn{2}{|c|}{ 苗 }} & 苞 & $\cong$ & \multirow{3}{*}{ 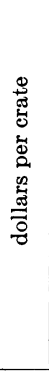 } & 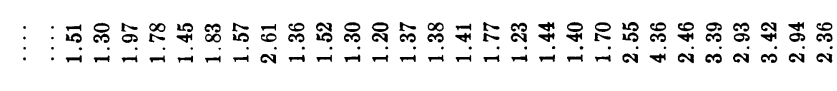 \\
\hline & & ठึ. & $\simeq$ & & 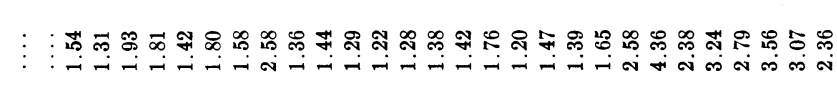 \\
\hline & & 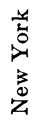 & $=$ & & 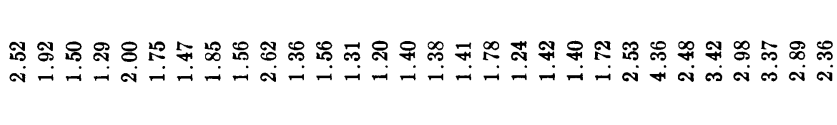 \\
\hline \multirow{3}{*}{\multicolumn{2}{|c|}{ 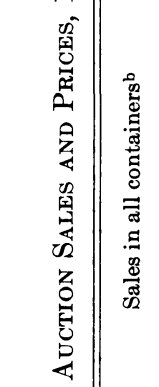 }} & $\stackrel{\vec{\pi}}{\stackrel{\pi}{0}}$ & 오 & \multirow{9}{*}{ 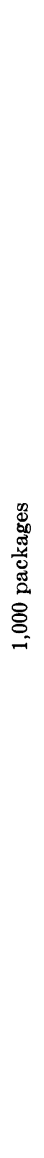 } & 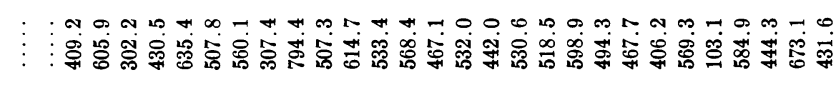 \\
\hline & & తึّ & $\infty$ & & $\begin{array}{l}\vdots \\
\vdots \\
\vdots\end{array}$ \\
\hline & & 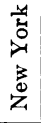 & $\infty$ & & 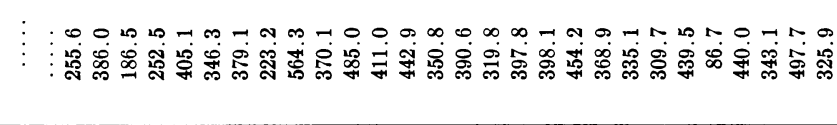 \\
\hline \multirow{2}{*}{\multicolumn{2}{|c|}{ 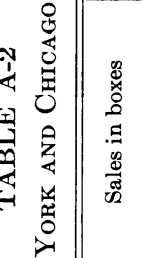 }} & 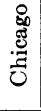 & $\sim$ & & 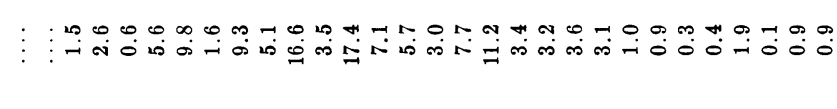 \\
\hline & & 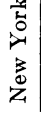 & 0 & & 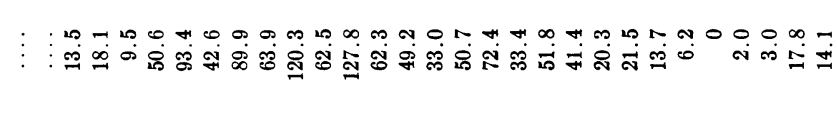 \\
\hline \multirow{5}{*}{ 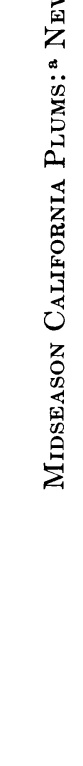 } & \multirow{2}{*}{ 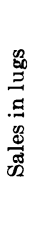 } & 荵 & 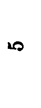 & & $\vdots \vdots \vdots \begin{array}{c}0 \\
\vdots\end{array}$ \\
\hline & & 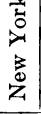 & 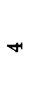 & & 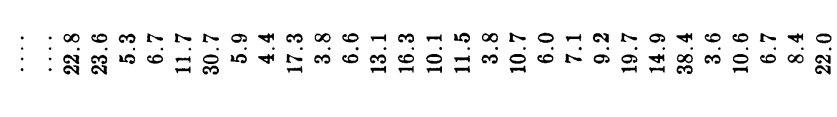 \\
\hline & \multirow{2}{*}{ 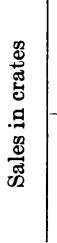 } & 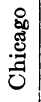 & $\infty$ & & 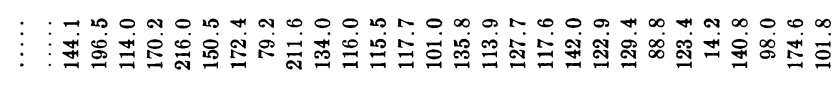 \\
\hline & & 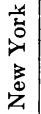 & N & & 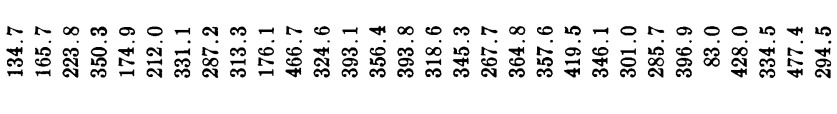 \\
\hline & $\stackrel{\varpi}{\check{\varpi}}$ & & - & & $\begin{aligned} \vdots & \vdots\end{aligned}$ \\
\hline
\end{tabular}




\begin{tabular}{|c|c|c|c|c|c|}
\hline \multirow{3}{*}{ 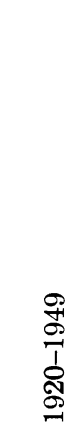 } & \multirow{3}{*}{ 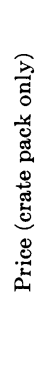 } & 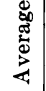 & ๑ & \multirow{3}{*}{ 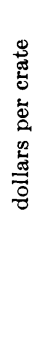 } & 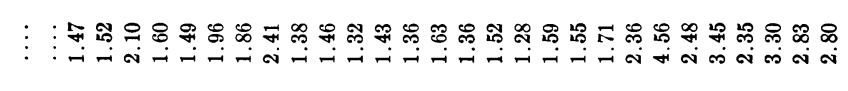 \\
\hline & & 胥 & $\cong$ & & 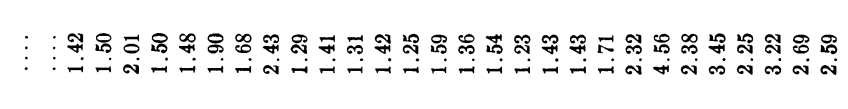 \\
\hline & & 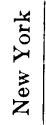 & $\Rightarrow$ & & 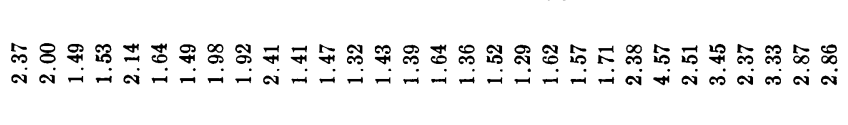 \\
\hline 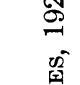 & & $\begin{array}{l}\overrightarrow{\Phi J} \\
\stackrel{0}{0} \\
\end{array}$ & 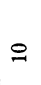 & & 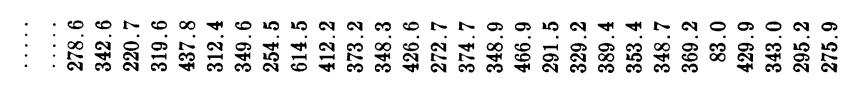 \\
\hline 公 & 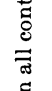 & : & 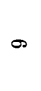 & & 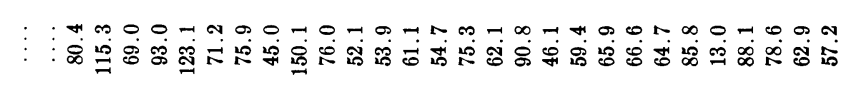 \\
\hline 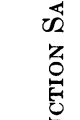 & 苟 & $\begin{array}{l}3 \\
z \\
0 \\
0 \\
0 \\
0 \\
z \\
z\end{array}$ & $\infty$ & & 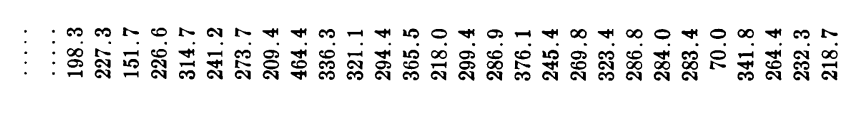 \\
\hline 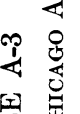 & 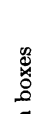 & 巻 & $N$ & & 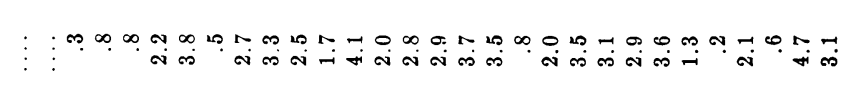 \\
\hline 商 & 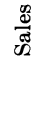 & $\begin{array}{l}\text { 咅 } \\
0 \\
\vdots \\
z \\
z\end{array}$ & 0 & & 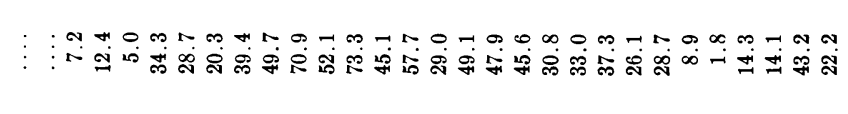 \\
\hline 省 & $\stackrel{\substack{00 \\
g}}{g}$ & 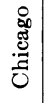 & 20 & 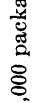 & 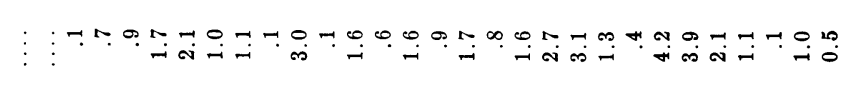 \\
\hline 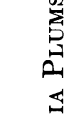 & 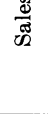 & $\begin{array}{l}2 \\
\vdots \\
0 \\
z \\
3 \\
0 \\
z\end{array}$ & $\sigma$ & & 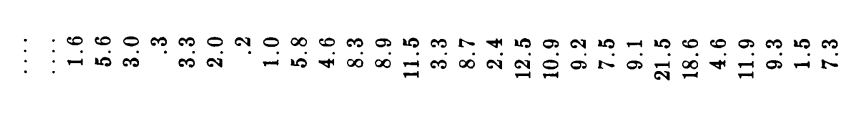 \\
\hline 总 & 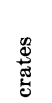 & 宽 & $\infty$ & & $\begin{array}{l}\vdots \\
\vdots\end{array}$ \\
\hline 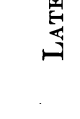 & 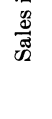 & 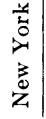 & N & & 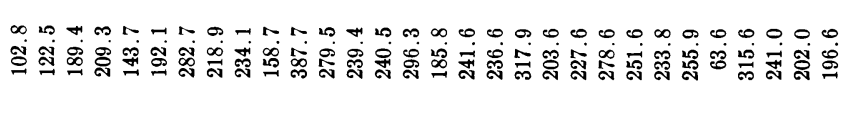 \\
\hline & 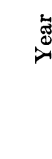 & & $\rightarrow$ & & $\begin{aligned} & \end{aligned}$ \\
\hline
\end{tabular}




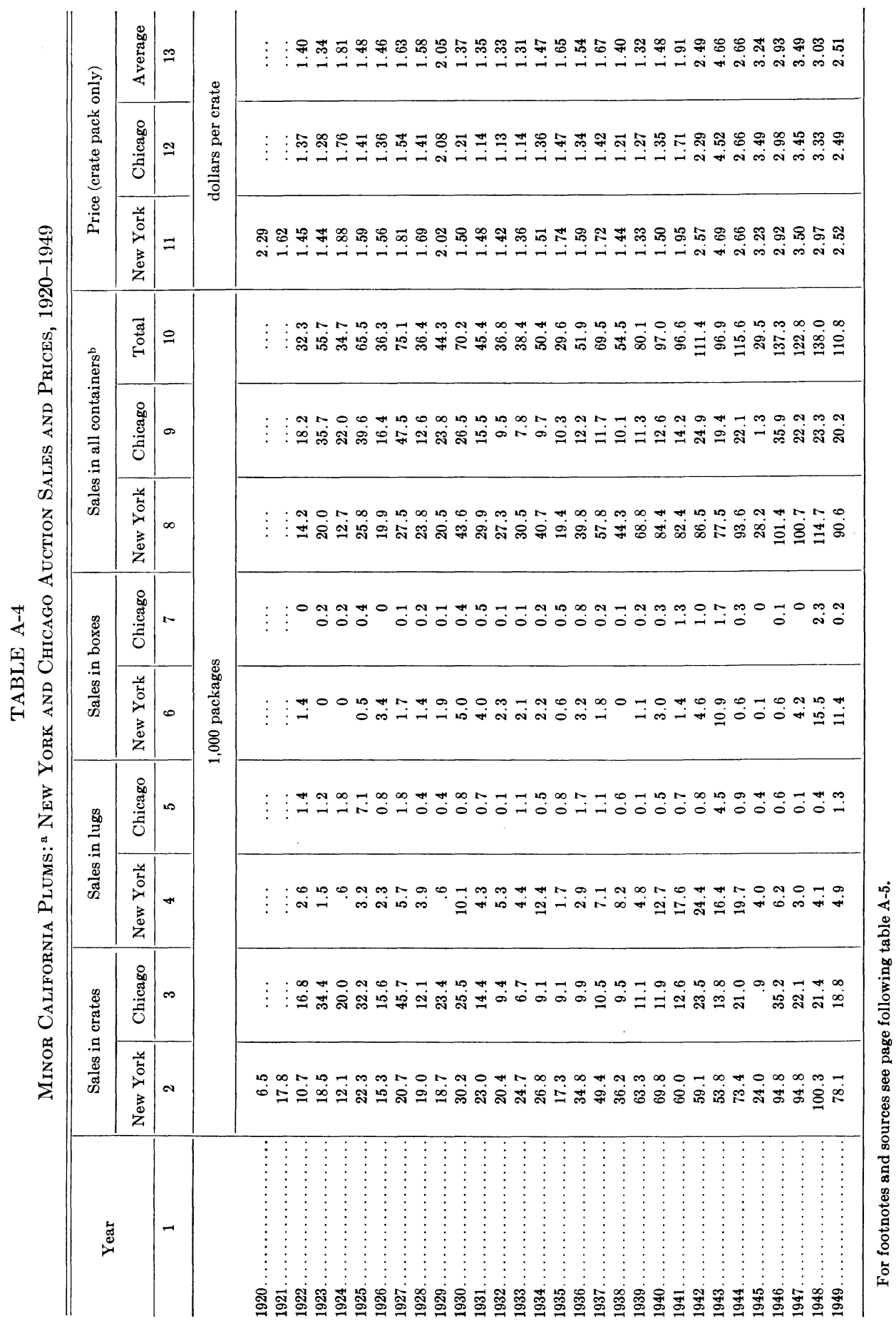




\begin{tabular}{|c|c|c|c|c|c|}
\hline \multirow{3}{*}{\multicolumn{2}{|c|}{$\Phi$}} & 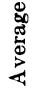 & $\cong$ & \multirow{3}{*}{ 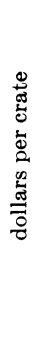 } & 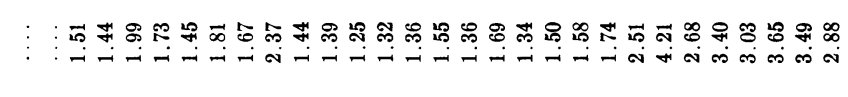 \\
\hline & & 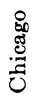 & $\cong$ & & 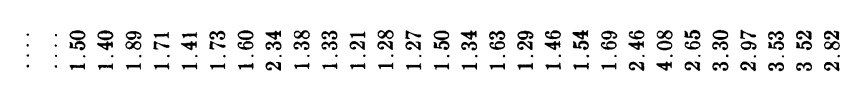 \\
\hline & & 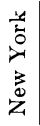 & $=$ & & 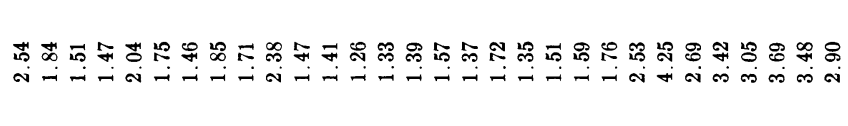 \\
\hline 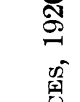 & 总 & 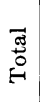 & 음 & & 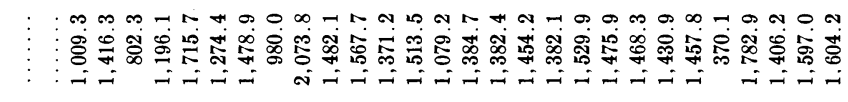 \\
\hline 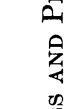 & 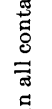 & 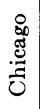 & $\infty$ & & 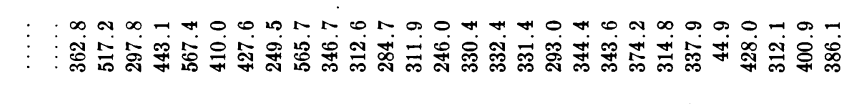 \\
\hline 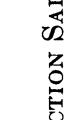 & 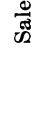 & 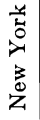 & $\infty$ & & 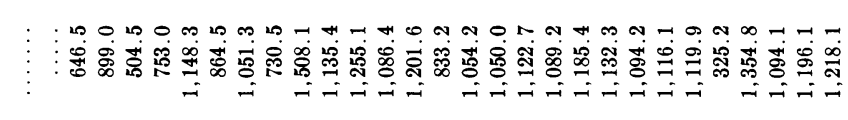 \\
\hline 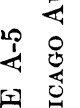 & 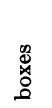 & 胥 & $N$ & & 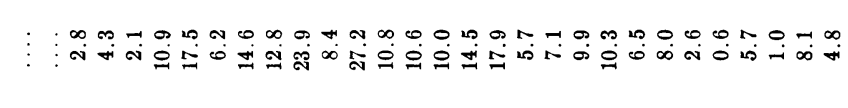 \\
\hline 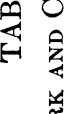 & 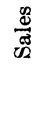 & 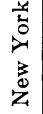 & 0 & 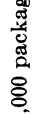 & 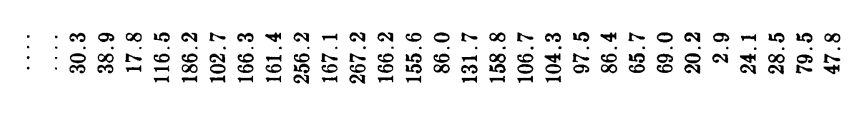 \\
\hline 竞 & $\stackrel{\substack{0 \\
\Xi}}{\Xi}$ & 苋 & 10 & & : \\
\hline$\sum_{\substack{n \\
\vdots}}^{\infty}$ & 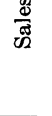 & 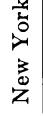 & + & & 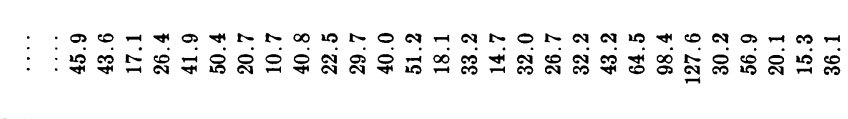 \\
\hline 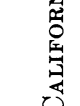 & 惌 & 宽 & $\infty$ & & 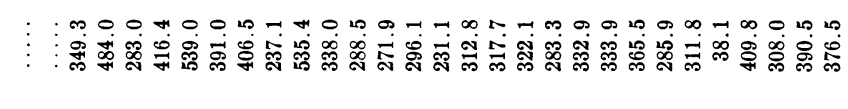 \\
\hline 㝵 & 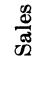 & 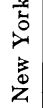 & N & & 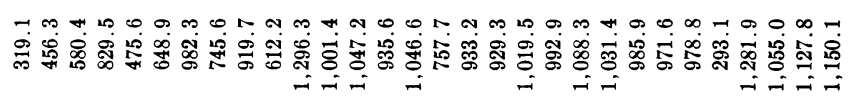 \\
\hline & 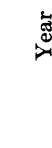 & & - & & $\begin{aligned} & 0\end{aligned}$ \\
\hline
\end{tabular}




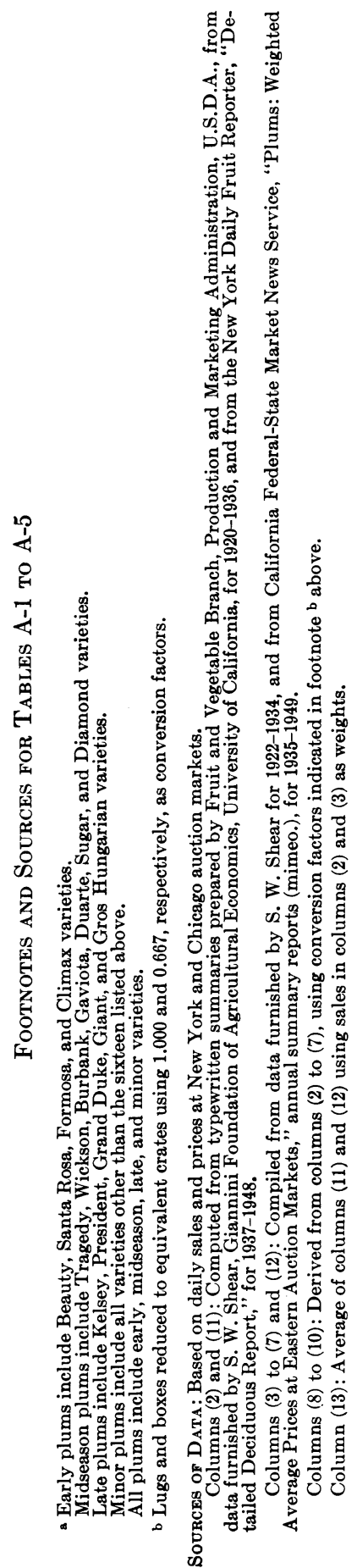




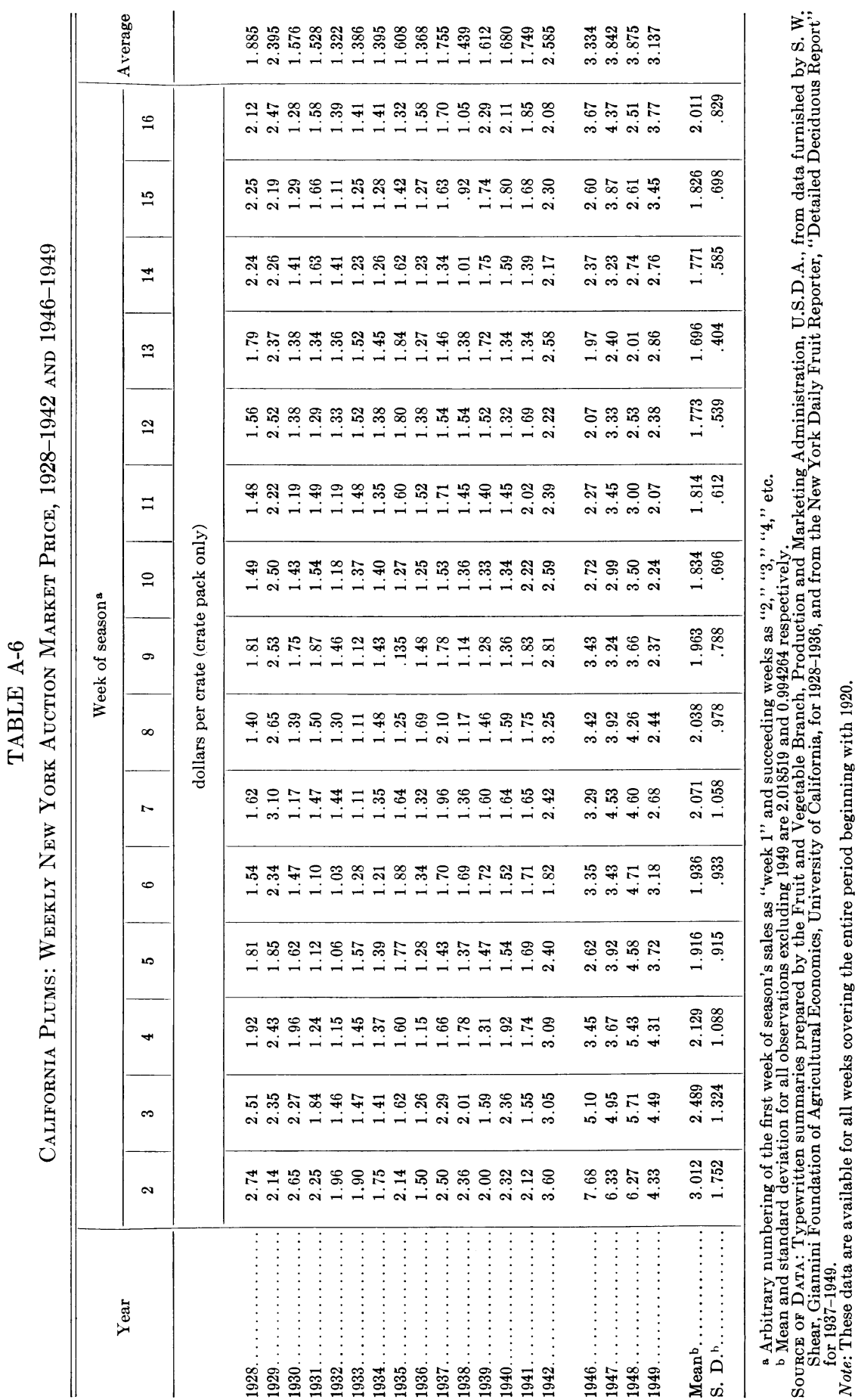




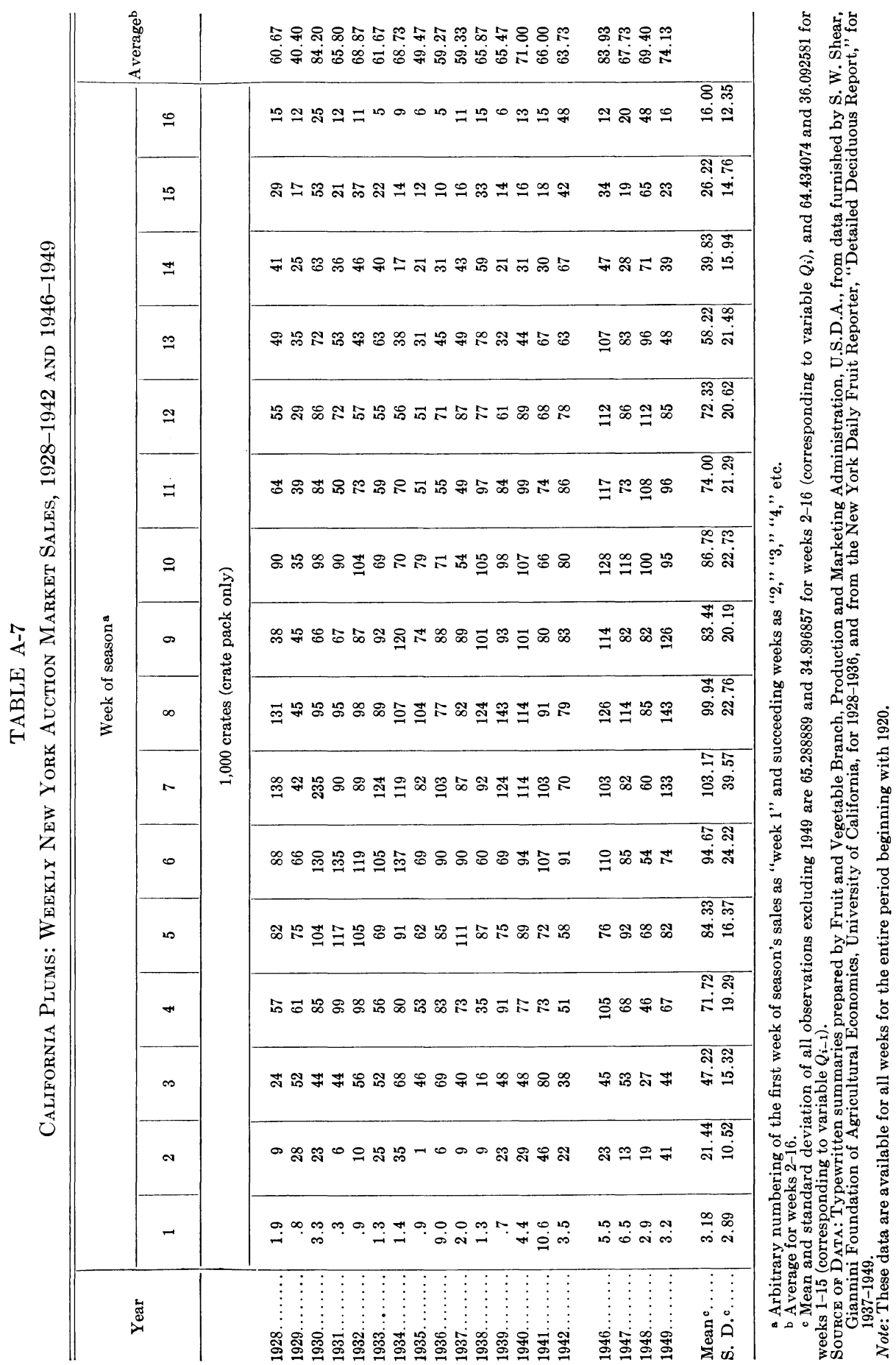


TABLE A-8

Beauty Plums: New York Auction Price and Sales Data * Used in Size Analysis, 1937-1948

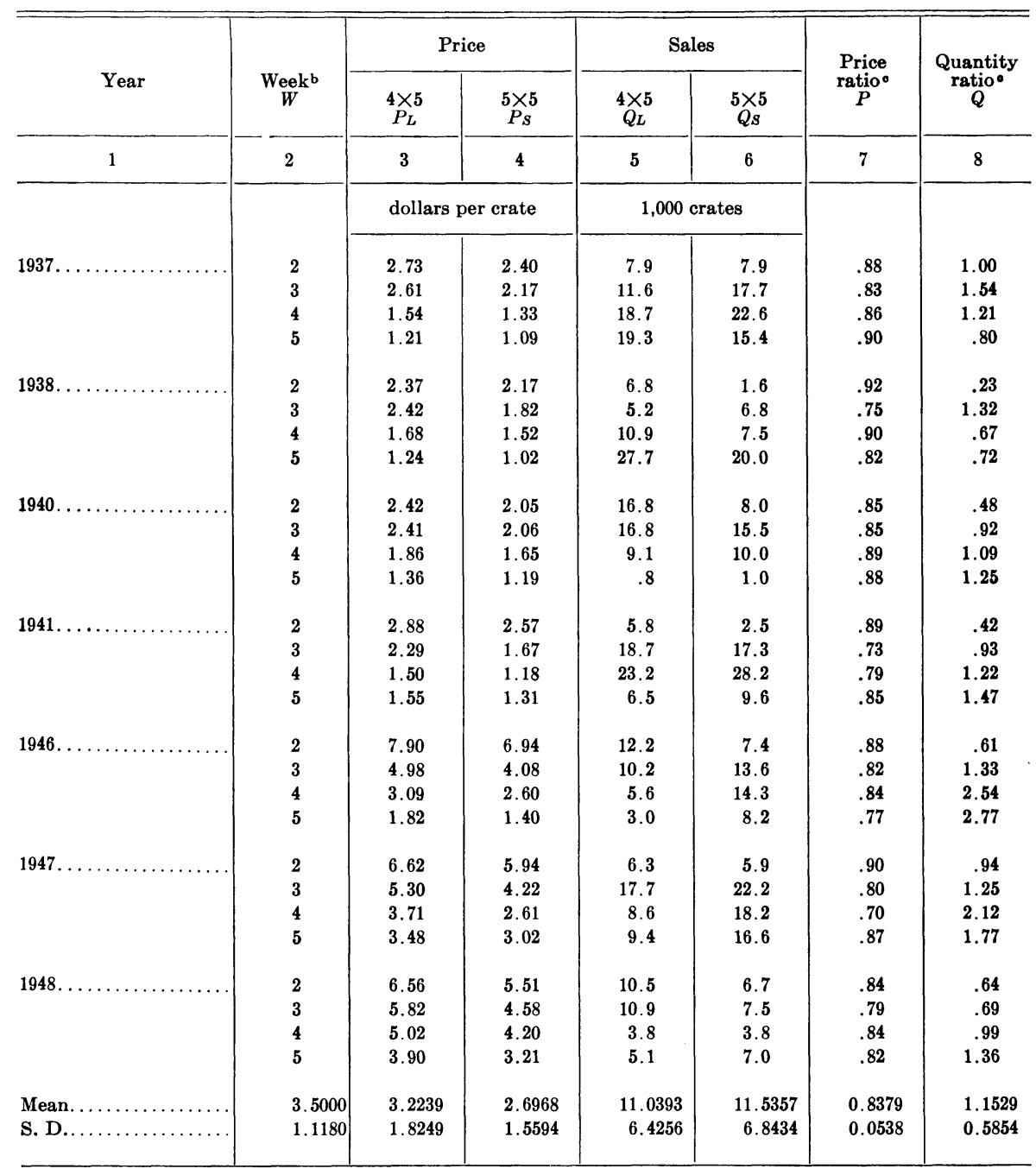

For footnotes and sources see page following table A-11. 
TABLE A-9

Tragedy Plums: New York Auction Price and Sales Data ${ }^{a}$ Used in Size ANalysis, 1937-1948

\begin{tabular}{|c|c|c|c|c|c|c|c|}
\hline \multirow[b]{2}{*}{ Year } & \multirow[b]{2}{*}{$\underset{W}{\text { Week }^{b}}$} & \multicolumn{2}{|c|}{ Price } & \multicolumn{2}{|c|}{ Sales } & \multirow{2}{*}{$\begin{array}{l}\text { Price } \\
\text { ratio } \\
P P\end{array}$} & \multirow{2}{*}{$\begin{array}{c}\text { Quantity } \\
\text { ratio }^{\circ} \\
Q\end{array}$} \\
\hline & & $\underset{P_{L}}{5 \times 5}$ & $\underset{P S}{5 \times 6}$ & $\underset{Q_{L}}{5 \times 5}$ & $\underset{Q S}{5 \times 6}$ & & \\
\hline \multirow{6}{*}{1937.} & 2 & 3 & 4 & 5 & 6 & 7 & 8 \\
\hline & & \multicolumn{2}{|c|}{ dollars per crate } & \multicolumn{2}{|c|}{1,000 crates } & & \\
\hline & 2 & 2.26 & 2.09 & 1.6 & 3.2 & .92 & 2.03 \\
\hline & 3 & 2.08 & 1.89 & 6.1 & 7.1 & .91 & 1.17 \\
\hline & 4 & 2.20 & 2.03 & 13.4 & 6.4 & .92 & .48 \\
\hline & 5 & 2.23 & 2.01 & 8.8 & 4.2 & .90 & .48 \\
\hline \multirow[t]{4}{*}{$1938 \ldots \ldots \ldots \ldots \ldots \ldots$} & 2 & 1.48 & 1.22 & 7.8 & 13.2 & .82 & 1.70 \\
\hline & 3 & 1.25 & 1.01 & 13.5 & 22.6 & .81 & 1.69 \\
\hline & 4 & 1.48 & 1.25 & 6.1 & 8.6 & .84 & 1.41 \\
\hline & 5 & 1.67 & 1.39 & 5.3 & 4.7 & .83 & .88 \\
\hline \multirow[t]{4}{*}{$1940 \ldots \ldots \ldots \ldots \ldots \ldots$} & 2 & 1.84 & 1.61 & 6.3 & 6.6 & .88 & 1.04 \\
\hline & 3 & 1.57 & 1.35 & 17.6 & 18.9 & .86 & 1.07 \\
\hline & 4 & 1.71 & 1.50 & 15.4 & 15.2 & .88 & .99 \\
\hline & 5 & 1.88 & 1.60 & 3.8 & 5.4 & .85 & 1.44 \\
\hline \multirow[t]{4}{*}{$1941 \ldots \ldots \ldots \ldots \ldots \ldots$} & 2 & 2.09 & 1.79 & 4.2 & 1.9 & .86 & .45 \\
\hline & 3 & 1.80 & 1.51 & 13.2 & 11.0 & .84 & .83 \\
\hline & 4 & 2.14 & 1.81 & 6.4 & 8.4 & .85 & 1.31 \\
\hline & 5 & 2.43 & 2.16 & 3.3 & 3.6 & .89 & 1.06 \\
\hline \multirow[t]{4}{*}{$1946 \ldots \ldots \ldots \ldots \ldots \ldots$} & 2 & 4.57 & 3.78 & 2.3 & 7.0 & .83 & 3.04 \\
\hline & 3 & 3.35 & 2.82 & 10.5 & 15.8 & .84 & 1.50 \\
\hline & 4 & 4.30 & 3.71 & 6.6 & 10.1 & .86 & 1.53 \\
\hline & 5 & 4.75 & 3.85 & 8.3 & 7.5 & .81 & .90 \\
\hline \multirow[t]{4}{*}{$1947 \ldots \ldots \ldots \ldots \ldots \ldots$} & 2 & 4.74 & 3.95 & 4.7 & 11.1 & .83 & 2.38 \\
\hline & 3 & 3.85 & 3.13 & 5.6 & 10.9 & .81 & 1.95 \\
\hline & 4 & 3.80 & 2.88 & 6.1 & 11.8 & .76 & 1.93 \\
\hline & 5 & 4.08 & 3.41 & 1.7 & 5.0 & .84 & 2.89 \\
\hline \multirow[t]{4}{*}{$1948 \ldots \ldots \ldots \ldots \ldots \ldots$} & 2 & 4.94 & 4.23 & 4.1 & 9.1 & .86 & 2.20 \\
\hline & 3 & 4.92 & 4.20 & 3.8 & 6.5 & .85 & 1.70 \\
\hline & 4 & 5.59 & 4.93 & 3.6 & 6.2 & .88 & 1.71 \\
\hline & 5 & 5.69 & 5.32 & 1.0 & .9 & .93 & .87 \\
\hline Mean. . & 3.5000 & 3.0246 & 2.5868 & 6.8250 & 8.6750 & 0.8557 & 1.4511 \\
\hline S. D............. & 1.1180 & 1.4141 & 1.2201 & 4.2780 & 4.9631 & 0.0385 & .6577 \\
\hline
\end{tabular}

For footnotes and sources see page following table A-11. 
TABLE A-10

Wickson Plums: New York Auction Price and Sales Data Used in Size Analysis, 1937-1948

\begin{tabular}{|c|c|c|c|c|c|c|c|}
\hline \multirow{2}{*}{ Year } & \multirow[b]{2}{*}{$\underset{W}{W^{b}}$} & \multicolumn{2}{|c|}{ Price } & \multicolumn{2}{|c|}{ Sales } & \multirow{2}{*}{$\begin{array}{l}\text { Price } \\
\text { ratio }^{\circ} \\
P\end{array}$} & \multirow{2}{*}{$\begin{array}{c}\text { Quantity } \\
\text { ratio } \\
Q\end{array}$} \\
\hline & & $\stackrel{3 \times 4}{P_{L}}$ & $\underset{P S}{4 \times 4}$ & $\underset{Q_{L}}{3 \times 4}$ & $\underset{Q_{S}}{4 \times 4}$ & & \\
\hline \multirow{6}{*}{1937.} & 2 & 3 & 4 & 5 & 6 & 7 & 8 \\
\hline & & \multicolumn{2}{|c|}{ dollars per crate } & \multicolumn{2}{|c|}{1,000 crates } & & \\
\hline & 2 & 1.97 & 1.80 & 3.6 & 4.0 & .91 & 1.11 \\
\hline & 3 & 1.94 & 1.84 & 8.5 & 8.5 & .95 & 1.00 \\
\hline & 4 & 1.99 & 1.91 & 3.3 & 10.4 & .96 & 3.19 \\
\hline & 5 & 1.65 & 1.50 & 4.4 & 13.5 & .91 & 3.05 \\
\hline \multirow[t]{4}{*}{1938.} & 2 & 1.46 & 1.33 & 6.0 & 3.3 & .91 & .55 \\
\hline & 3 & 1.27 & 1.12 & 7.5 & 10.5 & .88 & 1.41 \\
\hline & 4 & 1.18 & 1.09 & 4.8 & 8.8 & .92 & 1.84 \\
\hline & 5 & 1.49 & 1.51 & 2.6 & 2.5 & 1.01 & .97 \\
\hline \multirow[t]{4}{*}{1940.} & 2 & 2.02 & 1.91 & 1.9 & 2.9 & .95 & 1.55 \\
\hline & 3 & 1.72 & 1.55 & 5.1 & 10.2 & .90 & 1.99 \\
\hline & 4 & 1.56 & 1.43 & 4.7 & 9.9 & .92 & 2.11 \\
\hline & 5 & 1.17 & 1.13 & 1.8 & 12.5 & .97 & 6.94 \\
\hline \multirow[t]{4}{*}{$1941 \ldots \ldots \ldots \ldots \ldots \ldots$} & 2 & 1.73 & 1.55 & 8.4 & 7.9 & .90 & .94 \\
\hline & 3 & 1.80 & 1.55 & 4.9 & 8.5 & .86 & 1.73 \\
\hline & 4 & 1.95 & 1.69 & 1.4 & 9.3 & .87 & 6.74 \\
\hline & 5 & 2.12 & 1.96 & .3 & 3.1 & .92 & 11.92 \\
\hline \multirow[t]{4}{*}{1946.} & 2 & 4.22 & 3.88 & 5.5 & 5.6 & .92 & 1.02 \\
\hline & 3 & 4.07 & 3.67 & 1.6 & 5.8 & .90 & 3.74 \\
\hline & 4 & 3.57 & 3.16 & 7.6 & 16.0 & .89 & 2.11 \\
\hline & 5 & 3.38 & 3.08 & 5.0 & 8.9 & .91 & 1.78 \\
\hline \multirow[t]{4}{*}{$1947 \ldots$} & 2 & 4.33 & 3.76 & 4.4 & 3.8 & .87 & .86 \\
\hline & 3 & 4.59 & 4.26 & 6.8 & 8.6 & .93 & 1.26 \\
\hline & 4 & 4.01 & 3.42 & 4.9 & 14.9 & .85 & 3.02 \\
\hline & 5 & 3.87 & 3.39 & .7 & 6.0 & .88 & 9.15 \\
\hline \multirow[t]{4}{*}{1948.} & 2 & 4.08 & 3.91 & 6.2 & 3.9 & .96 & 6.31 \\
\hline & 3 & 4.55 & 4.11 & 3.2 & 5.2 & .90 & 1.66 \\
\hline & 4 & 4.47 & 3.65 & .4 & 2.4 & .82 & 6.41 \\
\hline & 5 & 3.35 & 2.85 & 2.0 & 8.4 & .85 & 4.15 \\
\hline Mean.... & 3.5000 & 2.6968 & 2.4289 & 4.1964 & 7.6893 & 0.9079 & 3.1611 \\
\hline S. D....... & 1.1180 & 1.2158 & 1.0656 & 2.3491 & 3.7352 & 0.0406 & 2.7878 \\
\hline
\end{tabular}

For footnotes and sources see page following table A-11. 
TABLE A-11

President Plums: New York Auction Price and Sales Data a Used in Size Analysis, 1937-1948

\begin{tabular}{|c|c|c|c|c|c|c|c|}
\hline \multirow{2}{*}{ Year } & \multirow{2}{*}{$\begin{array}{c}\text { Week } \\
W\end{array}$} & \multicolumn{2}{|c|}{ Price } & \multicolumn{2}{|c|}{ Sales } & \multirow{2}{*}{$\begin{array}{l}\text { Price } \\
\text { ratio }^{c} \\
\qquad P\end{array}$} & \multirow{2}{*}{$\begin{array}{c}\text { Quantity } \\
\text { ratio }^{\mathrm{c}} \\
Q\end{array}$} \\
\hline & & $\stackrel{4 \times 4}{P_{L}}$ & $\underset{P S}{4 \times 5}$ & $\begin{array}{c}4 \times 4 \\
Q_{L}\end{array}$ & $\underset{Q_{S}}{4 \times 5^{\mathrm{d}}}$ & & \\
\hline \multirow[t]{2}{*}{1} & 2 & 3 & 4 & 5 & 6 & 7 & 8 \\
\hline & & \multicolumn{2}{|c|}{ dollars per crate } & \multicolumn{2}{|c|}{1,000 crates } & & \\
\hline \multirow[t]{7}{*}{$1937 \ldots \ldots \ldots$} & 2 & 2.56 & 2.25 & 3.4 & 2.6 & .88 & .76 \\
\hline & 3 & 1.99 & 1.68 & 12.3 & 16.1 & .84 & 1.31 \\
\hline & 4 & 1.81 & 1.50 & 9.2 & 12.2 & .83 & 1.32 \\
\hline & 5 & 1.80 & 1.51 & 7.4 & 7.5 & .84 & 1.02 \\
\hline & 6 & 2.35 & 1.92 & 2.2 & 4.5 & .82 & 2.05 \\
\hline & 7 & 2.47 & 1.94 & 1.3 & 3.8 & .79 & 2.99 \\
\hline & 8 & 2.30 & 1.48 & 2.0 & 7.0 & .64 & 3.44 \\
\hline \multirow[t]{7}{*}{1938.} & 2 & 2.30 & 1.69 & 3.3 & 11.7 & .73 & 3.60 \\
\hline & 3 & 1.83 & 1.57 & 10.9 & 23.0 & .86 & 2.11 \\
\hline & 4 & 1.58 & 1.30 & 12.0 & 28.8 & .82 & 2.40 \\
\hline & 5 & 1.24 & .96 & 7.9 & 23.9 & .77 & 3.03 \\
\hline & 6 & 1.38 & .95 & 3.0 & 16.6 & .69 & 5.54 \\
\hline & 7 & 1.43 & 1.07 & 1.5 & 9.5 & .75 & 6.24 \\
\hline & 8 & 1.62 & 1.24 & .8 & 4.9 & .77 & 5.91 \\
\hline \multirow[t]{7}{*}{1940.} & 2 & 2.32 & 1.93 & .8 & 4.4 & .83 & 5.60 \\
\hline & 3 & 1.93 & 1.58 & 4.4 & 16.1 & .82 & 3.70 \\
\hline & 4 & 1.61 & 1.29 & 7.8 & 28.5 & .80 & 3.64 \\
\hline & 5 & 1.76 & 1.32 & 4.2 & 11.1 & .75 & 2.67 \\
\hline & 6 & 2.01 & 1.65 & 3.3 & 7.9 & .82 & 2.42 \\
\hline & 7 & 2.51 & 1.98 & 1.2 & 5.2 & .79 & 4.20 \\
\hline & 8 & 2.60 & 2.26 & 1.8 & 2.7 & .87 & 1.46 \\
\hline \multirow[t]{7}{*}{$1941 \ldots \ldots \ldots \ldots$} & 2 & 2.72 & 2.38 & 3.6 & 3.9 & .88 & 1.09 \\
\hline & 3 & 2.25 & 1.88 & 10.0 & 19.1 & .84 & 1.91 \\
\hline & 4 & 1.96 & 1.57 & 9.5 & 20.5 & .80 & 2.15 \\
\hline & 5 & 1.82 & 1.38 & 7.1 & 19.5 & .76 & 2.76 \\
\hline & 6 & 1.91 & 1.30 & 4.1 & 12.4 & .68 & 3.02 \\
\hline & 7 & 2.03 & 1.54 & 3.4 & 6.3 & .76 & 1.86 \\
\hline & 8 & 2.25 & 1.75 & 3.9 & 7.7 & .78 & 1.95 \\
\hline \multirow[t]{7}{*}{$1946 \ldots$} & 2 & 3.36 & 2.38 & 6.0 & 12.6 & .71 & 2.09 \\
\hline & 3 & 3.05 & 2.13 & 7.7 & 22.0 & .70 & 2.85 \\
\hline & 4 & 2.99 & 1.98 & 8.6 & 37.4 & .66 & 4.37 \\
\hline & 5 & 3.43 & 2.32 & 4.5 & 14.7 & .68 & 3.27 \\
\hline & 6 & 3.22 & 2.49 & 5.2 & 12.3 & .77 & 2.35 \\
\hline & 7 & 4.82 & 3.94 & 2.4 & 5.0 & .82 & 2.06 \\
\hline & 8 & 4.50 & 3.37 & 1.3 & 2.5 & .75 & 1.90 \\
\hline \multirow[t]{7}{*}{1947.} & 2 & 5.43 & 4.17 & 1.0 & 4.7 & .77 & 4.62 \\
\hline & 3 & 4.64 & 3.17 & 4.4 & 15.4 & .68 & 3.52 \\
\hline & 4 & 3.22 & 2.25 & 7.9 & 36.4 & .70 & 4.60 \\
\hline & 5 & 4.56 & 3.01 & 2.4 & 14.0 & .66 & 5.75 \\
\hline & 6 & 4.85 & 3.68 & 4.1 & 10.5 & .76 & 2.58 \\
\hline & 7 & 5.16 & 3.91 & 7.2 & 10.6 & .76 & 1.46 \\
\hline & 8 & 4.93 & 3.67 & 5.4 & 12.5 & .74 & 2.31 \\
\hline
\end{tabular}


TABLE A-11-Continued

\begin{tabular}{|c|c|c|c|c|c|c|c|}
\hline \multirow{2}{*}{ Year } & \multirow{2}{*}{$\underset{W}{\text { Week }^{\mathbf{b}}}$} & \multicolumn{2}{|c|}{ Price } & \multicolumn{2}{|c|}{ Sales } & \multirow{2}{*}{$\begin{array}{l}\text { Price } \\
\text { ratioc }_{P}^{\circ}\end{array}$} & \multirow{2}{*}{ 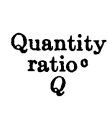 } \\
\hline & & $\stackrel{4 \times 4}{P_{L}}$ & $\underset{P S}{4 \times 5}$ & $\stackrel{4 \times 4}{Q_{L}}$ & $\underset{Q_{S}}{4 \times 5^{\mathrm{d}}}$ & & \\
\hline \multirow[t]{2}{*}{1} & 2 & 3 & 4 & 5 & 6 & 7 & 8 \\
\hline & & \multicolumn{2}{|c|}{ dollars per crate } & \multicolumn{2}{|c|}{1,000 crates } & & \\
\hline \multirow[t]{7}{*}{1948.} & 2 & 3.89 & 2.71 & 6.4 & 4.8 & .70 & .75 \\
\hline & 3 & 3.78 & 2.52 & 3.0 & 5.1 & .67 & 1.72 \\
\hline & 4 & 3.88 & 2.89 & 9.7 & 11.1 & .74 & 1.14 \\
\hline & $\mathbf{5}$ & 4.15 & 3.09 & 3.8 & 4.5 & .74 & 1.17 \\
\hline & 6 & 4.57 & 3.11 & 3.8 & 7.1 & .68 & 1.89 \\
\hline & 7 & 4.32 & 3.09 & 4.1 & 5.8 & .72 & 1.43 \\
\hline & 8 & 4.18 & 2.56 & 2.9 & 4.6 & .61 & 1.60 \\
\hline Mean. . & 5.0000 & 2.9239 & 2.1900 & 4.9816 & 12.0612 & 0.7598 & 2.7261 \\
\hline S. D.... & 2.0000 & 1.1877 & 0.8385 & 3.0789 & 8.4803 & 0.0665 & 1.4245 \\
\hline
\end{tabular}

\section{Footnotes ANd Sources for Tables A-8 to A-11}

a The same values of the index of U.S. nonagricultural income payments were used for all weeks of each season, as follows:

For Beauty, Tragedy, and Wickson-1937, 110; 1938, 99; 1940, 114;1941, 138; 1946, 250; 1947, 276; 1948, 302. Mean and standard deviation are 184.1429 and 81.4694 respectively.

For President-1937, 109; 1938, 101; 1940, 116;1941, 144; 1946, 260; 1947, 284; 1948, 309. Mean and standard deviation are 189.0000 and 84.4850 respectively.

b The designation for week of the season is arbitrary. The first set of price and sales data of each season used in the analysis is labeled week 2; subsequent weeks are numbered in sequence.

- Price and quantity ratios relate to price (or sales) of smaller size divided by price (or sales) of larger size. That is

$$
P=P_{S} \div P_{L} \quad \text { and } \quad Q=Q_{S} \div Q_{L}
$$

The figures shown were computed from the original unrounded data.

$d$ Includes sales of all sizes 3-4 $\times 5$ and smaller.

Sources of DAta: Based on daily sales and prices at New York auction market.

Columns (3) to (6): Tabulated from typewritten summaries prepared by the Fruit and Vegetable Branch, Production and Marketing Administration, U.S.D.A.

Columns (7) and (8): Computed. 
TABLE A-12

California Plums: New York Auction Price Premiums and Quantity Ratios Used in Size Analysis, 1937-1948

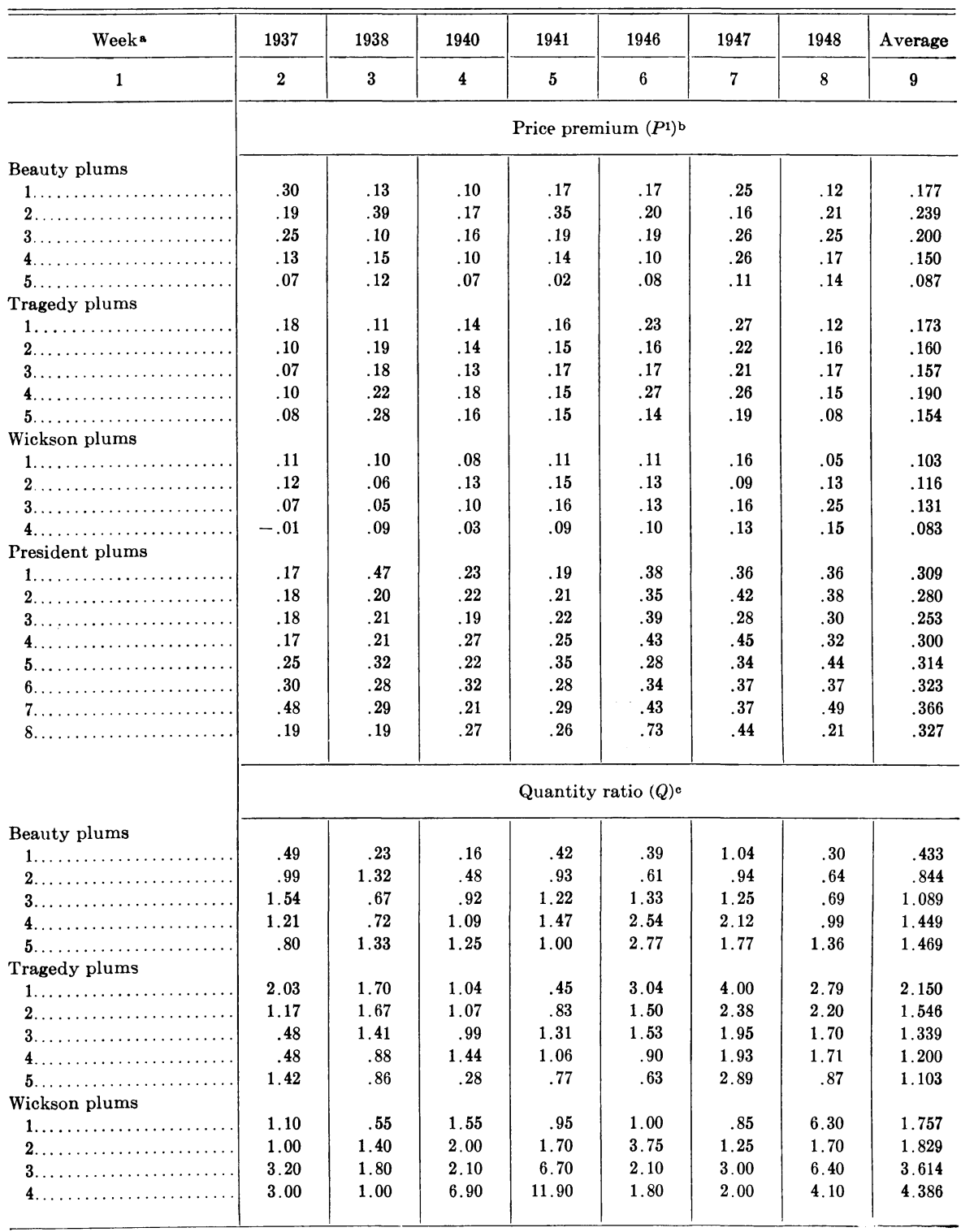


TABLE A-12-Continued

\begin{tabular}{|c|c|c|c|c|c|c|c|c|}
\hline Week $^{\mathbf{a}}$ & 1937 & 1938 & 1940 & 1941 & 1946 & 1947 & 1948 & Average \\
\hline \multirow[t]{2}{*}{1} & 2 & 3 & 4 & 5 & 6 & 7 & 8 & 9 \\
\hline & \multicolumn{8}{|c|}{ Quantity Ratio $(Q)^{\mathrm{c}}$} \\
\hline \multicolumn{9}{|l|}{ President plums } \\
\hline $1 \ldots \ldots \ldots \ldots$ & 1.44 & 2.86 & 4.55 & .70 & 1.14 & 2.78 & .63 & 2.014 \\
\hline $2 \ldots$ & .88 & 1.82 & 2.70 & 1.18 & 1.69 & 2.08 & 1.25 & 1.657 \\
\hline 3. & .88 & 1.89 & 2.32 & 1.25 & 2.44 & 2.50 & .76 & 1.720 \\
\hline 4. & 1.27 & 2.38 & 1.67 & 1.54 & 1.89 & 2.56 & .71 & 1.717 \\
\hline 5 & .67 & 3.57 & 1.35 & 1.75 & 1.11 & 1.16 & 1.19 & 1.543 \\
\hline 6 . & .40 & 4.16 & 2.38 & 1.12 & 1.12 & .72 & .90 & 1.543 \\
\hline 7. & .38 & 4.54 & .91 & .99 & 1.03 & 1.04 & 1.15 & 1.434 \\
\hline 8. & .33 & 1.96 & 1.33 & .77 & 1.28 & .61 & .66 & 0.991 \\
\hline
\end{tabular}

a The designation for week of the season is arbitrary. The first set of price and sales data used in the analysis of factors affecting premium paid for larger sizes is labeled week 1 ; subsequent weeks are numbered in sequence. b Price premium relates to price differential between larger and smaller sizes divided by the average price for sales of all sizes (of the given variety) made during the entire season. That is, $P^{\prime}=\left(P_{L}-P_{S}\right) \div P_{T}$ where $P_{L}$ and $P_{S}$ refer to the weekly prices for sales of large and small sizes and $P_{T}$ is the average season price. For this purpose $4 \times 5$ and $5 \times 5$ were considered large and small sizes for Beauty, $5 \times 5$ and $5 \times 6$ for Tragedy, $3 \times 4$ and $4 \times 4$ for Wickson, and $4 \times 4$ and $4 \times 5$ for President.

c Quantity ratios refer to sales of small size divided by sales of large size (for the same week). The sizes used are those indicated in footnote $b$.

Note: The arithmetic averages and standard deviations of the two series are the following:

\begin{tabular}{|c|c|c|c|c|}
\hline \multirow{2}{*}{ Variety } & \multicolumn{2}{|c|}{ Price premium } & \multicolumn{2}{|c|}{ Quantity ratio } \\
\hline & Mean & S. D. & Mean & S. D. \\
\hline $\begin{array}{l}\text { Beauty.... } \\
\text { Traged. . } \\
\text { Wickson... } \\
\text { President.. }\end{array}$ & $\begin{array}{l}0.170571 \\
0.166857 \\
0.108214 \\
0.308929\end{array}$ & $\begin{array}{l}0.079496 \\
0.053333 \\
0.048848 \\
0.106548\end{array}$ & $\begin{array}{l}1.056571 \\
1.467429 \\
2.896429 \\
1.577500\end{array}$ & $\begin{array}{l}0.587415 \\
0.814895 \\
2.536270 \\
0.981941\end{array}$ \\
\hline
\end{tabular}

Source of DAtA: Based on typewritten summaries prepared (from daily sales and prices at New York auction market) by the Fruit and Vegetable Branch, Production and Marketing Administration, U. S. Department of Agriculture. 
TABLE A-13

California Plums: Annual Average Marketing Charges, a 1920-1948

\begin{tabular}{|c|c|c|c|c|c|c|c|c|c|}
\hline \multirow{2}{*}{ Year } & \multirow{2}{*}{ Picking } & \multirow{2}{*}{ Hauling } & \multirow{2}{*}{$\begin{array}{l}\text { Packing } \\
\text { (door- } \\
\text { to-door) }\end{array}$} & \multirow{2}{*}{ Loading } & \multirow{2}{*}{$\begin{array}{l}\text { Pre- } \\
\text { cooling }\end{array}$} & \multicolumn{2}{|c|}{ Transportation } & \multirow{2}{*}{$\begin{array}{c}\text { Selling } \\
\text { charges }\end{array}$} & \multirow{2}{*}{ Total } \\
\hline & & & & & & Freight & $\begin{array}{c}\text { Refriger- } \\
\text { ation }\end{array}$ & & \\
\hline \multirow[t]{2}{*}{1} & 2 & 3 & 4 & 5 & 6 & 7 & 8 & 9 & 10 \\
\hline & \multicolumn{9}{|c|}{ dollars per crate } \\
\hline 1920. & .06 & .03 & .35 & .03 & $\ldots$ & .38 & .11 & .18 & 1.14 \\
\hline $1921 \ldots$ & .06 & .03 & .35 & .03 & $\ldots$ & .51 & .11 & .13 & 1.22 \\
\hline 1922. & .06 & .03 & .35 & .03 & $\ldots$ & .45 & .10 & .11 & 1.13 \\
\hline 1923 & .06 & .03 & .35 & .03 & $\ldots$ & .45 & .10 & .10 & 1.12 \\
\hline 1924 & .06 & .03 & .35 & .03 & $\ldots$ & .45 & .10 & .14 & 1.16 \\
\hline $1925 \ldots$ & .06 & .03 & .35 & .03 & $\ldots$ & .45 & .10 & .12 & 1.14 \\
\hline $1926 \ldots$ & .06 & .03 & .35 & .03 & $\ldots$ & .45 & .10 & .10 & 1.12 \\
\hline 1927. & .06 & .03 & .35 & .03 & $\ldots$ & .45 & .10 & .13 & 1.15 \\
\hline $1928 \ldots \ldots \ldots$ & .06 & .03 & .35 & .03 & $\ldots$ & .42 & .10 & .12 & 1.11 \\
\hline $1929 \ldots \ldots \ldots$ & .06 & .03 & .37 & .03 & $\ldots$ & .42 & .10 & .17 & 1.18 \\
\hline $1930 \ldots$ & .06 & .03 & .36 & .03 & $\ldots$ & .42 & .10 & .10 & 1.10 \\
\hline 1931. & .05 & .03 & .36 & .03 & $\ldots$ & .45 & .10 & .10 & 1.12 \\
\hline 1932. & .05 & .03 & .32 & .03 & $\ldots$ & .45 & .10 & .09 & 1.07 \\
\hline $1933 \ldots$ & .05 & .03 & .28 & .03 & $\ldots$ & .45 & .09 & .09 & 1.02 \\
\hline 1934. & .05 & .03 & .31 & .03 & $\ldots:$ & .45 & .09 & .10 & 1.06 \\
\hline $1935 \ldots$ & .06 & .02 & .32 & .03 & .01 & .45 & .09 & .11 & 1.09 \\
\hline 1936. & .06 & .03 & .32 & .03 & .02 & .45 & .09 & .10 & 1.10 \\
\hline $1937 \ldots$ & .07 & .03 & .32 & .03 & .03 & .43 & .08 & .12 & 1.11 \\
\hline 1938. & .07 & .03 & .34 & .03 & .03 & .45 & .08 & .09 & 1.12 \\
\hline 1939. & .07 & .03 & .34 & .03 & .03 & .45 & .08 & .10 & 1.13 \\
\hline $1940 \ldots$ & .07 & .03 & .35 & .03 & .03 & .49 & .09 & .11 & 1.20 \\
\hline $1941 \ldots$ & .08 & .03 & .38 & .03 & .03 & .49 & .09 & .12 & 1.25 \\
\hline 1942. & .15 & .04 & .50 & .04 & .03 & .52 & .10 & .18 & 1.56 \\
\hline $1943 \ldots$ & .21 & .05 & .66 & .05 & .03 & .52 & .10 & .29 & 1.91 \\
\hline $1944 \ldots \ldots \ldots$ & .31 & .05 & .74 & .06 & .04 & .52 & .10 & .19 & 2.01 \\
\hline $1945 \ldots \ldots \ldots$ & .35 & .05 & .71 & .06 & .04 & .52 & .10 & .24 & 2.07 \\
\hline $1946 \ldots \ldots \ldots$ & .34 & .05 & .76 & .06 & .05 & .52 & .10 & .21 & 2.09 \\
\hline $1947 \ldots \ldots \ldots$ & .34 & .05 & .78 & .06 & .05 & .56 & .11 & .26 & 2.21 \\
\hline $1948 \ldots \ldots \ldots$ & .32 & .05 & .83 & .06 & .05 & .56 & .11 & .24 & 2.22 \\
\hline
\end{tabular}

a For standard crate in interstate shipments.

b Calculated at 7 per cent of weighted average New York-Chicago auction price.

Source of DATA: California Tree Fruit Agreement, "Plums, 1944" (mimeo.), table 16 for 1920-1937 (reporting results of the 1936-1937 survey conducted by the Bureau of Agricultural Economics, the Production and Marketing Administration, and the California Tree Fruit Agreement). For 1938-1948 the data are based on unpublished information from the California Crop and Livestock Reporting Service and from the California Grape and Tree Fruit League. The information secured was modified to secure data comparable to those reported for earlier years. Note: Where adjustments were necessary to obtain comparability such modifications were upward. Thus charges for late years, and possibly for the earlier period, may be overstated. 

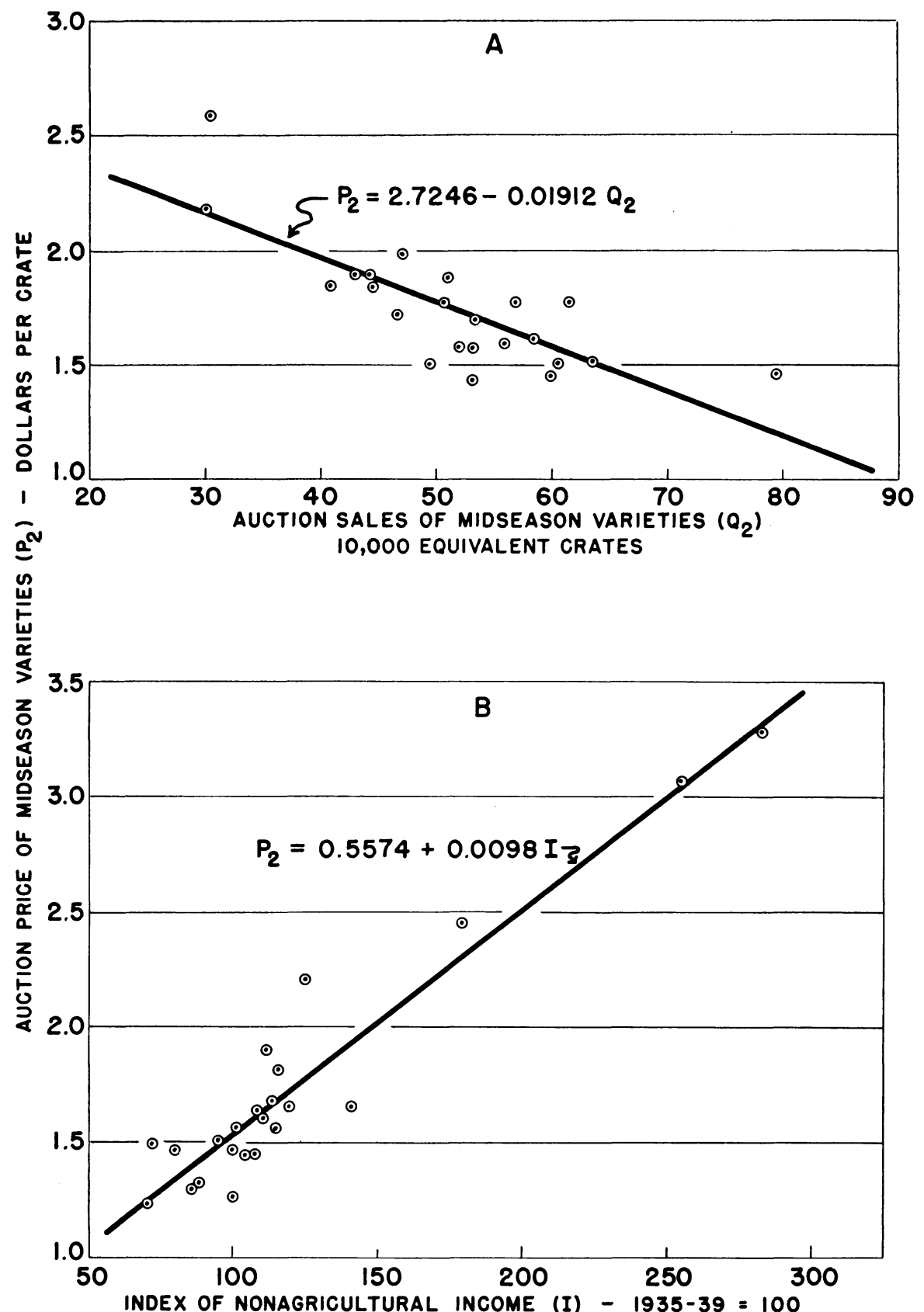

Fig. B-1. Midseason California plums: net regressions of auction price on (A) auction sales of midseason varieties and $(B)$ index of nonagricultural income. Based on equation (2.1). 

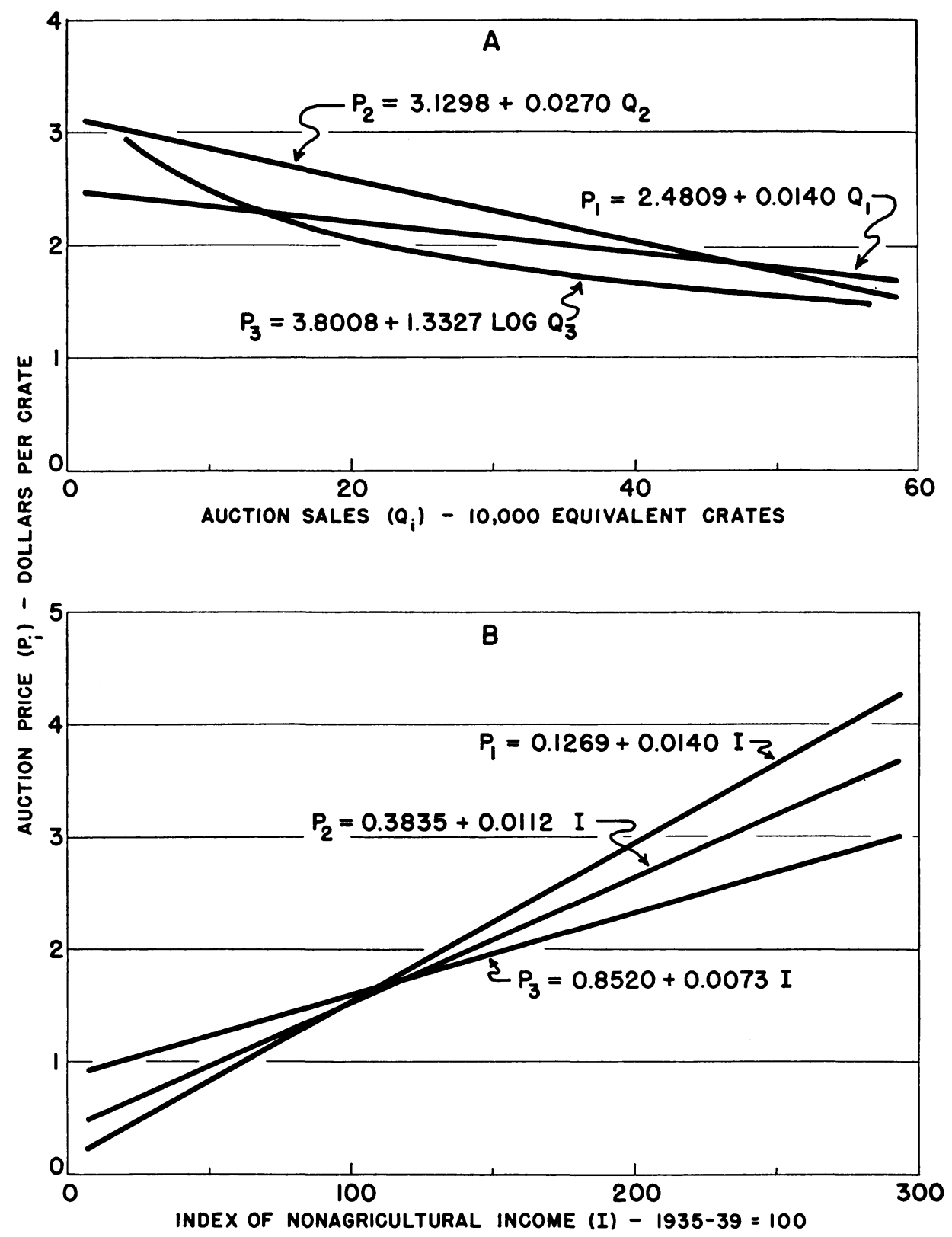

Fig. B-2. Late California plums : net regressions of auction price on (A) auction sales of late varieties and (B) index of nonagricultural income. Based on equation (3.1). 

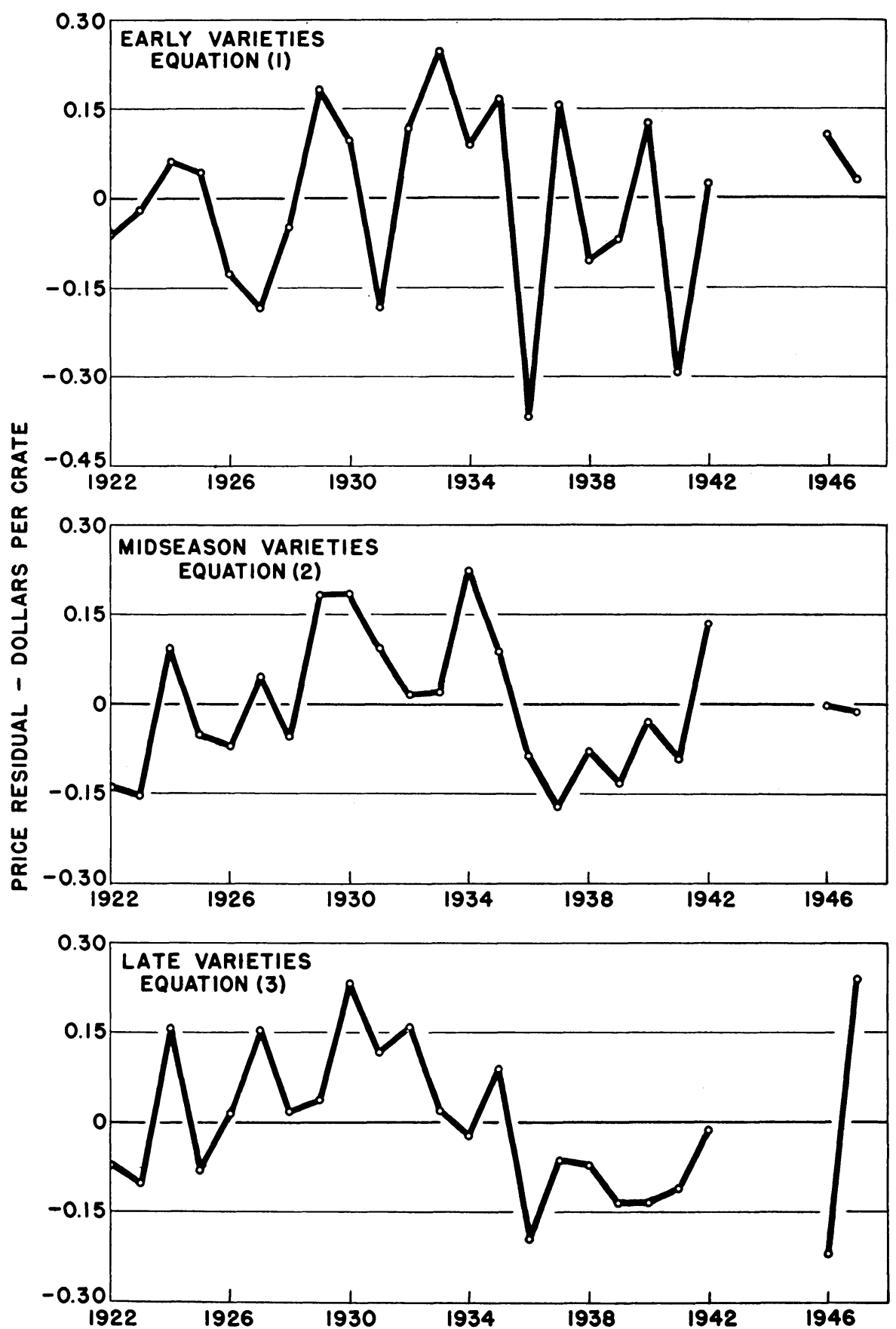

Fig. B-3. California plums : time series plot of residuals for varietal analysis. Based on equations (1), (2), and (3). 
TABLE B-1

Data for Shift Variables Used in Varietal Analysis, 1922-1949

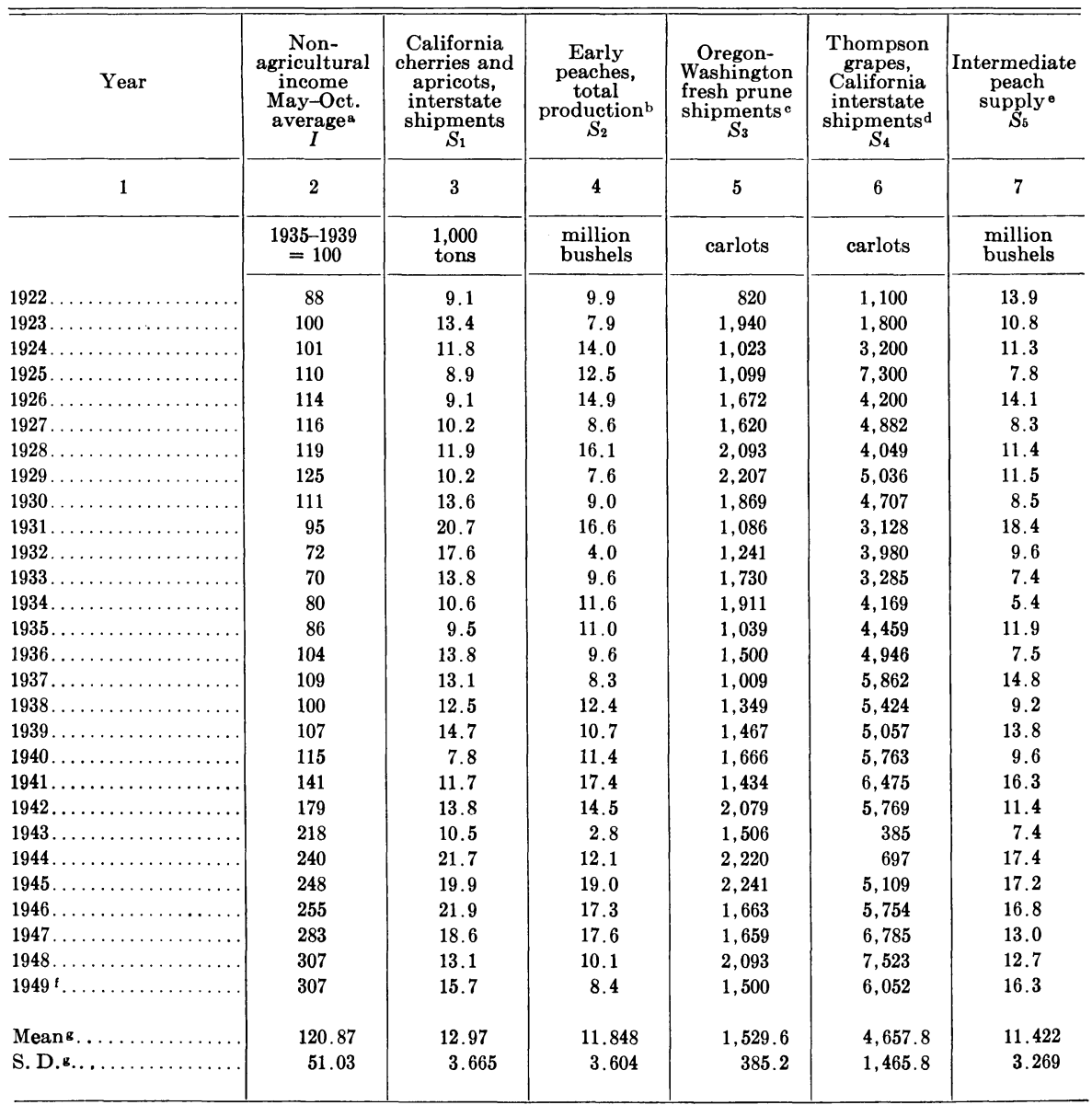

simple average of monthly figures for May-October

b Total production in Georgia, South Carolina, North Carolina, and Arkansas.

c Total shipments, including varying but not large quantities sold in intrastate fresh and processing outlets.

d May include small quantities of intrastate shipments for 1922-1926.

- Total production in New York, New Jersey, Pennsylvania, Illinois, Michigan, Virginia, and Tennessee plus interstate shipments of California freestone peaches converted to a bushel basis at 24 tons per 1,000 bushels (of 48 pounds).

f Preliminary (unofficial) data.

g For 1922-1942 plus 1946-1947.

SOURCES OF DATA:

Column 2: 1922-1928: United States Bureau of Agricultural Economics, "Nonagricultural Income Payments, United States, 1909 to date; Index Numbers, Adjusted for Seasonal Variation, 1935-1939=100." Washington, D.C., 2 p. Mimeo. (April 11, 1944).

1929-1949: United States Bureau of Domestic and Foreign Commerce, "National Income Supplement to Survey of Current Business." Washington, D.C., July 1947 (table 48), 54 p., and subsequent issues of "Survey of Current Business."

Columns 3, 4, and 7: United States Bureau of Agricultural Economics, "Fruits-Noncitrus: Production Farm Disposition, Value, and Utilization of Sales, 1889-1944." Washington, D.C., May 1948,106 p., and subsequent mimeo. releases.

Column 5: 1920-1923: United States Department of Agriculture, "Carload Shipments of Fruits and Melons from Stations in the United States, for Calendar Years 1920, 1921, 1922, and 1923." Statistical Bul. No. 8, February 1925, pp. 56-58.

1924: United States Department of Agriculture, “Carload Shipments of Fruits and Vegetables from States in the United States, for Calendar Years 1924 and 1925." Statistical Bul. No. 19, February 1927, pp. 52-54.

1925-1949: California Federal-State Market News Service, "Interstate Shipments of California Deciduous Tree Fruits," annual summary reports (mimeo.).

Column 6: 1922-1926: S. W. Shear and H. F. Gould, "Economic Status of the Grape Industry." University of California, Agricultural Experiment Station Bul. 429, June 1927, pp. 46-47, supplemented by estimates for 1923 and 1924 based on eleven eastern auction market sales.

1927-1949: California Federal-State Market News Service, "Interstate Shipments of California Grapes," annual summary reports (mimeo.). 
TABLE B-2

California Plums: Intercorrelation, Means, and Standard Deviation of Series Used in Varietal Regression ANalysis, 1922-1942 Plus 1946-1947

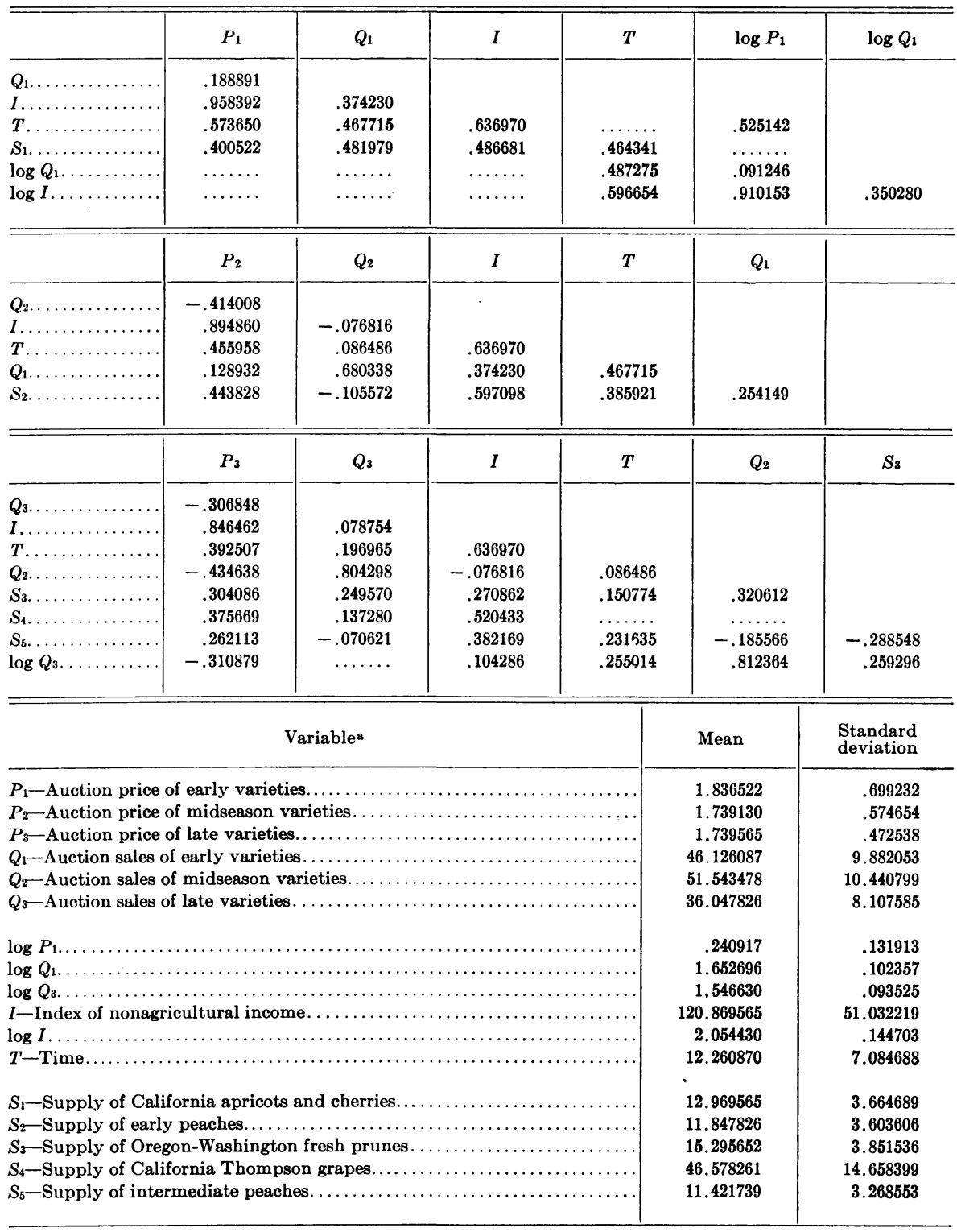

anits used are: dollars per crate for auction prices; 10,000 equivalent crates for auction sales; $1935-1939=100$ for $I$; years, with origin at 1921 , for $T ; 1,000$ tons for $S_{1} ;$ million bushels for $S_{2}$ and $S_{6} ; 100$ carlots for $S_{3}$ and $S_{4}$. For complete description of the variables see tables A-1, A-2, A-3, and B-1. 
TABLE B-3

California Plums: Price Residuals for Varietal Regression Analysis, 1922-1942 PLUS 1946-1949

\begin{tabular}{|c|c|c|c|c|c|}
\hline Year & Equation 1 & Equation 2 & Equation 3 & Equation 2.1 & Equation 3.1 \\
\hline & \multicolumn{5}{|c|}{ dollars per crate } \\
\hline 1922. & -.062 & -.141 & -.073 & -.111 & -.181 \\
\hline $1923 \ldots \ldots \ldots \ldots \ldots \ldots$ & -.019 & -.156 & -.103 & -.062 & -.089 \\
\hline $1924 \ldots$ & .062 & .093 & .156 & .017 & .216 \\
\hline $1925 \ldots$ & .045 & -.055 & -.083 & -.016 & -.140 \\
\hline $1926 \ldots$ & -.126 & -.071 & .014 & .006 & -.024 \\
\hline $1927 \ldots$ & -.183 & .045 & .153 & .124 & .146 \\
\hline $1928 \ldots \ldots$ & -.049 & -.053 & .018 & -.065 & .113 \\
\hline $1929 \ldots \ldots$ & .183 & .183 & .036 & .432 & .404 \\
\hline $1930 \ldots \ldots \ldots \ldots$ & .100 & .185 & .234 & .250 & .278 \\
\hline$\ldots \ldots \ldots \ldots \ldots \ldots$ & -.183 & .097 & .118 & .017 & .043 \\
\hline $1932 \ldots \ldots \ldots \ldots \ldots \ldots$ & .120 & .014 & .161 & .229 & .004 \\
\hline 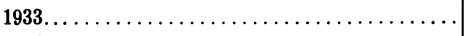 & .249 & .018 & .019 & -.008 & .084 \\
\hline $1934 \ldots \ldots \ldots \ldots \ldots \ldots \ldots \ldots \ldots \ldots \ldots \ldots \ldots$ & .091 & .225 & -.021 & .131 & .098 \\
\hline 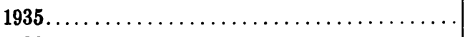 & .166 & .089 & .088 & -.111 & -.018 \\
\hline 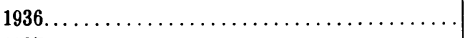 & -.367 & -.086 & -.193 & -.133 & -.211 \\
\hline $1937 \ldots \ldots \ldots \ldots \ldots$ & .156 & -.171 & -.067 & .006 & -.148 \\
\hline $1938 \ldots \ldots \ldots \ldots$ & -.103 & -.080 & -.075 & -.276 & -.057 \\
\hline $1939 \ldots \ldots \ldots \ldots$ & .067 & -.133 & -.137 & -.157 & -.189 \\
\hline $1940 \ldots \ldots \ldots \ldots \ldots$ & .127 & -.029 & -.137 & -.122 & -.211 \\
\hline $1941 \ldots \ldots \ldots \ldots \ldots$ & -.292 & -.091 & -.114 & -.277 & -.130 \\
\hline $1942 \ldots \ldots \ldots \ldots \ldots \ldots$ & .026 & .135 & -.012 & .152 & .133 \\
\hline $1943 \ldots \ldots \ldots \ldots \ldots$ & $\ldots \ldots$ & $\ldots$ & $\ldots$ & $\ldots$ & $\ldots$ \\
\hline $1944 \ldots \ldots \ldots \ldots \ldots$ & $\ldots$ & $\ldots$ & $\ldots$ & $\ldots$ & $\ldots$ \\
\hline $1945 \ldots \ldots \ldots \ldots \ldots \ldots$ & $\cdots$ & $\ldots$ & $\ldots$ & $\ldots$ & $\ldots$ \\
\hline $1946 \ldots \ldots \ldots \ldots \ldots \ldots$ & .104 & -.001 & -.222 & .013 & -.325 \\
\hline $1947 \ldots \ldots \ldots \ldots$ & .029 & -.015 & .242 & -.041 & .207 \\
\hline $1948 \ldots \ldots \ldots \ldots \ldots \ldots$ & .297 & -.354 & -.358 & -.326 & -.559 \\
\hline $1949 \ldots \ldots \ldots \ldots \ldots \ldots \ldots \ldots \ldots \ldots \ldots \ldots \ldots$ & -.780 & -1.994 & -.515 & -1.367 & -.631 \\
\hline
\end{tabular}

Source of Data: Derived from equations of section B, applied to data for 1922-1949, excluding 1943-1945. 


\begin{tabular}{|c|c|c|c|c|c|c|c|}
\hline & & & & 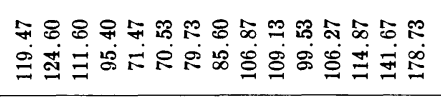 & 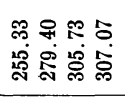 & & 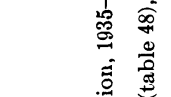 \\
\hline 宓 & & $\stackrel{\bullet}{\circ}$ & & 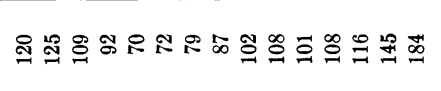 & 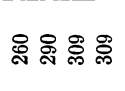 & 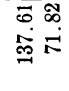 & 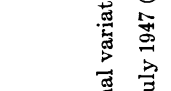 \\
\hline 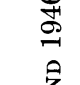 & & $\stackrel{2}{-2}$ & & 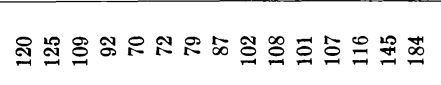 & 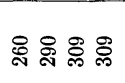 & 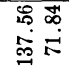 & 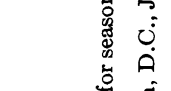 \\
\hline$\stackrel{\leftrightarrow}{\mathcal{H}}$ & & $\Xi$ & & 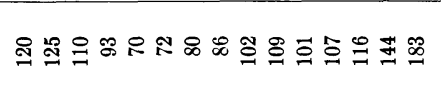 & 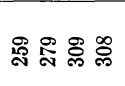 & 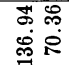 & 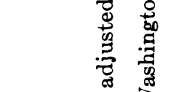 \\
\hline 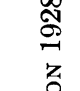 & & $\cong$ & & 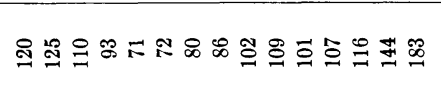 & 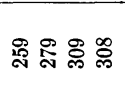 & 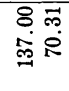 & 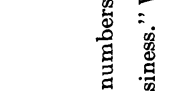 \\
\hline 焉 & & $\simeq$ & & 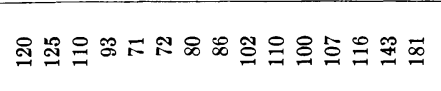 & 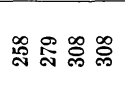 & 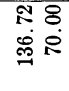 & 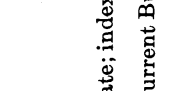 \\
\hline$\stackrel{\vec{n}}{\vec{a}}$ & & $=$ & & 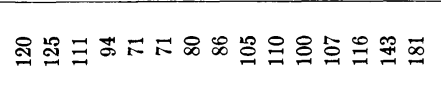 & 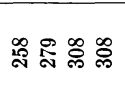 & 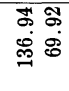 & 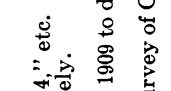 \\
\hline 至 & 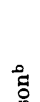 & 음 & \& & 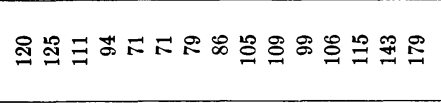 & 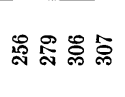 & 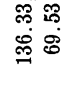 & 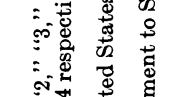 \\
\hline 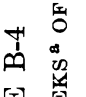 & 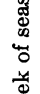 & $\theta$ & $\underset{\mathscr{g}}{\mathscr{\varpi}}$ & 呆哭 & 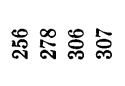 & 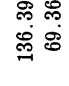 & 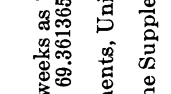 \\
\hline 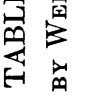 & & $\infty$ & & 蛋 & 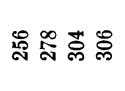 & 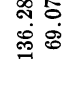 & 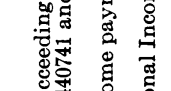 \\
\hline 占 & & $n$ & & 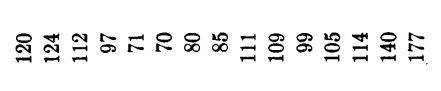 & 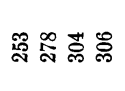 & 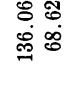 & 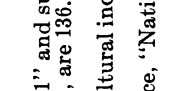 \\
\hline 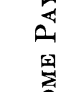 & & 0 & & 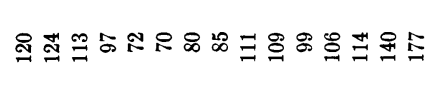 & 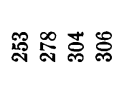 & 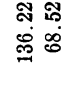 & 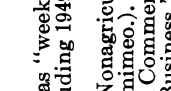 \\
\hline 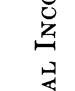 & & 10 & & 寻 怘品 & 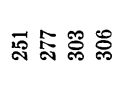 & $\begin{array}{l}0 \\
\infty \\
\infty \\
\infty\end{array}$ & 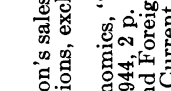 \\
\hline 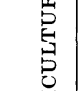 & & + & & 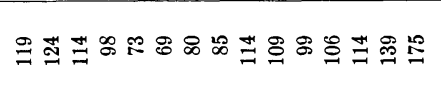 & 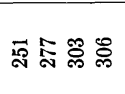 & 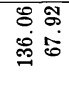 & 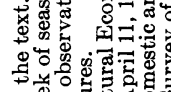 \\
\hline 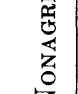 & & $\infty$ & & 气苟 & 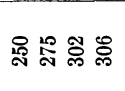 & 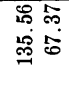 & 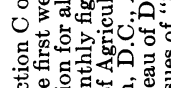 \\
\hline$\dot{\dot{2}}$ & & N & & 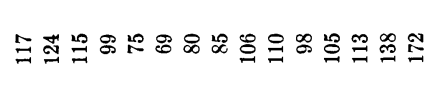 & 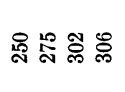 & 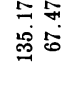 & . \\
\hline 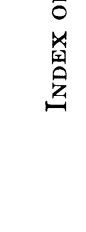 & & & & 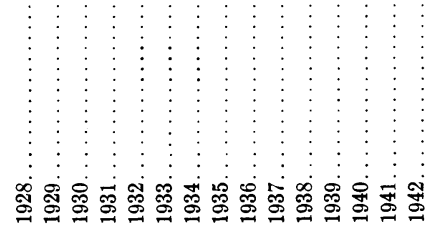 & 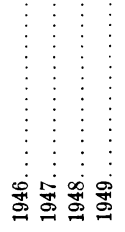 & 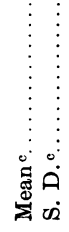 & 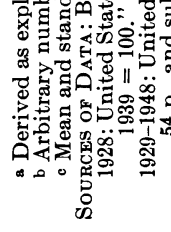 \\
\hline
\end{tabular}


TABLE B-5

California Plums: Intercorrelation, Means, and Standard Deviations of Series Used in Weekly Regression Analysis, 1928-1942 plus 1946-1948

\begin{tabular}{|c|c|c|c|c|c|c|c|c|}
\hline & & $P_{i}$ & $Q_{i}$ & $Q_{i-1}$ & $I$ & $W$ & $W Q_{i}$ & $W I$ \\
\hline $\begin{array}{l}X_{2} \\
X_{7} \\
X_{3} \\
W \\
X_{4} \\
X_{5} \\
X_{6}\end{array}$ & $\begin{array}{l}Q_{i} \\
Q_{i-1} \\
I \\
W \\
W Q_{i} \\
W I \\
W^{2}\end{array}$ & $\begin{array}{r}-.176018 \\
-.246596 \\
.793713 \\
-.230601 \\
-.223341 \\
.304577 \\
-.188156\end{array}$ & $\begin{array}{r}.751004 \\
.089444 \\
-.250489 \\
.763150 \\
-.049714 \\
-.397153\end{array}$ & $\begin{array}{r}.076629 \\
.112262 \\
\ldots \ldots \ldots \\
.168684 \\
-.055516\end{array}$ & $\begin{array}{l}.009294 \\
.163386 \\
.696077 \\
.009153\end{array}$ & $\begin{array}{l}.320495 \\
.646309 \\
.978010\end{array}$ & $\begin{array}{l}.377179 \\
.162559\end{array}$ & .632778 \\
\hline \multicolumn{6}{|c|}{ Variable $^{a}$} & \multicolumn{2}{|c|}{ Mean } & $\begin{array}{l}\text { Standard } \\
\text { deviation }\end{array}$ \\
\hline \multicolumn{6}{|c|}{ 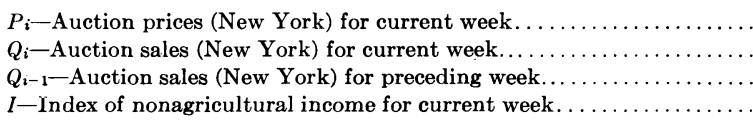 } & $\begin{array}{r}2 . \\
6 . \\
6 . \\
136 . \\
9 . \\
54 . \\
1,230 . \\
99 .\end{array}$ & & $\begin{array}{r}.994264 \\
3.489686 \\
3.609258 \\
69.361654 \\
4.320494 \\
32.972024 \\
921.190780 \\
79.517433\end{array}$ \\
\hline
\end{tabular}

a Units used are: dollars per crate for auction prices; 10,000 crates for auction sales; and $1935-1939=100$ for $I$. For complete description of the variables see tables A-6, A-7, and B-4. 


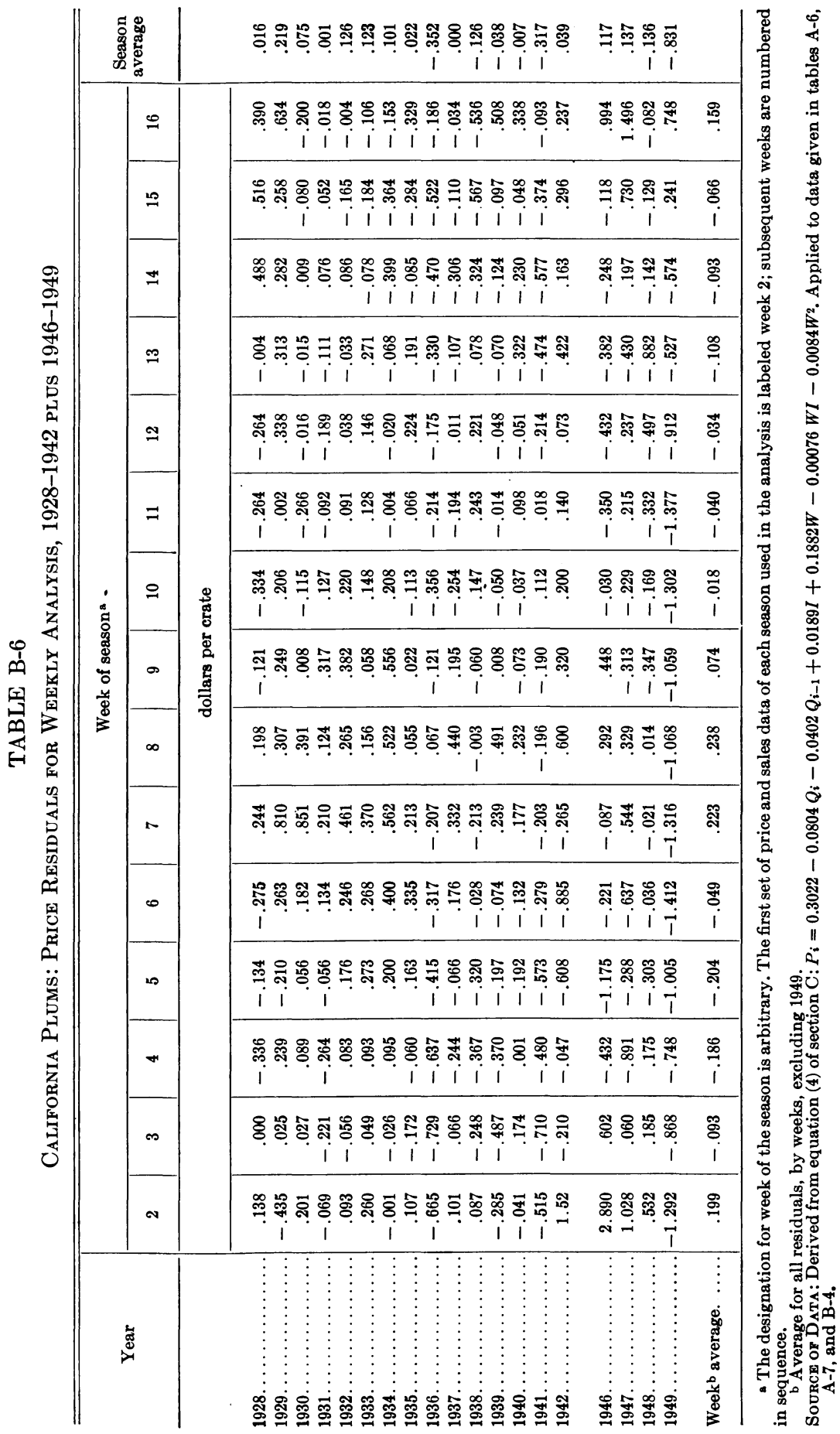




\section{TABLE B-7}

Calculation of Chi-Square Values for Testing the Goodness of Fit for Normal Curve of Error Fitted to Distribution of Weekly Residuals

\begin{tabular}{|c|c|c|c|c|c|c|c|}
\hline & \multirow{2}{*}{ Class limits } & \multicolumn{3}{|c|}{ Considering 270 residcals } & \multicolumn{3}{|c|}{ Considering 269 residuals } \\
\hline & & $\begin{array}{c}\text { Observed } \\
\text { frequency } \\
f_{0}\end{array}$ & $\begin{array}{l}\text { Theoretical } \\
\text { frequency } \\
f\end{array}$ & $\frac{\left(f_{0}-f\right)^{2}}{f}$ & $\begin{array}{c}\text { Observed } \\
\text { frequency } \\
f_{0}\end{array}$ & $\begin{array}{c}\text { Theoretical } \\
\text { frequency } \\
f\end{array}$ & $\frac{\left(f_{0}-f\right)^{2}}{f}$ \\
\hline .600 and & more. . & 10 & 15.0 & 1.67 & 9 & 9.5 & .03 \\
\hline .450 to & $.599 \ldots \ldots$ & 10 & 10.3 & 2.43 & 10 & 14.0 & 1.14 \\
\hline .300 to & $.449 \ldots$ & 17 & 26.1 & 3.17 & 17 & 25.7 & 2.95 \\
\hline .150 to & $.299 \ldots$ & 45 & 35.8 & 2.36 & 45 & 38.4 & 1.13 \\
\hline .000 to & $.149 \ldots$ & 46 & 41.8 & .42 & 46 & 46.9 & .02 \\
\hline-.150 to - & $-.001 \ldots$ & 56 & 41.8 & 4.82 & 56 & 46.9 & 1.77 \\
\hline-.300 to - & $-.151 \ldots$ & 39 & 35.8 & .29 & 39 & 38.4 & .01 \\
\hline-.450 to - & $-.301 \ldots$ & 26 & 26.1 & .00 & 26 & 25.7 & .00 \\
\hline-.600 to - & $-.451 \ldots$ & 11 & 16.3 & 1.72 & 11 & 14.0 & .64 \\
\hline \multirow[t]{2}{*}{ less than } & $-.600 \ldots \ldots \ldots$ & 10 & 15.0 & 1.67 & 10 & 9.5 & .03 \\
\hline & & & & 18.55 & & & 7.72 \\
\hline \multicolumn{2}{|c|}{.600 and more. } & 10 & 15.0 & 1.67 & 9 & 9.5 & .03 \\
\hline .400 to & $.599 \ldots$ & 14 & 23.9 & 4.10 & 14 & 21.1 & 2.39 \\
\hline .200 to & $.399 \ldots$ & 43 & 41.5 & .05 & 43 & 42.9 & .00 \\
\hline .000 to & $.199 \ldots$ & 61 & 54.6 & .75 & 61 & 61.0 & .00 \\
\hline-.200 to - & $-.001 \ldots$ & 69 & 54.6 & 3.80 & 69 & 61.0 & 1.05 \\
\hline-.400 to - & $-.201 \ldots$ & 47 & 41.5 & .73 & 47 & 42.9 & .39 \\
\hline-.600 to - & $-.401 \ldots$ & 16 & 23.9 & 2.61 & 16 & 21.1 & 1.23 \\
\hline \multirow[t]{2}{*}{ less than } & $-.600 \ldots$ & 10 & 15.0 & 1.67 & 10 & 9.5 & .03 \\
\hline & & & & 15.38 & & & 5.12 \\
\hline \multicolumn{2}{|c|}{.750 and more. } & 6 & 6.3 & .01 & 5 & 3.2 & 1.01 \\
\hline .500 to & $.749 \ldots$ & 11 & 18.6 & 3.11 & 11 & 14.5 & .84 \\
\hline .250 to & $.499 \ldots \ldots$ & 30 & 43.5 & 4.19 & 30 & 43.0 & 3.93 \\
\hline .000 to & $.249 \ldots \ldots \ldots$ & 81 & 66.6 & 3.11 & 81 & 73.8 & .70 \\
\hline-.250 to & $-.001 \ldots \ldots \ldots$ & 84 & 66.6 & 4.55 & 84 & 73.8 & 1.41 \\
\hline-.500 to & $-.251 \ldots$ & 42 & 43.5 & .05 & 42 & 43.0 & .02 \\
\hline-.750 to & $-.501 \ldots$ & 12 & 18.6 & 2.34 & 12 & 14.5 & .43 \\
\hline \multirow[t]{2}{*}{ less than } & $-.750 \ldots$ & 4 & 6.3 & .84 & 4 & 3.2 & .20 \\
\hline & & & & 18.20 & & & 8.54 \\
\hline
\end{tabular}

a The standard deviation of residuals is 0.3764 for all 270 observations and 0.3317 for 269 observations (where residual for week 2 of 1946 is excluded).

Note: The values of $\chi^{2}$ for selected values of $P$ and $n$ are

\begin{tabular}{c|c|c|c|c|c}
\hline$n$ & $P=.50$ & .10 & .05 & .02 & .01 \\
\hline $7 \ldots \ldots \ldots \ldots \ldots \ldots \ldots \ldots \ldots \ldots \ldots \ldots$ & 6.35 & 12.02 & 14.07 & 16.62 & 18.48 \\
$9 \ldots \ldots \ldots \ldots \ldots$ & 8.34 & 14.68 & 16.92 & 19.68 & 21.67 \\
\hline
\end{tabular}

Source of Data: Applied to data in table B-6. 
TABLE B-8

California Plums: Intercorrelation of Series Used in Size Analysis 1937-1948 (EXCLUdING 1939 AND 1943-1945)

\begin{tabular}{|c|c|c|c|c|c|c|}
\hline \multirow[b]{3}{*}{ 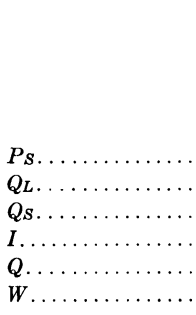 } & $P_{L}$ & $P S$ & $Q_{L}$ & $Q s$ & $P$ & $Q$ \\
\hline & \multicolumn{6}{|c|}{ Beauty variety } \\
\hline & $\begin{array}{r}.993476 \\
-.201757 \\
-.230270 \\
.777607 \\
-.149851 \\
-.509282\end{array}$ & $\begin{array}{r}-.211548 \\
-.269237 \\
.739306 \\
\ldots \ldots \ldots \\
\ldots \ldots \ldots\end{array}$ & $\begin{array}{r}.750221 \\
-.317439 \\
-.316333 \\
.013174\end{array}$ & $\begin{array}{r}-.080767 \\
.292128 \\
.274001\end{array}$ & $\begin{array}{l}\ldots \ldots \\
-.467972 \\
-.148389\end{array}$ & $\begin{array}{r}.324422 \\
.527095\end{array}$ \\
\hline & \multicolumn{6}{|c|}{ Tragedy variety } \\
\hline $\begin{array}{l}P_{s} \ldots \ldots \ldots \ldots \ldots \ldots \\
Q_{L} \ldots \ldots \ldots \ldots \ldots \ldots \\
Q_{s} \ldots \ldots \ldots \ldots \ldots \ldots \\
I \ldots \ldots \ldots \ldots \ldots \ldots \\
Q \ldots \ldots \ldots \ldots \ldots \ldots \ldots \\
W \ldots \ldots \ldots \ldots \ldots \ldots\end{array}$ & $\begin{array}{r}.993250 \\
-.514427 \\
-.264166 \\
.957804 \\
\ldots \ldots \ldots \\
\ldots \ldots \ldots\end{array}$ & $\begin{array}{r}-.524185 \\
-.309626 \\
.931438 \\
\ldots \ldots \ldots \\
\ldots \ldots \ldots\end{array}$ & $\begin{array}{r}.733822 \\
-.442129 \\
\ldots \ldots \ldots \\
\ldots \ldots \ldots\end{array}$ & $\begin{array}{c}-.107105 \\
\ldots \ldots \\
\ldots \ldots\end{array}$ & $\begin{array}{r}-.400679 \\
.091279\end{array}$ & -.328095 \\
\hline \multirow{3}{*}{$\begin{array}{l}P s \ldots \ldots \ldots \ldots \ldots \\
Q_{L} \ldots \ldots \ldots \ldots \ldots \ldots \\
Q_{s} \ldots \ldots \ldots \ldots \ldots \ldots \\
I \ldots \ldots \ldots \ldots \ldots \ldots \\
Q \ldots \ldots \ldots \ldots \ldots \ldots \\
W \ldots \ldots \ldots \ldots \ldots \ldots\end{array}$} & \multicolumn{6}{|c|}{ Wickson variety } \\
\hline & $\begin{array}{r}.994302 \\
-.101969 \\
-.173747 \\
.959654 \\
\ldots \ldots \ldots \\
\ldots \ldots \ldots\end{array}$ & $\begin{array}{r}-.073553 \\
-.189381 \\
.944275 \\
\ldots \ldots \ldots \\
\ldots \ldots \ldots\end{array}$ & $\begin{array}{r}.365755 \\
-.122287 \\
\ldots \ldots \\
\ldots \ldots\end{array}$ & $\begin{array}{r}-.100940 \\
\ldots \ldots \\
\ldots \ldots\end{array}$ & $\begin{array}{r}-.115478 \\
.000000\end{array}$ & .512709 \\
\hline & \multicolumn{6}{|c|}{ President variety } \\
\hline $\begin{array}{l}P s \ldots \ldots \ldots \ldots \ldots \\
Q_{L} \ldots \ldots \ldots \ldots \ldots \ldots \\
Q_{s} \ldots \ldots \ldots \ldots \ldots \ldots \\
I \ldots \ldots \ldots \ldots \ldots \ldots \\
Q \ldots \ldots \ldots \ldots \ldots \ldots \\
W \ldots \ldots \ldots \ldots \ldots\end{array}$ & $\begin{array}{r}.975796 \\
-.223571 \\
-.273663 \\
.894172 \\
\ldots \ldots \ldots \\
\ldots \ldots\end{array}$ & $\begin{array}{r}-.214256 \\
-.324210 \\
.812914 \\
\ldots \ldots \ldots \\
\ldots \ldots \ldots\end{array}$ & $\begin{array}{r}.702959 \\
-.033109 \\
\ldots \ldots \\
\ldots \ldots\end{array}$ & $\begin{array}{r}-.047509 \\
\ldots \ldots \\
\ldots \ldots\end{array}$ & $\begin{array}{l}-.271150 \\
-.182689\end{array}$ & .047638 \\
\hline
\end{tabular}

For the meaning of the variables see tables A-8 to A-11. 


\section{The Addition of Recent Data}

The equations presented in the text were derived from the data available at the time of their computation. Subsequently, all data relating to the 1948 and 1949 seasons have become available. It is desirable, therefore, to substitute these recent values of the independent variables into the various equations in order to secure an indication of how well the formulations apply to more recent periods. The residuals determined in the varietal analyses for the 1948 and 1949 seasons and those secured in the weekly analysis for 1949 are included in tables B-3 and B-6. They are not, however, plotted on the several regression charts.

It should be pointed out that the use of the equations generally indicates prices considerably above those actually realized. In other words, the residuals secured are negative and of substantial magnitude. For 1948 the residuals for the varietal analysis, although large, are within the range specified by three standard errors of estimate. The residuals for both the varietal and weekly analyses for 1949 are much larger-generally more than three times the standard error of estimate.

This result, secured by the use of 1948 and 1949 data, indicates that these equations must be used with particular caution. Possibly as additional postwar data can be utilized, it may be possible to determine the cause for the large negative residuals in 1949. It may be that conditions during this season were drastically different from those prevailing earlier. On the other hand, it may be that the equations derived are not entirely suitable for describing the interrelation which actually exists. For example, the depressive effect of a large quantity remaining unharvested - as was the case in 1949-has not been adequately reflected. A preliminary check seems to indicate that in all cases (i.e., for equations $1,2,3$, and 4 ) the net regression of auction price on the index of nonagricultural income was determined to be larger than would be the case with the inclusion of more recent data. Thus the large negative residuals secured for 1948 and 1949 would be considerably reduced, without unduly affecting the residuals obtained for previous years, merely by reducing this net regression coefficient. 


\section{LITERATURE CITED}

\section{California Federal-State Market News Service.}

1935-1947. Plums: weighted average prices at eastern auction markets by varieties, by weeks, by markets. Annual summary reports. (Mimeo.)

California Tree Fruit Agreement.

1935-1947 (except for 1938, 1942, and 1943 when none were issued). Annual reports. Sacramento. (Mimeo.)

Cochran, D., and C. H. OrcutT.

1949. Application of least squares regression to relationships containing autocorrelated error terms. Jour. Amer. Statis. Assn., March: 32-61.

Cochran, W. G.

1939. The use of the analysis of variance in enumeration by sampling. Jour. Amer. Statis. Assn., Sept.: 492-510.

\section{EzeKIEL, M.}

1930. Methods of correlation analysis. 1st ed. xiv +427 p. John Wiley and Sons, New York.

Fisher, R. A.

1946. Statistical methods for research workers. 10th ed. xv +354 p. Oliver and Boyd, London.

FOYTIK, JERRY.

1949. The California plum industry: an economic study. vii +401 p. (Unpublished Ph.D. thesis.)

HART, B. I.

1942. Significance levels for the ratio of the mean square successive difference to the variance. Ann. Math. Stat., 445-47.

Herns, A. E.

1940. On the solution of linear difference differential equations. Jour. Math. and Physics, 19: 153-57.

Hoos, Sidney.

1941. An investigation on complementarity relations between fresh fruits. Jour. Farm Econ., May: 421-33. (Also: a reply by A. Kozlick, ibid., Aug.: 654-56; and a rejoinder by Hoos, ibid., May (1942): 528-29).

Kuznets, G. M., and L. R. KLein.

1943. A statistical analysis of the domestic demand for lemons, 1921-1941. $v+112 \mathrm{p}$. The Giannini Foundation, Berkeley. Report no. 84. (Mimeo.)

Mehren, G. L., and H. E. Erdman.

1946. An approach to the determination of intraseasonal shifting of demand. Jour. Farm Econ., May: 587-96.

Production and Marketing Administration (U.S.D.A.), Fruit and Vegetable Branch.

1920-1948. California plums: New York auction market sales and prices, in crates, by varieties and by weeks. (Typed.) Washington, D.C. These summaries were prepared from data furnished by S. W. Shear, Giannini Foundation, Berkeley, for 1920-1936, and from the New York Daily Fruit Reporter, "Detailed deciduous report" for 1937-1948. For some years supplemental data on a size basis are also given.

Rauchenstein, Emil.

1928. Economic aspects of the fresh plum industry. Calif. Agr. Expt. Sta. Bul. 459: 1-26.

Schultz, Henry.

1938. The theory and measurement of demand. xxxi +817 p. Univ. of Chicago Press. Chicago. 
SheAR, S. W.

1922-1934. Data on Chicago auction market sales and prices of California plums, by varieties. (Unpublished.)

Thompson, J. M.

1938. Some theoretical aspects of controlled marketing. Jour. Farm Econ., May: 495503.

U. S. Bureau of Domestic and Foreign Commerce.

1947. National income supplement to Survey of Current Business. 54 p. Washington, D.C.

1948. Survey of Current Business. Monthly issues since January, 1948. Washington, D.C.

U. S. Department of Agriculture.

1934-1938. Carlot unloads of certain fruits and vegetables in 66 cities. Annual summaries. Washington, D.C.

Von Neumann, J.

1941. Distribution of the ratio of the mean square successive difference to the variance. Ann. Math. Statis., 367-95.

Von Neumann, J., R. H. Kent, H. R. Bellinson, and B. I. Hart.

1941. The mean square successive difference. Ann. Math. Statis., 153-62.

WAUGH, F. V.

1943. Choice of the dependent variable in regression analysis. Jour. Amer. Statis. Assn., June: 210-14. (Also "Comments" on above by M. Ezekiel, ibid., 214-16.)

WaUgh, F. V., E. L. Burtis, and A. F. Wolf.

1936. The controlled distribution of a crop among independent markets. Quar. Jour. Econ., Nov.: 1-41. 

The journal Hilgardia is published at irregular intervals, in volumes of about 600 pages. The number of issues per volume varies.

Subscriptions are not sold. The periodical is sent as published only to libraries, or to institutions in foreign countries having publications to offer in exchange.

You may obtain a single copy of any issue free, as long as the supply lasts; please request by volume and issue number from:

\section{Publications Office \\ College of Agriculture \\ Berkeley 4, California}

The limit to nonresidents of California is 10 separate issues on a single order. $A$ list of the issues still available will be sent on request. 